Universidade de São Paulo

Instituto de Astronomia, Geofísica e Ciências Atmosféricas

Departamento de Astronomia

Victor Hugo da Cunha Oliveira

\title{
Caracterização dinâmica dos sistemas múltiplos de planetas extrassolares
}

\author{
São Paulo
}

abril de 2010 

Victor Hugo da Cunha Oliveira

\section{Caracterização dinâmica dos sistemas múltiplos de planetas extrassolares}

Dissertação apresentada ao Departamento de Astronomia do Instituto de Astronomia, Geofísica e Ciências Atmosféricas da Universidade de São Paulo como parte dos requisitos para a obtenção do título de Mestre em Ciências.

Mestrado em Astronomia

Orientadora: Prof ${ }^{\mathrm{a}}$. Dra ${ }^{\mathrm{a}}$. Tatiana Alexandrovna Michtchenko

São Paulo

abril de 2010 

Para a minha esposa, companheira para toda a vida. 



\section{Agradecimentos}

Agradeço ao Soberano Criador do Universo, acima de tudo, sempre.

Agradeço à minha esposa pela paciência, compreensão e carinho nas horas que dediquei a este Trabalho. Aos meus pais, que por toda a minha vida têm me dado o suporte necessário em todas as etapas e circunstâncias. À minha orientadora desde o Trabalho de Graduação, e agora deste Mestrado, a Prof ${ }^{a}$. Dr ${ }^{a}$. Tatiana Alexandrova Michtchenko, por toda a atenção, suporte e ensinamentos a mim transmitidos, ao Prof ${ }^{o}$. Dr. Sylvio Ferraz-Mello, pelas aulas do Mestrado e por ter me apresentado e indicado à Professora Tatiana. Ao Prof ${ }^{\circ}$ Dr. Roberto Boczko, Prof ${ }^{\circ}$ Dr. Ramachrisna Teixeira e à Prof ${ }^{\mathrm{a}}$. Dr ${ }^{\mathrm{a}}$. Silvia C. F. Rossi pelos ensinamentos durante o curso de Mestrado no IAG. Aos colegas Adrian Rodriguez Colucci, Alan Jorge Alves do Carmo, Eduardo Andrade Ines e Gleidson Gomes da Silva pelas discussões profícuas, dicas e sugestões. Ao colega Marcos Tadeu dos Santos por ter recalculado dados para utilização nesta dissertação. Aos colegas Gustavo Rocha da Silva, Vinícius Moris Placco e Robson dos Santos França, este último, colega de trabalho fora do IAG, por ajudas preciosas na confecção desta dissertação em LATEX.

Esta dissertação foi escrita em IATEX com a classe IAGTESE, para teses e dissertações do IAG. 

"Se não existe vida fora da Terra, então o Universo é um grande desperdício de espaço."

Carl Sagan (1934-1996)

"O olho do homem é feito de modo que se lhe vê por ele a virtude. A nossa pupila diz que quantidade de homens há dentro de nós. Afirmamo-nos pela luz que fica debaixo da sobrancelha. As pequenas consciências piscam o olho, as grandes lançam raios. Se não há nada que brilhe debaixo da pálpebra, é que nada há que pense no cérebro, é que nada há que ame no coração. Quem ama quer, e aquele que quer relampeja e cintila. A resolução enche os olhos de fogo; admirável fogo que se compõe da combustão de pensamentos tímidos."

Victor Hugo (1802- 1885)

"Enquanto viverdes submergidos no tempo e no espaço, não podereis intuir sequer o que existe mais além, nas regiões do espírito." 



\section{Resumo}

O presente trabalho tem por objetivo a caracterização dinâmica dos sistemas múltiplos de planetas extrassolares. O critério de classificação escolhido é baseado na proposta publicada inicialmente em Ferraz-Mello et al. (2005) e posteriormente modificada em Michtchenko et al. (2007). Para a obtenção dos parâmetros planetários orbitais foi feita uma pesquisa em diversos catálogos e artigos disponíveis para posterior criação de um catálogo próprio. Este incluiu somente sistemas extrassolares múltiplos, ou seja, sistemas que contêm dois ou mais planetas orbitando a estrela. Foram feitas simulações númericas de estabilidade dinâmica dos sistemas do catálogo próprio com tempos de integração de 200 mil até 21 milhões de anos. Ao todo, foram analisados 37 sistemas múltiplos extrassolares, divididos em 50 subsistemas considerando-se a estrela e dois planetas em órbitas consecutivas. Estes foram submetidos ao total de 68 simulações computacionais. Os sistemas que apresentaram um cenário de estabilidade dinâmica foram posteriormente separados em três classes: ressonantes, seculares ou hierárquicos. Mais ainda, o comportamento secular desses sistemas foi classificado conforme o movimento do ângulo $\Delta \varpi$ : oscilatório em torno de $0^{\circ}$, oscilatório em torno de $180^{\circ}$ ou circulatório. Os resultados das simulações são mostrados para todos os sistemas estudados. 



\section{Abstract}

The aim of the present work is a dynamic classification of multiple extrasolar systems. The characterization criterion used is based on a criterion proposed initially in Ferraz-Mello et al. (2005) and modified in Michtchenko et al. (2007). To obtain orbital parameters of the extrasolar systems, a search was done into several available catalogues and the scientific literature. A new catalogue was compiled containing only multiple extrasolar systems, that is, systems with two or more planets in orbit of the host star. Numerical simulations of dynamical stability of the cataloged systems were done considering pairs of planets on the consecutive orbits. Totally, 37 multiple extrasolar systems were analyzed, decomposed in 50 sub-systems each one consisting of the host star and two planets. The time evolution of those were simulated over time spans from 200 thousand years to 21 million years in 68 numerical simulations. The systems which have presented a dynamical stability were subsequently classified in resonants, secular or hierarchical and their secular behavior was classified with respect of the angle $\Delta \varpi$ as oscillation around $0^{\circ}$, oscillation around $180^{\circ}$ or circulation. The result of all simulations are presented here for the analyzed systems. 



\section{Lista de Figuras}

1.1 Distribuição dos pares planetários nas órbitas consecutivas no plano $\left(T_{1} / T_{2}\right.$, $e$ ), onde $T_{1}$ e $T_{2}$ são períodos dos planetas, e é a maior excentricidade do par. A posição nominal das ressonâncias de movimentos médios é dada por picos, cuja altura é inversa à ordem de ressonância. Os pares formados por planetas do Sistema Solar estão indicados por cruzes. . . . . . . . . . . . . 31

2.1 Relação empírica Massa X Luminosidade (Carrol e Ostlie, 1996) . . . . . . 39

4.1 Problema de 2-corpos em coordenadas retangulares (Roy, 1978) . . . . . 50

4.2 Problema de 2-corpos em coordenadas polares (Roy, 1978) . . . . . . . . . 52

4.3 Coordenadas eclípticas $($ Roy, 1978) f . . . . . . . . . . . 55

4.4 Problema de 3-corpos em coordenadas retangulares (Roy, 1978) . . . . . . 60

6.1 Semi-eixo maior de Júpiter em função do tempo . . . . . . . . . . . . . . . 71

6.2 Excentricidade de Júpiter em função do tempo . . . . . . . . . . . . . . . . 71

6.3 Inclinação de Júpiter em função do tempo . . . . . . . . . . . . . . . . . . 71

6.4 Semi-eixo maior de Saturno em função do tempo . . . . . . . . . . . . . . . 71

6.5 Excentricidade de Saturno em função do tempo . . . . . . . . . . . . . . . 71

6.6 Inclinação de Saturno em função do tempo . . . . . . . . . . . . . . . . . . 71

6.7 Ângulo $\Delta \varpi$ em função do tempo para Sol-Júpiter-Saturno . . . . . . . . . 72

6.8 FFT do ângulo $\Delta \varpi$ em função do tempo para Sol-Júpiter-Saturno . . . . . 72

$6.9 \mathrm{KH}$ de $e_{1}$ para Sol-Júpiter-Saturno . . . . . . . . . . . . . . . . . 73

$6.10 \mathrm{KH}$ de $e_{2}$ para Sol-Júpiter-Saturno . . . . . . . . . . . . . . 73

6.11 Ângulo $\Delta \varpi$ em função do tempo para GJ $876 \mathrm{dc} \ldots$. . . . . . . . . . . . 75 
$6.12 \mathrm{KH}$ de $e_{1}$ para GJ $876 \mathrm{dc} \ldots \ldots \ldots \ldots$. . . . . . . . . . . . . . . . . . . .

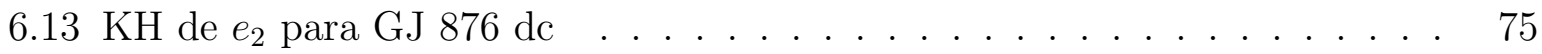

6.14 Ângulo $\Delta \varpi$ em função do tempo para GJ $876 \mathrm{cb}$. . . . . . . . . . . . . . 76

6.15 FFT do ângulo $\Delta \varpi$ em função do tempo para GJ $876 \mathrm{cb}$. . . . . . . . . . 77

$6.16 \mathrm{KH}$ de $e_{1}$ para GJ $876 \mathrm{cb} \ldots \ldots \ldots \ldots . \ldots \ldots 77$

$6.17 \mathrm{KH}$ de $e_{2}$ para GJ $876 \mathrm{cb} \ldots \ldots \ldots \ldots \ldots \ldots$

$6.18 \mathrm{KH}$ de $e_{2}$ para GJ $876 \mathrm{cb}$ - filtro 145 a 147 anos . . . . . . . . . . . 78

6.19 Semi-eixo maior de HD 73526 c em função do tempo . . . . . . . . . . . . 79

6.20 Excentricidade de HD 73526 b em função do tempo . . . . . . . . . . . . . 79

6.21 Ângulo $\Delta \varpi$ em função do tempo para HD 73526 bc calculado por Marcos

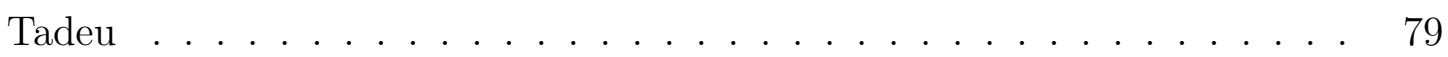

6.22 Zoom do ângulo $\Delta \varpi$ em função do tempo para HD 73526 bc calculado por Marcos Tadeu . . . . . . . . . . . . . . . . . . 80

6.23 FFT do ângulo $\Delta \varpi$ em função do tempo para HD 73526 bc $\quad$. . . . . . . . 80

$6.24 \mathrm{KH}$ de $e_{1}$ para HD73526 bc . . . . . . . . . . . . . . . . . . . . . 80

$6.25 \mathrm{KH}$ de $e_{2}$ para HD 73526 bc . . . . . . . . . . . . . . . . . 80

$6.26 \mathrm{KH}$ de $e_{1}$ para HD 73526 bc - filtro 4761 a 5025 anos . . . . . . . . . . 81

$6.27 \mathrm{KH}$ de $e_{2}$ para HD 73526 bc - filtro 4761 a 5025 anos . . . . . . . . . . . 81

6.28 Ângulo $\Delta \varpi$ em função do tempo para HD $160691 \mathrm{~cd}$. . . . . . . . . . . . 82

$6.29 \mathrm{KH}$ de $e_{1}$ para HD $160691 \mathrm{~cd} \ldots \ldots$. . . . . . . . . . . . 82

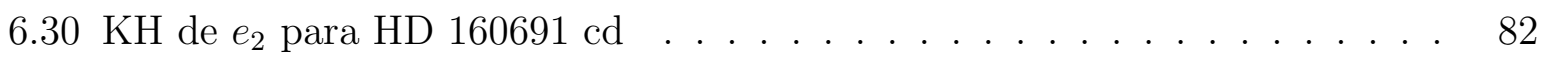

6.31 Ângulo $\Delta \varpi$ em função do tempo para HD $160691 \mathrm{db}$. . . . . . . . . . . . 83

6.32 Zoom do ângulo $\Delta \varpi$ em função do tempo para HD $160691 \mathrm{db}$. . . . . . . 83

$6.33 \mathrm{KH}$ de $e_{1}$ para HD $160691 \mathrm{db} \ldots \ldots . \ldots . \ldots . \ldots . \ldots . \ldots$

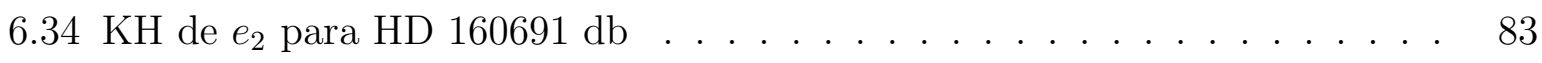

$6.35 \mathrm{KH}$ de $e_{1}$ para HD $160691 \mathrm{db}$ com filtro de 0,011 /ano . . . . . . . . 84

$6.36 \mathrm{KH}$ de $e_{2}$ para HD $160691 \mathrm{db}$ com filtro de $0,011 /$ ano . . . . . . . . . . 84

6.37 Ângulo $\Delta \varpi$ em função do tempo para HD 160691 be . . . . . . . . . . . . 85

$6.38 \mathrm{KH}$ de $e_{1}$ para HD 160691 be . . . . . . . . . . . . . . . . 85

$6.39 \mathrm{KH}$ de $e_{2}$ para HD 160691 be . . . . . . . . . . . . . . . . 85

$6.40 \mathrm{KH}$ de $e_{1}$ para HD 160691 be filtrado . . . . . . . . . . . . . . 86 
$6.41 \mathrm{KH}$ de $e_{2}$ para HD 160691 be filtrado . . . . . . . . . . . . . . . 86

6.42 Ângulo $\Delta \varpi$ em função do tempo para $55 \mathrm{Cnc}$ eb . . . . . . . . . . . . . . 87

6.43 Zoom do ângulo $\Delta \varpi$ em função do tempo para 55 Cnc eb . . . . . . . . . 87

$6.44 \mathrm{KH}$ de $e_{1}$ para $55 \mathrm{Cnc}$ eb . . . . . . . . . . . . . . . . 87

$6.45 \mathrm{KH}$ de $e_{2}$ para $55 \mathrm{Cnc}$ eb . . . . . . . . . . . . . . . 87

6.46 Ângulo $\Delta \varpi$ em função do tempo para 55 Cnc bc . . . . . . . . . . . . . . 88

6.47 Zoom do ângulo $\Delta \varpi$ em função do tempo para $55 \mathrm{Cnc}$ bc $\ldots . . . .88$

$6.48 \mathrm{KH}$ de $e_{1}$ para $55 \mathrm{Cnc} \mathrm{bc} \mathrm{.} \mathrm{.} \mathrm{.} \mathrm{.} \mathrm{.} \mathrm{.} \mathrm{.} \mathrm{.} \mathrm{.} \mathrm{.} \mathrm{.} \mathrm{.} \mathrm{.} \mathrm{.} \mathrm{.} 88$

$6.49 \mathrm{KH}$ de $e_{2}$ para $55 \mathrm{Cnc}$ bc . . . . . . . . . . . . . . . . . 88

$6.50 \mathrm{KH}$ de $e_{1}$ para $55 \mathrm{Cnc}$ bc filtrado . . . . . . . . . . . . . . . 89

$6.51 \mathrm{KH}$ de $e_{2}$ para $55 \mathrm{Cnc}$ bc filtrado . . . . . . . . . . . . . . . 89

6.52 Ângulo $\Delta \varpi$ em função do tempo para 55 Cnc cf . . . . . . . . . . . . . . . 89

$6.53 \mathrm{KH}$ de $e_{1}$ para $55 \mathrm{Cnc}$ cf . . . . . . . . . . . . . . . . 90

$6.54 \mathrm{KH}$ de $e_{2}$ para $55 \mathrm{Cnc}$ cf . . . . . . . . . . . . . . . . 90

6.55 Ângulo $\Delta \varpi$ em função do tempo para $55 \mathrm{Cnc}$ fd . . . . . . . . . . . . . . . 90

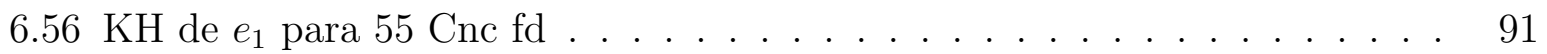

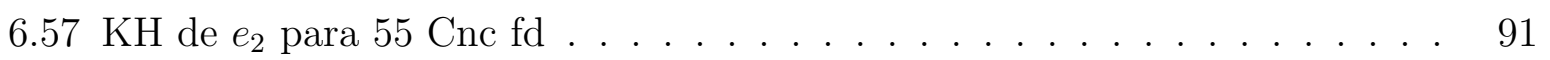

6.58 excentricidade do planeta para 55 Cnc d em função do tempo . . . . . . . 91

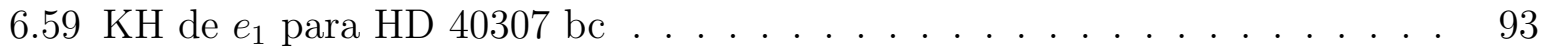

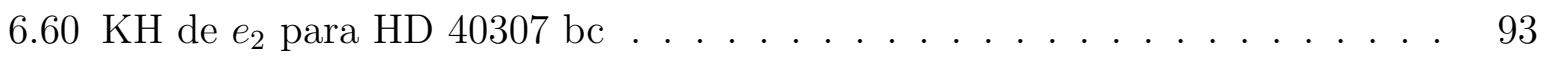

6.61 Ângulo $\Delta \varpi$ em função do tempo para HD 40307 bc, e=0,01; w=0,1 $\ldots 9$

6.62 Zoom do ângulo $\Delta \varpi$ em função do tempo para HD 40307 bc, e=0,01; w=0,1 94

$6.63 \mathrm{KH}$ de $e_{1}$ para HD $40307 \mathrm{bc}, \mathrm{e}=0,01 ; \mathrm{w}=0,1^{\circ} \ldots \ldots \ldots$. . . . . . . 94

$6.64 \mathrm{KH}$ de $e_{2}$ para HD $40307 \mathrm{bc}, \mathrm{e}=0,01 ; \mathrm{w}=0,1^{\circ} \ldots \ldots \ldots$

6.65 Ângulo $\Delta \varpi$ em função do tempo para HD $40307 \mathrm{~cd}$. . . . . . . . . . . . . 95

6.66 Zoom do ângulo $\Delta \varpi$ em função do tempo para HD $40307 \mathrm{~cd}$. . . . . . . . 95

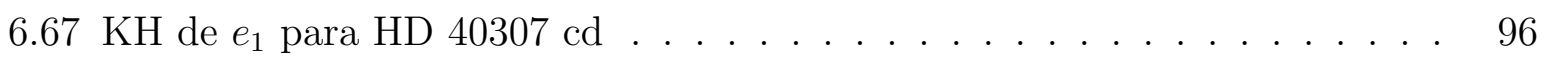

$6.68 \mathrm{KH}$ de $e_{2}$ para HD $40307 \mathrm{~cd} \ldots \ldots$. . . . . . . . . . . . 96

$6.69 \mathrm{KH}$ de $e_{1}$ para HD $40307 \mathrm{~cd}$ com filtro . . . . . . . . . . . . . . 96

$6.70 \mathrm{KH}$ de $e_{2}$ para HD 40307 cd com filtro . . . . . . . . . . . . . . 96 
7.1 Distribuição dos pares planetários nas órbitas consecutivas no plano $\left(T_{1} / T_{2}\right.$, e), onde $T_{1}$ e $T_{2}$ são períodos dos planetas, e é a maior excentricidade do par. A posição nominal das ressonâncias de movimentos médios é dada por picos, cuja altura é inversa à ordem de ressonância. Os pares formados por planetas do Sistema Solar estão indicados por cruzes. Essa figura é similar a Figura 1.1 da Introdução, porém é construída com os dados compilados neste trabalho.

A.1 Ângulo $\Delta \varpi$ em função do tempo para Sol-Mercúrio-Vênus . . . . . . . . . 123

A.2 KH de $e_{1}$ para Sol-Mercúrio-Vênus . . . . . . . . . . . . . . . 123

A.3 KH de $e_{2}$ para Sol-Mercúrio-Vênus . . . . . . . . . . . . . . . . . . 123

A.4 Ângulo $\Delta \varpi$ em função do tempo para Sol-Vênus-Terra . . . . . . . . . . . 124

A.5 KH de $e_{1}$ para Sol-Vênus-Terra . . . . . . . . . . . . . . . . 124

A.6 KH de $e_{2}$ para Sol-Vênus-Terra . . . . . . . . . . . . . . . . . 124

A.7 Ângulo $\Delta \varpi$ em função do tempo para Sol-Terra-Marte . . . . . . . . . . . 125

A.8 KH de $e_{1}$ para Sol-Terra-Marte . . . . . . . . . . . . . . . . . 125

A.9 KH de $e_{2}$ para Sol-Terra-Marte . . . . . . . . . . . . . . . 125

A.10 Ângulo $\Delta \varpi$ em função do tempo para Sol-Marte-Júpiter . . . . . . . . . . 126

A.11 KH de $e_{1}$ para Sol-Marte-Júpiter . . . . . . . . . . . . . . . 126

A.12 KH de $e_{2}$ para Sol-Marte-Júpiter . . . . . . . . . . . . . . . 126

A.13 Ângulo $\Delta \varpi$ em função do tempo para Sol-Saturno-Urano . . . . . . . . . . 127

A.14 KH de $e_{1}$ para Sol-Saturno-Urano . . . . . . . . . . . . . . . . . 127

A.15 KH de $e_{2}$ para Sol-Saturno-Urano . . . . . . . . . . . . . . . . 127

A.16 Ângulo $\Delta \varpi$ em função do tempo para Sol-Urano-Netuno . . . . . . . . . . 128

A.17 KH de $e_{1}$ para Sol-Urano-Netuno . . . . . . . . . . . . . . . 128

A.18 KH de $e_{2}$ para Sol-Urano-Netuno . . . . . . . . . . . . . . . . . 128

B.1 Ângulo $\Delta \varpi$ em função do tempo para HD 45364 bc . . . . . . . . . . . . . 129

B.2 Zoom do ângulo $\Delta \varpi$ em função do tempo para HD 45364 bc . . . . . . . . 129

B.3 KH de $e_{1}$ para HD 45364 bc . . . . . . . . . . . . . . . 130

B.4 KH de $e_{2}$ para HD 45364 bc . . . . . . . . . . . . . . . . . 130

B.5 KH de $e_{1}$ para HD 45364 bc com filtro . . . . . . . . . . . . 130 
B.6 KH de $e_{2}$ para HD 45364 bc com filtro . . . . . . . . . . . . . . . . 130

B.7 Ângulo $\Delta \varpi$ em função do tempo para GJ 581 eb - Mayor . . . . . . . . . . 131

B.8 Zoom do ângulo $\Delta \varpi$ em função do tempo para GJ 581 eb - Mayor . . . . . 131

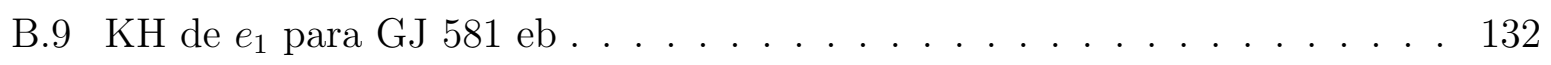

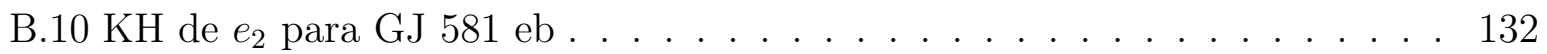

B.11 KH de $e_{1}$ para GJ 581 eb - filtro 173 a 175 anos . . . . . . . . . . . . . . . 132

B.12 FFT do ângulo $\Delta \varpi$ para GJ $581 \mathrm{eb} \ldots$. . . . . . . . . . . . . . . . 132

B.13 Semi-eixo maior de 47 Uma b em função do tempo - Fischer, 2002 . . . . 133

B.14 Excentricidade de 47 Uma b em função do tempo - Fischer, 2002 . . . . . . 133

B.15 Ângulo $\Delta \varpi$ em função do tempo para 47 Uma bc . . . . . . . . . . . . . . 134

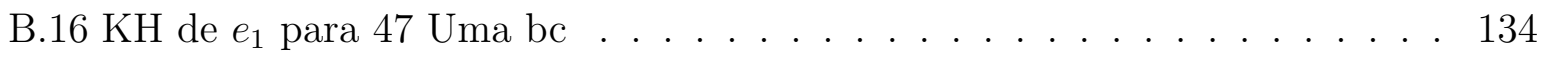

B.17 KH de $e_{2}$ para $47 \mathrm{Uma} \mathrm{bc} \mathrm{.} \mathrm{.} \mathrm{.} \mathrm{.} \mathrm{.} \mathrm{.} \mathrm{.} \mathrm{.} \mathrm{.} \mathrm{.} \mathrm{.} \mathrm{.} \mathrm{.} \mathrm{.} \mathrm{.} \mathrm{.} \mathrm{.} \mathrm{.} 134$

B.18 KH de $e_{2}$ para 47 Uma bc filtrado . . . . . . . . . . . . . . . . 134

B.19 Semi-eixo de HD 128311 b em função do tempo - (Vogt et al., 2005) . . . . 135

B.20 Excentricidade de HD 128311 b em função do tempo - (Vogt et al., 2005) 135

B.21 Semi-eixo de HD 128311 c em função do tempo - (Fischer e Valenti, 2005) 136

B.22 Excentricidade de HD 128311 c em função do tempo - (Fischer e Valenti,

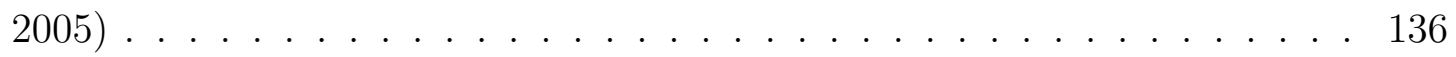

B.23 Semi-eixo de HD 82943 c em função do tempo - (Mayor et al., 2004) . 137

B.24 Excentricidade de HD 82943 c em função do tempo - (Mayor et al., 2004) 137

B.25 Ângulo $\Delta \varpi$ em função do tempo para HD $82943 \mathrm{cb}$. . . . . . . . . . . . . 138

B.26 Zoom do ângulo $\Delta \varpi$ em função do tempo para HD $82943 \mathrm{cb}$. . . . . . . . 138

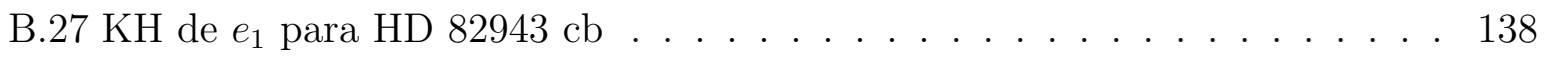

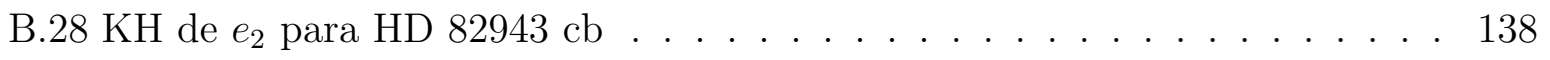

B.29 Ângulo $\Delta \varpi$ em função do tempo para HD 82943 bd . . . . . . . . . . . . . 139

B.30 Zoom do ângulo $\Delta \varpi$ em função do tempo para HD 82943 bd . . . . . . . . 139

B.31 KH de $e_{1}$ para HD 82943 bd . . . . . . . . . . . . . . . . . . . 139

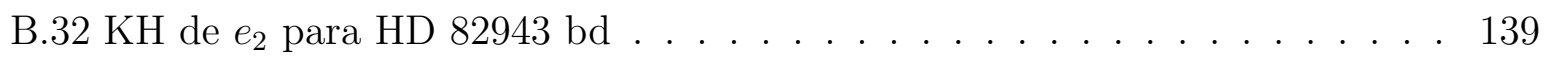

B.33 Ângulo $\Delta \varpi$ em função do tempo para HD 60532 bc . . . . . . . . . . . . . 140

B.34 Zoom do ângulo $\Delta \varpi$ em função do tempo para HD 60532 bc . . . . . . . . 140

B.35 KH de $e_{1}$ para HD 60532 bc . . . . . . . . . . . . . . . . . 140 
B.36 KH de $e_{2}$ para HD 60532 bc . . . . . . . . . . . . . . . . . 140

B.37 KH de $e_{1}$ para HD 60532 bc - filtro de 350 a 450 anos . . . . . . . . . . . . 141

B.38 KH de $e_{2}$ para HD 60532 bc - filtro de 350 a 450 anos . . . . . . . . . . . . 141

B.39 Ângulo $\Delta \varpi$ em função do tempo para HD 108874 bc . . . . . . . . . . . . 142

B.40 KH de $e_{1}$ para HD 108874 bc . . . . . . . . . . . . . . . . . 142

B.41 KH de $e_{2}$ para HD 108874 bc . . . . . . . . . . . . . . . . . 142

B.42 Semi-eixo de HD 102272 c em função do tempo . . . . . . . . . . . . . . . 143

B.43 Excentricidade de HD 102272 c em função do tempo . . . . . . . . . . . . 143

B.44 Semi-eixo maior de BD 202457 b em função do tempo .......... 144

B.45 Excentricidade de BD 202457 c em função do tempo . . . . . . . . . . . . 144

B.46 Semi-eixo maior de HD 181433 c em função do tempo . . . . . . . . . . . . 145

B.47 Excentricidade de HD 181433 c em função do tempo . . . . . . . . . . . . 145

B.48 Ângulo $\Delta \varpi$ em função do tempo para GJ 581 bc . . . . . . . . . . . . . . 146

B.49 Zoom do ângulo $\Delta \varpi$ em função do tempo para GJ 581 bc . . . . . . . . . 146

B.50 KH de $e_{1}$ para GJ 581 bc . . . . . . . . . . . . . . . . . . . . 146

B.51 KH de $e_{2}$ para GJ 581 bc . . . . . . . . . . . . . . . . . . . . 146

B.52 Ângulo $\Delta \varpi$ em função do tempo para GJ $581 \mathrm{~cd}$. . . . . . . . . . . . . . 147

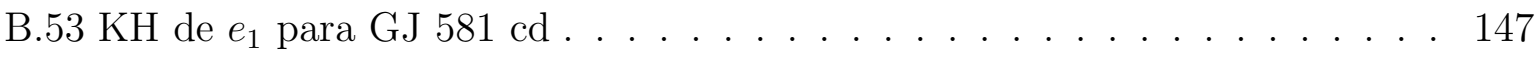

B.54 KH de $e_{2}$ para GJ $581 \mathrm{~cd} \ldots \ldots \ldots \ldots \ldots \ldots . \ldots \ldots$

B.55 Ângulo $\Delta \varpi$ em função do tempo para GJ 581 bc - Mayor . . . . . . . . . . 148

B.56 Zoom do ângulo $\Delta \varpi$ em função do tempo para GJ 581 bc - Mayor . . . . . 148

B.57 KH de $e_{1}$ para GJ 581 bc - Mayor . . . . . . . . . . . . . . . . . . 148

B.58 KH de $e_{2}$ para GJ 581 bc - Mayor . . . . . . . . . . . . . . . . 148

B.59 Ângulo $\Delta \varpi$ em função do tempo para GJ $581 \mathrm{~cd}$ - Mayor . . . . . . . . . . 149

B.60 Zoom do ângulo $\Delta \varpi$ em função do tempo para GJ $581 \mathrm{~cd}$ - Mayor . . . . . 149

B.61 KH de $e_{1}$ para GJ $581 \mathrm{~cd}$ - Mayor . . . . . . . . . . . . . . . . . . 149

B.62 KH de $e_{2}$ para GJ 581 cd - Mayor . . . . . . . . . . . . . . . . . 149

B.63 Ângulo $\Delta \varpi$ em função do tempo para HD 155358 bc . . . . . . . . . . . . 150

B.64 KH de $e_{1}$ para HD 155358 bc . . . . . . . . . . . . . . . . . 150

B.65 KH de $e_{2}$ para HD 155358 bc . . . . . . . . . . . . . . . 150

B.66 Ângulo $\Delta \varpi$ em função do tempo para HD 37124 bd . . . . . . . . . . . . . 151 
B.67 KH de $e_{1}$ para HD 37124 bd . . . . . . . . . . . . . . . . . . 151

B.68 KH de $e_{2}$ para HD 37124 bd . . . . . . . . . . . . . . . . . . . 151

B.69 Ângulo $\Delta \varpi$ em função do tempo para HD 37124 dc . . . . . . . . . . . . . 152

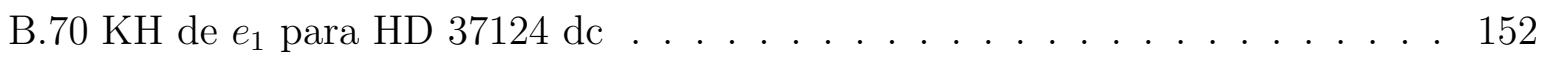

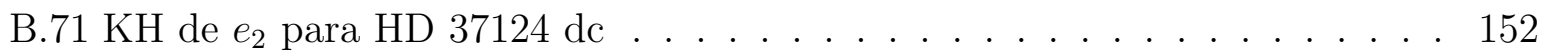

B.72 Ângulo $\Delta \varpi$ em função do tempo para HD 69830 bc . . . . . . . . . . . . . 153

B.73 KH de $e_{1}$ para HD 69830 bc . . . . . . . . . . . . . . . . 153

B.74 KH de $e_{2}$ para HD 69830 bc . . . . . . . . . . . . . . . . 153

B.75 Ângulo $\Delta \varpi$ em função do tempo para HD $69830 \mathrm{~cd}$. . . . . . . . . . . . . 154

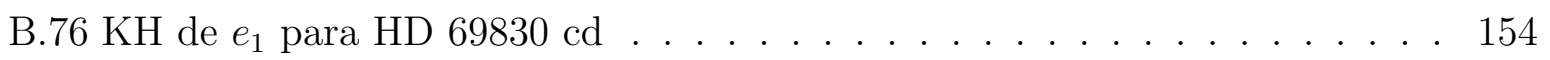

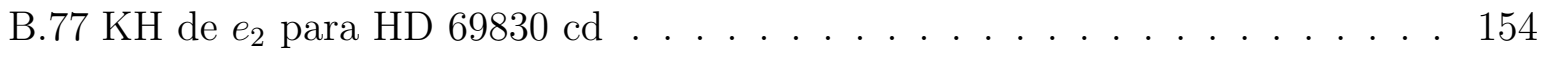

B.78 Ângulo $\Delta \varpi$ em função do tempo para HD 177830 bc . . . . . . . . . . . . 155

B.79 Zoom do ângulo $\Delta \varpi$ em função do tempo para HD 177830 bc . . . . . . . 155

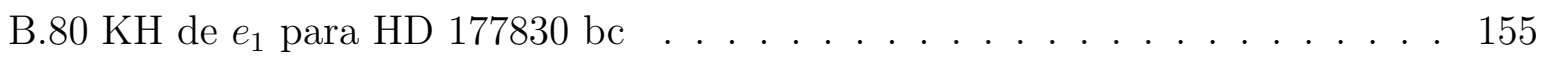

B.81 KH de $e_{2}$ para HD 177830 bc . . . . . . . . . . . . . . . . . 155

B.82 Semi-eixo maior de HD 183263 c em função do tempo . . . . . . . . . . . . 156

B.83 Excentricidade de HD 183263 c em função do tempo ......... 156

B.84 Ângulo $\Delta \varpi$ em função do tempo para HD 183263 bc . . . . . . . . . . . . 157

B.85 KH de $e_{1}$ para HD $183263 \mathrm{bc} \ldots \ldots \ldots \ldots$

B.86 KH de $e_{2}$ para HD $183263 \mathrm{bc} \ldots \ldots \ldots \ldots$. . . . . . . . . . 157

B.87 KH de $e_{2}$ para HD 183263 bc com filtro . . . . . . . . . . . . . . . 158

B.88 Semi-eixo maior de HD 202206 c em função do tempo . . . . . . . . . . . . 158

B.89 Semi-eixo maior de HD 202206 c em função do tempo . . . . . . . . . . . . 159

B.90 Excentricidade de HD 202206 c em função do tempo . . . . . . . . . . . 159

B.91 Ângulo $\Delta \varpi$ em função do tempo para HD 202206 bc . . . . . . . . . . . . 159

B.92 Zoom do ângulo $\Delta \varpi$ em função do tempo para HD 202206 bc . . . . . . . 159

B.93 KH de $e_{1}$ para HD 202206 bc com dados de Marcos Tadeu . . . . . . . . . 160

B.94 KH de $e_{2}$ para HD 202206 bc com dados de Marcos Tadeu . . . . . . . . . 160

B.95 KH de $e_{2}$ para HD 202206 bc com dados de Marcos Tadeu - filtro 430 a 440

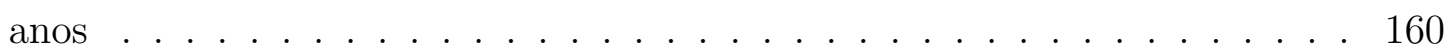

B.96 Ângulo $\Delta \varpi$ em função do tempo para $v$ Andrômeda cd . . . . . . . . . . . 161 
B.97 KH de $e_{1}$ para $v$ Andrômeda cd . . . . . . . . . . . . . . . . . 161

B.98 KH de $e_{2}$ para $v$ Andrômeda cd . . . . . . . . . . . . . . . . . . . 161

B.99 Ângulo $\Delta \varpi$ em função do tempo para HD 12661 bc . . . . . . . . . . . . . 162

B.100 KH de $e_{1}$ para HD 12661 bc . . . . . . . . . . . . . . . . . 162

B.101 KH de $e_{2}$ para HD 12661 bc . . . . . . . . . . . . . . . . . 162

B.102 Ângulo $\Delta \varpi$ em função do tempo para HD 74156 bd . . . . . . . . . . . . 163

B.103 KH de $e_{1}$ para HD $74156 \mathrm{bd} \ldots \ldots \ldots \ldots$

B.104KH de $e_{2}$ para HD 74156 bd . . . . . . . . . . . . . . . 163

B.105 KH de $e_{1}$ para HD 74156 bd com filtro . . . . . . . . . . . . . . . . 164

B.106 KH de $e_{2}$ para HD 74156 bd com filtro . . . . . . . . . . . . . 164

B.107 Ângulo $\Delta \varpi$ em função do tempo para HIP 14810 cd . . . . . . . . . . . . 165

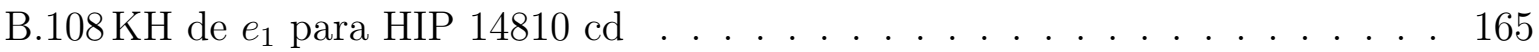

B.109 KH de $e_{2}$ para HIP $14810 \mathrm{~cd} \ldots \ldots \ldots$. . . . . . . . . . 166

B.110 KH de $e_{2}$ para HIP $14810 \mathrm{~cd}$ com filtro . . . . . . . . . . . . . 166

B.111 Ângulo $\Delta \varpi$ em função do tempo para HD 181433 bc . . . . . . . . . . . . 167

B.112 KH de $e_{1}$ para HD 181433 bc . . . . . . . . . . . . . . . 167

B.113 KH de $e_{2}$ para HD 181433 bc . . . . . . . . . . . . . . . 167

B.114 Ângulo $\Delta \varpi$ em função do tempo para $v$ Andrômeda bc . . . . . . . . . . 168

B.115 KH de $e_{1}$ para $v$ Andrômeda bc . . . . . . . . . . . . . . . . . 168

B.116 KH de $e_{2}$ para $v$ Andrômeda bc . . . . . . . . . . . . . . . . 168

B.117 Ângulo $\Delta \varpi$ em função do tempo para HD 74156 dc . . . . . . . . . . . . 169

B.118 KH de $e_{1}$ para HD $74156 \mathrm{dc} \ldots \ldots \ldots \ldots \ldots$

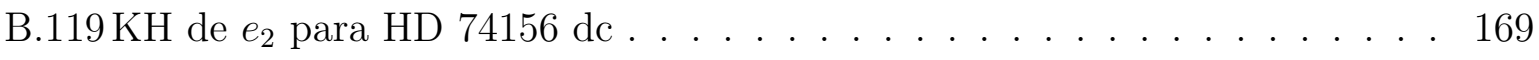

B.120 Ângulo $\Delta \varpi$ em função do tempo para HD $11506 \mathrm{cb}$. . . . . . . . . . . . 170

B.121 KH de $e_{1}$ para HD $11506 \mathrm{cb} \ldots \ldots$. . . . . . . . . . . . 170

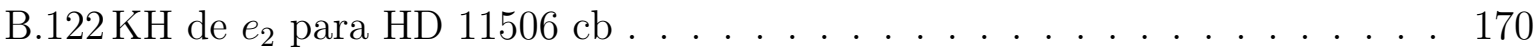

B.123 Ângulo $\Delta \varpi$ em função do tempo para HIP 14810 bc . . . . . . . . . . . . 171

B.124 KH de $e_{1}$ para HIP 14810 bc . . . . . . . . . . . . . . . . . . . 171

B.125 KH de $e_{2}$ para HIP 14810 bc . . . . . . . . . . . . . . . . . . 171

B.126 KH de $e_{1}$ para HIP 14810 bc com filtro . . . . . . . . . . . . . . . 172

B.127 KH de $e_{2}$ para HIP 14810 bc com filtro . . . . . . . . . . . . . . . 172 
B.128 Ângulo $\Delta \varpi$ em função do tempo para HD 169830 bc . . . . . . . . . . . . 173

B.129 KH de $e_{1}$ para HD 169830 bc . . . . . . . . . . . . . . . . 173

B.130 KH de $e_{2}$ para HD 169830 bc . . . . . . . . . . . . . . . . 173

B.131 Ângulo $\Delta \varpi$ em função do tempo para HD 147018 bc . . . . . . . . . . . . 174

B.132 KH de $e_{1}$ para HD 147018 bc . . . . . . . . . . . . . . . . . 174

B.133 KH de $e_{2}$ para HD 147018 bc . . . . . . . . . . . . . . . . . . 174

B.134 KH de $e_{1}$ para HD 147018 bc com filtro . . . . . . . . . . . . 175

B.135 KH de $e_{2}$ para HD 147018 bc com filtro . . . . . . . . . . . . . . . 175

B.136 Ângulo $\Delta \varpi$ em função do tempo para HD 168443 bc . . . . . . . . . . . . 176

B.137 KH de $e_{1}$ para HD 168443 bc . . . . . . . . . . . . . . 176

B.138 KH de $e_{2}$ para HD 168443 bc . . . . . . . . . . . . . . . . 177

B.139 KH de $e_{2}$ para HD 168443 bc com filtro . . . . . . . . . . . . . . . 177

B.140 Ângulo $\Delta \varpi$ em função do tempo para HD 11964 cb . . . . . . . . . . . . 178

B.141 KH de $e_{1}$ para HD $11964 \mathrm{cb} \ldots \ldots \ldots \ldots \ldots$. . . . . . . . . . 178

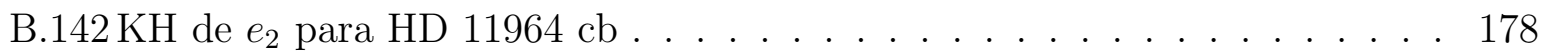

B.143 Excentricidade de HAT-P-13 b em função do tempo . . . . . . . . . . . . 179

B.144 Ângulo $\Delta \varpi$ em função do tempo para HD 38529 bc ......... 180

B.145 KH de $e_{1}$ para HD 38529 bc . . . . . . . . . . . . . . . . . . . 180

B.146 KH de $e_{2}$ para HD 38529 bc . . . . . . . . . . . . . . . . . 180

B.147 Ângulo $\Delta \varpi$ em função do tempo para HD 190360 cb . . . . . . . . . . . . 181

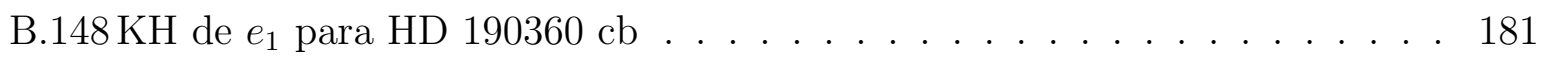

B.149 KH de $e_{2}$ para HD $190360 \mathrm{cb} \ldots \ldots \ldots$. . . . . . . . . . . . . 181

B.150 Ângulo $\Delta \varpi$ em função do tempo para HD 47186 bc . . . . . . . . . . . 182

B.151 KH de $e_{1}$ para HD 47186 bc . . . . . . . . . . . . . . . 182

B.152 KH de $e_{2}$ para HD 47186 bc . . . . . . . . . . . . . . . . . . . . . 182

B.153 Ângulo $\Delta \varpi$ em função do tempo para HD 217107 bc . . . . . . . . . . . . 183

B.154 KH de $e_{1}$ para HD 217107 bc . . . . . . . . . . . . . . 183

B.155 KH de $e_{2}$ para HD 217107 bc . . . . . . . . . . . . . . 183

B.156 Ângulo $\Delta \varpi$ em função do tempo para HD 68988 bc . . . . . . . . . . . . 184

B.157 KH de $e_{1}$ para HD 68988 bc . . . . . . . . . . . . . . . 184

B.158 KH de $e_{2}$ para HD 68988 bc . . . . . . . . . . . . . . . . 184 
B.159 Ângulo $\Delta \varpi$ em função do tempo para HD 187123 bc . . . . . . . . . . . . 185

B.160 KH de $e_{1}$ para HD 187123 bc . . . . . . . . . . . . . . . . 185

B.161 KH de $e_{2}$ para HD 187123 bc . . . . . . . . . . . . . 185 


\section{Lista de Tabelas}

6.1 Resultados das simulações para os planetas do Sistema Solar . . . . . . . . 73

6.2 Resultados das simulações para os sistemas múltiplos extrassolares . . . . . 98

6.3 Resultados das simulações para os sistemas múltiplos extrassolares - complemento . . . . . . . . . . . . . . . . . . . . . . . 99

6.4 Lista dos sistemas com configuração instável . . . . . . . . . . . . . . . . 99

6.5 Períodos orbitais e razões dos períodos de planetas em órbitas consecutivas 100

6.5 Períodos orbitais e razões dos períodos de planetas em órbitas consecutivas 101

6.5 Períodos orbitais e razões dos períodos de planetas em órbitas consecutivas 102

6.5 Períodos orbitais e razões dos períodos de planetas em órbitas consecutivas 103

C.1 Tabela dos parâmetros orbitais utilizados nas simulações .......187

C.2 Tabela dos parâmetros orbitais utilizados nas simulações - continuação 188

C.3 Tabela dos parâmetros orbitais utilizados nas simulações - continuação 189

C.4 Tabela dos parâmetros orbitais utilizados nas simulações - continuação 190 



\section{Sumário}

1. INTRODUÇÃO . . . . . . . . . . . . . . . . . . . . . 29

2. MÉTODOS DE DETECÇÃO . . . . . . . . . . . . . . . . . . . 33

2.1 Velocidade Radial . . . . . . . . . . . . . . . . . . 33

2.2 Astrometria . . . . . . . . . . . . . . . . . . . 35

2.3 Fotometria (Trânsito) . . . . . . . . . . . . . . . . 35

2.4 Timing . . . . . . . . . . . . . . . . . . 36

2.5 Microlensing . . . . . . . . . . . . . . . 36

2.6 Reflexão ou imagem direta . . . . . . . . . . . . . . . . . . . . . 37

2.7 Massas das estrelas . . . . . . . . . . . . . . . . . . . . . . . . . . 37

3. CLASSIFICAÇÃA DINÂMICA . . . . . . . . . . . . . . . . . 41

3.1 Movimentos ressonantes . . . . . . . . . . . . . . . . 42

3.1 .1 Sistemas ressonantes . . . . . . . . . . . . . . . . . . 42

3.1.2 Ressonância entre períodos orbitais . . . . . . . . . . . . . . . . . . 42

3.1.3 Ressonância Spin-Órbita . . . . . . . . . . . . . . . . 44

3.2 Subclasse da Classe I ou Sistemas Quase-Ressonantes . . . . . . . . . . . . 45

3.3 Movimentos seculares . . . . . . . . . . . . . . . . . . . . 45

3.3.1 Sistemas seculares com interações fortes . . . . . . . . . . . . 46

3.3.2 Sistemas hierárquicos . . . . . . . . . . . . . . . . 47

4. CONCEITOS BÁSICOS DE DINÂMICA ORBITAL . . . . . . . . . . . . . 49

4.1 Problema de 2 -corpos . . . . . . . . . . . . . . . . . . . . . . 49 
4.2 Transformação dos elementos orbitais em coordenadas espaciais . . . . . . 55

4.3 Transformação das coordenadas espaciais em elementos orbitais . . . . . . 57

4.4 Problema de 3 -corpos . . . . . . . . . . . . . . . . . . . . . . 59

5. CATÁLOGO DE SISTEMAS MÚLTIPLOS EXTRASSOLARES . . . . . . . 63

5.1 Criação de um catálogo próprio . . . . . . . . . . . . . . 63

5.2 Coleta de dados . . . . . . . . . . . . . . . . . . . . 64

5.3 Simulações numéricas da dinâmica dos planetas extrassolares . . . . . . . . 65

5.4 Preparação das simulações . . . . . . . . . . . . . . . . . . 67

6. SIMULAÇÕES DA DINÂMICA DOS SISTEMAS MÚLTIPLOS EXTRASSOLA-

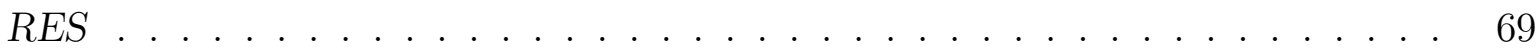

6.1 Sistema Solar . . . . . . . . . . . . . . . . . 70

6.1 .1 Sol-Júpiter-Saturno . . . . . . . . . . . . . . . 70

6.2 Alguns Sistemas Extrassolares . . . . . . . . . . . . . . 74

6.2 .1 GJ $876 \mathrm{dc} \ldots \ldots \ldots \ldots \ldots \ldots \ldots$

6.2 .2 GJ $876 \mathrm{cb} \ldots \ldots \ldots \ldots \ldots$

$6.2 .3 \mathrm{HD} 73526 \mathrm{bc} \ldots \ldots \ldots \ldots \ldots$

6.2 .4 HD $160691 \mathrm{~cd} \ldots \ldots \ldots \ldots . \ldots \ldots$

6.2 .5 HD $160691 \mathrm{db} \ldots \ldots \ldots \ldots \ldots$

6.2 .6 HD 160691 be . . . . . . . . . . . . . . . . . 85

$6.2 .755 \mathrm{Cnc}$ eb . . . . . . . . . . . . . . . . 87

$6.2 .855 \mathrm{Cnc}$ bc . . . . . . . . . . . . . . . . . 88

$6.2 .955 \mathrm{Cnc}$ cf . . . . . . . . . . . . . . . 89

$6.2 .1055 \mathrm{Cnc} f \mathrm{fd} \ldots \ldots \ldots . \ldots \ldots 9 . \ldots \ldots$

$6.2 .11 \mathrm{HD} 40307 \mathrm{bc} \ldots \ldots \ldots \ldots$. . . . . . . . . . . . . . . . . . 92

6.2 .12 HD $40307 \mathrm{~cd} \ldots \ldots \ldots \ldots$. . . . . . . . . . . . . . . . 95

6.3 Dados compilados para os sistemas extrassolares . . . . . . . . . . . . . 97

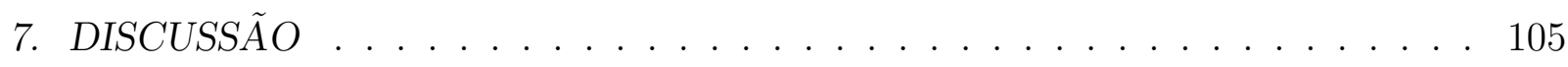

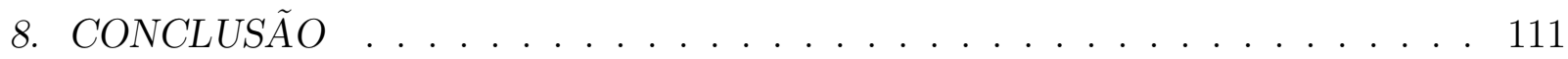

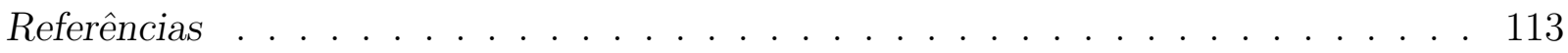


A. Demais simulações para o Sistema Solar . . . . . . . . . . . . . . . . . . . 123

A.1 Sol-Mercúrio-Vênus . . . . . . . . . . . . . . . . . . . . . . . . . 123

A.2 Sol-Vênus-Terra . . . . . . . . . . . . . . . . . . . . . . . . 124

A.3 Sol-Terra-Marte . . . . . . . . . . . . . . . . . . 125

A.4 Sol-Marte-Júpiter . . . . . . . . . . . . . . . . . . . . . . 126

A.5 Sol-Saturno-Urano . . . . . . . . . . . . . . . . . . . . 127

A.6 Sol-Urano-Netuno . . . . . . . . . . . . . . . . . . . . . . . . . . . . . . . . 128

B. Demais simulações para os sistemas extrassolares . . . . . . . . . . . . . . . . . 129

B.1 Classe I - ressonantes . . . . . . . . . . . . . . . . . . . . . . . . . . 129

B.1.1 HD 45364 bc . . . . . . . . . . . . . . . . . . . . . 129

B.1.2 GJ 581 eb (Mayor et al., 2009) . . . . . . . . . . . . . . 131

B.1.3 47 Uma bc . . . . . . . . . . . . . . . . . . . 133

B.1.4 HD 128311 bc . . . . . . . . . . . . . . . . . 135

B.1.5 HD $82943 \mathrm{cb} \ldots \ldots \ldots \ldots \ldots \ldots$

B.1.6 HD 60532 bc . . . . . . . . . . . . . . . . . . . 140

B.1.7 HD 108874 bc . . . . . . . . . . . . . . . . . . . . . 142

B.1.8 HD 102272 bc . . . . . . . . . . . . . . . . . . . . 143

B.2 Classe II - seculares . . . . . . . . . . . . . . . . . . . . . . . . 144

B.2.1 BD 202457 bc . . . . . . . . . . . . . . . . . 144

B.2.2 HD $181433 \mathrm{~cd} \ldots \ldots \ldots \ldots$. . . . . . . . . . . . 145

B.2.3 GJ 581 bc . . . . . . . . . . . . . . . . . . . 146

B.2.4 GJ $581 \mathrm{~cd} \ldots \ldots \ldots \ldots \ldots \ldots$

B.2.5 GJ 581 bc (Mayor et al., 2009) . . . . . . . . . . . . . . . 148

B.2.6 GJ $581 \mathrm{~cd}$ (Mayor et al., 2009) . . . . . . . . . . . . . . . . 149

B.2.7 HD 155358 bc . . . . . . . . . . . . . . . 150

B.2.8 HD 37124 bd . . . . . . . . . . . . . . . . . . . . . . 151

B.2.9 HD $37124 \mathrm{dc} \ldots \ldots \ldots \ldots \ldots$

B.2.10 HD $69830 \mathrm{bc} \ldots \ldots \ldots \ldots \ldots \ldots$

B.2.11 HD $69830 \mathrm{~cd} \ldots \ldots \ldots \ldots \ldots \ldots$ 


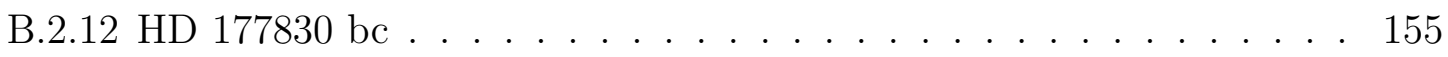

B.2.13 HD $183263 \mathrm{bc} \ldots \ldots \ldots \ldots \ldots \ldots$

B.2.14 HD 202206 bc . . . . . . . . . . . . . . . . . 158

B.2.15 v Andrômeda cd . . . . . . . . . . . . . . . . . . 161

B.2.16 HD 12661 bc . . . . . . . . . . . . . . . . . 162

B.2.17 HD 74156 bd . . . . . . . . . . . . . . . . . 163

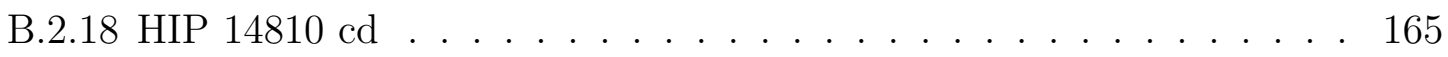

B.3 Classe III - hierárquicos . . . . . . . . . . . . . . . . . . 167

B.3.1 HD 181433 bc . . . . . . . . . . . . . . . . . 167

B.3.2 v Andrômeda bc . . . . . . . . . . . . . . . . . . . . . 168

B.3.3 HD $74156 \mathrm{dc} \ldots \ldots \ldots \ldots$

B.3.4 HD $11506 \mathrm{cb} \ldots \ldots \ldots \ldots \ldots$

B.3.5 HIP 14810 bc . . . . . . . . . . . . . . . . . 171

B.3.6 HD $169830 \mathrm{bc} \ldots \ldots \ldots \ldots \ldots \ldots$

B.3.7 HD 147018 bc . . . . . . . . . . . . . . . . . . 174

B.3.8 HD 168443 bc . . . . . . . . . . . . . . . . 176

B.3.9 HD $11964 \mathrm{cb} \ldots \ldots \ldots \ldots \ldots$

B.3.10 HAT-P-13 bc . . . . . . . . . . . . . . . . . . . 179

B.3.11 HD 38529 bc . . . . . . . . . . . . . . . . . . 180

B.3.12 HD $190360 \mathrm{cb} \ldots \ldots \ldots \ldots$. . . . . . . . . . . . 181

B.3.13 HD 47186 bc . . . . . . . . . . . . . . . . . . 182

B.3.14 HD $217107 \mathrm{bc} \ldots \ldots \ldots \ldots$. . . . . . . . . . . . 183

B.3.15 HD 68988 bc . . . . . . . . . . . . . . . . 184

B.3.16 HD 187123 bc . . . . . . . . . . . . . . . 185

C. Parâmetros orbitais utilizados nas simulações . . . . . . . . . . . . . . 187 
Capítulo 1

\section{INTRODUÇÃO}

A detecção de planetas extrassolares é bastante recente. Em 1992 um professor de Astronomia e Astrofísica da Universidade Estadual da Pensilvânia Alexander Wolszczan e Dail Frail do Observatório Rádio-Astrônomico Nacional do Novo México, EUA, com observações feitas no Observatório de Arecibo, Porto Rico, detectaram dois planetas de dimensões terrestres em volta do pulsar PSR1257+12. A comprovação veio em 1994 e desde então, na presente data (6 de abril de 2010), aproximadamente 442 planetas e 47 sistemas planetários já tiveram detecção comprovada (Catálogo da OSBPM). A descoberta do primeiro planeta em torno de uma estrela da Sequiência Principal (51 Pegasi) foi anunciada em 1995 (Mayor et al., 1995) e de um sistema de planetas múltiplos, em torno de $v$ Andromedae, em 1999 (Butler et al., 1999).

A existência de planetas extrassolares já era cogitada muito antes de sua primeira detecção. Povos antigos como os gregos - Demócritus, ( 460-370 A.C.), Epicurus, (341270 A.C.) - supunham que podiam existir outros sistemas planetários. Giordano Bruno na Europa do século XVI foi condenado à morte na fogueira por ousar declarar que a Terra era somente um entre milhares de outros mundos que existiam no Universo.

Os exoplanetas são objetos muito distantes, pequenos em relação ao tamanho da estrela que orbitam e ofuscados pelo brilho da estrela central; estes fatos dificultam a observação direta por telescópios convencionais. A grande maioria dos planetas encontrados até agora provém dos métodos de detecção indireta da interação gravitacional do planeta com o movimento de uma estrela central, conhecido como velocidade radial. Outros métodos de detecção planetária são: astrometria, trânsito ou fotometria, timing, microlensig e reflexão ou imagem direta. 
A descoberta de planetas além do Sistema Solar desafia as teorias convencionais sobre o nascimento e evolução dos planetas e oferece novas evidências para a melhor compreensão da formação do nosso próprio Sistema Solar e da estrutura do Universo. Além disso, vale a expectativa de se encontrarem planetas similares ao nosso e saber se existe vida como a nossa em outro lugar do Cosmos.

Os planetas descobertos exibem surpreendente variedade de parâmetros físicos e dinâmicos, muito diferentes dos padrões do Sistema Solar. Frequentemente eles possuem massas muito grandes e estão localizados em distâncias extremamente pequenas em relação à estrela central, estes últimos conhecidos como "Júpiteres quentes". As suas órbitas são frequentemente muito achatadas, com excentricidades altas. São detectados planetas em torno de estrelas binárias e triplas, como também em torno de pulsares. Vários sistemas planetários estão envolvidos em ressonâncias de movimentos médios, um cenário não detectado entre os planetas do Sistema Solar. Essas observações nos levam à questão de que se o nosso sistema planetário é uma exceção à regra ou não.

O presente projeto se insere nas atividades do grupo de Dinâmica de Sistemas Planetários do IAG-USP que evoluiu nos últimos anos para o estudo dos planetas fora do Sistema Solar. Um dos objetivos deste projeto é a classificação dinâmica de sistemas planetários extrassolares conhecidos, cujo descobrimento está crescendo rapidamente. Devido à descoberta ser recente e à grande variedade dos parâmetros dinâmicos, não existe ainda padrão estabelecido para classificar esses sistemas. Além disso, existem dificuldades intrínsecas na determinação precisa das órbitas planetárias, devido às técnicas de detecção utilizadas, como também das massas das estrelas. Por outro lado, a caracterização dinâmica é muito importante na hora de escolher a metodologia adequada para estudo estatístico e de estabilidade dos sistemas.

Uma proposta inicial foi elaborada no grupo de Dinâmica do IAG (Ferraz-Mello et al., 2005) e (Michtchenko et al., 2007) e está ilustrada na Figura 1.1. Dois parâmetros orbitais foram escolhidos como cruciais numa descrição de um sistema planetário. Um deles é a distância mútua entre dois planetas, que conforme a $3^{\text {a }}$ lei de Kepler pode ser apresentada como razão de períodos orbitais. Outro parâmetro é apresentado por excentricidades das órbitas que possivelmente carregam a informação sobre a evolução dinâmica de um sistema desde a sua formação até o presente. 
Descritos por dois parâmetros escolhidos, os sistemas podem ser divididos em três classes. A Classe I inclui os sistemas envolvidos em principais ressonâncias de movimentos médios. Este possui uma subclasse com sistemas de excentricidades baixas que não estão envolvidos em ressonâncias de movimentos médios, mas estão bastante próximas a uma. A Classe II descreve os sistemas dos planetas com forte interação secular e, finalmente, a Classe III inclui os sistemas chamados hierárquicos, que são suficientemente distantes para produzir interações mútuas muito fracas.

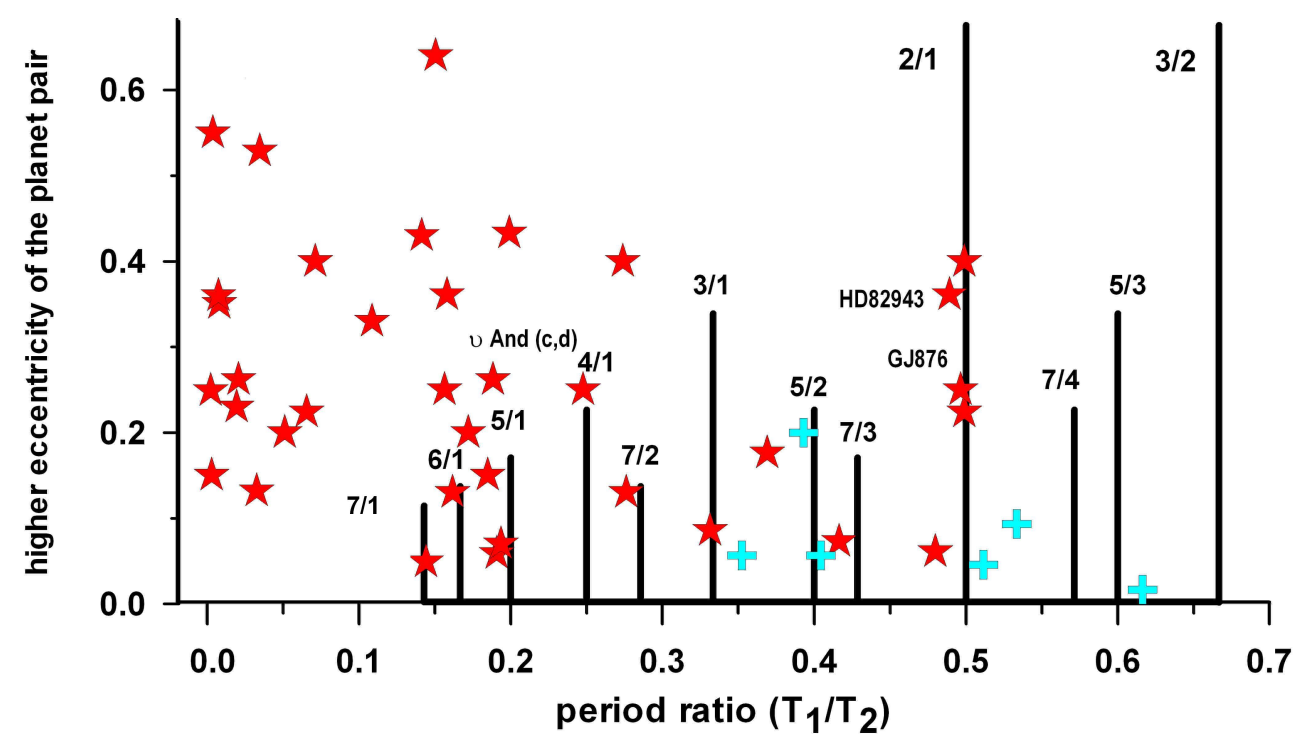

Figura 1.1: Distribuição dos pares planetários nas órbitas consecutivas no plano $\left(T_{1} / T_{2}, e\right)$, onde $T_{1}$ e $T_{2}$ são períodos dos planetas, e é a maior excentricidade do par. A posição nominal das ressonâncias de movimentos médios é dada por picos, cuja altura é inversa à ordem de ressonância. Os pares formados por planetas do Sistema Solar estão indicados por cruzes.

A realização deste projeto constituiu-se das seguintes etapas:

- Criação de um catálogo próprio de sistemas múltiplos extrassolares.

- Simulações numéricas de dinâmica orbital dos sistemas do catálogo próprio.

- Classificação dinâmica dos sistemas extrassolares estudados em: ressonantes, seculares e hierárquicos.

- Caracterização do ângulo $\Delta \varpi$ como: oscilatório em torno de $0^{\circ}$, oscilatório em torno de $180^{\circ}$ ou circulatório. 
Por meio da criação de um catálogo próprio de planetas múltiplos extrassolares, foi possível caracterizar dinamicamente os sistemas múltiplos de planetas extrassolares utilizandose parâmetros pré-estabelecidos. As simulações computacionais permitiram a análise dos dados contidos no catálogo, visando averiguar a estabilidade dos sistemas planetários e, por conseguinte, a confiabilidade dos elementos orbitais utilizados para posterior classificação dinâmica. As simulações foram aplicadas primeiramente aos planetas do Sistema Solar para mostrar a confiabilidade das simulações. 
Capítulo 2

\section{MÉTODOS DE DETECÇÃO}

Até o presente momento, abril de 2010, o panorama dos métodos de detecção distribuise do seguinte modo entre os 442 planetas extrassolares descobertos: 412 por velocidade radial, 71 por fotometria (trânsito), 10 por microlensing, 11 por reflexão ou imagem direta e 9 por timing. Planetas detectados somente por astrometria ainda não foram confirmados. O fato da soma ser maior do que os 442 detectados é devido ao método de velocidade radial ser utilizado geralmente como método complementar para comprovar a detecção de determinado planeta observado por outro método.

\subsection{Velocidade Radial}

O método de velocidade radial é o mais utilizado atualmente na descoberta de novos planetas. Consiste em uma análise de Efeito Doppler no espectro de uma estrela. A velocidade radial é a componente da velocidade orbital da estrela ao redor do baricentro do sistema formado pela estrela e os planetas, projetada na direção de visada do observador. Ao medir a velocidade radial de uma estrela que se aproxima do observador, o espectro da estrela se aproximará do azul (blueshift) e a velocidade será negativa. Se a estrela está se afastando do observador, o espectro se aproximará do vermelho (redshift) e a velocidade será positiva. Para relacionar essas medições com a presença de planetas, é necessário comparar as linhas do espectro da estrela com as linhas de um mesmo elemento obtidas em laboratório. Na existência de planetas orbitando a estrela, haverá uma mudança periódica do azul para o vermelho na medição da velocidade Doppler, o que, apesar de ser uma detecção bastante sutil, indica a presença de um planeta perturbando o movimento da estrela. 
Pelo efeito Doppler, o comprimento de onda de uma fonte que está se movimentando com velocidade $v$, incluindo a correção relativística, é deslocado por:

$$
\frac{\Delta \lambda}{\lambda}=\frac{v}{c} \cos \theta\left(\frac{1}{1-\frac{v^{2}}{c^{2}}}\right)^{\frac{1}{2}}
$$

onde $\theta$ é o ângulo entre o vetor velocidade e a linha de visada. Quando a velocidade é muito menor que a velocidade da luz, a componente de velocidade na direção do observador, velocidade radial $V_{r}$ estará relacionada com o deslocamento espectral por:

$$
\frac{\Delta \lambda}{\lambda}=\frac{V_{r}}{c} .
$$

Em (Beaugé et al., 2007) é mostrado que, em um sistema baricêntrico (em relação ao centro de massa do sistema), a velocidade radial completa de uma estrela em função do tempo $t$ é dada por:

$$
V_{r}(t)=\sum_{i=1}^{N} K_{i}\left[\cos \left(f_{i}+w_{i}\right)+e_{i} \cos w_{i}\right]+V_{r_{0}}
$$

onde

$$
K_{i}=\frac{m_{i} \operatorname{sen} I_{i}}{M} \frac{2 \pi a_{i}}{T_{i} \sqrt{1-e_{i}^{2}}}
$$

e

$$
M=\sum_{i=0}^{N} m_{i}
$$

é a massa total do sistema (estrela e planetas). Os elementos $f$ (anomalia verdadeira), $w$ (argumento do pericentro ou periastro), $e$ (excentricidade), $a$ (semi-eixo maior da órbita), $I$ (inclinação do plano orbital em relação ao plano do céu), T (período de translação) referemse ao(s) planeta(s) com número total igual a N. $V_{r_{0}}$ é a velocidade radial do baricentro com relação às estrelas de fundo, pois, lembrando, os observadores (nós, na Terra) nos movemos com uma velocidade aproximada de $30 \mathrm{~km} / \mathrm{s}$.

As massas dos planetas são dadas em função do seno da inclinação $(m \times \operatorname{sen} I)$, não sendo possível a separação com o método de velocidade radial. As massas informadas são geralmente valores mínimos de massas, assumindo-se que as inclinações são máximas.

Em sistemas ressonantes há uma dificuldade maior na obtenção desses dados, pois movimentos ressonantes causam repetições periódicas na curva de velocidade radial obtida da estrela, o que, em certas circunstâncias, pode dificultar a separação dos componentes para obtenção dos elementos orbitais (Giuppone et al., 2009). 
A grande maioria dos cerca de 442 planetas descobertos até agora foram detectados por este método.

\subsection{Astrometria}

A astrometria é o método mais antigo utilizado na tentativa de busca de planetas extrassolares e é utilizado amplamente na descoberta de estrelas binárias. Consiste em determinar o movimento próprio de uma estrela, tomando como referência estrelas muito distantes que mantêm aparência fixa no plano celeste. Se não existir nenhum planeta ao redor de uma estrela, esta descreverá uma linha reta no céu. Se existir um ou mais planetas em volta desta estrela, ela descreverá um movimento de zig-zag no céu, pois ela e os demais planetas mover-se-ão em torno de um centro de massa, que, por sua vez, mover-se-á em linha reta no céu. Esse movimento aparente é uma projeção do movimento da estrela ao redor do centro de gravidade do sistema - elipse - e o movimento de todo o sistema no espaço - uma reta. Deve-se levar em conta nas medições o fato de que o observador (na Terra) também está em movimento. Um dos problemas das técnicas astrométricas é a precisão nos resultados, pois medem-se ângulos da ordem de milissegundos de arco e a medição exige um longo período de tempo. Por outro lado, este método permite determinar a massa do planeta e sua inclinação em relação à linha de visada.

\subsection{Fotometria (Trânsito)}

Essa técnica também é conhecida como ocultação ou trânsito. É similar à ocorrência de um eclipse, onde a passagem de um planeta em frente à estrela diminui a intensidade do brilho da estrela observada na Terra com o passar do tempo. É limitada pelo fato de o brilho da estrela ser muito intenso comparado com a diminuição causada pela passagem do planeta - é algo como se observar uma mosca passando em frente ao farol de um carro a quilômetros de distância. Também é limitada geometricamente, pois para que essa observação ocorra é necessário que a estrela, o planeta e a Terra estejam no mesmo plano de movimento, também chamado edge-on. Com esta técnica é possível se obter a inclinação em relação à linha de visada e os raios dos planetas e da estrela, porém ela é falha na determinação precisa da excentricidade orbital. 


\subsection{Timing}

É um método de detecção que pode ser traduzido como Tempo de Chegada de Sinais Periódicos. Usado para detectar planetas ao redor de pulsares. O fato de os pulsares emitirem pulsos a intervalos de tempo regular com precisão muito elevada (até a ordem de milésimos de segundos) permite a detecção de corpos de pequena massa que possam orbitar o pulsar através de variações no tempo de chegada dos pulsos. A interação gravitacional do planeta com o pulsar ao longo de sua órbita produz uma variação no período de precessão do pulsar, o que pode ser detectado. Esse método foi o usado pelo professor Alexander Wolszczan e Dail Frail (Wolszczan e Frail, 1992) na detecção do primeiro sistema planetário, em redor do pulsar PSR1257+12 em 1992, no Observatório de Arecibo em Porto Rico, em convênio com a Universidade do Estado da Pensilvânia. Este método tem aplicações bastante restritas porque é difícil de se observar planetas ao redor dos pulsares, pois pulsares são objetos raros.

\subsection{Microlensing}

É um método de detecção previsto pela Teoria da Relatividade Geral de Einstein. Consiste das medições dos efeitos das "lentes gravitacionais". O campo gravitacional de uma estrela desvia a luz de uma estrela mais distante. A luz da estrela distante ao chegar a um observador na Terra produzirá duas imagens, ocasionadas pelo desvio da estrela intermediária que age como lente. A presença de um planeta orbitando a estrela intermediária produzirá uma terceira imagem, ou uma perturbação nas imagens produzidas. Detecção pioneira feita pelos grupos OGLE (Optical Gravitational Lensing Experiment da Universidade de Varsóvia, Andrzej Udalski e Observatório Las Campanas, Chile) e MOA (Microlensign Observations in Astrophysics - Japão e Nova Zelândia, Mt. John Observatory), os quais utilizam técnicas de detecção de imagens avançadas com câmeras CCD. Existe também a limitação da observação no qual as estrelas intermediária e distante devem estar no mesmo plano do observador. 


\subsection{Reflexão ou imagem direta}

É um método simples que consiste na detecção direta da imagem de um planeta produzido por uma estrela, assim como vemos os planetas do nosso sistema solar pela reflexão da luz solar, porém, é muito difícil de ser aplicado. O problema consiste em utilizar um telescópio que consiga detectar a intensidade da luz refletida pelo planeta, pois esta é totalmente ofuscada pela luz emitida pela estrela. A obtenção dos parâmetros orbitais não é possível de se obter com a imagem direta, sendo necessária a comprovação pelo método de velocidade radial.

\subsection{Massas das estrelas}

A massa das estrelas tem papel fundamental nos estudos de dinâmica planetária. A partir da massa são inferidos todos os outros parâmetros essenciais para o entendimento dos sistemas estelares e de sua evolução.

A determinação da massa de uma estrela pode ser obtida sabendo-se a solução do problema de 2-corpos de Newton e da $3^{\text {a }}$ Lei de Kepler. Portanto, a massa de uma estrela só pode ser determinada diretamente quando existe outra estrela companheira no sistema em questão, ou seja, existe uma interação gravitacional entre pelo menos duas estrelas. Medindo-se o período orbital de uma estrela em torno do baricentro, resta conhecer o valor do semi-eixo maior da órbita estelar para inferir a massa. Tal parâmetro só pode ser obtido conhecendo-se a distância do sistema até o observador. Outra possibilidade de determinação de massas de estrelas vem do estudo de estrelas binárias espectroscópicas de linhas duplas, as quais nem sempre exibem informações necessárias para se determinar com precisão as massas das duas estrelas do sistema. Nesses casos, a formulação da chamada função de massa é essencial para o estudo e estimativa das massas dessas estrelas.

Até o presente momento, não há confirmações de detecções de planetas orbitando o baricentro de um sistema estelar binário. O cenário atual é de planetas orbitando estrelas que não são binárias ou de planetas orbitando estrelas que fazem parte de um sistema binário, porém, a distância entre as estrelas é tão grande $\left(\sim 10^{3}\right.$ unidades astronômicas - U.A.) que a interação com a companheira binária pode ser desprezada nas simulações desta dissertação. 
Neste estudo, dos 37 sistemas extrassolares múltiplos analisados, somente 5 são sistemas cujas estrelas principais pertencem a um sistema binário. A maior separação entre as binárias está no sistema HD 38529 ( 12.000 U.A.) e a menor no sistema $v$ Andrômeda ( 750 U. A.). Para que algum tipo de influência da estrela companheira binária fosse significante, a distância entre elas deveria ser menor que 300 U. A., no mínimo (Desidera e Barbieri, 2006) .

No caso de estrelas individuais, como as estrelas não possuem uma estrela companheira para inferir suas massas diretamente, usam-se modelos como as relações empíricas de Massa x Luminosidade, onde, medindo-se a luminosidade da estrela, estima-se a massa.

\section{Relação Massa X Luminosidade}

O cálculo das massas das estrelas em sistemas binários levou a uma conhecida relação empírica entre a massa de uma estrela e sua luminosidade. Essa relação permite estimar a massa da estrela baseado no seu tipo espectral. Para grandes massas (acima de 3 massas solares), a luminosidade é aproximadamente proporcional ao cubo da massa $\rightarrow \mathrm{L} \sim M^{3}$. Para pequenas massas (menos de uma massa solar), a dependência é aproximadamente $\rightarrow$ $\mathrm{L} \sim M^{4,5}$. De acordo com essa relação, uma estrela cerca de mil vezes mais brilhante que o Sol tem aproximadamente 10 massas solares, por exemplo. 


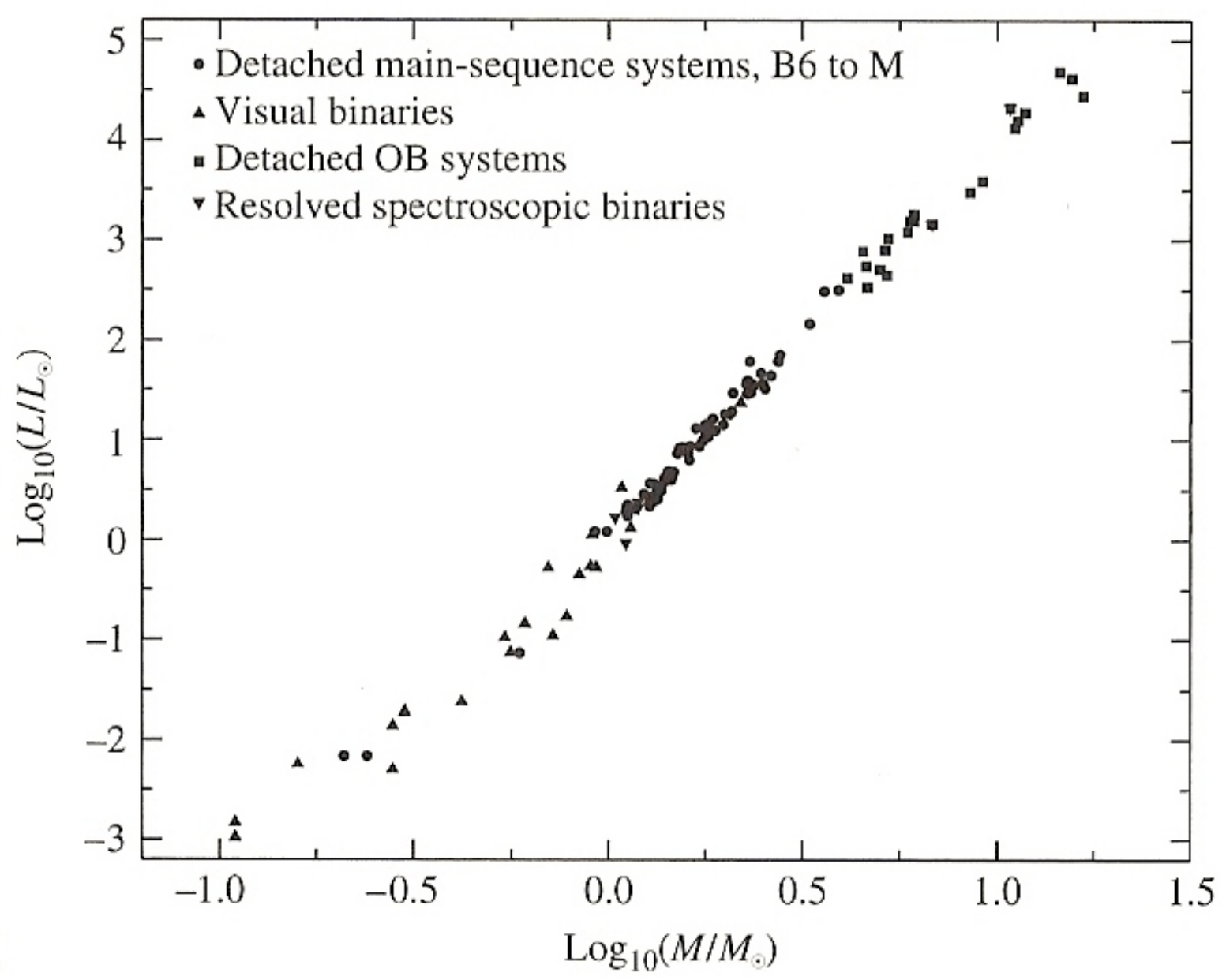

Figura 2.1: Relação empírica Massa X Luminosidade (Carrol e Ostlie, 1996) 
Capítulo 3

\section{CLASSIFICAÇÃO DINÂMICA}

A caracterização dinâmica dos sistemas múltiplos extrassolares que é o escopo desta dissertação segue a classificação exposta no trabalho Dynamics of the Extra-solar Planetary Systems de T.A. Michtchenko, S. Ferraz-Mello and C. Beaugé (Michtchenko et al., 2007), que é baseada na classificação de S. Ferraz-Mello no trabalho Extrasolar Planetary Systems (Ferraz-Mello et al., 2005).

Do ponto de vista dinâmico, a distância mútua entre os planetas é a característica mais importante do sistema. De acordo com a $3^{\mathrm{a}}$ Lei de Kepler, ela está relacionada com a razão dos períodos orbitais dos planetas. Vale a pena lembrar que períodos orbitais são parâmetros primários do conjunto das observações e, portanto, livre das incertezas relacionadas às massas. Excentricidades das órbitas planetárias também são importantes porque elas possivelmente trazem informações da evolução dinâmica do sistema. Usando esses dois parâmetros, e selecionando apenas os pares de planetas em órbitas consecutivas é possível montar o gráfico que já foi mostrado anteriormente (Figura 1.1) e que é reconstruído ao final desta dissertação. Neste gráfico também consta a posição nominal das ressonâncias de baixa ordem de movimentos médios, como dada pela $3^{\text {a }}$ Lei de Kepler.

A posição do par de planetas com respeito à ressonância de movimentos médios define seu comportamento qualitativo. Para distinguir tipos de comportamento planetários, são usadas 3 classes propostas em (Ferraz-Mello et al., 2005). Para o propósito desse estudo, esta classificação é levemente modificada, como no trabalho de (Michtchenko et al., 2007) e os sistemas são divididos, portanto, em classes, I, II e III.

A Classe I inclui os pares próximos $\left(0,2<T_{1} / T_{2}<1\right)$ envolvidos em uma das ressonâncias de movimentos médios, onde $T_{1}$ e $T_{2}$ são os períodos orbitais dos planetas in- 
terno e externo, respectivamente. A Classe II inclui planetas que não estão envolvidos nas ressonâncias de movimentos médios mas ainda próximos uns dos outros $\left(0,14<T_{1} / T_{2}<\right.$ 1) sujeitos a fortes interações gravitacionais mútuas. A Classe III inclui os pares de planetas que estão muito separados $\left(T_{1} / T_{2}<0,14\right)$ e, consequentemente, interagem fracamente. Estes sistemas são frequentemente chamados de sistemas hierárquicos (Ford et al., 2000); (Lee e Peale, 2003). Deve-se enfatizar que os valores de intervalos de razões de períodos $\left(T_{1} / T_{2}\right)$ são escolhidos arbitrariamente baseando-se no cenário disponível até o momento.

Vale a pena alertar aqui sobre a possível dificuldade de distinguir as populações de Classe I e Classe II. Estas dificuldades crescem principalmente devido às incertezas na determinação dos parâmetros físicos e orbitais dos planetas (Ford, 2005).

\subsection{Movimentos ressonantes}

\subsubsection{Sistemas ressonantes}

Os sistemas ressonantes da Classe I estão sujeitos a fortes interações gravitacionais e são significativamente perturbados em escalas de tempo relativas às suas órbitas. Dois planetas muito próximos $\left(T_{1} / T_{2}>0,45\right)$ em órbitas muito excêntricas são incapazes de se manterem estáveis se não estiverem atados por uma ressonância de movimentos médios. A ressonância, na verdade, pode tanto ser responsável pela estabilidade, quanto pela instabilidade do sistema (Callegari Jr., 2006). A população de Classe I é geralmente caracterizada por planetas de grandes massas e altas excentricidades orbitais.

\subsubsection{Ressonância entre períodos orbitais}

Diz-se que dois corpos encontram-se em ressonância orbital ou ressonância de movimentos médios, quando a configuração exata do sistema se repete em intervalos regulares, o que quer dizer que o período orbital de um é uma fração exata do período do outro, em geral essa razão está próxima de números inteiros pequenos.

Toma-se por $p+q$ o período do sistema de maior período e por $p$ o período do sistema de menor período. A ressonância é caracterizada por:

$$
\frac{p+q}{p}
$$


A ordem da ressonância é caracterizada por um valor inteiro q. Quanto menor a ordem de uma ressonância mais forte ela é. A ressonância de menor ordem possível é a de ordem zero, não existindo limites para a maior ordem que possa existir. A largura e força de uma ressonância são inversamente proporcionais à sua ordem, portanto, ressonâncias de ordem muito grandes não costumam ser usuais para se estudar um determinado sistema.

A ressonância entre os períodos orbitais é a ressonância mais comum e recorrente nos sistemas estudados. Existem inúmeros casos no nosso Sistema Solar, como, por exemplo, entre Netuno e Plutão, Júpiter e os asteróides Troianos, os anéis de Saturno e entre diversas luas de Júpiter e Saturno.

\section{Ressonância Netuno - Plutão}

Descoberta por Cohen e Hubbard em 1965, é uma ressonância orbital de ordem um, cuja relação é 3/2. Netuno apresenta um período de translação em torno do Sol de 165 anos, enquanto que Plutão realiza o mesmo movimento em 248 anos. É conhecido que Plutão tem a órbita com a excentricidade mais alta no Sistema Solar, o que faz com que em determinadas épocas ele esteja mais próximo do Sol do que Netuno. A ressonância existente entre os períodos orbitais desses dois corpos é exatamente o que impede de haver uma colisão entre eles. Atualmente, foram descobertos muitos objetos na região de Plutão, conhecidos como trans-netunianos que estão envolvidos na mesma ressonância $3 / 2$ com Netuno.

\section{Ressonância Júpiter - Troianos}

A ressonância entre o planeta Júpiter e os asteróides Troianos é um exemplo clássico de ressonância 1/1, de ordem zero. Os asteróides Troianos são corpos que estão localizados nos Pontos Lagrangeanos ${ }^{1}$ do problema restrito de três corpos. Estes apresentam período orbital fixo em relação ao de Júpiter, devido a uma forte ressonância. Uns satélites externos jovianos apresentam movimento retrógrado em relação a Júpiter, o que pode indicar a

\footnotetext{
${ }^{1}$ Pontos descobertos por Joseph-Louis Lagrange (1736-1813), onde as forças gravitacionais de 3 diferentes corpos, com massa, cancelam-se exatamente. Por exemplo, para o sistema Sol-Terra-Lua, os pontos lagrangeanos $L_{1}, L_{2}$ e $L_{3}$ são pontos gravitacionalmente instáveis, já os pontos $L_{4}$ e $L_{5}$ são pontos gravitacionalmente estáveis. Os asteróides troianos estão em pontos lagrangeanos gravitacionalmente estáveis.
} 
mesma origem entre esses satélites e os asteróides Troianos, ou seja, que os satélites nada mais sejam do que Troianos capturados.

\section{Ressonância nos anéis de Saturno}

Sabe-se que um planeta pode originar perturbações gravitacionais nas órbitas das partículas de poeira de forma a aprisioná-las em ressonâncias orbitais com o planeta. Em relação aos anéis de Saturno, existem evidências de que as partículas de poeiras componentes dos anéis estejam em ressonância com Saturno e com seus satélites. Por exemplo, uma partícula na borda exterior do anel B (mais interno) de Saturno está em ressonância 2/1 com o satélite Mimas, o que quer dizer que circunda o planeta exatamente duas vezes para cada volta que o satélite completa. Outro exemplo: o limite exterior do anel A (mais externo) de Saturno está em ressonância 7/6 com as luas Janos e Epimeteu.

Órbitas que estão próximas de lugares ressonantes sofrem distorções excepcionalmente grandes porque os leves puxões gravitacionais das luas se repetem sistematicamente e, portanto, têm seu efeito acumulado com o passar do tempo. As ressonâncias são mais fortes em órbitas mais próximas da lua, mas quando elas são próximas demais diferentes ressonâncias lutam pelo controle e os movimentos tornam-se caóticos. Em todos os enormes anéis de Saturno, apenas umas poucas dezenas de lugares respondem à ressonância de satélites fortes.

O resultado dessas perturbações ressonantes varia. As fortes limpam materiais, e são responsáveis pelas bordas externas dos anéis A e B de Saturno. Em alguns lugares surgem clareiras, "vazios", lugares onde não existem grãos de poeira.

Ressonâncias análogas explicam a distribuição de material no cinturão de asteróides, no qual o Sol desempenha o papel do planeta e Júpiter o do satélite (Burns et al., 2003).

\subsubsection{Ressonância Spin-Órbita}

A chamada ressonância spin-órbita é a relação entre o período orbital e o período de translação. Como exemplos, temos no nosso Sistema Solar as ressonâncias spin-órbita entre Mercúrio e o Sol e entre a Terra e a Lua. Dividindo-se o período de translação de Mercúrio em torno do Sol pelo período de rotação, obtemos exatamente 1,5. Esta é uma ressonância de ordem um, cuja relação é 3/2. Isto significa dizer que a cada três voltas em 
torno do seu eixo, Mercúrio descreve duas voltas em torno do Sol.

A ressonância spin-órbita mais conhecida é a entre a Terra e a Lua. Esta é uma ressonância de ordem zero, cuja relação é $1 / 1$. Isto explica o porquê de a Lua ter sempre a mesma face observada da Terra. Esses exemplos ocorrem devido aos processos evolutivos que ocasionaram a dissipação de energia dos sistemas pelo efeito de marés.

Por ainda não ser possível identificar este tipo de ressonância nos sistemas extrassolares, ela não é analisada nesta dissertação.

\subsection{Subclasse da Classe I ou Sistemas Quase-Ressonantes}

Existe também uma subclasse peculiar de sistemas com planetas de baixa excentricidade que não estão capturados pela ressonância de movimentos médios, mas estão muito próximos de uma. Esses sistemas podem ser chamados de quase-ressonantes. A subclasse de planetas próximos a ressonâncias, ao contrário dos sistemas ressonantes, é populada por planetas de baixa excentricidade. Por exemplo, no Sistema Solar, os planetas Júpiter e Saturno estão próximos da ressonância 5/2 (Michtchenko e Ferraz-Mello, 2001a). Saturno e Urano estão próximos da ressonância 3/1 e os planetas Urano e Netuno, próximos da ressonância 2/1. Essas configurações de proximidade de ressonâncias podem gerar cenários de instabilidade no Sistema Solar exterior apesar de poderem se manter por centenas de milhares de anos (Michtchenko e Ferraz-Mello, 2001b). Essas configurações são ainda associadas com hipóteses de migrações durante a formação do Sistema Solar. A frequência e característica das ressonâncias de movimentos médios podem ser uma prova da natureza de migrações planetárias em sistemas com múltiplos planetas gigantes (Wright, 2009).

Os planetas terrestres do pulsar PSR $1257+12$ (PSR 1257+12 b e PSR 1257+12 c) também são um exemplo de proximidade de ressonância: $3 / 2$.

\subsection{Movimentos seculares}

Os movimentos seculares são aqueles que não se encaixam em algum tipo de ressonância de movimentos médios.

A variável característica do movimento secular é a diferença das longitudes:

$$
\Delta \varpi=\varpi_{2}-\varpi_{1} .
$$


onde:

$$
\varpi=\omega+\Omega
$$

é chamada de longitude do pericentro, onde $\omega$ é o argumento do pericentro e $\Omega$ é a longitude do nodo ascendente.

O comportamento secular de um par de planetas pode ser apresentado como a interação gravitacional de dois anéis com massas planetárias que, interagindo, mudam a forma, e (excentricidade), e a orientação mútua, $\Delta \varpi$ (diferença das longitudes), mas não mudam o tamanho, a (semi-eixo maior).

O movimento secular do ângulo $\Delta \varpi$ pode ser oscilatório em torno de $0^{\circ}$, oscilatório em torno de $180^{\circ}$ ou circulatório. Quando o ângulo $\Delta \varpi$ oscila em torno de $0^{\circ}$ ou de $180^{\circ}$, as excentricidades dos planetas externo e interno terão variações em antifase (quando uma for mínima a outra será máxima e vice-versa) devido à conservação do momento angular (Ferraz-Mello e Michtchenko, 2005) e (Michtchenko e Malhotra, 2004).

Em Michtchenko e Malhotra (2004) é estudado que em regime de moderadas a altas excentricidades, essa configuração de alinhamento pode se bifurcar em órbitas periódicas estáveis ou instáveis, pois no espaço de fase de altas excentricidades surge uma separatriz na fronteira da zona de ressonância não-linear.

\subsubsection{Sistemas seculares com interações fortes}

Nos sistemas seculares, Classe II, a interação gravitacional entre esses planetas deve ser forte, mas a conservação do momento angular limita as variações de excentricidades permitindo mantê-los em configurações estáveis mesmo se não estiverem capturados por uma ressonância de movimentos médios. Os sistemas dessa classe apresentam variações de longo período, descritas primeiramente como perturbações seculares, grandes variações de excentricidades e efeitos dinâmicos interessantes, como alinhamento ou anti-alinhamento da linha das ápsides (Michtchenko e Malhotra, 2004). Os membros da Classe II são localizados em regiões entre as ressonâncias de movimentos médios. Alguns desses sistemas tem excentricidades muito altas (e $>0,4)$ e podem ser considerados como possíveis candidatos para a Classe I, desde que a atualização de seus parâmetros orbitais possam colocá-los em uma ordem de ressonância de movimentos médios. 


\subsubsection{Sistemas hierárquicos}

Nos sistemas hierárquicos, Classe III, a interação gravitacional entre os planetas é mais fraca que na Classe II devido às grandes distâncias mútuas. A probabilidade de estarem capturados em uma ressonância de movimentos médios, que é de alta ordem neste domínio, é quase desprezível. A interação leva a variações de longo período nas excentricidades e variações uniformes ou quase uniformes de $\Delta \varpi$. Uma consequência da fraca interação gravitacional é a baixa sensibilidade das órbitas publicadas a pequenas variações. Isso significa que, apesar de os parâmetros orbitais dessa classe serem menos acurados que os parâmetros orbitais dos sistemas da Classe II, as simulações com sistemas de Classe III quase sempre mostram sistemas de configurações estáveis. A população de Classe III é facilmente identificada como baixos valores de $T_{1} / T_{2}$. Devido a fracas perturbações mútuas, estes sistemas residem em zonas estendidas de estabilidade nas quais eles facilmente podem sobrevivem por um longo tempo. Vale notar que alguns desses planetas têm grandes massas correspondentes a anãs marrons e todos eles têm altas excentricidades. 


\section{Capítulo 4}

\section{CONCEITOS BÁSICOS DE DINÂMICA ORBITAL}

\subsection{Problema de 2-corpos}

O problema de 2-corpos permite que se calcule as posições e velocidades, em dado instante, de dois corpos de massas conhecidas movendo-se sob a ação da força gravitacional mútua entre eles, conhecidas suas posições e velocidades iniciais.

No estudo de caracterização dinâmica dos sistemas extrassolares analisados é utilizado o modelo de 3-corpos, referente a uma estrela e dois planetas, onde suas trajetórias são integradas considerando-se a perturbação mútua entre os corpos envolvidos. Para obter solução para o problema estudado, são utilizadas as soluções do problema de 2-corpos, que é explicado a seguir.

Nos casos de sistemas extrassolares que contêm mais de dois planetas, as simulações são feitas sempre envolvendo a estrela e um par de planetas em órbitas consecutivas. Por exemplo: no caso do sistema HD 69830, têm-se três planetas: b, c, d, em ordem de distância crescente à estrela. As simulações são feitas primeiro considerando-se a estrela e os planetas b, c e depois a estrela e os planetas c, d. Está claro que essa é uma aproximação em primeira ordem e modelos mais complexos devem ser usados em sistemas com ressonância laplaciana de 3-corpos.

As equações mostradas a seguir são estudadas no curso de Mecânica Celeste e foram em sua grande maioria extraídas do livro Orbital Motion - Roy (1978), que pode ser consultado para uma análise mais completa do problema em questão. São mostradas apenas as equações pertinentes à construção do programa utilizado nas simulações deste estudo. 


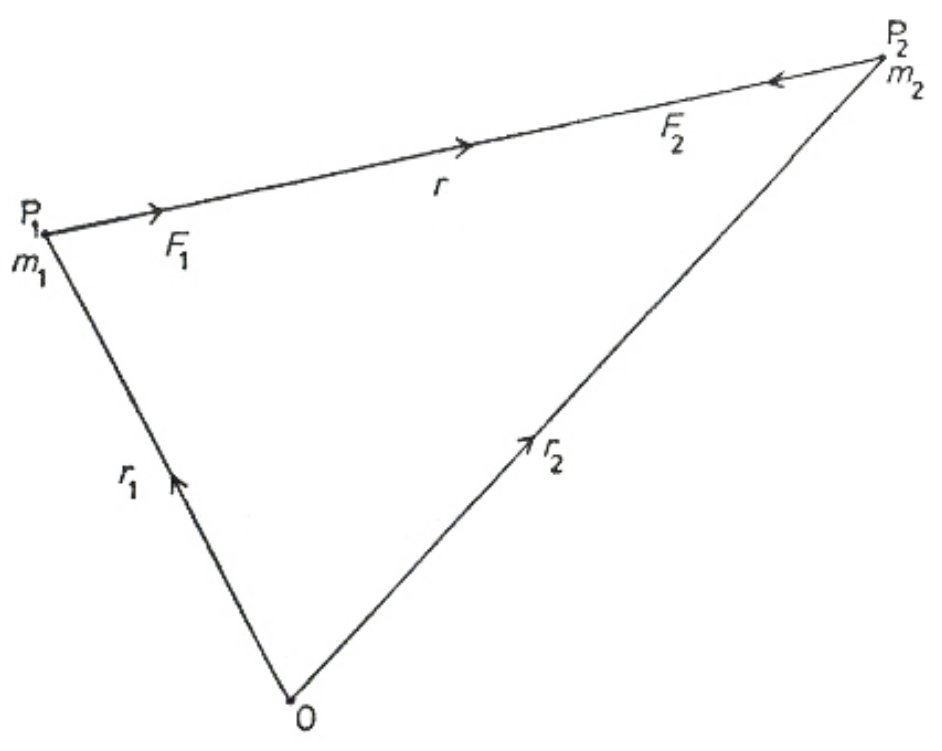

Figura 4.1: Problema de 2-corpos em coordenadas retangulares (Roy, 1978)

Solução para o problema de 2-corpos

De acordo com a Figura (4.1) a força de atração $\boldsymbol{F}_{\mathbf{1}}$ age na massa $m_{1}$ sobre o vetor $\boldsymbol{r}$ de posição em direção à massa $m_{2}$ enquanto a força $\boldsymbol{F}_{\mathbf{2}}$ age em $m_{2}$ na direção contrária.

Pela $3^{\text {a }}$ Lei de Newton (Ação e Reação), tem-se:

$$
F_{1}=-F_{2}
$$

e utilizando-se a Lei de Gravitação Universal para duas partículas separadas a uma distância $r$ :

$$
F=G \frac{m_{1} m_{2}}{r^{2}}
$$

Pode-se escrever $F_{1}$ e $F_{2}$ na forma vetorial:

$$
\begin{gathered}
F_{1}=G \frac{m_{1} m_{2}}{r^{2}} \frac{\boldsymbol{r}}{r} \\
F_{2}=-G \frac{m_{1} m_{2}}{r^{2}} \frac{\boldsymbol{r}}{r}
\end{gathered}
$$

A $2^{\text {a }}$ Lei de Newton diz o seguinte:

$$
\boldsymbol{F}=m \boldsymbol{a},
$$


ou, vetorialmente:

$$
\boldsymbol{F}=m \frac{d^{2} \mathbf{r}}{d t^{2}}
$$

Então, unindo as equações (4.3) e (4.4) com (4.6), surgem 2 outras equações:

$$
\begin{aligned}
& m_{1} \frac{d^{2} \boldsymbol{r}_{\mathbf{1}}}{d t^{2}}=G \frac{m_{1} m_{2}}{r^{2}} \frac{\boldsymbol{r}}{r}, \\
& m_{2} \frac{d^{2} \boldsymbol{r}_{\mathbf{2}}}{d t^{2}}=-G \frac{m_{1} m_{2}}{r^{2}} \frac{\boldsymbol{r}}{r}
\end{aligned}
$$

Os vetores $\boldsymbol{r}_{\mathbf{1}}$ e $\boldsymbol{r}_{\mathbf{2}}$ são respectivamente as distâncias do ponto de referência inercial (absoluto) da origem $\mathbf{O}$ às massas $m_{1}$ e $m_{2}$.

Somando as equações (4.7) e (4.8), resulta em:

$$
m_{1} \frac{d^{2} \boldsymbol{r}_{\mathbf{1}}}{d t^{2}}+m_{2} \frac{d^{2} \boldsymbol{r}_{\mathbf{2}}}{d t^{2}}=0
$$

Integrando-se (4.9) uma vez:

$$
m_{1} \frac{d \boldsymbol{r}_{\mathbf{1}}}{d t}+m_{2} \frac{d \boldsymbol{r}_{\mathbf{2}}}{d t}=\boldsymbol{a}
$$

E mais uma vez:

$$
m_{1} \boldsymbol{r}_{\mathbf{1}}+m_{2} \boldsymbol{r}_{\mathbf{2}}=\boldsymbol{a} t+\boldsymbol{b}
$$

onde $\mathbf{a}$ e b são vetores constantes.

Introduzindo o vetor $\mathbf{R}$ como o vetor posição do centro de massa das massas $m_{1}$ e $m_{2}$ :

$$
M \boldsymbol{R}=m_{1} \boldsymbol{r}_{\mathbf{1}}+m_{2} \boldsymbol{r}_{\mathbf{2}}
$$

e

$$
M=m_{1}+m_{2} .
$$

Agrupando as equações (4.12) com (4.10) e (4.13) com (4.11), mostra-se que o centro de massa do sistema se move com velocidade constante:

$$
M \frac{d R}{d t}=a
$$

por uma reta dada por:

$$
M R=a t+b .
$$

Cancelando as massas e subtraindo (4.8) de (4.7) resulta:

$$
\frac{d^{2}\left(\boldsymbol{r}_{\mathbf{1}}-\boldsymbol{r}_{\mathbf{2}}\right)}{d t^{2}}=G\left(m_{1}+m_{2}\right) \frac{\boldsymbol{r}}{r^{3}} .
$$


Sabendo que:

$$
r_{1}-r_{2}=-r
$$

a equação (4.16) fica simplificada:

$$
\frac{d^{2} \boldsymbol{r}}{d t^{2}}+\frac{\mu \boldsymbol{r}}{r^{3}}=0
$$

onde:

$$
\mu=G\left(m_{1}+m_{2}\right)
$$

Essa é a equação de movimento de um corpo no campo gravitacional gerado por outro.

Fazendo o produto vetorial de $\mathbf{r}$ com a equação (4.18), obtem-se:

$$
\boldsymbol{r} \times \frac{d^{2} \boldsymbol{r}}{d t^{2}}=0
$$

Integrando:

$$
r \times \frac{d \boldsymbol{r}}{d t}=c
$$

onde c é um vetor constante que representa o momento angular. Sendo este vetor constante, apontando para a mesma direção para todo tempo $t$, o movimento de um corpo em relação a outro resulta num plano definido pela direção de $\mathbf{c}$.

Introduzindo as coordenadas polares $r$ e $\theta$ neste plano, como na Figura (4.2) a componente vetorial de velocidade sobre o vetor radial que une $m_{1}$ a $m_{2}$ é $\dot{r}$ e a componente vetorial de velocidade, perpendicular a esse mesmo vetor é r $\dot{\theta}$.

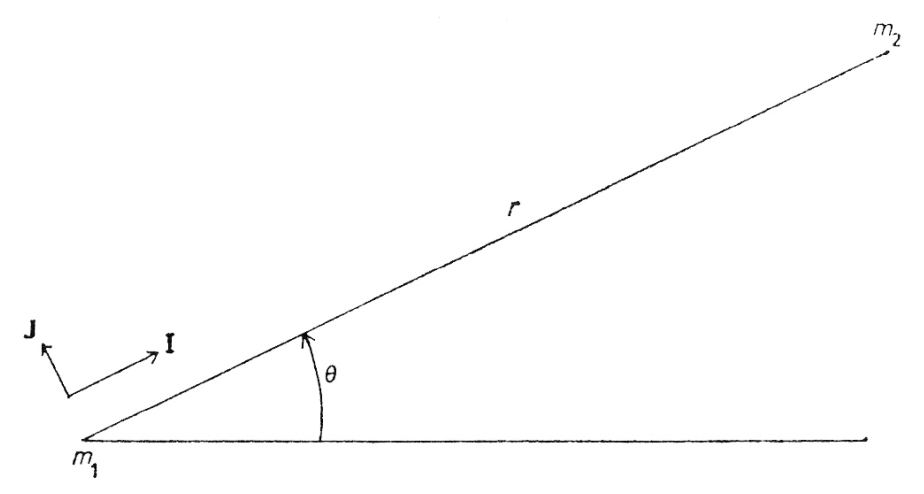

Figura 4.2: Problema de 2-corpos em coordenadas polares (Roy, 1978)

O que significa:

$$
\dot{\boldsymbol{r}}=\boldsymbol{I} \dot{\boldsymbol{r}}+\boldsymbol{J} \dot{r}
$$


onde I e J são vetores unitários sobre e perpendicularmente ao vetor radial.

Então, das equações (4.21) e (4.22):

$$
\boldsymbol{I} r \times(\boldsymbol{I} \dot{r}+\boldsymbol{J} r \dot{\theta})=r^{2} \dot{\theta} K=\boldsymbol{c},
$$

onde K é um vetor unitário perpendicular ao plano da órbita. Reescrevendo:

$$
r^{2} \dot{\theta}=c
$$

onde a constante $c$ é duas vezes a razão da área varrida pelo vetor radial, representando a forma matemática da $2^{\mathrm{a}}$ Lei de Kepler. Essa equação é conhecida como integral da área.

Agora, fazendo o produto escalar de $\dot{r}$ com a equação (4.18):

$$
\dot{\boldsymbol{r}} \cdot \frac{d^{2} \boldsymbol{r}}{d t^{2}}+\mu \frac{\dot{\boldsymbol{r}} \cdot \boldsymbol{r}}{r^{3}}=0 .
$$

Integrando-se uma vez:

$$
\frac{1}{2} \dot{\boldsymbol{r}} \cdot \dot{\boldsymbol{r}}-\frac{\mu}{r}=C
$$

onde $\mathrm{C}$ é uma constante e $\dot{\boldsymbol{r}} \cdot \dot{\boldsymbol{r}}$ é igual a $v^{2}$, obtem-se:

$$
\frac{1}{2} v^{2}-\frac{\mu}{r}=C
$$

A quantidade $\mathrm{C}$ é a energia total normalizada pelo coeficiente de massa. A primeira parte da equação $\left(\frac{1}{2} v^{2}\right)$ corresponde à energia cinética e a segunda parte $\left(-\frac{\mu}{r}\right)$ corresponde à energia potencial do sistema.

De volta à Figura (4.2) e introduzindo as componentes de aceleração em $P_{2}$ sobre e perpendicularmente ao vetor radial, respectivamente:

$$
\ddot{r}-r \dot{\theta^{2}}
$$

e

$$
\frac{1}{r} \frac{d}{d t}\left(r^{2} \dot{\theta}\right)
$$

Então a equação (4.18) pode ser escrita como:

$$
\boldsymbol{I}\left(\ddot{r}-r \dot{\theta^{2}}\right)+\boldsymbol{J}\left[\frac{1}{r} \frac{d}{d t}\left(r^{2} \dot{\theta}\right)\right]+\frac{\mu}{r^{3}} \boldsymbol{I} r=0 .
$$

Igualando os coeficientes dos vetores se obtem:

$$
\ddot{r}-r \dot{\theta^{2}}=-\frac{\mu}{r^{2}},
$$




$$
\frac{1}{r} \frac{d}{d t}\left(r^{2} \dot{\theta}\right)=0
$$

A integral da equação (4.32) é o momento angular da equação (4.24).

Substituindo $u=\frac{1}{r}$ e eliminando o tempo das equações (4.31), (4.32) e (4.24) obtem-se:

$$
\frac{d^{2} u}{d \theta^{2}}+u=\frac{\mu}{c^{2}}
$$

A solução geral desta equação é:

$$
u=\frac{\mu}{c^{2}}+A \cos (\theta-w),
$$

onde $A$ e $w$ são duas constantes de integração.

Reintroduzindo $r$, a equação (4.34) apresenta a trajetória do corpo:

$$
r=\frac{c^{2} / \mu}{1+\left(A c^{2} / \mu\right) \cos (\theta-w)} .
$$

A equação polar de uma seção cônica pode ser escrita como:

$$
r=\frac{p}{1+e \cos (\theta-w)}
$$

tal que

$$
p=\frac{c^{2}}{\mu}
$$

$\mathrm{e}$

$$
e=\frac{A c^{2}}{\mu}
$$

Então fica mostrada a trajetória do problema de 2-corpos, que é uma seção cônica. A $1^{a}$ Lei de Kepler - Lei das órbitas elípticas - é um caso especial da solução geral. De fato, a órbita de um corpo relativa ao outro é classificada de acordo com o valor da excentricidade e. Ou seja:

- para $0 \leqslant \mathrm{e}<1$ a órbita é uma elipse

- para e = 1 a órbita é uma parábola

- para e $>1$ a órbita é uma hipérbole

Nesta dissertação, interessa somente a solução referente ao movimento elíptico, que será aprofundado conseguintemente. 


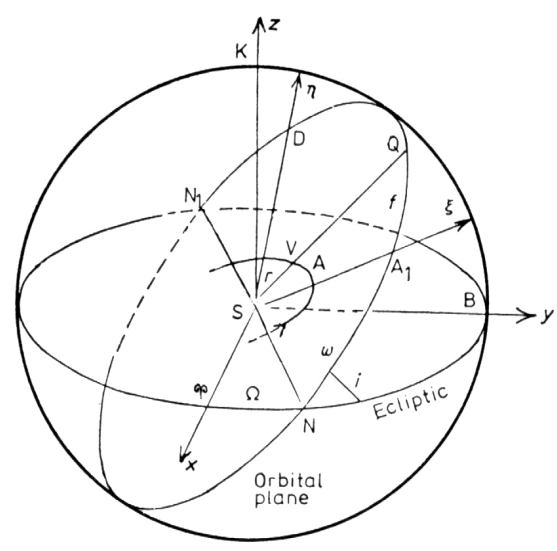

Figura 4.3: Coordenadas eclípticas (Roy, 1978)

\subsection{Transformação dos elementos orbitais em coordenadas espaciais}

Uma órbita é unicamente definida por 6 parâmetros: $a$ (semi-eixo maior da órbita), $e$ (excentricidade), $i$ (inclinação do plano orbital sobre o plano fundamental de referência), $\omega$ (argumento do pericentro), $\Omega$ (longitude do nodo ascendente) e $M$ (anomalia média). Desses, a inclinação e a longitude do nodo ascendente fixam o plano da órbita no espaço, o semi-eixo maior e a excentricidade fixam o tamanho e achatamento da elipse e o argumento do pericentro fixa a elipse no plano. Por último, a anomalia média fixa a posição do planeta na órbita em dado instante.

Partindo-se da Figura (4.3), pode-se mostrar que um corpo em movimento orbital no espaço tem as seguintes relações entre seus elementos $\omega, \Omega$ e $i$ :

$$
\begin{gathered}
l_{1}=\cos \Omega \cos \omega-\operatorname{sen} \Omega \operatorname{sen} \omega \cos i, \\
m_{1}=\operatorname{sen} \Omega \cos \omega-\cos \Omega \operatorname{sen} \omega \cos i, \\
n_{1}=\operatorname{sen} \omega \operatorname{sen} i, \\
l_{2}=-\cos \Omega \operatorname{sen} \omega-\operatorname{sen} \Omega \cos \omega \cos i, \\
m_{2}=-\operatorname{sen} \Omega \operatorname{sen} \omega+\cos \Omega \cos \omega \cos i, \\
n_{2}=\cos \omega \operatorname{sen} i
\end{gathered}
$$


sendo E a anomalia excêntrica, obtida da equação da $3^{\text {a }}$ Lei de Kepler:

$$
E-e \operatorname{sen} E=n(t-\tau)=M
$$

onde $\tau$ corresponde ao instante em que o corpo passa pelo pericentro, $t$ é um instante qualquer (época) e $n$ é o movimento médio, ou frequência do movimento orbital, dado por:

$$
n=\frac{2 \pi}{T}=\sqrt{\frac{\mu}{a^{3}}}
$$

onde $\mu$ já foi escrito na equação (4.19) e é reescrito agora:

$$
\mu=G(M+m)
$$

onde $G$ é a constante de gravitação universal, $M$ é a massa da estrela e $m$ é a massa do planeta. Nota-se que $\mu$ tem valor constante durante todo o programa.

Os seis vetores obtidos anteriormente permitem-nos calcular as coordenadas da posição e velocidade de um corpo numa órbita elíptica:

$$
\begin{gathered}
x=a l_{1} \cos E+b l_{2} \operatorname{sen} E-a e l_{1}, \\
y=a m_{1} \cos E+b m_{2} \operatorname{sen} E-a e m_{1}, \\
z=a n_{1} \cos E+b n_{2} \operatorname{sen} E-a e n_{1},
\end{gathered}
$$

onde $b$, o semi-eixo menor da órbita, está relacionado com o semi-eixo maior e a excentricidade pela fórmula de uma elipse.

$$
b=a \sqrt{\left(1-e^{2}\right)} .
$$

Sendo $r$ dado por:

$$
r=a(1-e \cos E)
$$

as velocidades são obtidas derivando-se as posições em relação ao tempo:

$$
\begin{gathered}
v_{x}=\frac{n a}{r}\left(b l_{2} \cos E-a l_{1} \operatorname{sen} E\right), \\
v_{y}=\frac{n a}{r}\left(b m_{2} \cos E-a m_{1} \operatorname{sen} E\right), \\
v_{z}=\frac{n a}{r}\left(b n_{2} \cos E-a n_{1} \operatorname{sen} E\right) .
\end{gathered}
$$




\subsection{Transformação das coordenadas espaciais em elementos orbitais}

Agora a posição $(\mathrm{x}, \mathrm{y}, \mathrm{z})$ e a velocidade $\left(v_{x}, v_{y}, v_{z},\right)$ são conhecidas e devemos obter os elementos orbitais.

O valor de $r$ é obtido a seguir:

$$
r^{2}=x^{2}+y^{2}+z^{2},
$$

então

$$
r=\sqrt{x^{2}+y^{2}+z^{2}} .
$$

A velocidade v é dada por:

$$
v^{2}=v_{x}^{2}+v_{y}^{2}+v_{z}^{2},
$$

então:

$$
v=\sqrt{v_{x}^{2}+v_{y}^{2}+v_{z}^{2}} .
$$

O momento angular, $c$, é resultado do produto vetorial $r \times v$, como mostrado na equação (4.21).

Sendo assim, tem-se:

$$
\begin{aligned}
& c_{x}=y v_{z}-z v_{y}, \\
& c_{y}=z v_{x}-x v_{z}, \\
& c_{z}=x v_{y}-y v_{x},
\end{aligned}
$$

onde

$$
c^{2}=c_{x}^{2}+c_{y}^{2}+c_{z}^{2},
$$

então

$$
c=\sqrt{c_{x}^{2}+c_{y}^{2}+c_{z}^{2}} .
$$

A equação de energia para um movimento elíptico é mostrada a seguir:

$$
v^{2}=\mu\left(\frac{2}{r}-\frac{1}{a}\right) .
$$

Isolando-se $a$, obtem-se o valor do primeiro elemento orbital, o semi-eixo maior:

$$
a=\frac{\mu r}{2 \mu-v^{2} r},
$$

sendo $\mu, r$ e $v^{2}$ dados pelas equações (4.19), (4.57) e (4.58), respectivamente. 
A quantidade $p$ está definida na equação (4.37) e está relacionada à excentricidade pela seguinte fórmula:

$$
p=a\left(1-e^{2}\right)
$$

Isolando $e$ da equação (4.67), tem-se o valor da excentricidade:

$$
e=\sqrt{1-\frac{p}{a}}
$$

As componentes do momento angular também podem ser expressas do seguinte modo:

$$
\begin{gathered}
c_{x}=c \operatorname{sen} i \operatorname{sen} \Omega, \\
c_{y}=-c \operatorname{sen} i \cos \Omega, \\
c_{z}=c \cos i
\end{gathered}
$$

Da equação (4.71) sai o valor da inclinação:

$$
\cos i=\frac{c_{z}}{c}
$$

isolando-se $i$ :

$$
i=\arccos \left(\frac{c_{z}}{c}\right)
$$

Combinando-se as equações (4.69) e (4.70) obtem-se:

$$
\tan \Omega=-\frac{c_{x}}{c_{y}},
$$

isolando-se $\Omega$, tem-se o valor da longitude do nodo ascendente:

$$
\Omega=\arctan \left(-\frac{c_{x}}{c_{y}}\right) .
$$

Para se obter o valor do argumento do pericentro, é necessário introduzir os seguintes vetores:

$$
\begin{aligned}
f_{1} & =-\frac{\mu}{r} x+c_{z} v_{y}-c_{y} v_{z}, \\
f_{2} & =-\frac{\mu}{r} y+c_{x} v_{z}-c_{z} v_{x}, \\
f_{3} & =-\frac{\mu}{r} z+c_{y} v_{x}-c_{x} v_{y} .
\end{aligned}
$$

Assim, calcula-se o valor do argumento do pericentro, que vem de:

$$
\tan w=\frac{c f_{3}}{f_{2} c_{x}-f_{1} c_{y}},
$$


isolando-se $w$ :

$$
w=\arctan \left(\frac{c f_{3}}{f_{2} c_{x}-f_{1} c_{y}}\right) .
$$

Por último, encontra-se o valor da anomalia média.

A anomalia excêntrica relaciona-se com o semi-eixo maior e a excentricidade pela equação (4.52)

Isolando-se E, tem-se:

$$
E=\arccos \left[\left(1-\frac{r}{a}\right) \frac{1}{e}\right]
$$

Reescrevendo a equação (4.45), obtém-se o valor da anomalia média:

$$
M=n(t-\tau)=E-e \operatorname{sen} E
$$

\subsection{Problema de 3-corpos}

As equações referentes a um problema de 3-corpos são equações de movimento relativo, onde a origem do sistema de referência é considerada dentro de um dos corpos, no caso, a estrela.

De acordo com as Leis de Newton, um sistema inercial tem a seguinte equação genérica de movimento relativo:

$$
m_{i} \ddot{\mathbf{R}}_{\mathbf{i}}=G \sum_{j=1}^{n} \frac{m_{i} m_{j}}{r_{i j}{ }^{3}} \mathbf{r}_{\mathbf{i j}}(j \neq i, i=1,2, \ldots n) .
$$

Nota-se que o vetor $\boldsymbol{r}_{\boldsymbol{i} \boldsymbol{j}}$ entre $m_{i}$ e $m_{j}$ tem direção de $m_{i}$ para $m_{j}$.

Portanto:

$$
\mathbf{r}_{\mathbf{i j}}=\mathbf{R}_{\mathbf{j}}-\mathbf{R}_{\mathbf{i}}=-\mathbf{r}_{\mathbf{j}_{\mathrm{i}}}
$$

Assumindo que o sistema de referência está na estrela, e denotando sua massa de m, com $\mathrm{i}=1$, tem-se:

$$
\ddot{\mathbf{R}}=G \sum_{j=2}^{n} \frac{m_{j}}{r_{j}{ }^{3}} \mathbf{r}_{\mathbf{j}}
$$

Para uma outra partícula de massa $m_{i}$, a equação de movimento é:

$$
\ddot{\mathbf{R}_{\mathbf{i}}}=G \sum_{j=1}^{n} \frac{m_{j}}{r_{i j}{ }^{3}} \mathbf{r}_{\mathbf{i j}} \cdot(i \neq 1, j \neq i)
$$




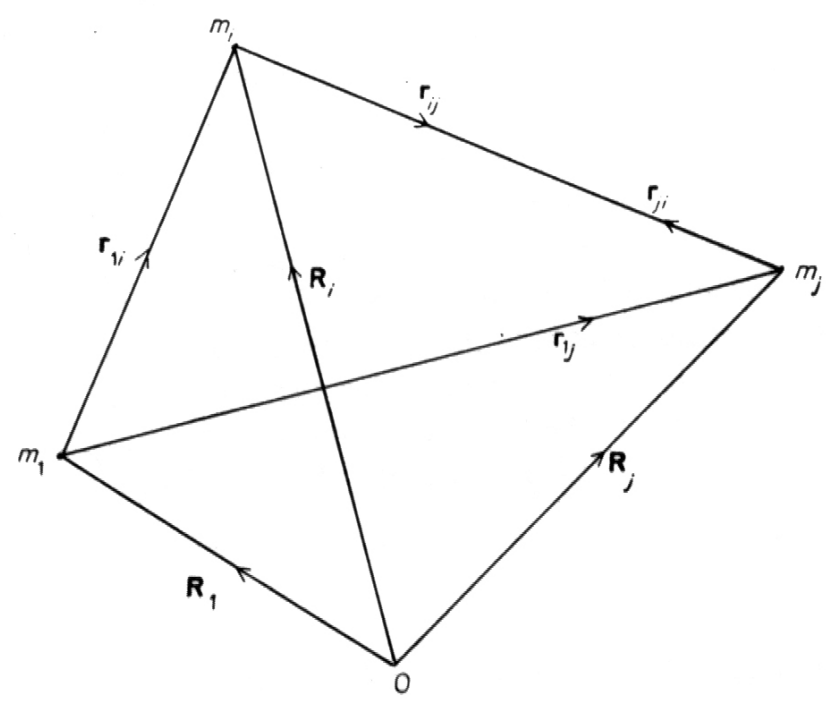

Figura 4.4: Problema de 3-corpos em coordenadas retangulares (Roy, 1978)

Subtraindo-se as duas equações acima (4.86) - (4.85):

$$
\ddot{\mathbf{r}_{\mathbf{i}}}=\ddot{\mathbf{R}_{\mathbf{i}}}-\ddot{\mathbf{R}}=-G\left(m+m_{i}\right) \frac{\mathbf{r}_{\mathbf{i}}}{r_{i}{ }^{3}}+G\left(\sum_{j=2}^{n} m_{j} \frac{\mathbf{r}_{\mathbf{i} \mathbf{j}}}{r_{i j}{ }^{3}}-\sum_{j=2}^{n} m_{j} \frac{\mathbf{r}_{\mathbf{j}}}{r_{j}{ }^{3}}\right) .
$$

Novamente o caso $\mathrm{i}=\mathrm{j}$ não é incluído na somatória.

Com sistema de referência em $m$ :

$$
\mathbf{r}_{\mathrm{ij}}=\mathbf{r}_{\mathrm{j}}-\mathbf{r}_{\mathbf{i}}
$$

então:

$$
\mathbf{r}_{\mathbf{i j}}{ }^{3}=\left[\left(\mathbf{r}_{\mathbf{i j}}-\mathbf{r}_{\mathbf{i}}\right) \cdot\left(\mathbf{r}_{\mathbf{j}}-\mathbf{r}_{\mathbf{i}}\right)\right]^{\frac{3}{2}}
$$

Realizando a substituição necessária, resulta na equação final de movimento no referencial relativo utilizada no programa:

$$
\ddot{\mathbf{r}_{\mathbf{i}}}+G\left(m+m_{i}\right) \frac{\mathbf{r}_{\mathbf{i}}}{r_{i}{ }^{3}}=G \sum_{j=2}^{n} m_{j}\left(\frac{\mathbf{r}_{\mathbf{j}}-\mathbf{r}_{\mathbf{i}}}{r_{i j}{ }^{3}}-\frac{\mathbf{r}_{\mathbf{j}}}{r_{j}{ }^{3}}\right)(j \neq i)
$$

Esta é a equação de movimento de uma massa $m_{i}$ em relação a uma massa $m$. Ela consiste de duas partes: a parte kepleriana e a parte de interação mútua ou perturbação. Se outras massas $m_{j}(\mathrm{j} \neq \mathrm{i})$ forem muito pequenas, o lado direito desta equação deve ser zero, resultando na equação de movimento do problema de 2-corpos. Os valores que i assume, $\mathrm{i}=2,3, \ldots$ n dependem do número de equações de movimento relativo requeridas no sistema 
estudado. Nas simulações que constam nesta dissertação, esta equação é utilizada com $\mathrm{n}=3$ (problema de 3 -corpos). 
Capítulo 5

\section{CATÁLOGO DE SISTEMAS MÚLTIPLOS EXTRASSOLARES}

\subsection{Criação de um catálogo próprio}

A criação de um catálogo contendo somente sistemas múltiplos extrassolares, seguindo critérios próprios, fez-se necessária devido à grande divergência de dados entre os principais catálogos existentes. Os dados foram obtidos pesquisando-se diversos catálogos publicados e/ou disponíveis ao público em geral. Dentre os critérios para a determinação dos dados, quando da existência destes em mais de um catálogo, destacam-se os seguintes, não ordenadamente: método da descoberta, conjunto de dados dos elementos orbitais, data de publicação, divulgação de dados, clareza dos resultados, comparação de dados com outros catálogos, citações e notoriedade da fonte.

Ressalte-se que os catálogos pesquisados nada mais são do que um guia para se chegar aos autores e pesquisadores dos trabalhos publicados.

Os catálogos objetos de pesquisa foram os seguintes:

- The Geneva Extrasolar Planet Search Programmes do Grupo de Geneva, em Genebra, Suíça, que tem entre seus maiores pesquisadores Michael Mayor, Stephane Udry, e Didier Queloz. O site na Internet é mantido por Dominique Naef e Stephane Udry (http://obswww.unige.ch/ naef/who_discovered_that_planet.html).

- The Extrasolar Planets Encyclopaedia do Grupo do Observatório Paris-MeudonNancay (OBSPM) cujos maiores expoentes são Jean Schneider (administrador do site) e M. Perryman (http://exoplanet.eu/catalog-all.php). 
- Masses and Orbital Characteristics of Extrasolar Planets do grupo de busca de exoplanetas da Califórnia \& Carnegie, formado, entre outros, pelos pesquisadores Paul Butler, Gregory Henry, Chris McCarthy e Jason Wright (http://exoplanets . org/almanacframe.html).

- Catalog of Nearby Exoplanets de R. P. Butler, J. T. Wright, G. W. Marcy, D. A. Fischer, S. S. Vogt, C. G. Tinney, H. R. A. Jones, B. D. Carter, J. A. Johnson, C. McCarthy e A. J. Penny (Butler et al., 2006) e (Jones et al., 2008).

- Ten New and Update Multi-planet Systems, and a Survey of Exoplanetary de J.T. Wright, S. Upadhyay, G. W. Marcy, D. A. Fischer, E. B. Ford e J. A. Johnson (Wright et al., 2009).

- Extrasolar Planetary Systems do Prof. ${ }^{\circ}$ Dr. ${ }^{\circ}$ Sylvio Ferraz-Mello do Grupo de Dinâmica de Sistemas Planetários do Instituto de Astronomia, Geofísica e Ciências Atmosféricas da Universidade de São Paulo (www.astro.iag.usp.br/ sylvio).

- List of extrasolar planets da Enciclopédia Livre Wikipedia (http://en.wikipedia. org/wiki/List_of_extrasolar_planets).

Devido ao fato de que constantemente novos planetas e sistemas extrassolares são descobertos ou têm sua existência comprovada, mas com elementos orbitais retificados, ou ainda, comprova-se a não existência de determinados planetas, faz-se necessário ressaltar que para cada um dos 37 sistemas extrassolares deste estudo foi estipulada uma data limite para escolha dos dados.

\subsection{Coleta de dados}

A incessante busca dos pesquisadores por planetas extrassolares faz com que os catálogos pesquisados para a composição desta dissertação sejam atualizados constantemente. É de suma importância, portanto, que seja estabelecida uma data limite para a pesquisa e procura por novos sistemas em tais catálogos, pois, do contrário, as simulações e análises ficariam inviáveis. A data final de pesquisa de dados para esta dissertação foi $\mathbf{1 8}$ de novembro de 2009. Quaisquer descobertas posteriores a esta data não foram incluídas neste trabalho. 
Na coleta de dados dos sistemas extrassolares nos catálogos citados anteriormente, alguns foram bastante simples de serem obtidos. No caso dos sistemas HAT-P-13 (Bakos et al., 2009), HD147018 (Ségransan et al., 2010) e BD 202457 (Niedzielski et al., 2009), por exemplo, o único catálogo que continha dados sobre tais sistemas era o da OBSPM. Vale lembrar que o site da Wikipedia também listava estes dados, referenciando a OBSPM como fonte. Em tais casos, geralmente o sistema todo ou seu último planeta a ser descoberto foram descobertos recentemente (2008 ou 2009) e, portanto, não foram atualizados em outros catálogos ou não foram objetos de pesquisa pelas equipes que mantêm esses catálogos.

Por outro lado, alguns outros sistemas continham vasta referência. É o caso, por exemplo, do sistema GJ 581, que é listado na grande maioria dos catálogos pesquisados e ainda consta nos trabalhos de S. Udry e H. Beust (Beust et al., 2008), J. T. Wright (Wright et al., 2009), Mayor (Mayor et al., 2009) etc.

\subsection{Simulações numéricas da dinâmica dos planetas extrassolares}

Existem dois modos de se estudar a estabilidade dos sistemas multi-planetários extrassolares, o analítico e o numérico. Os métodos analíticos, muito complexos, consistem em desenvolver modelos que estudam o espaço de fase completo de um sistema estudado. Os métodos analíticos existentes sempre utilizaram como objeto de estudo o nosso Sistema Solar, por ser o único conhecido até bem pouco tempo atrás. Existem muitos métodos utilizados atualmente que procuram conjugar os dois métodos. Os métodos numéricos, bem mais simples em implementação, têm como exemplo o utilizado neste estudo. O programa principal, que realiza a integração numérica das órbitas de um problema de N-corpos, é o Radau (RA15), desenvolvido por E. Everhart, do Departamento de Física da Universidade de Denver (Everhart, 1985). Este é um integrador de $15^{\mathrm{a}}$ ordem baseado no método de Runge-Kutta que possui uma linguagem apropriada para rápida execução. Este programa recebe os parâmetros em coordenadas retangulares: as posições $x, y, z$ e suas respectivas velocidades, $v_{x}, v_{y}, v_{z}$. Como os valores encontrados na literatura são os elementos orbitais, é necessário primeiramente fazer a transformação dos elementos orbitais dos planeta em torno de uma estrela para as suas respectivas coordenadas retangulares (posição e velocidade) num determinado tempo conhecido e, posteriormente fazer o caminho in- 
verso: partindo-se das coordenadas, obter os elementos orbitais, que são os dados de saída do programa de simulações. Ambos os procedimentos são explicados no capitulo 4 desta dissertação.

Por meio de programas de interação numérica, como o Radau, são integradas as equações exatas de movimento num referencial relativo. O problema deste método é que poucas configurações são possíveis de serem testadas e são necessários intervalos de tempos relativamente grandes (da ordem de Giga-anos) para se observar mudanças significativas em alguns sistemas, além do fato de que as incertezas dos parâmetros orbitais dos planetas extrassolares conhecidos não são muito bem determinadas (Ford, 2005).

Neste trabalho é aplicado o teste de estabilidade dinâmica puramente numérico em diversos problemas de 3-corpos do nosso Sistema; Sol-Mercúrio-Vênus, Sol-Vênus-Terra, Sol-Terra-Marte, Sol-Marte-Júpiter, Sol-Júpiter-Saturno, Sol-Saturno-Urano e Sol-UranoNetuno como elementos de comparação ao escopo deste estudo. Como já foi dito anteriormente, o foco deste trabalho é executar simulações de problemas de 3-corpos.

O intervalo de tempo padrão utilizado nas simulações foi de 200 mil anos e 1 milhão de anos, dependendo do caso. Alguns sistemas precisaram ser integrados por muito mais tempo para que se configurassem realmente como sistemas estáveis, como, por exemplo, os sistemas hierárquicos HD 11964 cb (5 milhões de anos) e HD 217107 bc (18 milhões de anos). A condição de estabilidade foi estipulada na obtenção de ao menos seis períodos do ângulo $\Delta \varpi$, conforme proposto no artigo (Michtchenko e Nesvorny, 1996).

Os valores de saída do programa de integração são os elementos orbitais (semi-eixo maior, excentricidade, inclinação da órbita, argumento do pericentro, longitude do nodo ascendente e anomalia média) em função do tempo.

Um modo prático e objetivo de se obter as características seculares de um sistema consiste em construir um gráfico em coordenadas polares ( $\mathrm{y}=\mathrm{r} \operatorname{sen} \theta, \mathrm{x}=\mathrm{r} \cos \theta$ ), onde o raio é dado pela excentricidade $\left(e_{1}\right.$ ou $\left.e_{2}\right)$ e o ângulo $\theta$ é $\Delta \varpi$ (diferença das longitudes de pericentro - equação (3.2)). 


\subsection{Preparação das simulações}

Algumas dificuldades inerentes a este estudo já foram citadas, como: obtenção da massa da estrela, obtenção dos parâmetros orbitais de sistemas ressonantes e divergência de dados entre catálogos. Outras dificuldades e limitações devem ser explicitadas.

O valor da inclinação da órbita do planeta em relação ao plano de referência é uma limitação para os dados de elementos orbitais obtidos por velocidade radial, pois no cálculo para obtenção dos elementos, torna-se impossível separar-se o valor da inclinação com o valor da massa do planeta $(m \times \operatorname{sen} I)$. Para efeito de cálculo, a partir dos valores de velocidades radiais, é assumido geralmente $\mathrm{I}=90^{\circ}$ (em relação ao plano do céu, pois, para determinação dos parâmetros, diz-se que o plano de referência está no plano do céu) o que corresponde a um plano orbital na linha de visada do observador terrestre (comumente chamado na literatura de "edge-on"). Isso também implica na obtenção de valores mínimos para as massas dos planetas (quanto maior o valor de sen $I$, menor o valor da massa e vice-versa).

Conseguintemente ao problema da inclinação, existe o problema dos valores do argumento do pericentro (ângulo medido desde o nodo ascendente até o pericentro) e da longitude do nodo ascendente (ângulo medido a partir de um ponto arbitrário - pontovernal - até o nodo ascendente dessa órbita, medido sobre o plano de referência da estrela, no sentido da translação do planeta. Como a inclinação tem um valor arbitrário, não é possível saber qual é o ponto de intersecção entre o plano da estrela e o plano da órbita do planeta. Sem saber qual é esse ponto de intersecção, não é possível medir o ângulo a partir deste ponto de intersecção até o pericentro. Para exemplificar: se a inclinação for igual a zero, a longitude do nodo ascendente é indeterminada, pois qualquer ponto pode ser a intersecção do plano da órbita com o plano de referência e o argumento do pericentro não existe (assim como para órbitas circulares). Em vista disso, o que se tem nos catálogos de referência são valores de longitude do pericentro ou longitude do periastro $(\varpi)$.

Para resolver esses problemas foi necessário adotar valores arbitrários para os elementos citados anteriormente. O valor escolhido para a inclinação das órbitas dos planetas em relação ao plano das estrelas foi $0,1^{\circ}$. Note-se que essa inclinação é diferente da inclinação do plano do céu, pois trata-se do plano de referência das órbitas planetárias. Para a longitude do nodo ascendente foi escolhido $0,1^{\circ}$ para o planeta interno e $180,1^{\circ}$ para o 
planeta externo de cada simulação de 3-corpos. O valor do argumento do pericentro é calculado pelo próprio programa, ao se subtrair o valor da longitude do pericentro (obtida do catálogo) e o valor da longitude do nodo (arbitrária).

Por fim, resta ainda o cálculo da anomalia média (valor algébrico angular de determinado corpo em uma órbita elíptica kepleriana em determinado tempo). O valor desse elemento orbital dificilmente é obtido diretamente dos catálogos. O que se tem é o valor do tempo de passagem do planeta pelo pericentro $(\tau)$. Escolhendo-se um tempo $t$ arbitrário (época) e conhecendo-se o período (obtido do catálogo), calcula-se a anomalia média pela equação:

$$
M=\frac{2 \pi(t-\tau)}{T}
$$

A época escolhida foi $t=0$. Este valor corresponde ao dia $1^{\circ}$ de janeiro de 4713 A.C. no calendário Juliano, foi adotado para efeito de simplificação dos cálculos e não interfere nas simulações, pois é um valor arbitrário e irrelevante em comparação ao tempo de simulação dos sistemas. 
Capítulo 6

\section{SIMULAÇÕES DA DINÂMICA DOS SISTEMAS MÚLTIPLOS EXTRASSOLARES}

O programa de integração numérica foi primeiramente testado utilizando-se os planetas do nosso Sistema Solar. A escolha do nosso Sistema para teste é evidente, pois, até o momento, trata-se do único sistema planetário do qual temos informações precisas e o conjunto dos 6 elementos orbitais planetários necessários às integrações apresenta-se de forma completa.

As simulações foram feitas utilizando-se o problema de 3-corpos no Sistema Solar, constituindo-se do Sol como corpo principal e dois planetas com órbitas subsequentes, resultando nas seguintes simulações: Sol-Mercúrio-Vênus, Sol-Vênus-Terra, Sol-Terra-Marte, Sol-Marte-Júpiter, Sol-Júpiter-Saturno, Sol-Saturno-Urano e Sol-Urano-Netuno. Os elementos orbitais iniciais foram obtidos do site do Jet Propulsion Laboratory, da NASA. Os valores das inclinações utilizados nas simulações referentes ao Sistema Solar têm como plano de referência o plano da eclíptica.

A geração dos gráficos e os métodos de filtragem utilizados nas simulações são feitas utilizando-se o software Origin.

Os gráficos, análises e classificações relativas às simulações dos planetas do nosso Sistema Solar são as mesmas que posteriormente são aplicadas aos sistemas extrassolares. Para todas as simulações, o ângulo $\Delta \varpi$ é medido em graus e varia de $0^{\circ}$ a $360^{\circ}$. A unidade de tempo nas figuras é sempre em anos. 


\subsection{Sistema Solar}

\subsubsection{Sol-Júpiter-Saturno}

Para o sistema Sol-Júpiter-Saturno a simulação foi de 1 milhão de anos.

As figuras a seguir mostram as integrações dos parâmetros orbitais semi-eixo maior, excentricidade e inclinação. Esses elementos são bastante úteis para mostrar o quão estáveis são os sistemas e só serão mostrados posteriormente neste trabalho para sistemas extrassolares de configuração instável. 


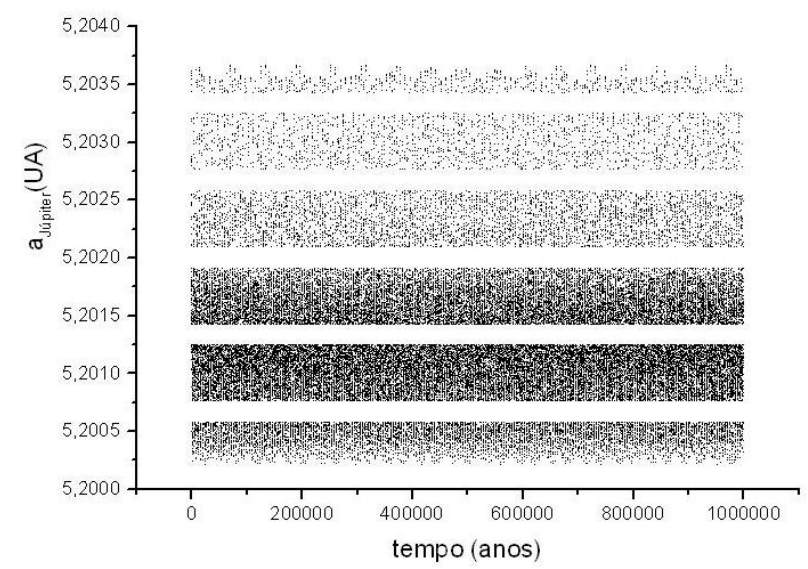

Figura 6.1: Semi-eixo maior de Júpiter em função do tempo

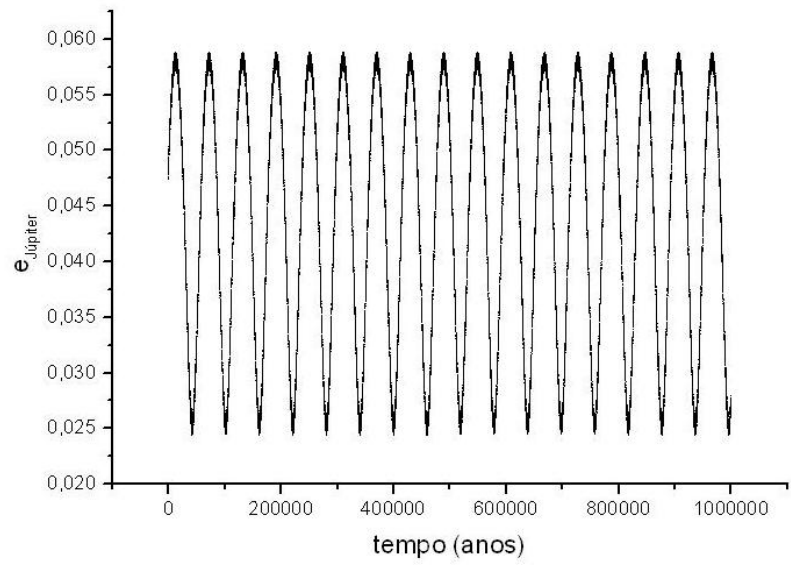

Figura 6.2: Excentricidade de Júpiter em função do tempo

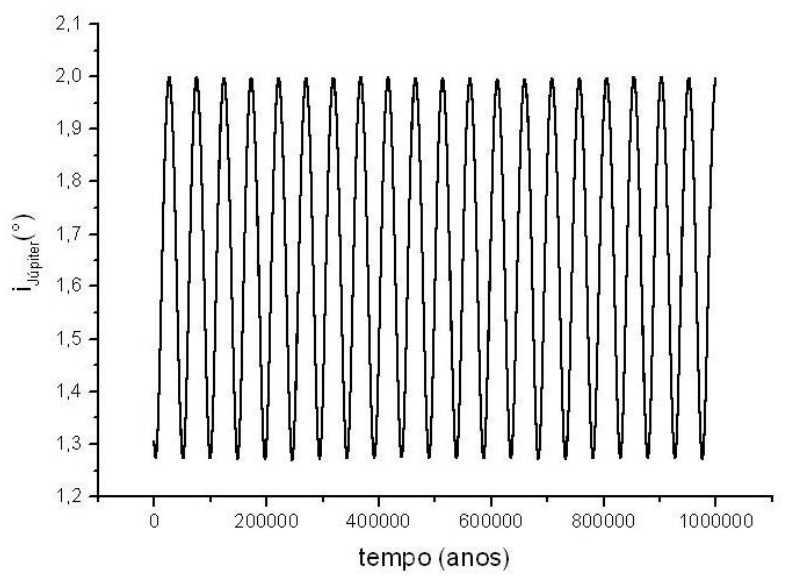

Figura 6.3: Inclinação de Júpiter em função do tempo

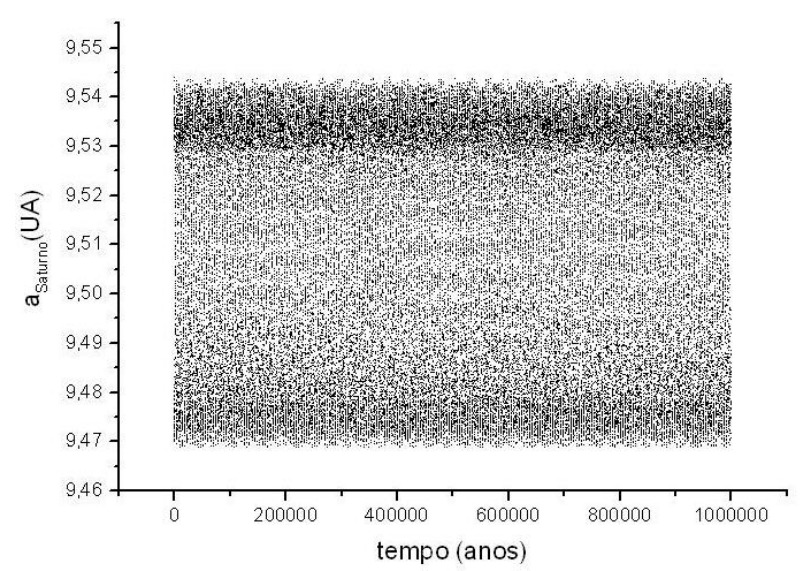

Figura 6.4: Semi-eixo maior de Saturno em função do tempo

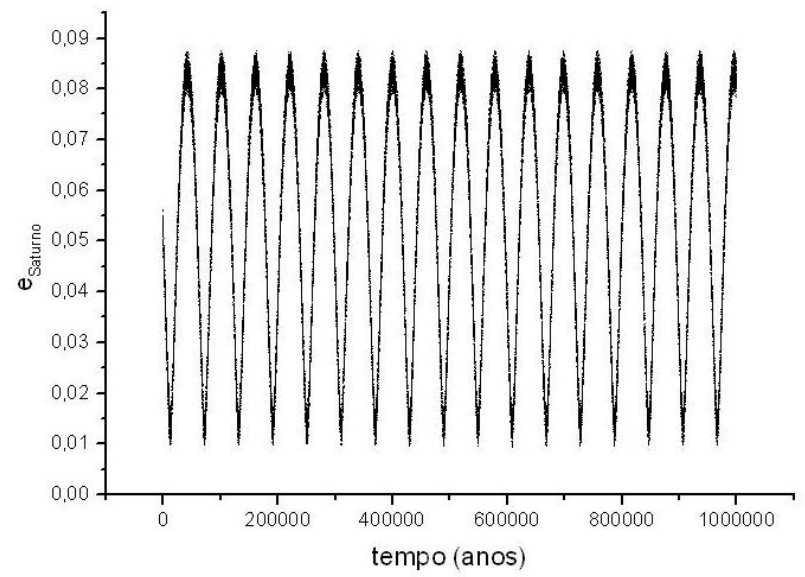

Figura 6.5: Excentricidade de Saturno em função do tempo

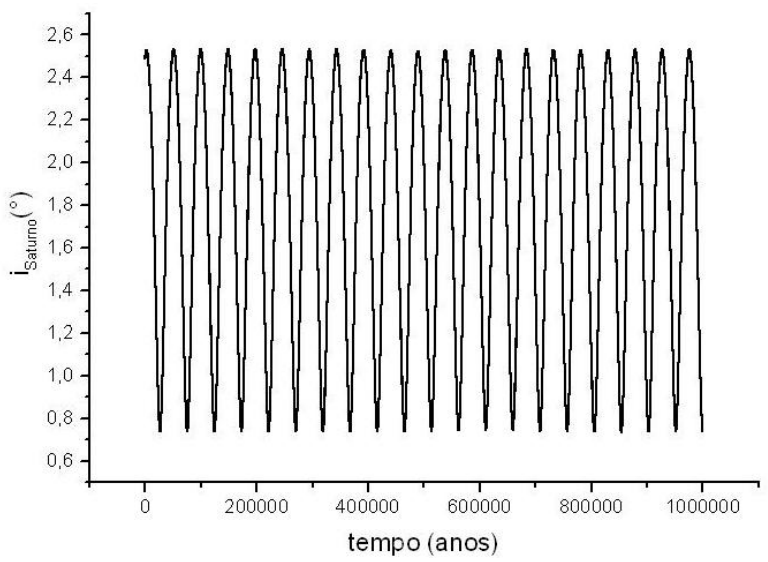

Figura 6.6: Inclinação de Saturno em função do tempo 
Observa-se dos gráficos gerados que o semi-eixo maior de Júpiter varia 0,00346 UA durante o intervalo de tempo simulado. O semi-eixo maior de Saturno varia cerca de 0,075 UA durante o mesmo período integrado de 1 milhão de anos. Júpiter tem variação de 0,034 em sua excentricidade e de $0,73^{\circ}$ em sua inclinação em relação ao plano da órbita. Já Saturno tem variação de 0,078 na excentricidade e $1,77^{\circ}$ na inclinação.

De acordo com o gráfico a seguir, é possível notar que o movimento do ângulo $\Delta \varpi$ é circulatório prógrado. Seu período secular é de aproximadamente 59.598 anos.

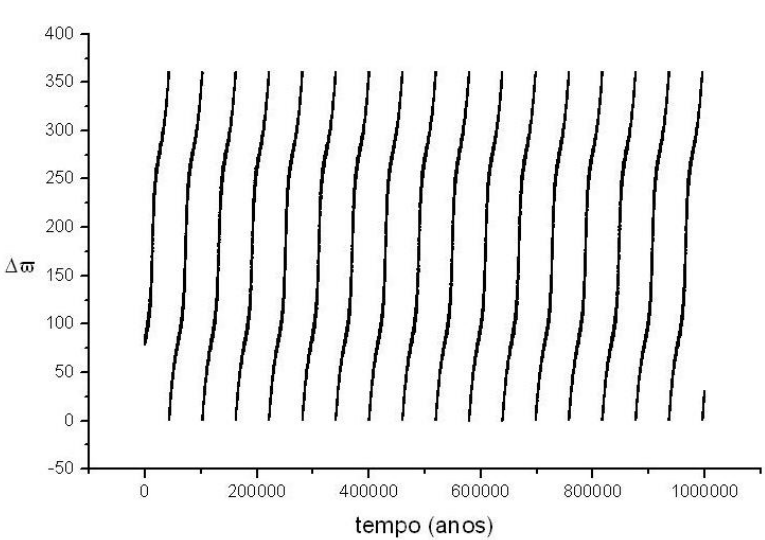

Figura 6.7: Ângulo $\Delta \varpi$ em função do tempo para Sol-Júpiter-Saturno

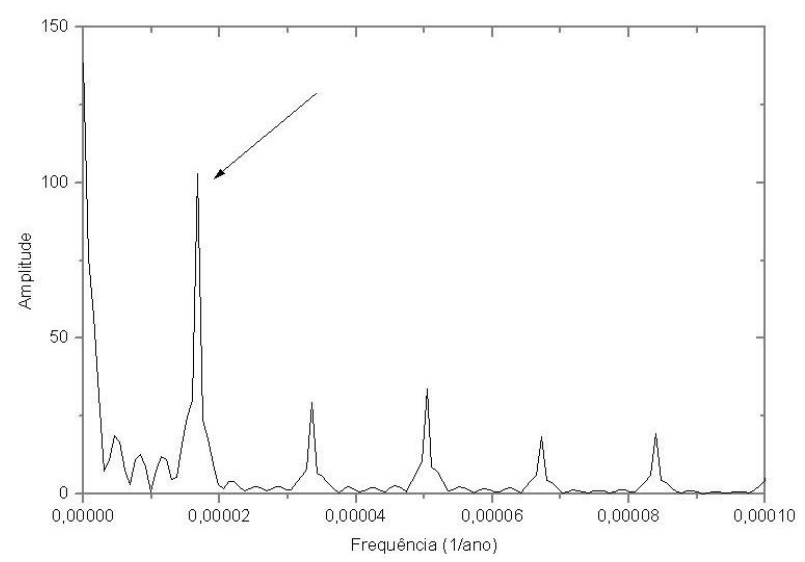

Figura 6.8: FFT do ângulo $\Delta \varpi$ em função do tempo para Sol-Júpiter-Saturno

A obtenção do período secular do ângulo $\Delta \varpi$ é feita gerando-se um gráfico da transformada de Fourier (FFT - Fast Fourier Transformed $)^{1}$ do ângulo $\Delta \varpi$ em função do tempo, que resulta em um gráfico da amplitude do ângulo $\Delta \varpi$ em função da frequência. O inverso do valor da menor frequência corresponde ao período secular predominante do ângulo $\Delta \varpi$. No caso do sistema Sol-Júpiter-Saturno, o menor valor de frequência corresponde a 1,678 x $10^{-5} 1$ /ano, fazendo $1 /\left(1,678 \times 10^{-5}\right)$, pois $f=1 / T$, onde $f$ é a frequência e $T$ o período, obtem-se o valor do período.

Utilizando coordenadas polares, são gerados os gráficos citados na seção 5.2. Na literatura, são também chamados de representações no espaço de fase e variáveis $\mathrm{KH}$, onde $\mathrm{K}=\mathrm{e} \cos \Delta \varpi \mathrm{e} H=\mathrm{e} \operatorname{sen} \Delta \varpi:$

O que se deve obter dos gráficos KH são os valores mínimos e máximos de e $\cos \Delta \varpi$ quando e $\operatorname{sen} \Delta \varpi=0$. Esses valores são obtidos manualmente dos gráficos.

Os valores mínimo e máximo para $\mathrm{KH}$ de $e_{1}$ para Sol-Júpiter-Saturno são -0,058 e

\footnotetext{
${ }^{1}$ mais detalhes em (OriginLab) e (Press et al., 1992)
} 


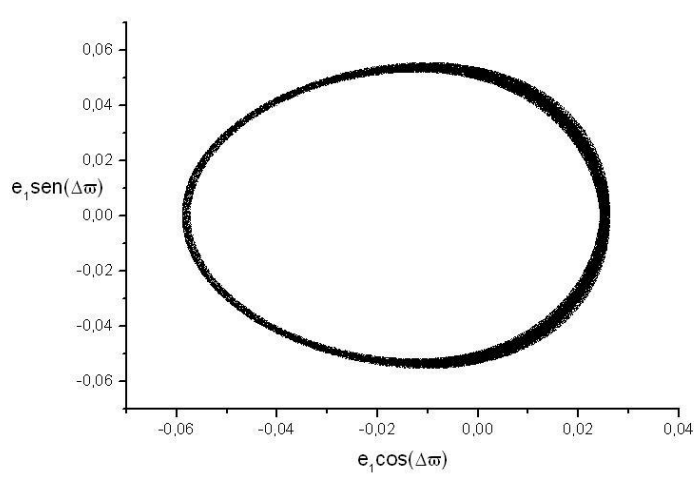

Figura 6.9: KH de $e_{1}$ para Sol-Júpiter-Saturno

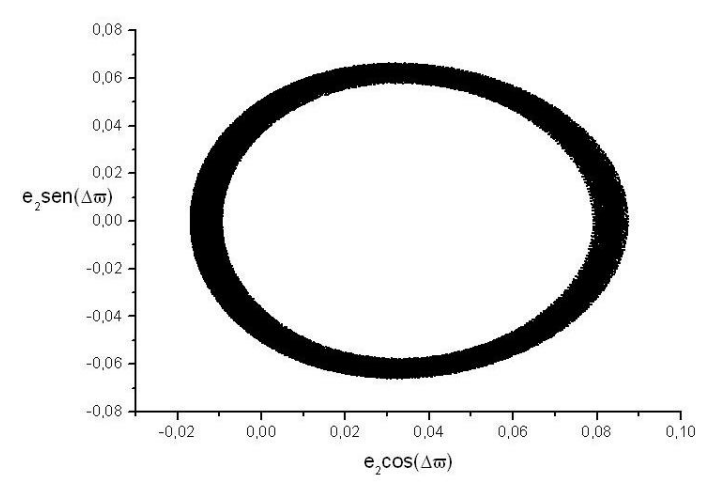

Figura 6.10: KH de $e_{2}$ para Sol-Júpiter-Saturno

0,025. Já para $e_{2}$ esses valores são -0,013 e 0,084. Note-se que se o mínimo é negativo para $e_{1}$, deve ser negativo para $e_{2}$ também. O mesmo ocorre com os valores máximos. Para o sistema Sol-Júpiter-Saturno o ângulo $\Delta \varpi$ circula, pois seu valor mínimo de KH é negativo e o máximo é positivo. Quando os valores mínimo e máximo de KH são negativos, diz-se que o ângulo $\Delta \varpi$ oscila em torno de $180^{\circ}$ e quando são positivos, o ângulo $\Delta \varpi$ oscila em torno de $0^{\circ}$.

As demais simulações no Sistema Solar são mostradas no Apêndice deste Trabalho.

A tabela dos dados compilados sobre o Sistema Solar é a seguinte:

Tabela 6.1 - Resultados das simulações para os planetas do Sistema Solar

\begin{tabular}{|c|c|c|c|c|c|c|c|}
\hline Sistema & Classe & $e_{1}$ Mín & $e_{1}$ Máx & $e_{2}$ Mín & $e_{2}$ Máx & Movimento do ângulo $\Delta \varpi$ & Período secular (anos) \\
\hline Mercúrio-Vênus & II & $-0,189$ & 0,206 & $-0,019$ & 0,005 & circulatório retrógrado & 438.172 \\
\hline Vênus-Terra & II & 0,006 & 0,019 & 0,008 & 0,17 & oscilatório $0^{\circ}$ & 131.452 \\
\hline Terra-Marte & II & $-0,020$ & 0,002 & $-0,084$ & 0,100 & circulatório prógrado & 582.143 \\
\hline Marte-Júpiter & II & $-0,063$ & 0,098 & $-0,048$ & 0,048 & circulatório retrógrado & 87.634 \\
\hline Júpiter-Saturno & I & $-0,058$ & 0,025 & $-0,013$ & 0,084 & circulatório prógrado & 59.598 \\
\hline Saturno-Urano & I & $-0,058$ & 0,043 & $-0,014$ & 0,085 & circulatório prógrado & 953.216 \\
\hline Urano-Netuno & I & $-0,047$ & $-0,026$ & $-0,035$ & $-0,005$ & oscilatório $180^{\circ}$ & 1.750 .806 \\
\hline
\end{tabular}

A classificação dos sistemas que compõem o Sistema Solar pode ser resumida do seguinte modo: os sistemas do Sistema Solar interior (planetas telúricos) compostos por Mercúrio-Vênus, Vênus-Terra e Terra-Marte, são seculares, Classe II, seguindo a classificação desta dissertação e caóticos segundo alguns autores (Laskar e Gastineau, 2009). O comportamento caótico dos planetas terrestres é definido pelas perturbações devido aos planetas gigantes ou interações com vários planetas. Este estudo está à parte da classi- 
ficação proposta nesta dissertação. Já os sistemas do Sistema Solar exterior, pertencem à subclasse da Classe I, sendo Júpiter-Saturno próximo à ressonância $5 / 2\left(T_{1} / T_{2}=0,4028\right)$, Saturno-Urano inseridos na quase-ressonância $3 / 1\left(T_{1} / T_{2}=0,3504\right)$ e Urano-Netuno na quase-ressonância 2/1 $\left(T_{1} / T_{2}=0,5093\right)$.

\subsection{Alguns Sistemas Extrassolares}

O procedimento adotado para simular os sistemas extrassolares é o mesmo utilizado para as simulações do Sistema Solar.

Todos os sistemas são caracterizados em relação ao comportamento do ângulo $\Delta \varpi$ independentemente de serem classificados como ressonantes ou seculares. Alguns sistemas apresentaram configuração instável nas simulações. Os fatos mais relevantes para esta instabilidade são, muito provavelmente, erros ou incertezas muito grandes na definição dos parâmetros orbitais divulgados nos catálogos. A ocorrência de instabilidade quase sempre coincide com os sistemas classificados como ressonantes em seus períodos orbitais. Como mostrado por (Giuppone et al., 2009), nesses sistemas, a determinação dos parâmetros orbitais torna-se uma tarefa mais difícil.

Para os sistemas de configuração instável houve mais de uma simulação, utilizandose valores de referência de outros catálogos/autores que não os escolhidos primeiramente. Os sistemas HD 82943 cb, HD 183263 bc e 47 Uma bc são exemplos de sistemas que apresentaram configurações de instabilidade com alguns autores e de estabilidade com outros. Já para os sistemas HD 73526 bc e HD 202206 bc foi possível obter situações de estabilidade, utilizando-se os valores calculados pelo colega Marcos Tadeu dos Santos, aluno de doutoramento do Departamento de Astronomia do IAG-SP, após uma primeira simulação em que os sistemas mostravam-se instáveis.

Em virtude da grande quantidade de sistemas simulados, são mostrados primeiramente neste capítulo, exemplos de cada caso relevante. Os demais casos estão no Apêndice desta dissertação.

\subsubsection{GJ $876 d c$}

O sistema GJ 876 dc mostra-se estável nas simulações e se trata de um caso hierárquico, Classe III, uma vez que os planetas não estão capturados numa ressonância de movimentos 
médios e a razão de períodos $T_{1} / T_{2}$ é pequena, mais precisamente, 0,063 .

O tempo de simulação para o sistema GJ 876 dc foi de 200 mil anos. O movimento do ângulo $\Delta \varpi$ tem uma alternância entre oscilatório em torno de $0^{\circ}$ e circulatório. Essa alternância ocorre devido a interferências de curto período, quando a excentricidade do planeta interno, $e_{1}$, tem valores muito próximos de zero, a excentricidade do planeta externo, $e_{2}$, é dispersada arbitrariamente, sendo um caso de falsa separatriz, gerando os valores negativos de KH na Figura (6.13). O período secular tem aproximadamente 839,1 anos.

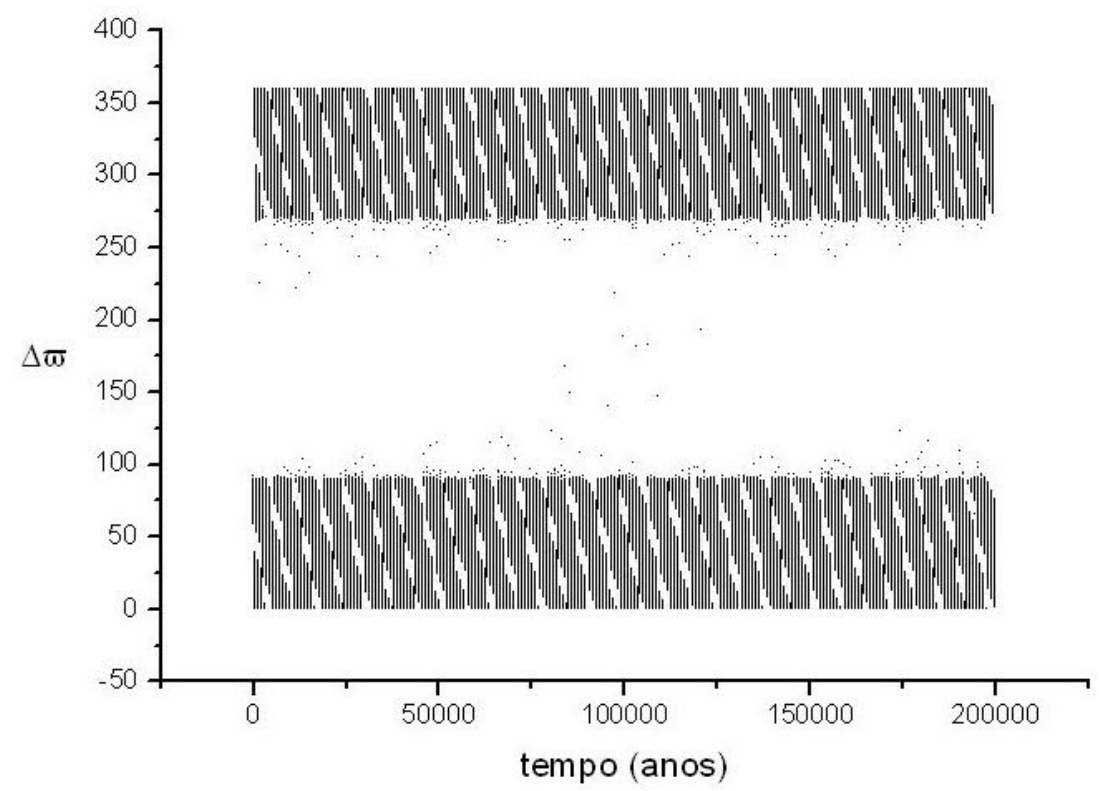

Figura 6.11: Ângulo $\Delta \varpi$ em função do tempo para GJ $876 \mathrm{dc}$

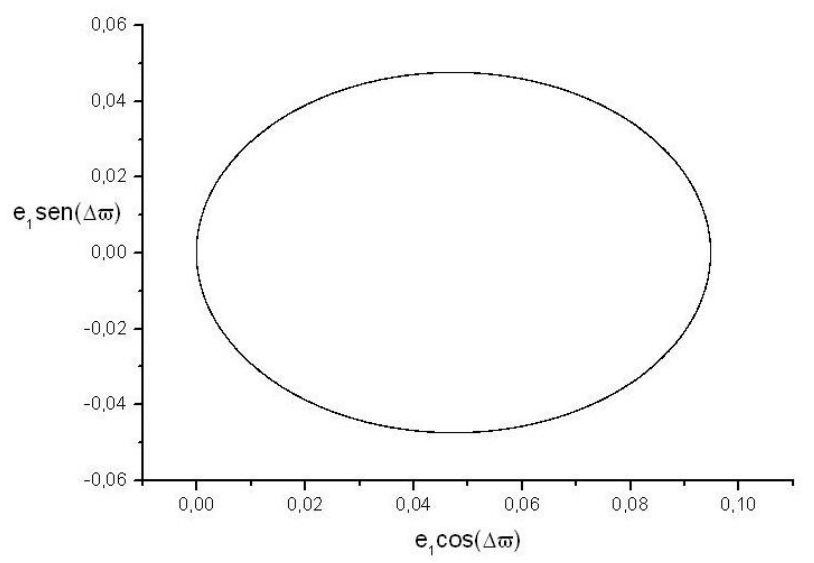

Figura 6.12: KH de $e_{1}$ para GJ $876 \mathrm{dc}$

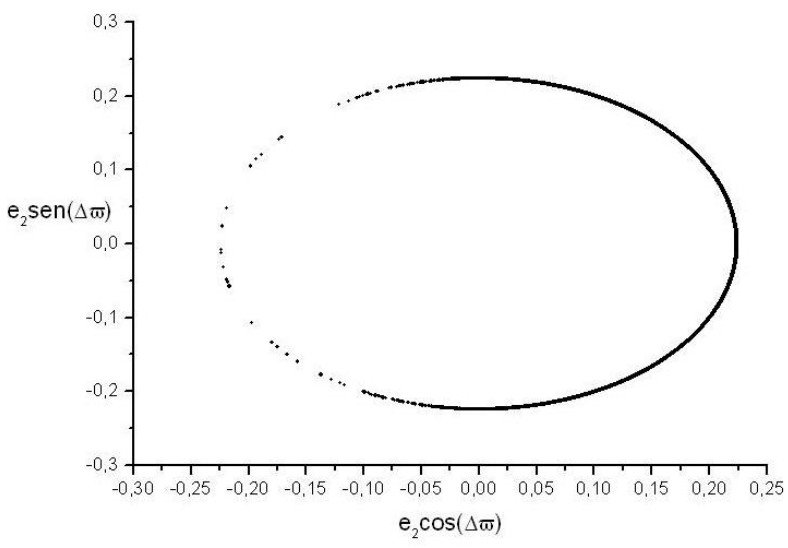

Figura 6.13: KH de $e_{2}$ para GJ $876 \mathrm{dc}$ 


\subsubsection{GJ $876 \mathrm{cb}$}

Este é um típico exemplo de caso ressonante, Classe I. A razão de períodos dos planetas GJ 876 b sobre GJ 876 c é igual a 2,008569545, ou seja, os planetas se encontram exatamente na ressonância 2/1 e a razão de períodos $T_{1} / T_{2}$ (GJ 876 c/GJ 876 b) é igual a 0,4978, ou seja, $\left(1>T_{1} / T_{2}>0,2\right)$. O gráfico de $\Delta \varpi$ em função do tempo não mostra informações visuais que possibilitem inferir o valor do período secular deste ângulo. Isso ocorre pois, em casos de ressonâncias, várias pertubações com diferentes intervalos de variações interferem no problema.

O tempo de simulação para o sistema GJ 876 cb foi de 200 mil anos. O movimento do ângulo $\Delta \varpi$ é inferido a partir da Figura (6.14) sendo oscilatório em torno de $0^{\circ}$.

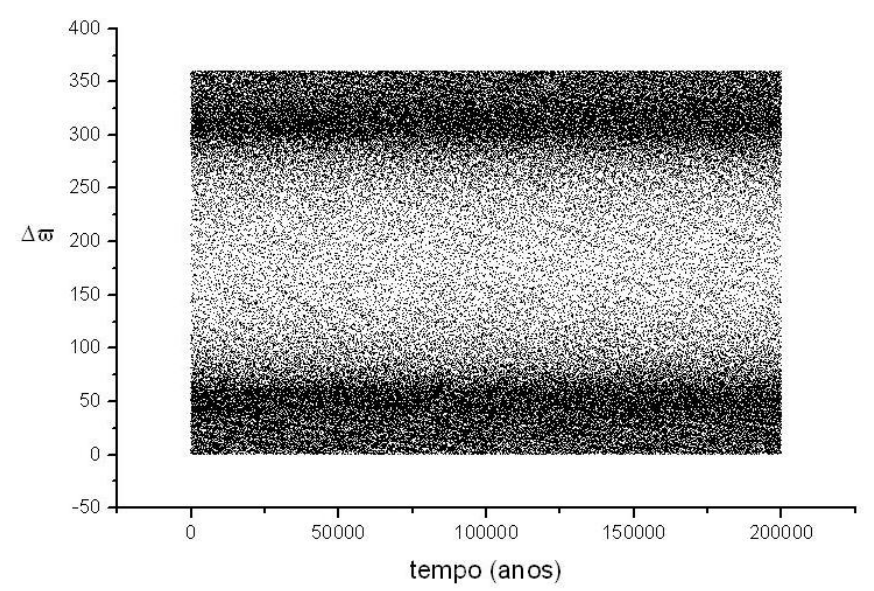

Figura 6.14: Ângulo $\Delta \varpi$ em função do tempo para GJ $876 \mathrm{cb}$

Analisando o período $\Delta \varpi$ aplicando filtragem por FFT, nota-se que as variações de curto período predominam para este sistema, podendo-se verificar que a amplitude dessas variações é muito maior que a amplitude da frequência secular do ângulo $\Delta \varpi$. O período secular para o sistema GJ 876 cb é de aproximadamente 146 anos.

A filtragem faz-se necessária para inferir os valores do gráfico de $\mathrm{KH}$ de $e_{2}$. A filtragem pelo método de médias adjacentes ${ }^{2}$ não se mostrou adequada para este sistema. A filtragem pelo método de FFT fica mais acurada uma vez conhecido o valor do período secular. Como visto anteriormente, este valor é de aproximadamente 146 anos. Limitando a banda

\footnotetext{
${ }^{2}$ Método de filtragem (Adjacent Averaging) calcula a média de uma certa quantidade de pontos especificados em torno de cada ponto do gráfico e o substitui com o valor da média calculada (OriginLab).
} 


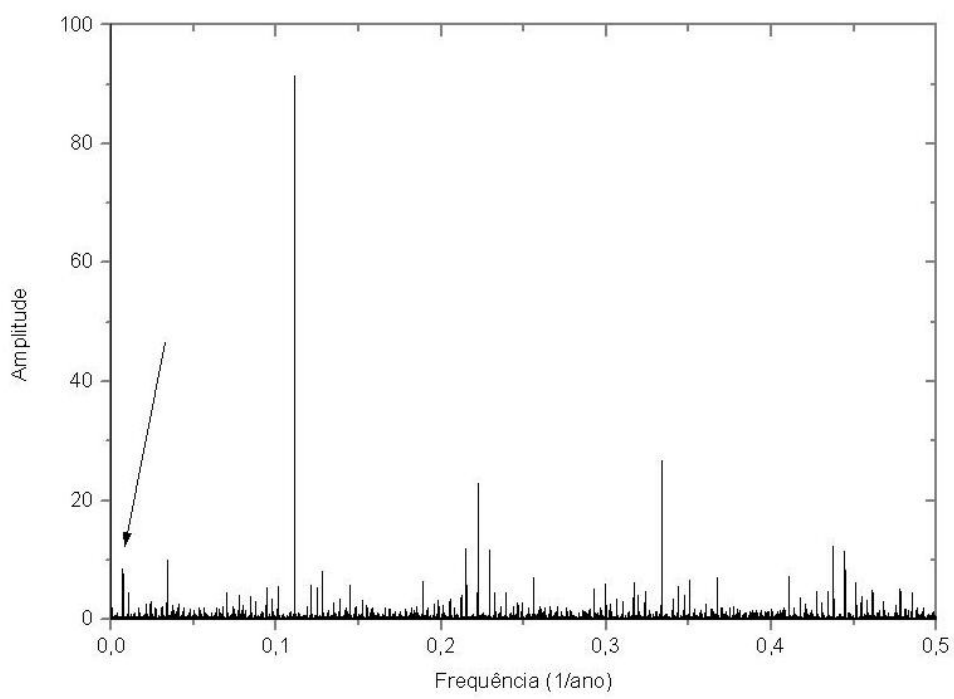

Figura 6.15: FFT do ângulo $\Delta \varpi$ em função do tempo para GJ $876 \mathrm{cb}$

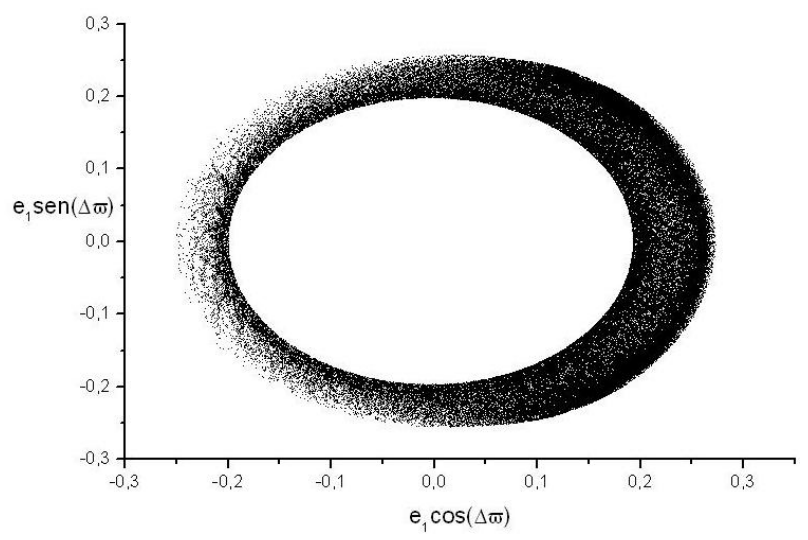

Figura 6.16: KH de $e_{1}$ para GJ $876 \mathrm{cb}$

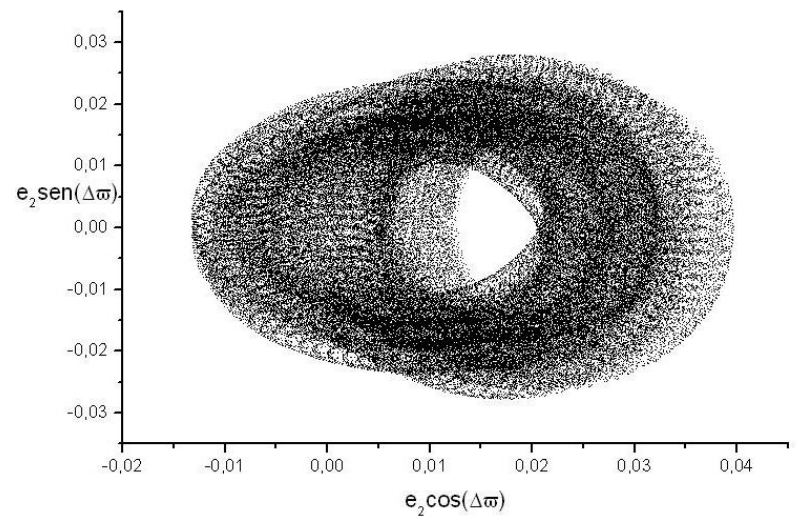

Figura 6.17: $\mathrm{KH}$ de $e_{2}$ para GJ $876 \mathrm{cb}$

de filtragem entre 0,00680 1/ano (147 anos) e 0,00689 1/ano (145 anos), gera-se a Figura (6.18) onde se pode notar que os valores de $e_{2}$ mínimo e máximo são da ordem de $10^{-5}$, ou seja, muito próximos a zero, mostrando a condição de falsa separatriz que ocorre quando a excentricidade de um planeta assume valores próximos a zero, gerando a alternância entre os movimentos oscilatório em torno de $0^{\circ}$ e circulatório. 


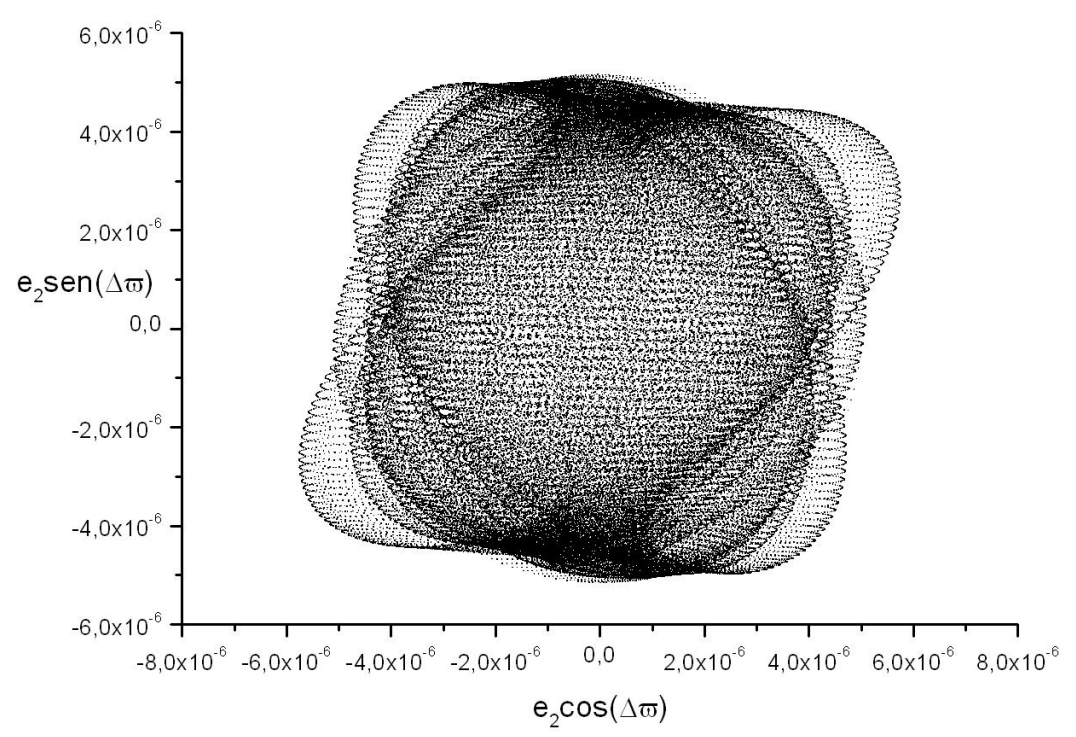

Figura 6.18: KH de $e_{2}$ para GJ 876 cb - filtro 145 a 147 anos

\subsubsection{HD 73526 bc}

As simulações iniciais deste sistema mostraram tratar-se de um caso de instabilidade. Como se pode constatar nos gráficos a seguir, por exemplo, o semi-eixo maior do planeta HD 73526 c (figura 6.19), representado por $a_{2}$ assume valores muito grandes, afastando-se da estrela, fato incomum para planetas em órbitas estáveis. Em outro exemplo (Figura 6.20), a excentricidade do planeta HD 73526 b assumiria valores muito próximos a 1. Fato igualmente impossível em se tratando de planetas, pois este valor de excentricidade é mais comum a cometas.

Em um pedido para o colega Marcos Tadeu dos Santos, aluno de doutoramento do Departamento de Astronomia do IAG-SP, os parâmetros orbitais do sistema HD 73526 bc foram recalculados por um novo método de ajuste de curvas de velocidade radial.

Com os novos parâmetros orbitais, foi possível obter uma situação de estabilidade para este sistema. Com simulações para um intervalo de 1 milhão de anos é possível determinar que o movimento do ângulo $\Delta \varpi$ é circulatório retrógrado, seu período secular tem aproximadamente 4.783 anos. Além disso, este sistema ressonante pertence à Classe I. 


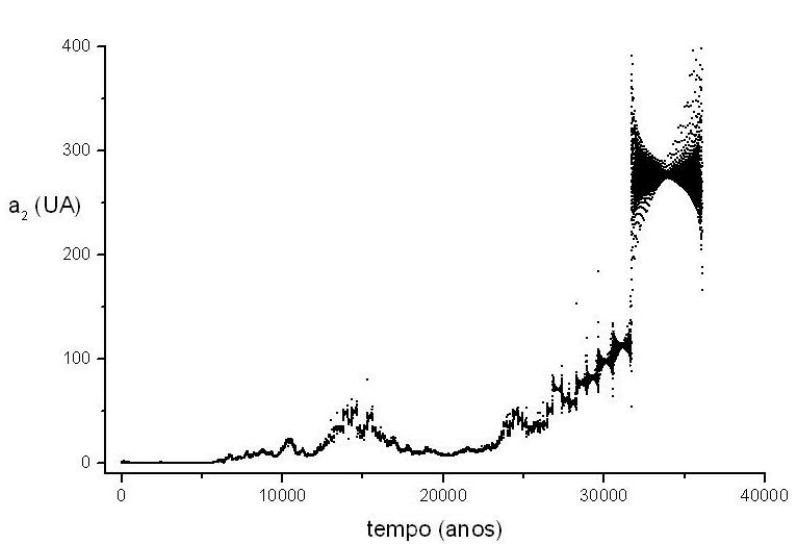

Figura 6.19: Semi-eixo maior de HD 73526 c em função do tempo

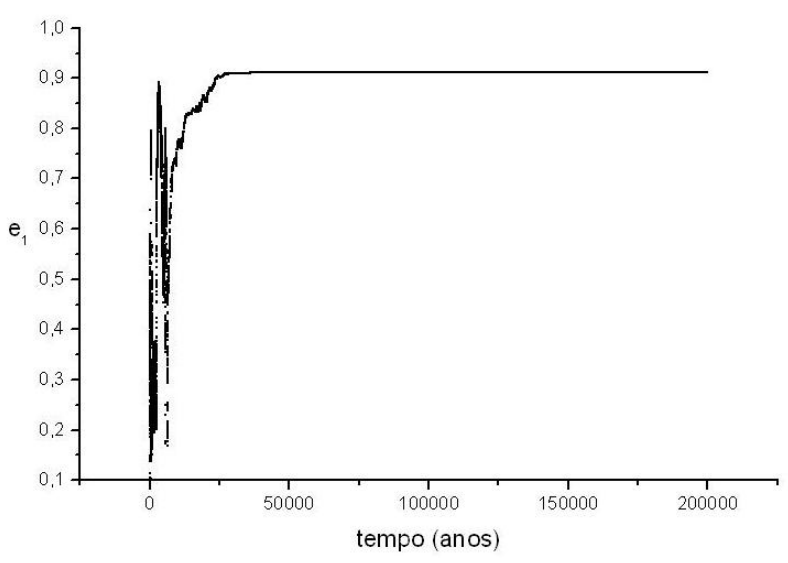

Figura 6.20: Excentricidade de HD 73526 b em função do tempo

O sistema HD 73526 bc também está inserido na situação de ressonância 2/1 (razão de períodos igual a 2,010133333). Devido à essa situação, como se pode ver na Figura (6.22) o ângulo $\Delta \varpi$ possui diversas variações.

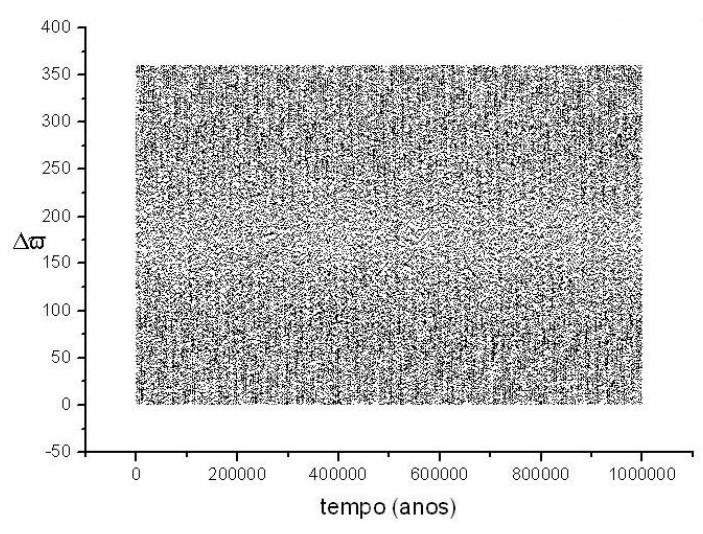

Figura 6.21: Ângulo $\Delta \varpi$ em função do tempo para HD 73526 bc calculado por Marcos Tadeu

Com um zoom na Figura (6.21), nota-se que a variação de longo período mais significativa (a do período secular) tem valor próximo a 4780 anos, que foi inferido a partir da filtragem por FFT do ângulo $\Delta \varpi$ (Figura 6.23).

Como se pode notar nas figuras (6.24) e (6.25), a incerteza para se obter os valores mínimos e máximos de $e_{1}$ e $e_{2}$ é muito grande. O método de médias adjacentes também não se mostrou satisfatório na obtenção desses dados, uma vez que a presença de diversas perturbações de curto período estão presentes na variação do ângulo $\Delta \varpi$. Pelo método FFT 


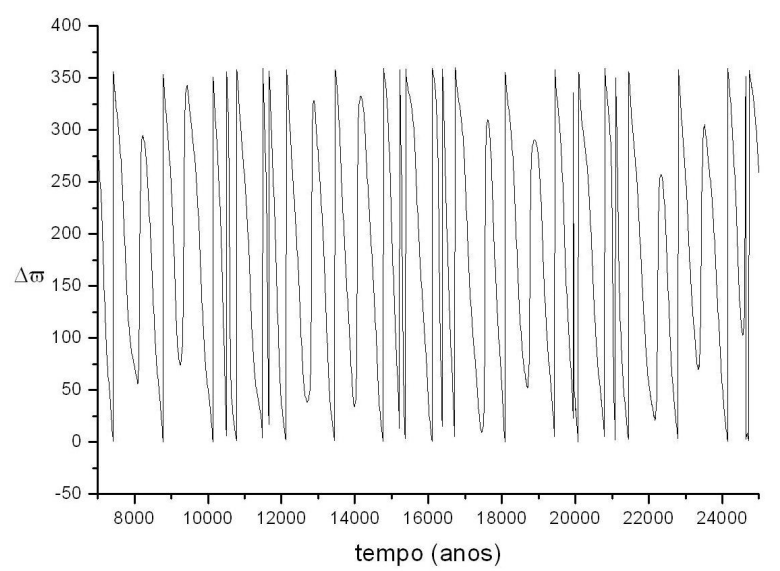

Figura 6.22: Zoom do ângulo $\Delta \varpi$ em função do tempo para HD 73526 bc calculado por Marcos Tadeu

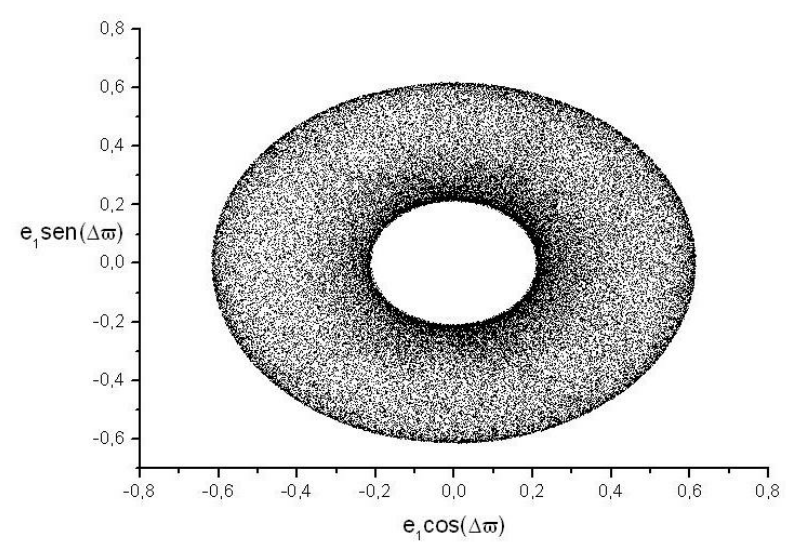

Figura 6.24: KH de $e_{1}$ para HD73526 bc

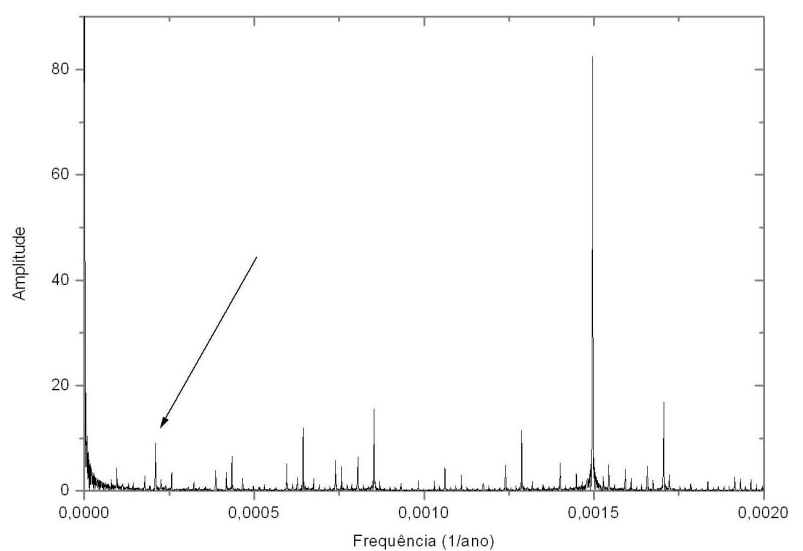

Figura 6.23: FFT do ângulo $\Delta \varpi$ em função do tempo para HD 73526 bc

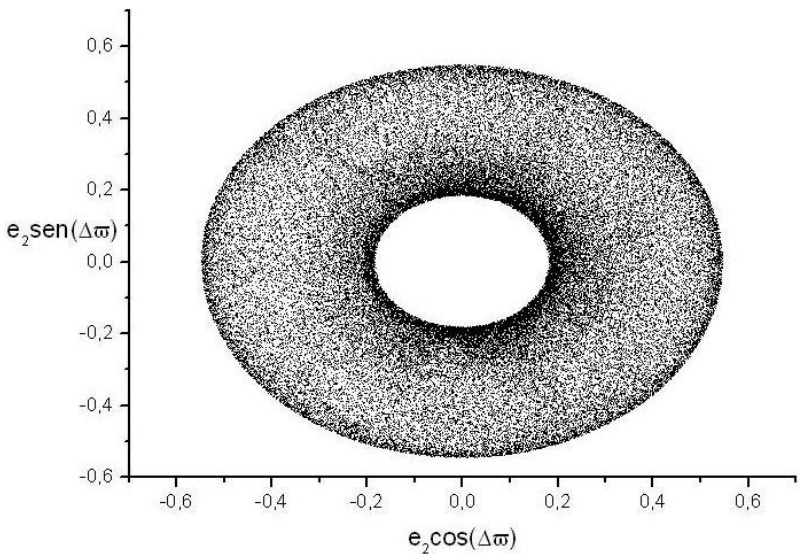

Figura 6.25: $\mathrm{KH}$ de $e_{2}$ para HD $73526 \mathrm{bc}$

utilizando banda de frequências entre 0,000199 1/ano (5025 anos) e 0,00021 1/ano (4761 anos) os gráficos de KH nas figuras (6.26) e (6.27) assumem uma forma mais adequada à obtenção dos dados. 


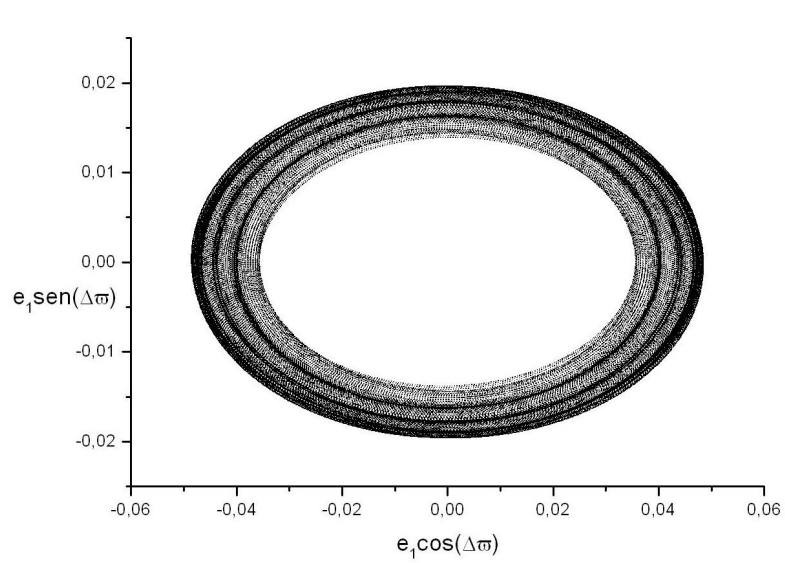

Figura 6.26: KH de $e_{1}$ para HD 73526 bc - filtro 4761 a 5025 anos

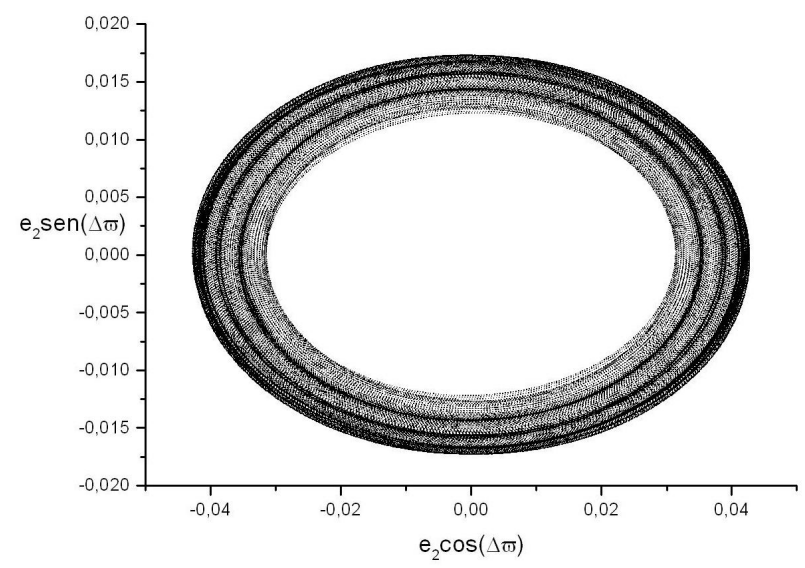

Figura 6.27: $\mathrm{KH}$ de $e_{2}$ para HD 73526 bc - filtro 4761 a 5025 anos 


\subsubsection{HD $160691 \mathrm{~cd}$}

A estrela HD 160691 é também chamada de $\mu$ Ara. Até o presente momento foram são conhecidos 4 planetas orbitando esta estrela, HD 160691 c, HD 160691 d, HD 160691 b e HD 160691 e, por ordem crescente de semi-eixos. O interessante é que para cada um dos 3 pares formados pelos planetas concomitantes tem-se uma classificação diferente.

O sistema HD 160691 cd é um sistema hierárquico, Classe III. O tempo de simulação foi de 1 milhão de anos. O movimento do ângulo $\Delta \varpi$ é circulatório retrógrado. Seu período secular é de aproximadamente 94.493 anos.

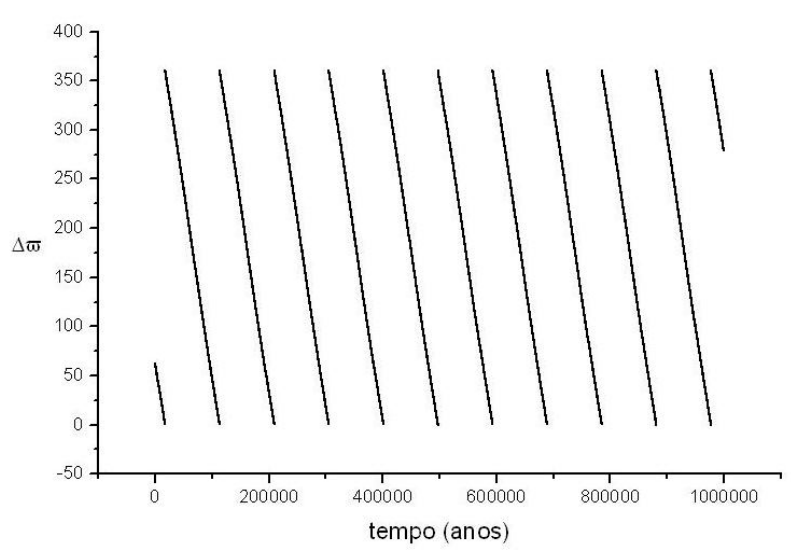

Figura 6.28: Ângulo $\Delta \varpi$ em função do tempo para HD $160691 \mathrm{~cd}$

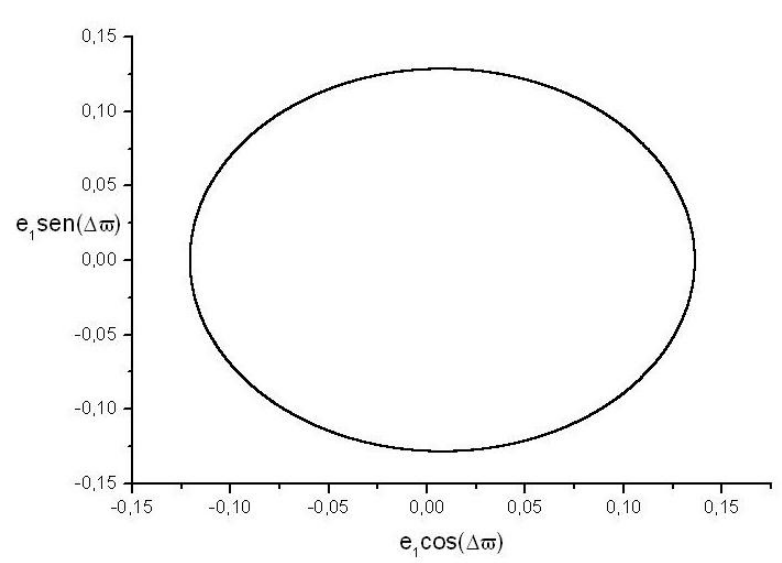

Figura 6.29: KH de $e_{1}$ para HD $160691 \mathrm{~cd}$

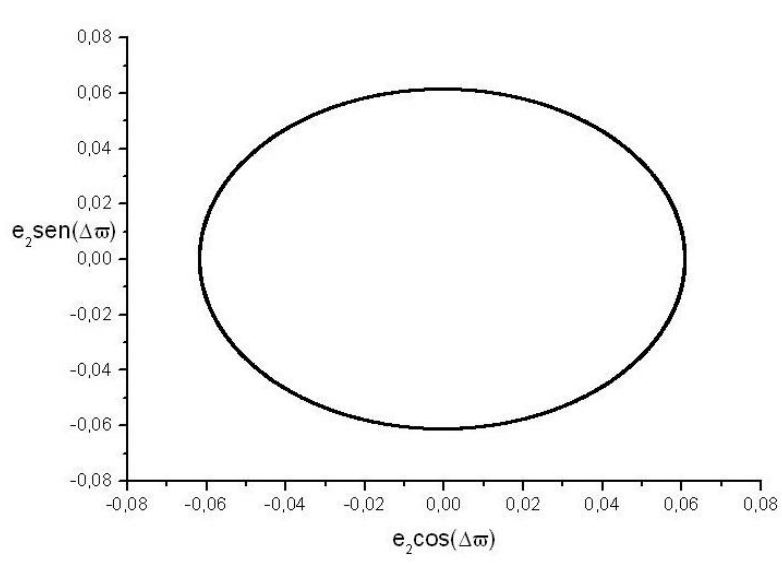

Figura 6.30: KH de $e_{2}$ para HD $160691 \mathrm{~cd}$ 


\subsubsection{HD $160691 \mathrm{db}$}

O sistema HD 160691 db é um sistema quase-ressonante e, portanto, é classificado como pertencente à subclasse da Classe I, de acordo com a classificação desta dissertação. O tempo de simulação foi de 200 mil anos. O movimento do ângulo $\Delta \varpi$ é circulatório retrógrado. Seu período secular é de aproximadamente 476,6 anos.

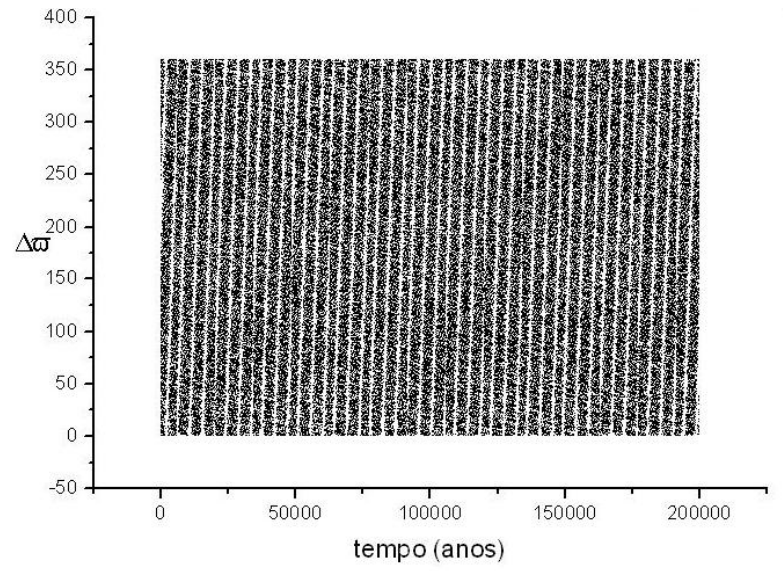

Figura 6.31: Ângulo $\Delta \varpi$ em função do tempo para HD $160691 \mathrm{db}$

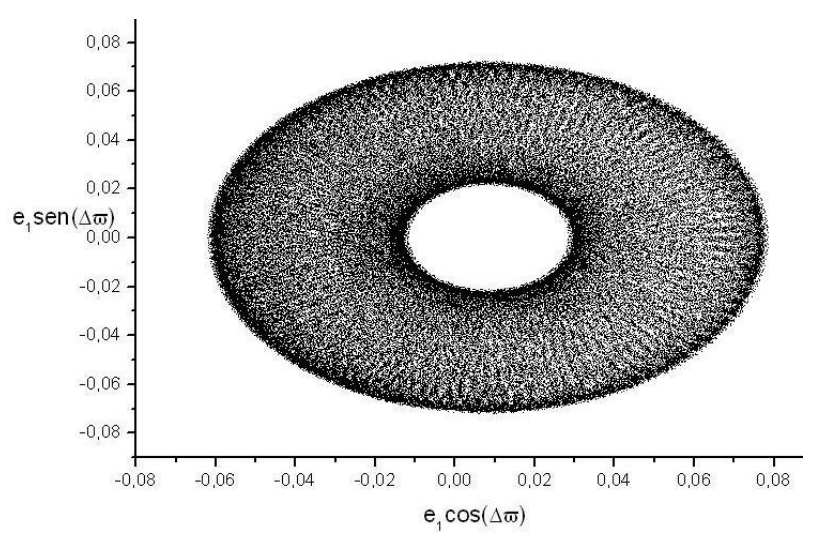

Figura 6.33: KH de $e_{1}$ para HD $160691 \mathrm{db}$

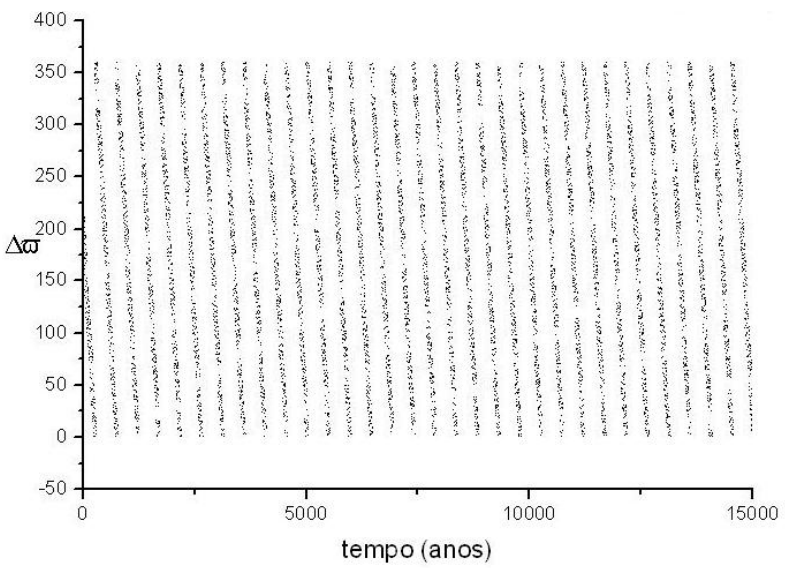

Figura 6.32: Zoom do ângulo $\Delta \varpi$ em função do tempo para HD $160691 \mathrm{db}$

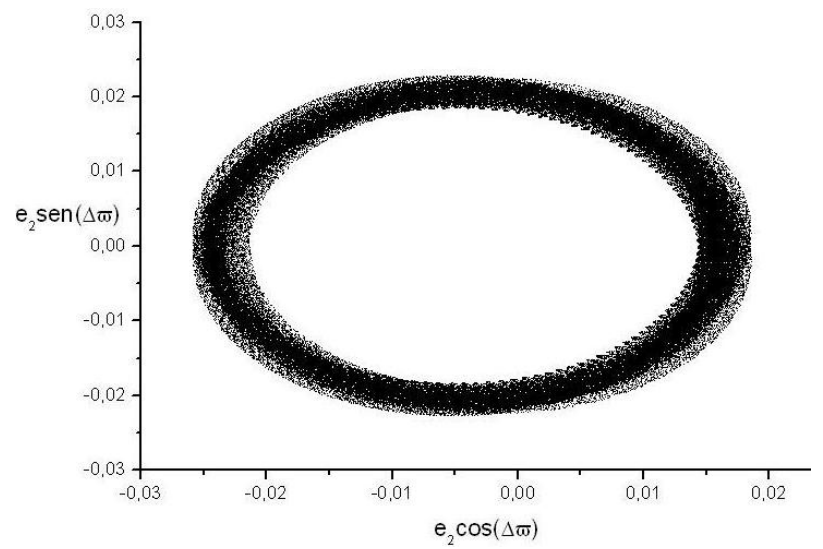

Figura 6.34: KH de $e_{2}$ para HD $160691 \mathrm{db}$

Nota-se das figuras (6.33) e (6.34) que a incerteza para obter-se os valores de $e_{1}$ e $e_{2}$ minímos e máximos é muito grande. Como se trata se um sistema quase-ressonante, o ângulo $\Delta \varpi$ também apresenta diversas interferências de perturbações de curto período. Como seu período secular é de 476,6 anos (obtido da filtragem por FFT), infere-se que os períodos curtos possuem valores menores do que valor do período secular. Fazendo-se 
os mesmos gráficos, utilizando o método de filtragem por FFT com um filtro passa baixo para frequências de corte 0,01 /ano que só permite que passem períodos com mais de 100 anos, é possível obter os valores de $e_{1}$ e $e_{2}$ minímos e máximos com maior precisão:

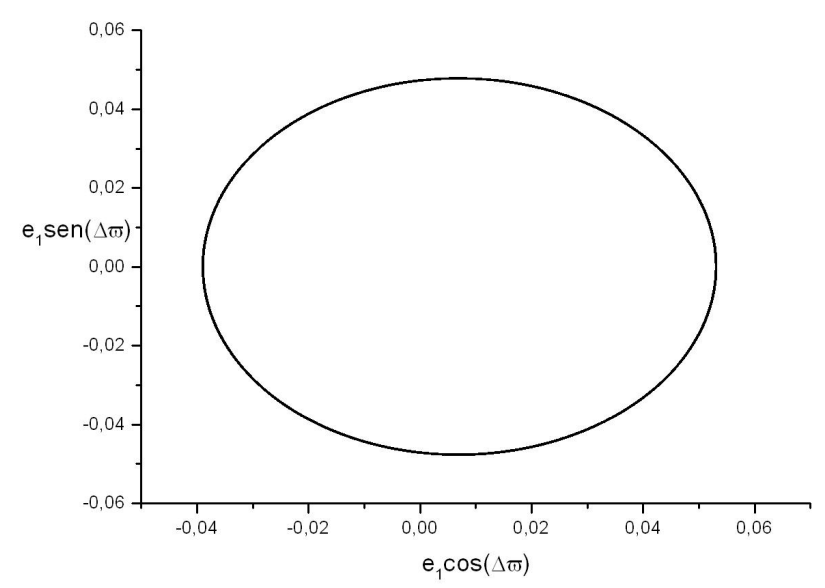

Figura 6.35: KH de $e_{1}$ para HD $160691 \mathrm{db}$ com filtro de 0,01 1/ano

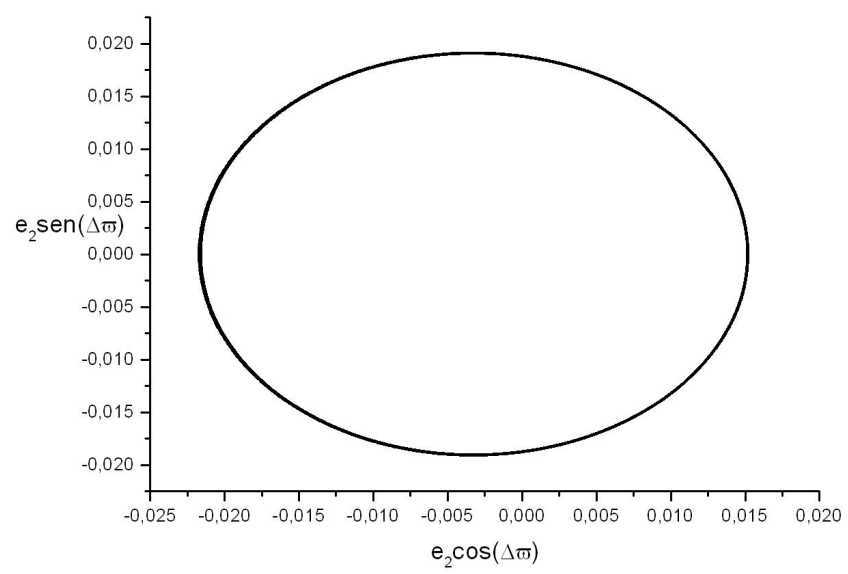

Figura 6.36: KH de $e_{2}$ para HD $160691 \mathrm{db}$ com filtro de 0,01 1/ano 


\subsubsection{HD 160691 be}

O sistema HD 160691 be é um sistema secular, Classe II, pois sua razão de períodos $\left(T_{1} / T_{2}\right)$ tem valor $0,219\left(1>T_{1} / T_{2}>0,14\right)$ e não está sujeito a ressonância de movimentos médios. O tempo de simulação foi de 1 milhão de anos. O movimento do ângulo $\Delta \varpi$ é circulatório retrógrado. Seu período é de aproximadamente 48.657 anos.

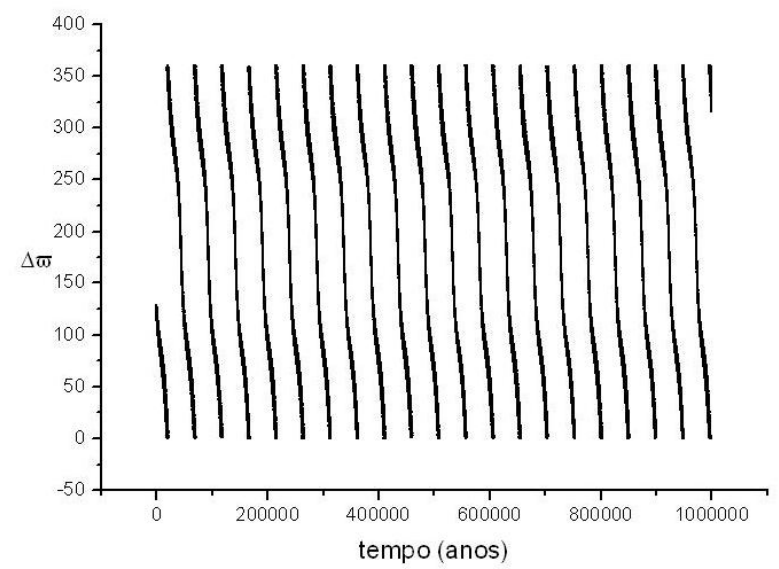

Figura 6.37: Ângulo $\Delta \varpi$ em função do tempo para HD 160691 be

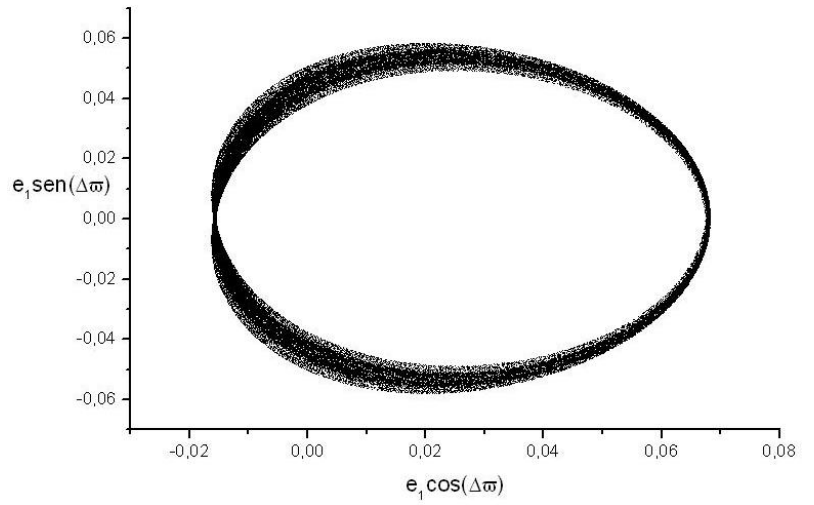

Figura 6.38: KH de $e_{1}$ para HD 160691 be

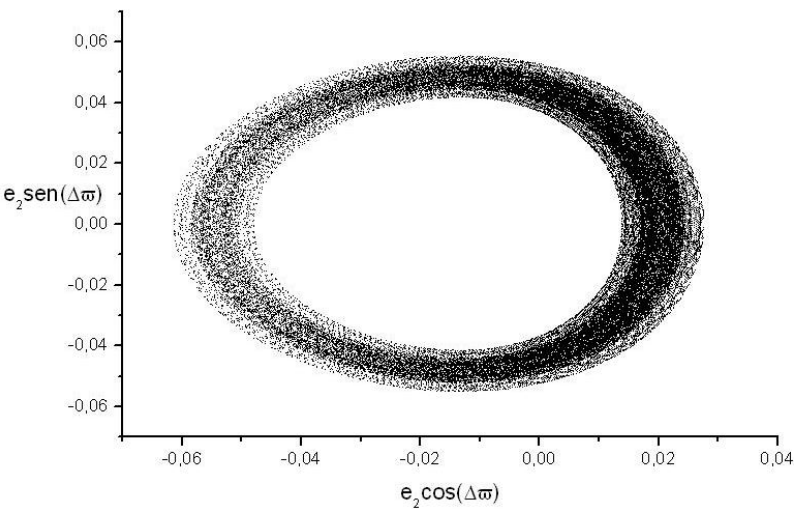

Figura 6.39: $\mathrm{KH}$ de $e_{2}$ para HD 160691 be

Assim como ocorre para o sistema HD 160691 db, devido à forte interação entre os planetas, a incerteza para obter-se os valores de $e_{1}$ e $e_{2}$ minímos e máximos é grande. Neste caso, porém, utilizando-se o método de médias adjacentes, com 50 pontos, obtém-se os gráficos para os quais a obtenção dos valores de $e_{1}$ e $e_{2}$ minímos e máximos tem muito mais precisão. 


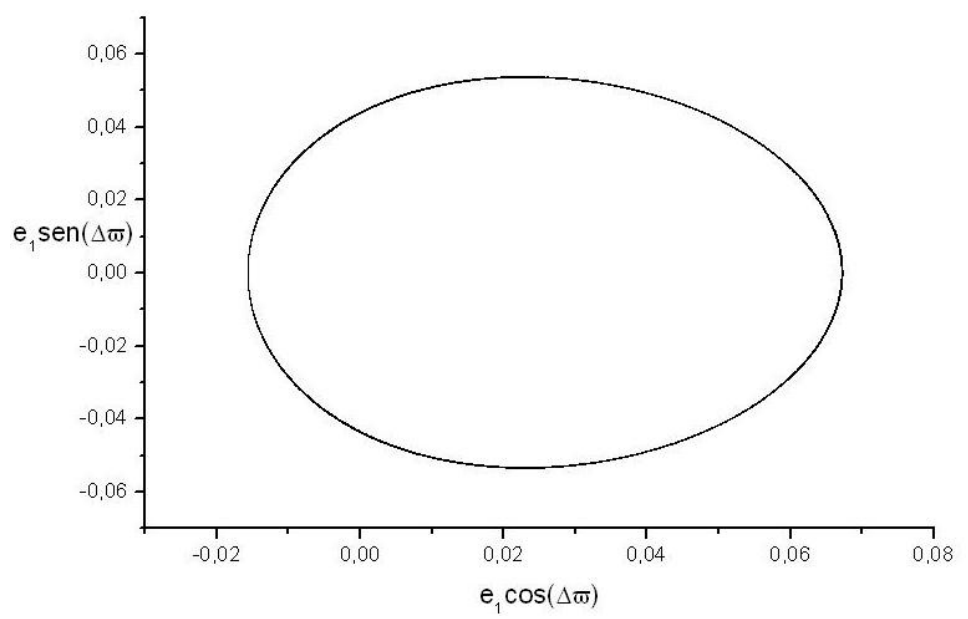

Figura 6.40: KH de $e_{1}$ para HD 160691 be filtrado

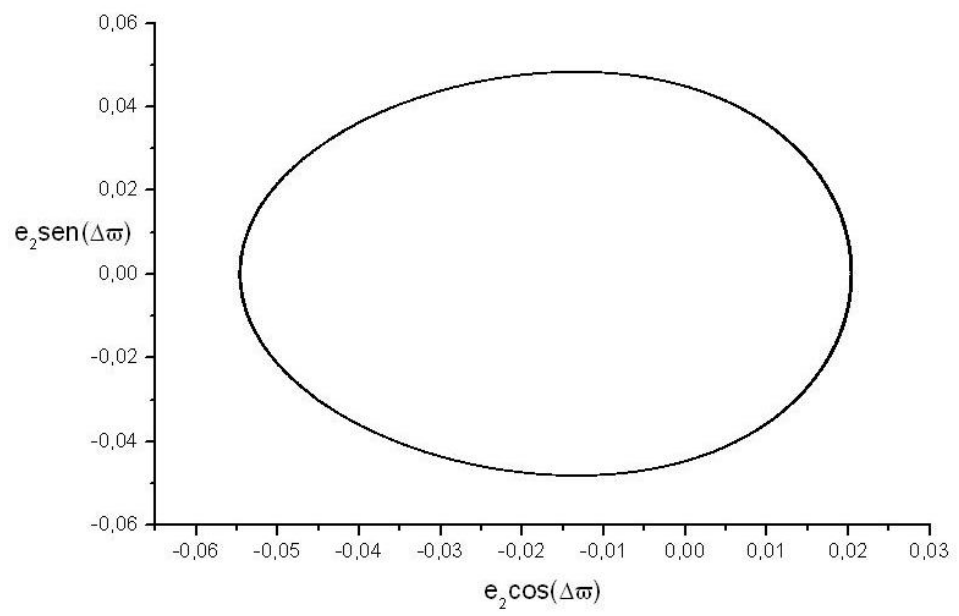

Figura 6.41: KH de $e_{2}$ para HD 160691 be filtrado 


\subsubsection{Cnc eb}

A estrela 55 Cancri, também chamada de $\rho$ Cancri, possui 5 planetas catalogados em sua órbita, sendo o sistema múltiplo com mais planetas catalogados até o presente momento. Assim como os sistemas de HD 160691, os pares de planetas de 55 Cnc enquadram-se nas 3 classificações abordadas nesta dissertação.

O sistema 55 Cnc eb é secular e, portanto, pertence à classe II. O tempo de simulação foi de 160 mil anos. O movimento do ângulo $\Delta \varpi$ é circulatório retrógrado. Seu período secular é de aproximadamente 275,3 anos.

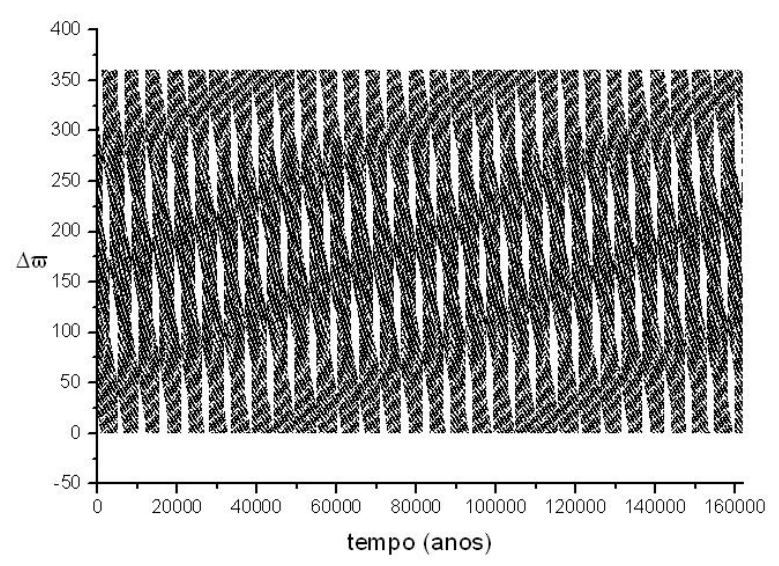

Figura 6.42: Ângulo $\Delta \varpi$ em função do tempo para $55 \mathrm{Cnc}$ eb

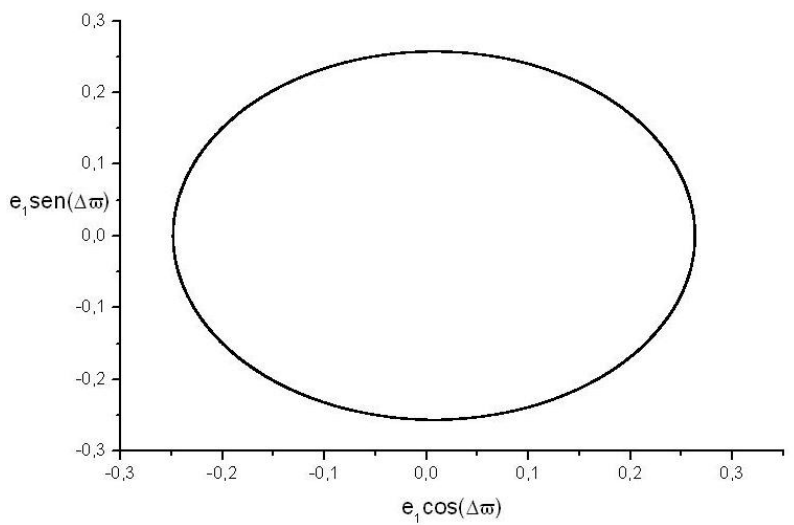

Figura 6.44: $\mathrm{KH}$ de $e_{1}$ para $55 \mathrm{Cnc}$ eb

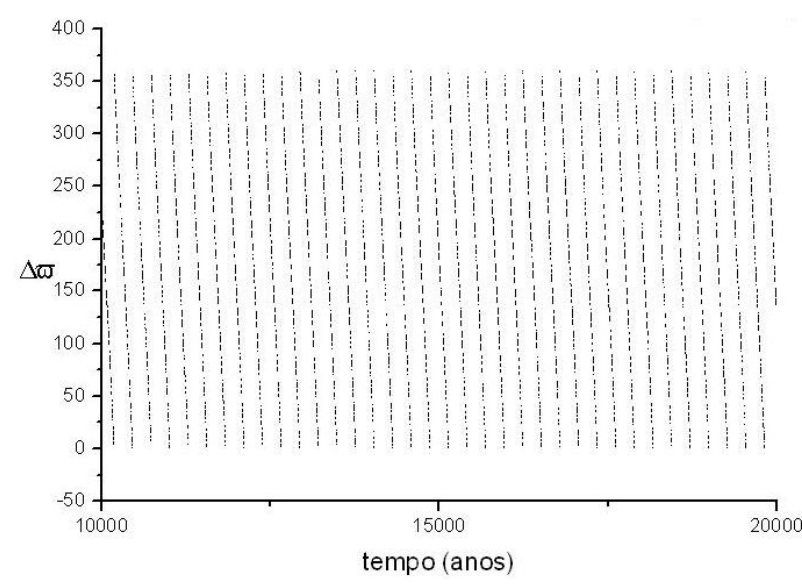

Figura 6.43: Zoom do ângulo $\Delta \varpi$ em função do tempo para $55 \mathrm{Cnc}$ eb

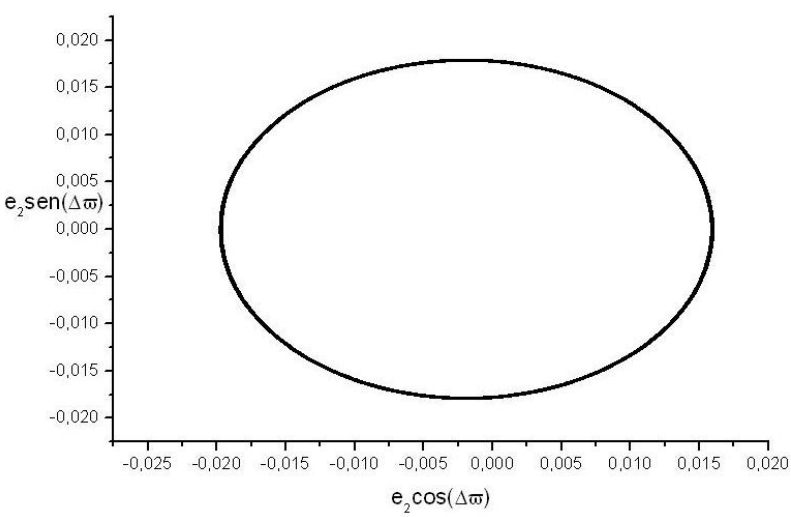

Figura 6.45: $\mathrm{KH}$ de $e_{2}$ para $55 \mathrm{Cnc}$ eb 


\subsection{8 $55 \mathrm{Cnc} b c$}

O sistema 55 Cnc bc é ressonante, ressonância 3/1, sendo da Classe I. O tempo de simulação foi de 200 mil anos. O movimento do ângulo $\Delta \varpi$ é circulatório prógrado. Seu período secular é de aproximadamente 606,8 anos.

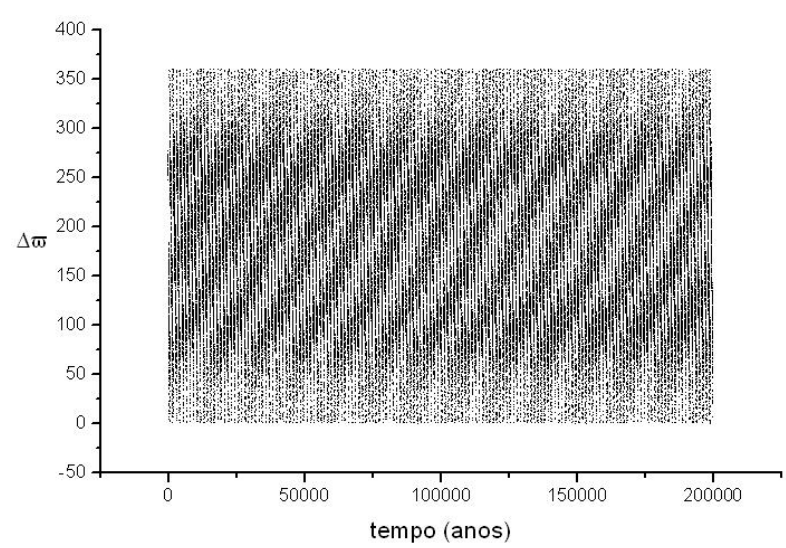

Figura 6.46: Ângulo $\Delta \varpi$ em função do tempo para $55 \mathrm{Cnc}$ bc

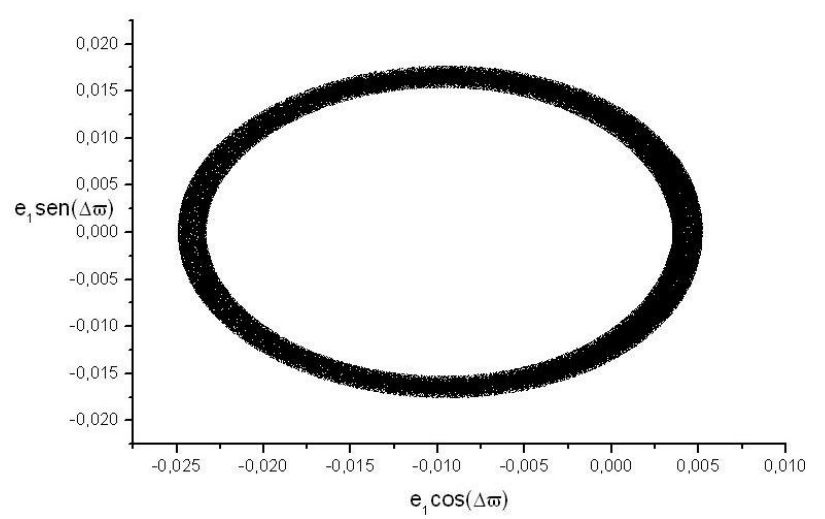

Figura 6.48: KH de $e_{1}$ para $55 \mathrm{Cnc}$ bc

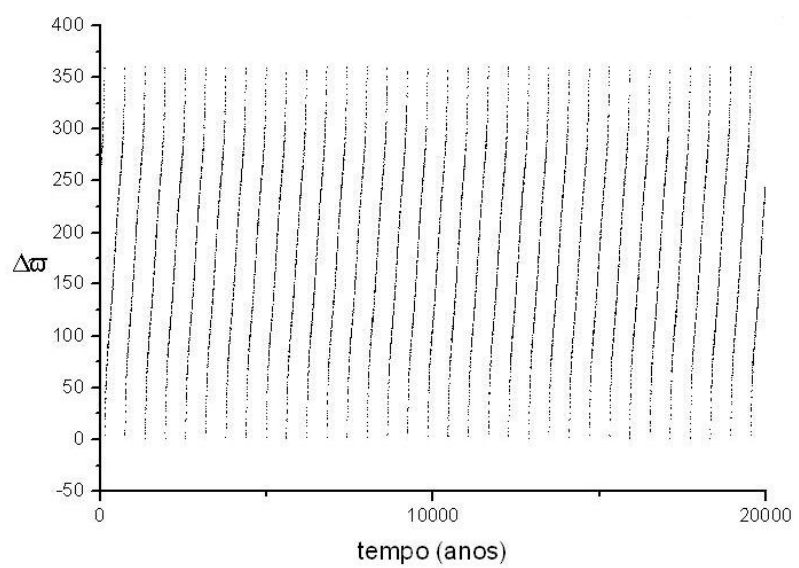

Figura 6.47: Zoom do ângulo $\Delta \varpi$ em função do tempo para $55 \mathrm{Cnc}$ bc

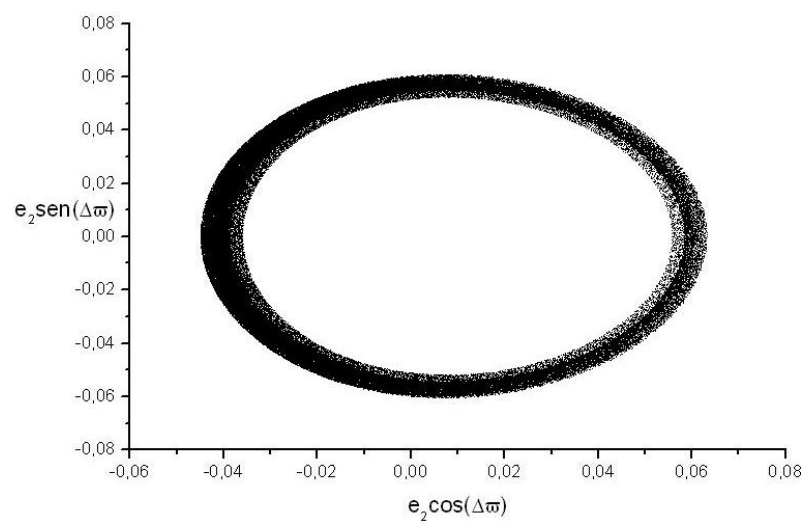

Figura 6.49: KH de $e_{2}$ para $55 \mathrm{Cnc}$ bc 
Utilizando o método de médias adjacentes, com 50 pontos, obtém-se valores mais apurados para $e_{1}$ e $e_{2}$ minímos e máximos:

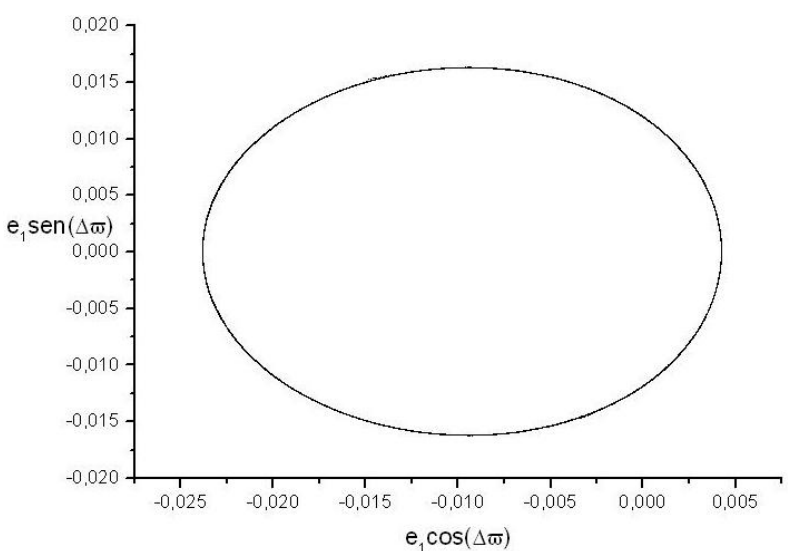

Figura 6.50: $\mathrm{KH}$ de $e_{1}$ para $55 \mathrm{Cnc}$ bc filtrado

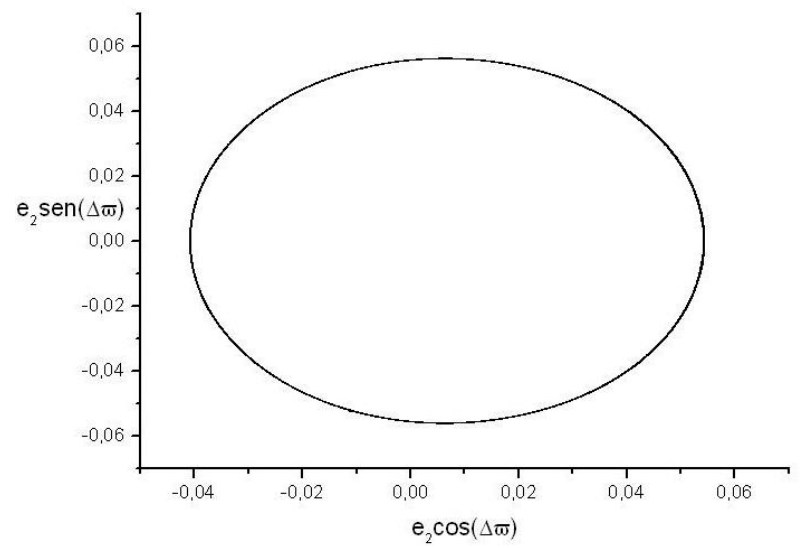

Figura 6.51: $\mathrm{KH}$ de $e_{2}$ para 55 Cnc bc filtrado

\subsubsection{Cnc cf}

O sistema 55 Cnc cf é secular, Classe II. O tempo de simulação foi de 700 mil anos. O movimento do ângulo $\Delta \varpi$ é circulatório retrógrado. Seu período secular é de aproximadamente 45.404 anos.

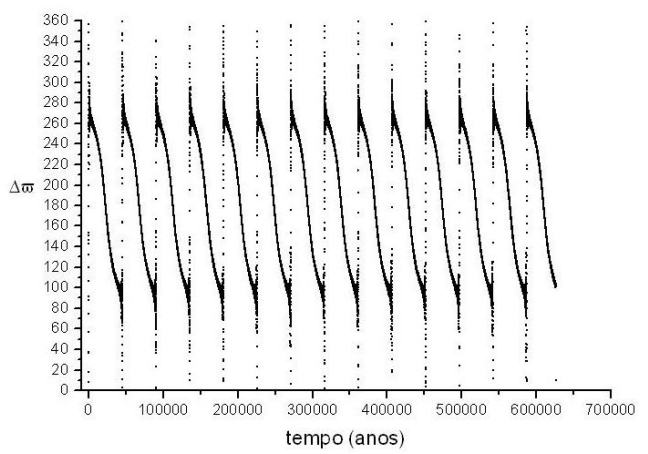

Figura 6.52: Ângulo $\Delta \varpi$ em função do tempo para 55 Cnc cf

É interessante notar como na figura 6.53 o comportamento do ângulo $\Delta \varpi$ fica evidente entre a oscilação em torno de $180^{\circ}$ (dois valores para $e_{1} \cos (\Delta \varpi)$ mínimo) e a circulação (valor positivo de $e_{1} \cos (\Delta \varpi)$ ). Essa alternância ocorre devido a interferência de curto período, quando a excentricidade do planeta externo $e_{2}$ passa muito próximo ao zero. 


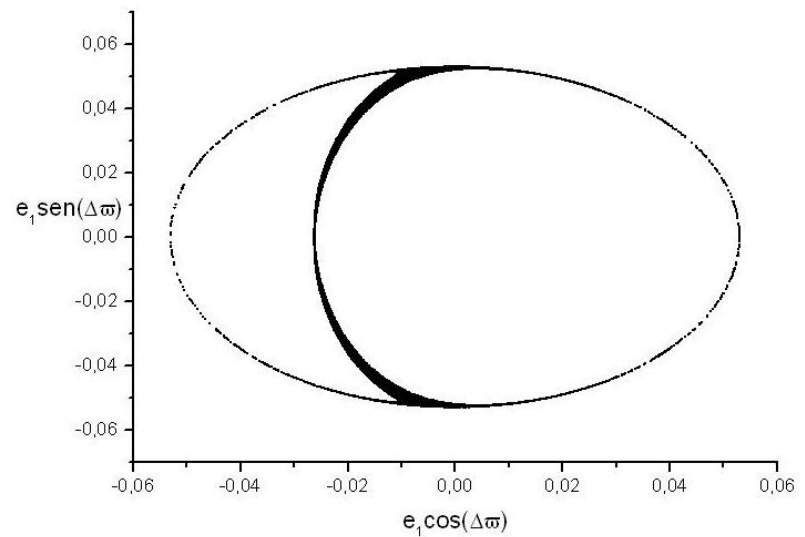

Figura 6.53: $\mathrm{KH}$ de $e_{1}$ para $55 \mathrm{Cnc} \mathrm{cf}$

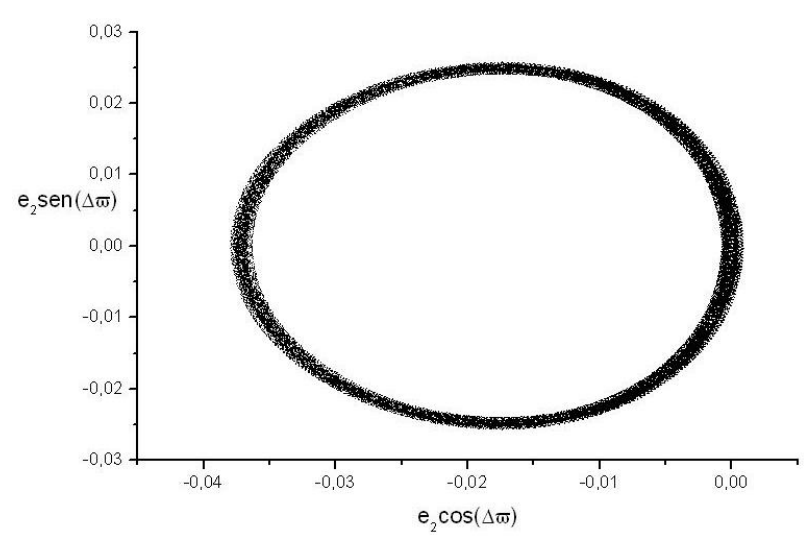

Figura 6.54: $\mathrm{KH}$ de $e_{2}$ para $55 \mathrm{Cnc}$ cf

\subsubsection{Cnc fd}

O sistema 55 Cnc fd é hierárquico, pertencente à Classe III. O tempo de simulação foi de 1 milhão de anos. O movimento do ângulo $\Delta \varpi$ é oscilatório em torno de $0^{\circ}$. Seu período secular é de aproximadamente 100.617 anos.

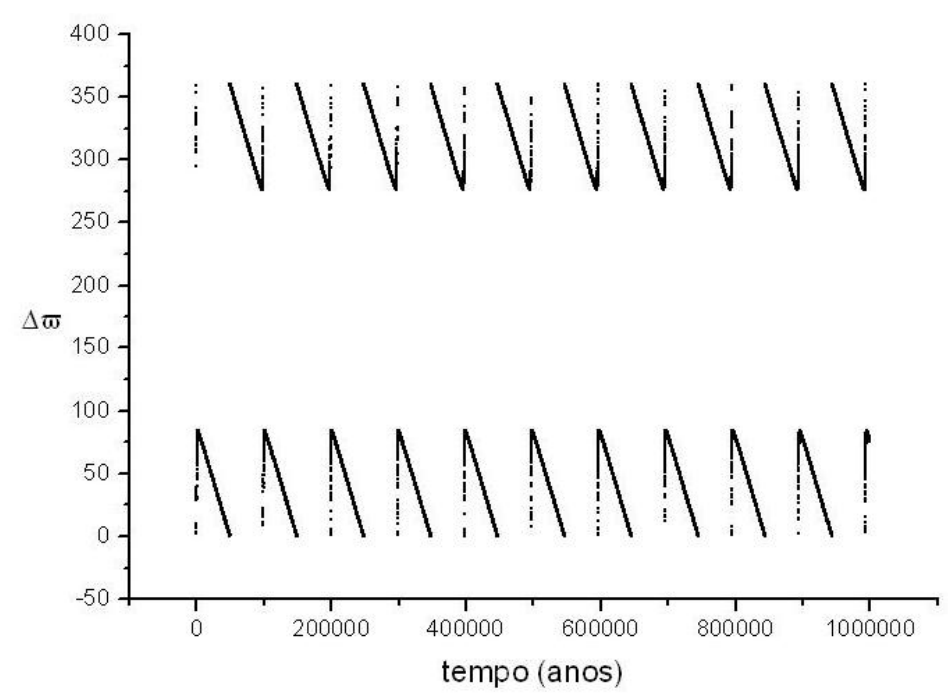

Figura 6.55: Ângulo $\Delta \varpi$ em função do tempo para $55 \mathrm{Cnc}$ fd

A Figura (6.57) não permite distinguir os valores mínimo e máximo, o que significa que a variação de $e_{2}$ tem amplitude muito pequena. Conforme a estimativa do erro embutido nos valores iniciais, pode-se considerar o valor de $e_{2}$ constante, como se pode constatar na Figura (6.58). 


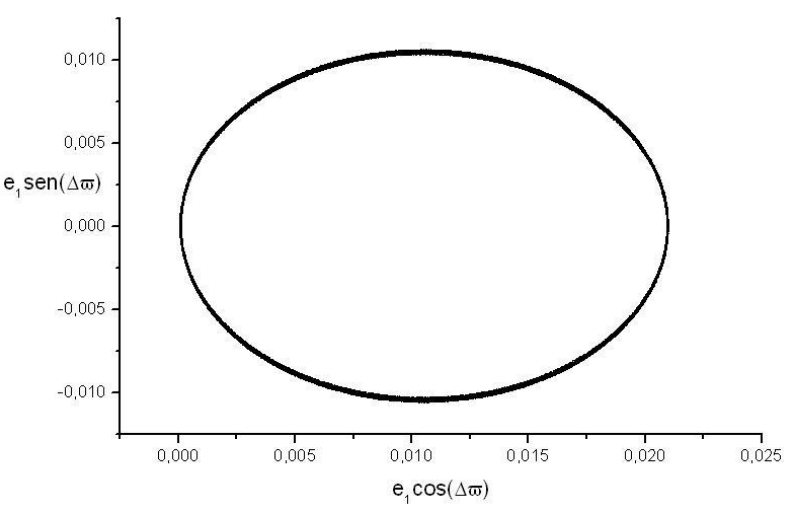

Figura 6.56: $\mathrm{KH}$ de $e_{1}$ para $55 \mathrm{Cnc}$ fd

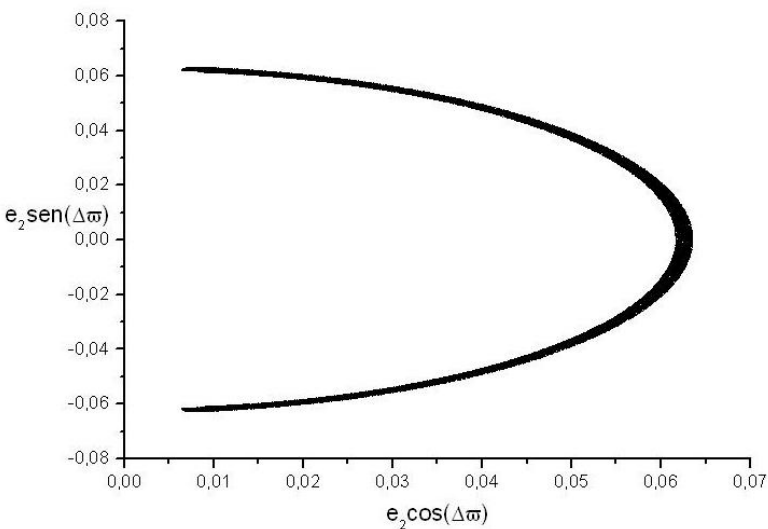

Figura 6.57: $\mathrm{KH}$ de $e_{2}$ para $55 \mathrm{Cnc}$ fd

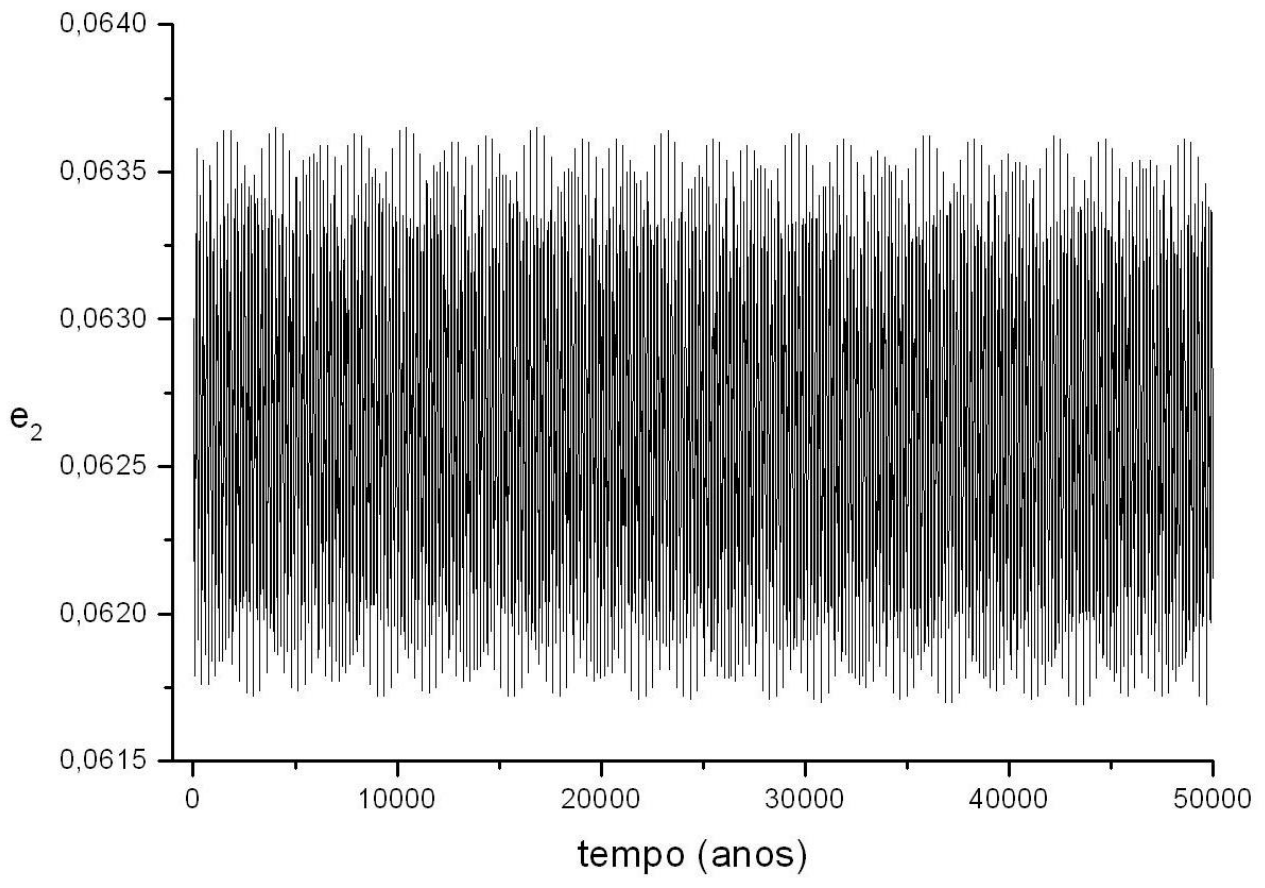

Figura 6.58: excentricidade do planeta para 55 Cnc d em função do tempo 


\subsubsection{HD 40307 bc}

Analisando separadamente o sistema HD 40307 e seus planetas bc e posteriormente cd, estes são classificados como secular, da Classe II, e quase-ressonante, da subclasse da Classe I, respectivamente. A razão de períodos de HD 40307 c sobre HD 40307 b é aproximadamente 2,2312, cujo inverso dá 0,4481 e a razão de períodos de HD 40307 d sobre HD 40307 c é aproximadamente 2,1268, cujo inverso é 0,4707.

Por outro lado, essa proximidade das razões de períodos com a ressonância $2 / 1$, traz uma atenção especial a este sistema. Levando em conta as incertezas nas obtenções dos dados dos sistemas estudados, é plausível considerar que os três planetas deste sistema estejam em ressonância 2/1 de períodos orbitais entre si. Ou seja, é possível que HD 40307 c (período 9,62 dias) esteja em ressonância 2/1 com HD 40307 b (período 4,3115) e HD 40307 d (período 20,46 dias) esteja em ressonância 2/1 com HD 40307 c. Isso resulta que HD 40307 d esteja em ressonância 4/1 com HD 40307 b. Tal ressonância é conhecida como ressonância de Laplace, graças ao astrônomo francês do final do século XVIII, Pierre-Simon de Laplace, que descobriu que os satélites galileanos Io, Europa e Ganimedes possuem a relação de períodos orbitais equivalente a 1:2:4, ou seja, para cada quatro órbitas que Io dá em torno de Júpiter, Europa dá exatamente duas, e Ganimedes dá exatamente uma.

A possibilidade de que tais planetas estejam em ressonância de períodos orbitais entre si justifica a dificuldade na obtenção dos parâmetros orbitais. Na referência (Mayor et al., 2009) os valores das excentricidades e longitudes do pericentro para os 3 planetas são arbitrariamente iguais a zero. Tais valores, incomuns na interação gravitacional entre três planetas, acarretam dificuldades nas simulações, devido à dificuldade de se obter precisão (na geração de gráficos, análise e cálculos do simulador).

Como se pode ver nas figuras (6.59) e (6.60) os valores iniciais arbitrários não resultam em gráficos de KH confiáveis. 


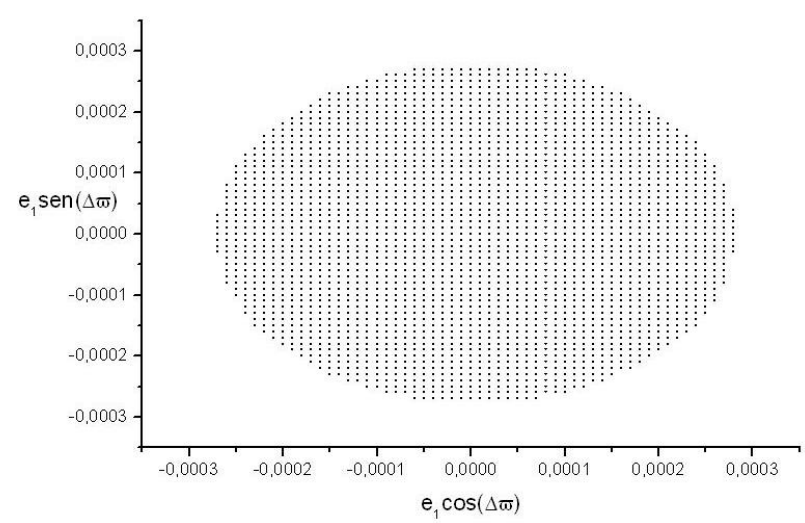

Figura 6.59: KH de $e_{1}$ para HD 40307 bc

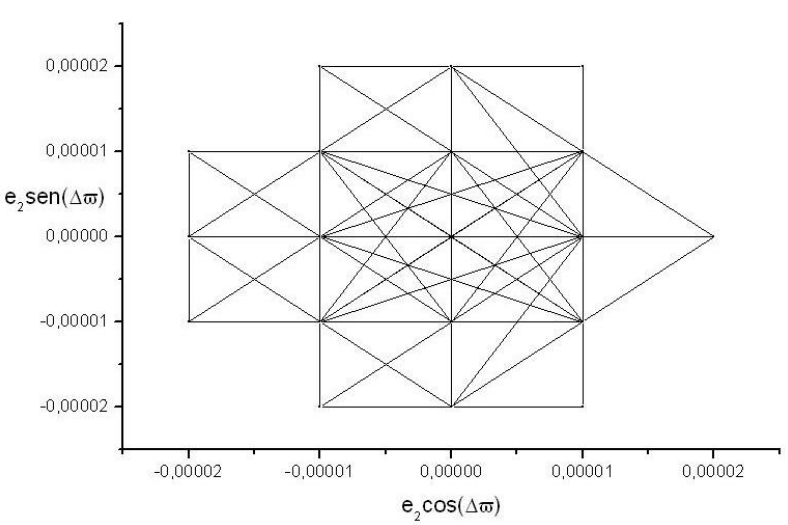

Figura 6.60: KH de $e_{2}$ para HD 40307 bc

Uma nova simulação foi feita então, com valores arbitrários de excentricidade iguais a 0,01 e longitudes do pericentro iguais $0,1^{\circ}$, com tempo de simulação para o sistema HD 40307 bc de 200 mil anos. O movimento do ângulo $\Delta \varpi$ é oscilatório em torno de $0^{\circ}$. Seu período secular é de aproximadamente 1.359 anos.

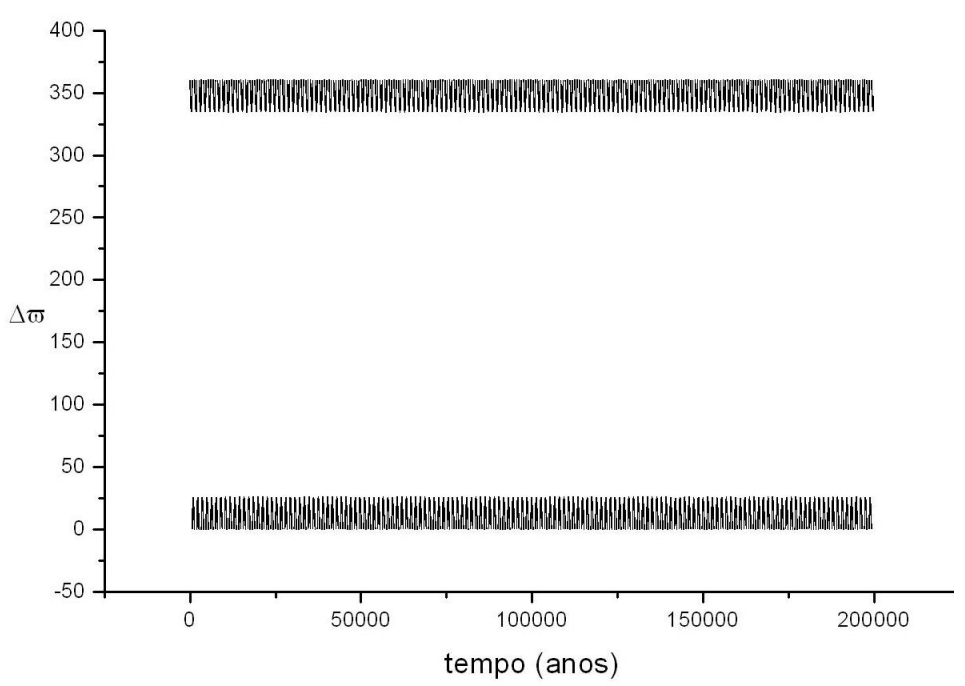

Figura 6.61: Ângulo $\Delta \varpi$ em função do tempo para HD 40307 bc, $\mathrm{e}=0,01 ; \mathrm{w}=0,1^{\circ}$ 
O movimento oscilatório do ângulo $\Delta \varpi$ é inferido a partir de um zoom no gráfico:

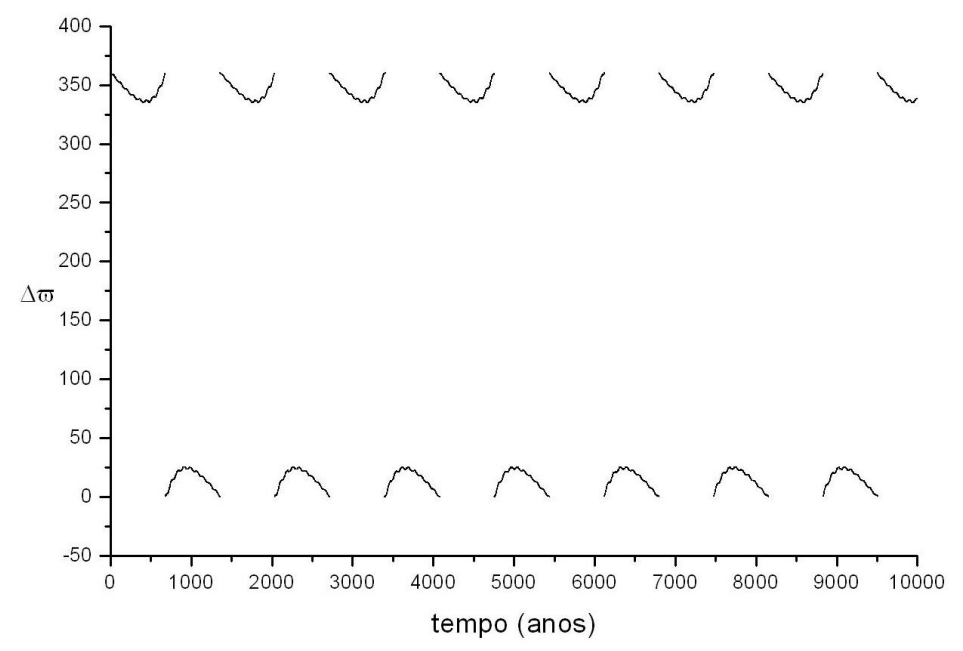

Figura 6.62: Zoom do ângulo $\Delta \varpi$ em função do tempo para HD $40307 \mathrm{bc}, \mathrm{e}=0,01 ; \mathrm{w}=0,1^{\circ}$

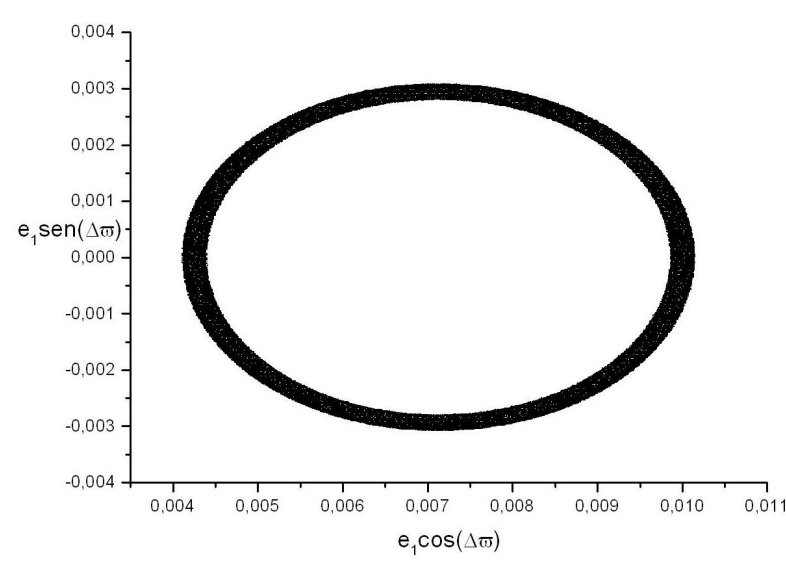

Figura 6.63: KH de $e_{1}$ para HD $40307 \mathrm{bc}, \mathrm{e}=0,01$; $\mathrm{w}=0,1^{\circ}$

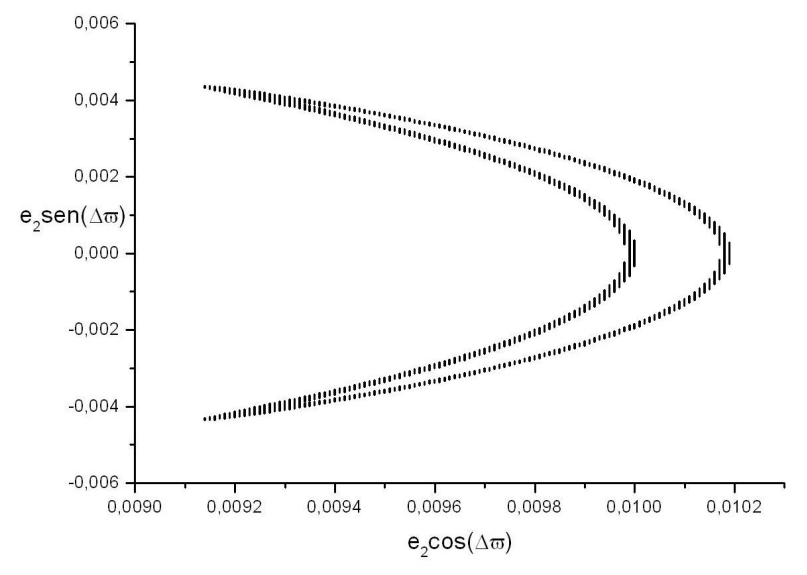

Figura 6.64: $\mathrm{KH}$ de $e_{2}$ para HD $40307 \mathrm{bc}, \mathrm{e}=0,01$; $\mathrm{w}=0,1^{\circ}$ 


\subsubsection{HD $40307 \mathrm{~cd}$}

Como exposto anteriormente para o sistema HD 40307 bc, a simulação para o sistema HD 40307 cd foi feita utilizando-se valores arbitrários de excentricidade iguais a 0,01 e longitudes do pericentro iguais a 0,1. O tempo de simulação para o sistema HD 40307 cd foi de 200 mil anos. O movimento do ângulo $\Delta \varpi$ é oscilatório em torno de $0^{\circ}$. Seu período secular é de aproximadamente 1.570 anos.

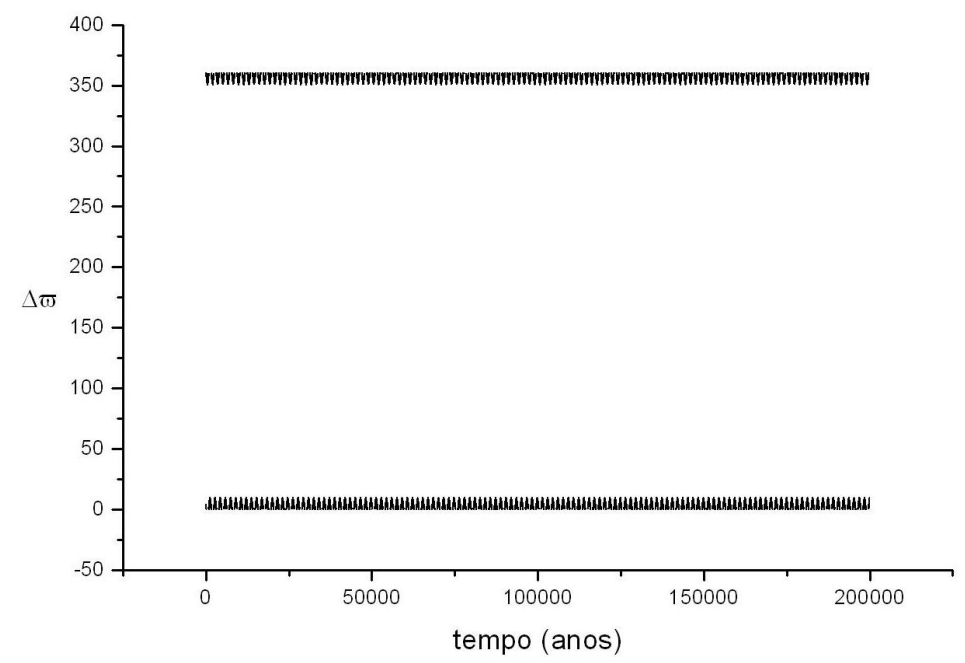

Figura 6.65: Ângulo $\Delta \varpi$ em função do tempo para HD $40307 \mathrm{~cd}$

O movimento oscilatório do ângulo $\Delta \varpi$ é inferido a partir de um zoom no gráfico:

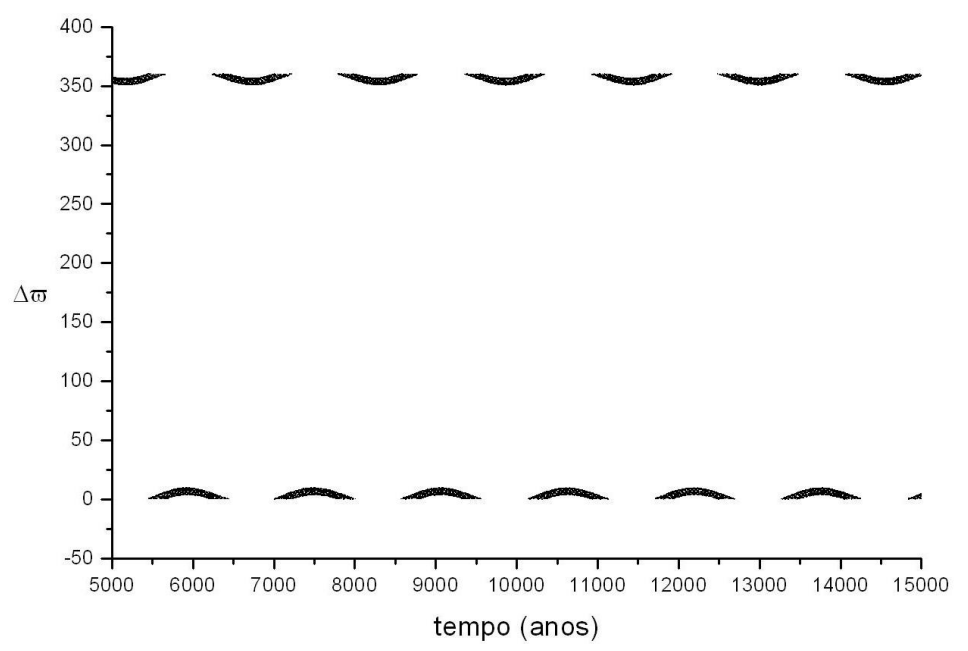

Figura 6.66: Zoom do ângulo $\Delta \varpi$ em função do tempo para HD $40307 \mathrm{~cd}$ 


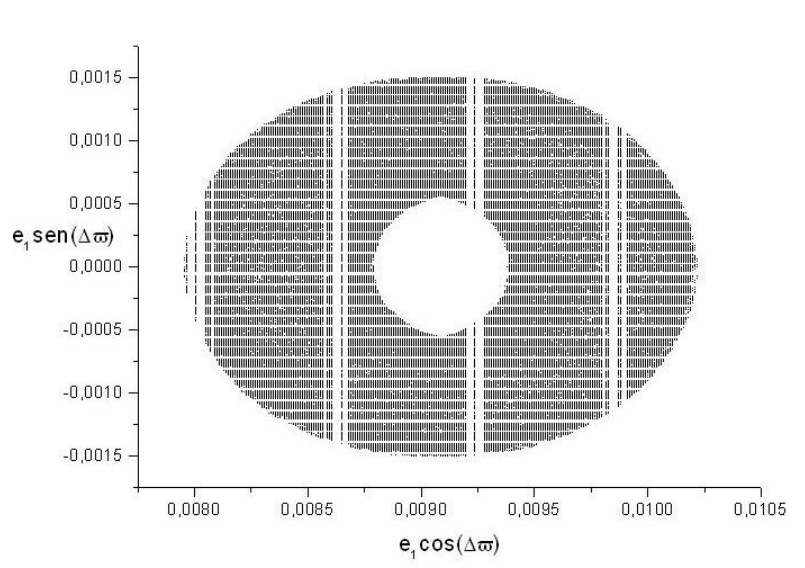

Figura 6.67: $\mathrm{KH}$ de $e_{1}$ para HD $40307 \mathrm{~cd}$

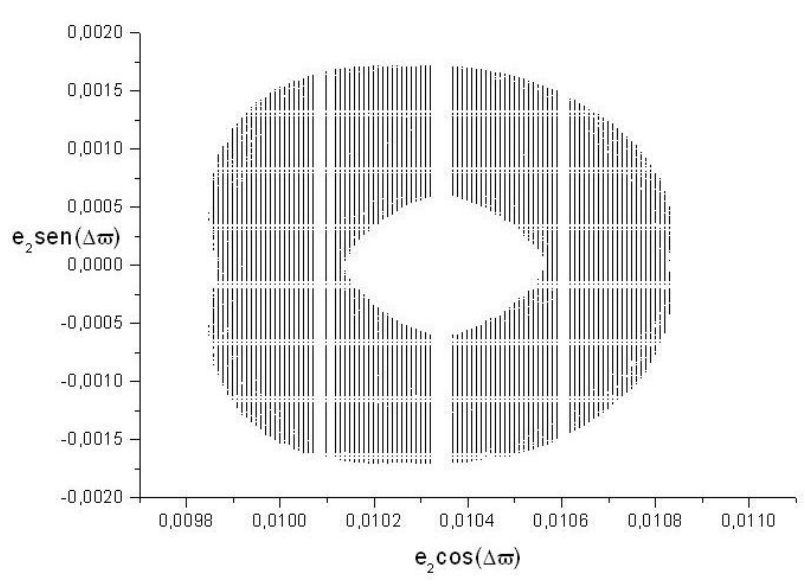

Figura 6.68: $\mathrm{KH}$ de $e_{2}$ para HD $40307 \mathrm{~cd}$

Utilizando o método de médias adjacentes, com 50 pontos, obtém-se dados mais precisos de $\mathrm{KH}$ de $e_{1}$ e $e_{2}$ para o sistema HD $40307 \mathrm{~cd}$ :

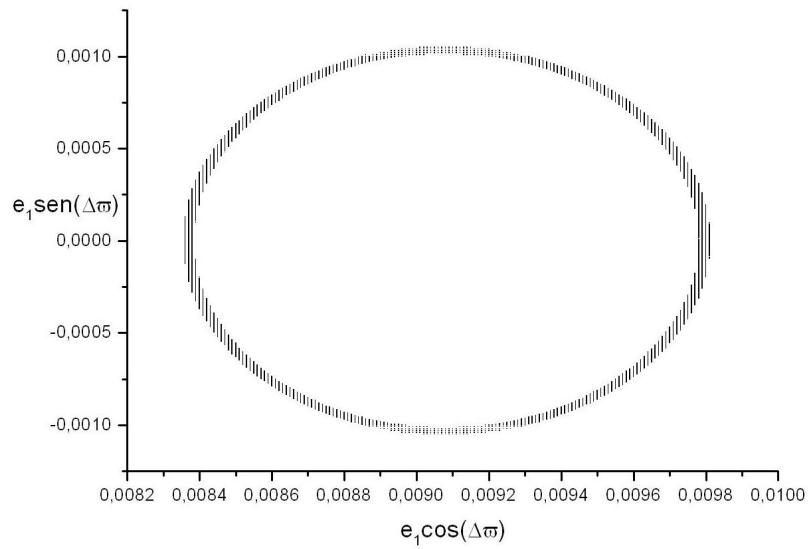

Figura 6.69: $\mathrm{KH}$ de $e_{1}$ para HD 40307 cd com filtro

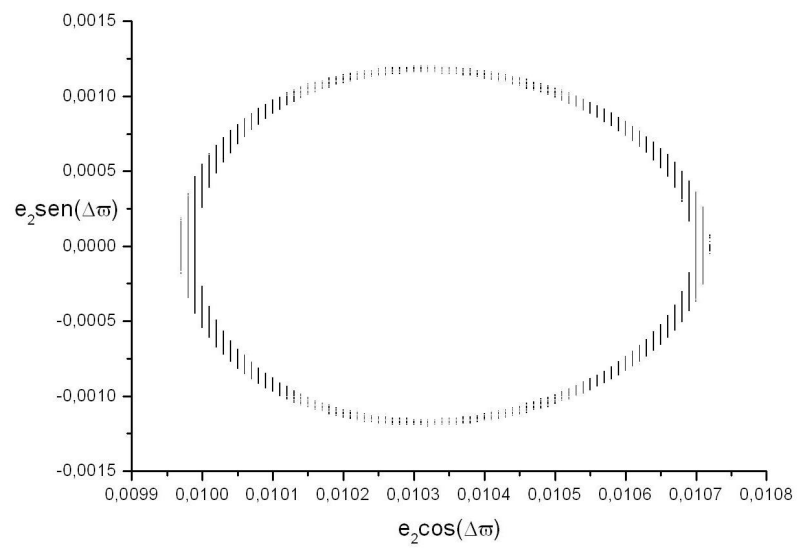

Figura 6.70: KH de $e_{2}$ para HD 40307 cd com filtro 


\subsection{Dados compilados para os sistemas extrassolares}

A tabela (6.2) mostra os dados compilados dos sistemas extrassolares. Os valores de e $\cos \Delta \varpi$ quando e sen $\Delta \varpi=0$ foram obtidos diretamente dos gráficos de KH. Os sistemas ou valores individuais marcados com asterico $(*)$ tiveram esses mesmos valores obtidos do método de médias adjacentes aplicado aos dados obtidos das simulações. Quando da impossibilidade de se utilizar este método, os gráficos foram gerados a partir do método de filtragem FFT. Esses sistemas ou valores estão marcados com duplo asterisco (**). O período secular é dado em anos. 
Tabela 6.2 - Resultados das simulações para os sistemas múltiplos extrassolares

\begin{tabular}{|c|c|c|c|c|c|c|c|}
\hline Sistema & Classe & $e_{1}$ Mín & $e_{1}$ Máx & $e_{2}$ Mín & $e_{2}$ Máx & Movimento do ângulo $\Delta \varpi$ & Período secular \\
\hline HD $45364 \mathrm{bc}^{*}$ & I & $-0,234$ & $-0,147$ & $-0,103$ & $-0,045$ & oscilação $180^{\circ}$ & 407,8 \\
\hline GJ $876 \mathrm{dc}$ & III & $\sim 0$ & 0,095 & $-0,224$ & 0,224 & oscilação $0^{\circ} /$ circ. retr. & 839,1 \\
\hline GJ $876 \mathrm{cb}$ & I & $-0,225$ & 0,234 & $\sim 0^{* *}$ & $\sim 0^{* *}$ & oscilação $0^{\circ} /$ circ. & 146,0 \\
\hline HD $73526 \mathrm{bc}^{* *}$ & I & $-0,042$ & 0,042 & $-0,036$ & 0,036 & circulatório retrógrado & $4.783,0$ \\
\hline HD $82943 \mathrm{cb}$ & I & $-0,402$ & 0,364 & $-0,057$ & 0,166 & circulatório retrógrado & 701,8 \\
\hline HD $160691 \mathrm{~cd}$ & III & $-0,121$ & 0,136 & $-0,062$ & 0,061 & circulatório retrógrado & $94.493,0$ \\
\hline HD $160691 \mathrm{db}^{* *}$ & I & $-0,039$ & 0,053 & $-0,022$ & 0,015 & circulatório retrógrado & 476,6 \\
\hline HD 160691 be* & II & $-0,016$ & 0,067 & $-0,055$ & 0,020 & circulatório retrógrado & $48.657,0$ \\
\hline HD 40307 bc & II & 0,004 & 0,010 & 0,001 & 0,010 & oscilação $0^{\circ}$ & $1.359,0$ \\
\hline HD 40307 cd* $^{*}$ & I & 0,008 & 0,010 & 0,001 & 0,010 & oscilação $0^{\circ}$ & 1570,0 \\
\hline HD 181433 bc & III & $-0,396$ & 0,435 & $-0,28$ & 0,28 & circulatório retrógrado & $456.583,0$ \\
\hline GJ 581 bc & II & $-0,094$ & 0,012 & $-0,074$ & 0,159 & circulatório prógrado & 401,9 \\
\hline GJ $581 \mathrm{~cd}$ & II & $-0,060$ & 0,192 & $-0,149$ & 0,103 & circulatório retrógrado & $28.850,0$ \\
\hline HD 155358 bc & II & $-0,18$ & $-0,027$ & $-0,22$ & $-0,082$ & oscilação $180^{\circ}$ & $2.366,0$ \\
\hline HD 37124 bd & II & $-0,055$ & 0,183 & $-0,14$ & 0,039 & circulatório retrógrado & $25.976,0$ \\
\hline HD $37124 \mathrm{dc}$ & II & 0,066 & 0,25 & 0,118 & 0,226 & oscilação $0^{\circ}$ & $12.164,0$ \\
\hline HD $60532 \mathrm{bc}^{* *}$ & I & $-0,113$ & 0,113 & $-0,015$ & 0,015 & circulatório retrógrado & 412,9 \\
\hline $55 \mathrm{Cnc}$ eb & II & $-0,248$ & 0,264 & $-0,02$ & 0,016 & circulatório retrógrado & 275,3 \\
\hline 55 Cnc bc* & I & $-0,024$ & 0,004 & $-0,040$ & 0,054 & circulatório prógrado & 606,8 \\
\hline 55 Cnc cf & II & $\begin{array}{l}-0,053 \text { e } \\
-0,026\end{array}$ & 0,053 & $-0,037$ & $\sim 0$ & oscilação $180^{\circ}$ / circ. retr. & $45.404,0$ \\
\hline $55 \mathrm{Cnc}$ fd & III & $\sim 0$ & 0,021 & $0,049^{*}$ & $0,063^{*}$ & oscilação $0^{\circ}$ & $100.617,0$ \\
\hline HD 69830 bc & II & $-0,061$ & 0,198 & $-0,143$ & 0,023 & circulatório retrógrado & $7.617,0$ \\
\hline HD $69830 \mathrm{~cd}$ & II & $-0,040$ & 0,130 & $-0,102$ & 0,07 & circulatório retrógrado & $76.887,0$ \\
\hline HD $177830 \mathrm{bc}$ & II & $-0,338$ & 0,410 & $-0,077$ & 0,030 & circulatório retrógrado & $4.085,0$ \\
\hline HD 108874 bc & I & $-0,278$ & $-0,052$ & $-0,253$ & $-0,043$ & oscilação $180^{\circ}$ & $13.443,0$ \\
\hline HD 183263 bc & II & $-0,439$ & $-0,112$ & $-0,351^{*}$ & $-0,115^{*}$ & oscilação $180^{\circ}$ & $6.895,5$ \\
\hline HD 202206 bc & II & $-0,437$ & 0,435 & $-0,313^{* *}$ & $0,316^{* *}$ & circulatório prógrado & 435,8 \\
\hline$v$ Andromeda bc & III & $-0,023$ & 0,078 & $-0,259$ & 0,258 & circulatório retrógrado & $32.600,0$ \\
\hline$v$ Andromeda cd & II & $-0,008$ & 0,300 & $-0,282$ & 0,239 & circulatório retrógrado & $7.477,0$ \\
\hline HD $12661 \mathrm{bc}$ & II & $-0,363$ & $-0,092$ & $-0,294$ & $-0,007$ & oscilação $180^{\circ}$ & $26.205,0$ \\
\hline 47 Uma bc & I & $-0,049$ & $\begin{array}{l}0,021 \mathrm{e} \\
0,05\end{array}$ & $0,001^{*}$ & $0,05^{*}$ & oscilação $0^{\circ}$ /circulatório & $218.268,0$ \\
\hline HD 74156 bd* $^{*}$ & II & 0,637 & 0,646 & 0,188 & 0,265 & oscilação $0^{\circ}$ & $6.408,0$ \\
\hline HD $74156 \mathrm{dc}$ & III & $-0,133$ & 0,503 & $-0,430$ & 0,424 & circulatório retrógrado & $7.087,0$ \\
\hline HD 11506 bc & III & $-0,214$ & 0,42 & $-0,255$ & 0,221 & circulatório retrógrado & $11.880,0$ \\
\hline HIP 14810 bc* & III & $-0,144$ & $-0,088$ & $-0,198$ & $-0,159$ & oscilação $180^{\circ}$ & $37.766,0$ \\
\hline HIP $14810 \mathrm{~cd}$ & III & 0,116 & 0,221 & $0,052^{*}$ & $0,213^{*}$ & oscilação $0^{\circ}$ & $24.210,0$ \\
\hline HD 169830 bc & III & $-0,193$ & 0,526 & $-0,359$ & 0,214 & circulatório retrógrado & $37.471,0$ \\
\hline HD 147018 bc* & III & $-0,445$ & 0,504 & $-0,146$ & 0,118 & circulatório retrógrado & $15.450,0$ \\
\hline HD 168443 bc & III & $-0,497$ & 0,568 & $-0,198^{*}$ & $0,16^{*}$ & circulatório retrógrado & $17.433,0$ \\
\hline HD $11964 \mathrm{cb}$ & III & $-0,3$ & 0,311 & $-0,061$ & 0,06 & circulatório retrógrado & $869.333,0$ \\
\hline HD 38529 bc & III & $-0,225$ & 0,263 & $-0,354$ & 0,357 & circulatório retrógrado & $118.978,0$ \\
\hline HD 190360 bc & III & $-0,009$ & 0,042 & $-0,3606$ & 0,360 & circulatório retrógrado & $1.044 .871,0$ \\
\hline HD 47186 bc & III & $-0,025$ & 0,04 & $-0,25$ & 0,25 & circulatório retrógrado & $5.419 .355,0$ \\
\hline HD $217107 \mathrm{bc}$ & III & $-0,132$ & 0,16 & $-0,517$ & 0,52 & circulatório retrógrado & $2.618 .474,0$ \\
\hline HD 68988 bc & III & $-0,15$ & 0,15 & $-0,031$ & 0,011 & circulatório retrógrado & 616,5 \\
\hline HD $187123 \mathrm{bc}$ & III & $-0,009$ & 0,014 & $-0,243$ & 0,243 & circulatório retrógrado & $13.252 .033,0$ \\
\hline
\end{tabular}


Em complemento à tabela (6.2) é apresentada a tabela (6.3) que contém simulações para o sistema GJ 581 contendo 4 planetas (Mayor et al., 2009) e simulação do sistema HD 82943 bd considerando a possível existência de um terceiro planeta (Beaugé et al., 2008). Para maiores detalhes, ver Apêndice B deste trabalho.

Tabela 6.3 - Resultados das simulações para os sistemas múltiplos extrassolares - complemento

\begin{tabular}{|l|l|l|l|l|l|l|l|}
\hline Sistema & Classe & $e_{1}$ Mín & $e_{1}$ Máx & $e_{2}$ Mín & $e_{2}$ Máx & Movimento do ângulo $\Delta \varpi$ & Período secular \\
\hline \hline GJ 581 eb (Mayor) & I & $\sim 0^{* *}$ & $\sim 0^{* *}$ & $-0,014$ & 0,008 & oscilação $180^{\circ} /$ circ. & 174,0 \\
\hline GJ 581 bc (Mayor) & II & $-0,095$ & $\sim 0$ & $\begin{array}{l}-0,168 \text { e } \\
-0,086\end{array}$ & 0,164 & oscilação $180^{\circ} /$ circ. prog. & 39,6 \\
\hline GJ 581 cd (Mayor) & II & $-0,003$ & 0,486 & $-0,395$ & 0,233 & circulatório retrógrado & 3273,0 \\
\hline HD 82943 bd & I & $-0,146$ & 0,073 & $-0,255$ & 0,355 & circulatório retrógrado & 842,6 \\
\hline
\end{tabular}

A tabela 6.4 mostra os sistemas múltiplos extrassolares que apresentaram configuração instável nas simulações. Os sistemas marcados com asterisco $\left(^{*}\right)$ foram simulados mais de uma vez, com outra fonte de dados, e apresentaram configuração estável.

Tabela 6.4 - Lista dos sistemas com configuração instável

\begin{tabular}{|c|}
\hline Sistema \\
\hline \hline BD 202457 bc (Niedzielski et al., 2009) \\
\hline HD 73526 bc* (Tinney et al., 2006) $^{*}$ 47 Uma bc* (Fischer et al., 2002) \\
\hline HD 128311 bc (Vogt et al., 2005) \\
\hline HD 128311 bc (Fischer e Valenti, 2005) \\
\hline HD 82943 cb* (Mayor et al., 2004) \\
\hline HD 181433 cd (Bouchy et al., 2009) \\
\hline HD 102272 bc (Niedzielski et al., 2009) \\
\hline HD 183263 bc* (OSBPM) \\
\hline HD 202206 bc* (Raymond et al., 2008) \\
\hline HD 202206 bc* (Correia et al., 2005) \\
\hline HAT-P-13 bc (Bakos et al., 2009) \\
\hline
\end{tabular}

A tabela 6.3 mostra os valores dos períodos orbitais de todos os planetas utilizados para simulações e ainda a razão de períodos $T_{1} / T_{2}$ dos planetas em órbitas consecutivas e o inverso dessa razão, $T_{2} / T_{1}$ : 
Tabela 6.5 - Períodos orbitais e razões dos períodos de planetas em órbitas consecutivas

\begin{tabular}{|c|c|c|c|}
\hline Planetas & Período (dias) & $T_{1} / T_{2}$ & $T_{2} / T_{1}$ \\
\hline HD $45364 \mathrm{~b}$ & 226,93 & 1,5108 & 0,6618 \\
\hline HD $45364 \mathrm{c}$ & 342,85 & & \\
\hline BD $202457 \mathrm{~b}$ & 379,63 & 1,6384 & 0,6103 \\
\hline BD $202457 \mathrm{c}$ & 622,00 & & \\
\hline GJ 581 e (Mayor) & 3,15 & 1,7046 & 0,5866 \\
\hline GJ 581 b (Mayor) & 5,37 & 2,4082 & 0,4152 \\
\hline GJ 581 c (Mayor) & 12,92 & 5,1665 & 0,1935 \\
\hline GJ 581 d (Mayor) & 66,80 & & \\
\hline GJ $876 \mathrm{~d}$ & 1,94 & 15,6572 & 0,0638 \\
\hline GJ $876 \mathrm{c}$ & 30,34 & 2,0085 & 0,4978 \\
\hline GJ 876 b & 60,94 & & \\
\hline HD 73526 b (Tinney) & 187,50 & 2,01 & 0,4975 \\
\hline HD 73526 c (Tinney) & 376,90 & & \\
\hline HD 73526 b (Marcos) & 187,94 & 2,0208 & 0,4948 \\
\hline HD 73526 c (Marcos) & 379,79 & & \\
\hline 47 Uma b (Fischer) & 1083,00 & 2,0221 & 0,4945 \\
\hline 47 Uma c (Fischer) & 2190,01 & & \\
\hline HD 128311 b (Vogt) & 458,60 & 2,0242 & 0,4940 \\
\hline HD 128311 c (Vogt) & 928,30 & & \\
\hline HD 128311 b (Fischer) & 420,51 & 2,1854 & 0,4575 \\
\hline HD 128311 c (Fischer) & 919,00 & & \\
\hline HD 82943 c (Mayor) & 219,40 & 1,98 & 0,50 \\
\hline HD 82943 b (Mayor) & 435,10 & & \\
\hline HD 82943 c (Beauge) & 218,70 & 2,0461 & 0,49 \\
\hline HD 82943 b (Beauge) & 447,50 & 2,0117 & 0,4971 \\
\hline HD 82943 d (Beauge) & 900,22 & & \\
\hline HD $160691 \mathrm{c}$ & 9,64 & 32,51 & 0,0307 \\
\hline HD $160691 \mathrm{~d}$ & 308,59 & 2,1075 & 0,4744 \\
\hline HD $160691 \mathrm{~b}$ & 643,89 & 4,5622 & 0,2191 \\
\hline HD $160691 \mathrm{e}$ & 3403,00 & & \\
\hline
\end{tabular}


Tabela 6.5 (Continuação)

\begin{tabular}{|c|c|c|c|}
\hline Planetas & Período (dias) & $T_{1} / T_{2}$ & $T_{2} / T_{1}$ \\
\hline HD $40307 \mathrm{~b}$ & 4,3115 & 2,2312 & 0,4481 \\
\hline HD $40307 \mathrm{c}$ & 9,62 & 2,1268 & 0,4701 \\
\hline HD $40307 \mathrm{~d}$ & 20,46 & & \\
\hline HD $181433 \mathrm{~b}$ & 9,3743 & 102,62 & 0,0097 \\
\hline HD 181433 c & 962,00 & 2,2577 & 0,4429 \\
\hline HD $181433 \mathrm{~d}$ & 2172,00 & & \\
\hline GJ 581 b (Beust) & 5,36 & 2,4078 & 0,4153 \\
\hline GJ 581 c (Beust) & 12,92 & 6,4385 & 0,1553 \\
\hline GJ 581 d (Beust) & 83,22 & & \\
\hline HD 155358 b & 195,00 & 2,7179 & 0,3679 \\
\hline HD $155358 \mathrm{c}$ & 530,00 & & \\
\hline HD 37124 b & 154,46 & 5,4616 & 0,183 \\
\hline $\mathrm{HD} 37124 \mathrm{c}$ & 843,60 & 2,7204 & 0,3675 \\
\hline HD $37124 \mathrm{~d}$ & 2295,00 & & \\
\hline HD $60532 \mathrm{~b}$ & 201,83 & 3,0077 & 0,3324 \\
\hline HD $60532 \mathrm{c}$ & 607,06 & & \\
\hline 55 Cnc e & 2,79 & 5,2386 & 0,1908 \\
\hline $55 \mathrm{Cnc}$ b & 14,65 & 3,029 & 0,3301 \\
\hline $55 \mathrm{Cnc} c$ & 44,37 & 5,8737 & 0,1702 \\
\hline 55 Cnc f & 260,66 & 20,6677 & 0,0485 \\
\hline $55 \mathrm{Cnc} \mathrm{d}$ & 5371,82 & & \\
\hline HD $69830 \mathrm{~b}$ & 8,66 & 3,6413 & 0,2746 \\
\hline HD $69830 \mathrm{c}$ & 31,56 & 6,2420 & 0,1602 \\
\hline HD $69830 \mathrm{~b}$ & 197,00 & & \\
\hline HD $177830 \mathrm{c}$ & 111,19 & 3,6683 & 0,2726 \\
\hline HD $177830 \mathrm{~b}$ & 407,88 & & \\
\hline HD 108874 b & 395,40 & 4,0612 & 0,2462 \\
\hline HD $108874 \mathrm{c}$ & 1605,80 & & \\
\hline HD 102272 b & 127,58 & 4,0758 & 0,2453 \\
\hline HD $102272 \mathrm{c}$ & 520,00 & & \\
\hline
\end{tabular}


Tabela 6.5 (Continuação)

\begin{tabular}{|c|c|c|c|}
\hline Planetas & Período (dias) & $T_{1} / T_{2}$ & $T_{2} / T_{1}$ \\
\hline HD 183263 b (OSBPM) & 634,23 & 4,6513 & 0,2149 \\
\hline HD $183263 \mathrm{c}$ & 2950,00 & & \\
\hline HD 183263 b (Wright) & 626,50 & 4,7565 & 0,2102 \\
\hline HD $183263 \mathrm{c}$ & 2980,00 & & \\
\hline HD 202206 b (Marcos) & 255,79 & 4,8292 & 0,2070 \\
\hline HD $202206 \mathrm{c}$ & 1235,28 & & \\
\hline HD 202206 b (Raymond) & 255,87 & 5,4066 & 0,1849 \\
\hline HD 202206 c & 1383,40 & & \\
\hline HD 202206 b (Correia) & 256,20 & 5,0616 & 0,1975 \\
\hline HD $202206 \mathrm{c}$ & 1296,80 & & \\
\hline$v$ Andromeda $\mathrm{b}$ & 4,62 & 52,24 & 0,0191 \\
\hline$v$ Andromeda $\mathrm{c}$ & 241,23 & 5,3480 & 0,1869 \\
\hline$v$ Andromeda d & 1290,10 & & \\
\hline HD $12661 \mathrm{~b}$ & 262,53 & 6,3954 & 0,1563 \\
\hline HD $12661 \mathrm{c}$ & 1679,00 & & \\
\hline 47 Uma b (Wittenmyer) & 1083,20 & 7,0033 & 0,1427 \\
\hline 47 Uma c (Wittenmyer) & 7586,00 & & \\
\hline HD $74156 \mathrm{~b}$ & 51,65 & 6,5169 & 0,1534 \\
\hline HD $74156 \mathrm{~d}$ & 336,60 & 7,3559 & 0,1359 \\
\hline HD $74156 \mathrm{c}$ & 2476,00 & & \\
\hline HD $11506 \mathrm{c}$ & 170,46 & 7,4504 & 0,1342 \\
\hline HD $11506 \mathrm{~b}$ & 1270,00 & & \\
\hline HIP 14810 b (OSBPM) & 6,67 & 22,1356 & 0,0451 \\
\hline HIP $14810 \mathrm{c}$ & 147,73 & 6,51 & 0,1535 \\
\hline HIP $14810 \mathrm{~d}$ & 962,00 & & \\
\hline HD $169830 \mathrm{~b}$ & 225,62 & 9,3165 & 0,1073 \\
\hline HD $169830 \mathrm{c}$ & 2102,00 & & \\
\hline HD 147018 b & 44,24 & 22,7868 & 0,0438 \\
\hline HD $147018 \mathrm{c}$ & 1008,00 & & \\
\hline HD 168443 b & 58,11 & 30,1051 & 0,0332 \\
\hline
\end{tabular}


Tabela 6.5 (Continuação)

\begin{tabular}{|c|c|c|c|}
\hline Planetas & Período (dias) & $T_{1} / T_{2}$ & $T_{2} / T_{1}$ \\
\hline HD $168443 \mathrm{c}$ & 1749,50 & & \\
\hline HD $11964 \mathrm{c}$ & 37,89 & 55,6757 & 0,0179 \\
\hline HD 11964 b & 2110,00 & & \\
\hline HAT-P-13 b & 2,92 & 146,93 & 0,0068 \\
\hline HAT-P-13 c & 428,50 & & \\
\hline HD 38529 b & 14,31 & 151,3002 & 0,0066 \\
\hline HD $38529 \mathrm{c}$ & 2165,00 & & \\
\hline HD $190360 \mathrm{c}$ & 17,10 & 169,0643 & 0,0059 \\
\hline HD 190360 b & 2891,00 & & \\
\hline HD $47186 \mathrm{~b}$ & 4,09 & 331,39 & 0,0030 \\
\hline HD $47186 \mathrm{c}$ & 1353,60 & & \\
\hline HD $217107 \mathrm{~b}$ & 7,13 & 590,79 & 0,0016 \\
\hline HD $217107 \mathrm{c}$ & 4210,00 & & \\
\hline HD 68988 b & 6,28 & 653,24 & 0,0015 \\
\hline HD 68988 c & 4100,00 & & \\
\hline HD $187123 \mathrm{~b}$ & 3,09 & 1194,8656 & 0,0008 \\
\hline HD $187123 \mathrm{c}$ & 3700,00 & & \\
\hline
\end{tabular}




\section{Capítulo 7}

\section{DISCUSSÃO}

A caracterização dinâmica dos sistemas múltiplos extrassolares, visa estabelecer panoramas que auxiliem os pesquisadores no entendimento dos sistemas planetários e do Universo.

Apesar da constante busca por novos sistemas, ainda não é possível caracterizar o nosso próprio Sistema como um sistema comum ou incrivelmente raro quando comparado aos

outros. À medida que os métodos de busca se aperfeiçoam, os satélites se modernizam, os computadores ficam mais poderosos e com mais capacidade de armazenamento e cálculo, são obtidas informações que respondem, aos poucos, as dúvidas mais intrigantes.

Nos primórdios da busca por planetas fora do Sistema Solar, apenas objetos com massas comparadas à massa de Júpiter e muito próximos à sua estrela eram encontrados a todo momento. Aos poucos, planetas com massas comparadas à da Terra vão sendo encontrados, como, por exemplo, os planetas que orbitam a estrela Gliese 581 (GJ 581). O desejo dos astrônomos concentra-se agora em encontrar planetas com massas próximas ao do nosso planeta, com distância (semi-eixo maior) próxima de 1 U.A. e, de preferência, que as estrelas que esses planetas orbitam, estejam na sequência principal do seu caminho evolutivo. Em suma, a busca é intensa por planetas parecidos com a Terra. A partir deste ponto, o conhecimento da composição química desses planetas passará a ser o grande desafio. Sendo estes telúricos (pois com massas comparadas a massa terreste não seriam gasosos), que composição teriam? Terão a composição que a Terra tem? Entretanto, como foi mostrado, os dados das massas dos planetas contêm o valor da inclinação embutido, o qual não é possível de se separar com o método de velocidade radial, o mais aclamado e utilizado método até hoje. As massas informadas são então valores mínimos de massas, 
para os quais a inclinação é máxima. Tal fato exige atenção, pois isto pode significar que muitos dos supostos planetas poderiam ser anãs marrons ou até mesmo estrelas vermelhas anãs com pouquíssimo brilho.

Um fator importante de ser ressaltado são as incertezas inerentes aos dados utilizados para construção do catálogo próprio. Em geral, as incertezas dos parâmetros orbitais dos planetas extrassolares conhecidos não são muito bem determinadas (Ford, 2005). O sistema HD 40307 bc, por exemplo, pode ser classificado como secular, Classe II e o sistema HD 40307 cd como quase-ressonante, Classe I. Porém, uma observação mais aprofundada nestes dois sistemas permite supor que os 3 planetas que orbitam a estrela HD 40307 estão na conhecida ressonância de Laplace, o que tornaria a classificação do sistema HD 40307 bc como Classe I, ressonante. Apesar do período orbital ser uma das variáveis com menor incerteza na sua obtenção, ele não está incólume às incertezas intrínsecas dos cálculos de sua obtenção. Sistemas classificados de acordo com o ângulo $\Delta \varpi$ com mais de uma designação, como por exemplo, GJ 876 dc, (oscilação $0^{\circ}$ / circulatório) podem realmente apresentar esta característica física ou estes resultados podem ser provenientes das incertezas propagadas no decorrer das simulações.

A preferência neste trabalho foi para os dados puros, obtidos sem cálculos auxiliares. As técnicas de médias adjacentes e FFT foram utilizadas quando os recursos de obtenção visual dos dados nos gráficos de KH mostraram-se insatisfatórios ou inviáveis.

No total, foram analisados 63 sistemas, resultando em 68 simulações, considerando-se todas as fontes pesquisadas. Considerando somente os sistemas provenientes de uma fonte apenas, foram analisados 50 sistemas. Considerando-se ainda, cada sistema constituindo todos os planetas que orbitam determinada estrela, então foram analisados 37 sistemas planetários.

Este projeto propõe a análise somente de pares de planetas nas órbitas consecutivas e não dos sistemas planetários como um todo. Isto pode ser justificado pelos seguintes motivos:

1. Ainda são poucos os sistemas catalogados com mais de 2 planetas. Neste trabalho, são 12 sistemas, de um total de 37.

2. As incertezas nos parâmetros orbitais permitem esta aproximação. 
3. Este modelo é bastante adequado para sistemas seculares e hierárquicos.

4. Aumento considerável do número de sistemas para análises estatísticas.

5. Existem poucos sistemas conhecidos com interações complexas de muitos corpos, como, por exemplo, em ressonância de Laplace. Neste trabalho, apenas HD 40307 e HD 82943 são candidatos a este tipo de ressonância.

A figura de distribuição dos pares planetários mostrada no começo do trabalho (Figura 1.1) foi reconstruída com os dados compilados neste trabalho (Figura 7.1). Os sistemas BD 202457 bc, HD128311 bc, HD 181433 cd, HD 102272 bc e HAT-P-13 bc não estão contidos nesta nova Figura, por apresentarem configurações de instabilidade de acordo com as simulações aqui efetuadas. Os sistemas contidos na tabela (6.3) também não foram incluídos, pois, para o sistema GJ 581 há um conjunto de simulações utilizando a fonte (Beust et al., 2008). No caso do sistema HD 82943, o par HD 82943 bd não foi incluído, pois não há comprovação da existência de um terceiro planeta neste sistema. Os pares de planetas consecutivos dos sistemas extrassolares são representados por estrelas vermelhas, já os do nosso Sistema Solar por cruzes azuis, cujas siglas significam: M-V: MercúrioVênus; V-T: Vênus-Terra; T-M: Terra-Marte; M-J: Marte-Júpiter; J-S: Júpiter-Saturno; S-U: Saturno-Urano e U-N: Urano-Netuno.

A Classe I, caracterizada geralmente por planetas de grande massas e altas excentricidades, compreende 10 dos sistemas analisados, sendo que dois deles, HD 160691 db e HD 40307 cd adequam-se à subclasse da Classe I, de sistemas quase-ressonantes. A ressonância 2/1 é a que contém mais pares de planetas: GJ 876 cd, HD 73526 bc e HD 82943 cb, seguida da ressonância 3/1: HD 60532 bc e 55 Cnc bc. As ressonâncias 4/1, 3/2 e 7/1 apresentam um par cada uma: HD 108874 bc, HD 45364 bc e 47 Uma bc, respectivamente. Este último sistema, a rigor, não se enquadra em nenhuma das classes discriminadas, porém, por se tratar de um sistema ressonante, ainda que de baixa ordem, foi classificado como pertencente à Classe I.

Os sistemas pertencentes à Classe II são os sistemas seculares identificados na Figura (7.1) em regiões entre as ressonâncias de movimentos médios. Ao todo, 17 sistemas foram classificados como pertencente a esta Classe, tendo como exemplos os sistemas HD 37124 bd (entre as ressonâncias 6/1 e 5/1), HD 160691 be (entre as ressonâncias 5/1 e 4/1), GJ 
581 bc (entre as ressonâncias 5/2 e 7/3) e ainda HD 74156 bd (entre as ressonâncias 7/1 e 6/1), cujo planeta HD 74156 b possui a maior excentricidade entre os planetas estudados: 0,64 .

Por fim, os sistemas da Classe III, também conhecidos como hierárquicos, possuem valores muito baixos de $T_{1} / T_{2}$ na Figura (7.1), distribuindo-se no lado esquerdo da mesma, pois $T_{1} / T_{2}<0,14$ para estes sistemas, porém, a maior excentricidade do par não segue uma regra definida. No total, 19 sistemas foram classificados como hierárquicos, como, por exemplo, os sistemas $55 \mathrm{Cnc}$ fd, com baixas excentricidades no par - 0,063 e 0,002 para os planetas $55 \mathrm{Cnc}$ f e $55 \mathrm{Cnc}$ d, respectivamente; o sistema GJ 876 dc, que tem como companheiro o sistema formado pelos planetas GJ $876 \mathrm{cb}$, que formam um sistema ressonante; o sistema HD 168443 bc que tem a maior excentricidade entre os hierárquicos no planeta HD 168443 b e o sistema HD 187123, cujo tempo de simulação foi o maior dentre os sistemas - 21 milhões de anos - e, ainda assim, resultou incompleta para obtenção de 5 períodos de $\Delta \varpi$. 


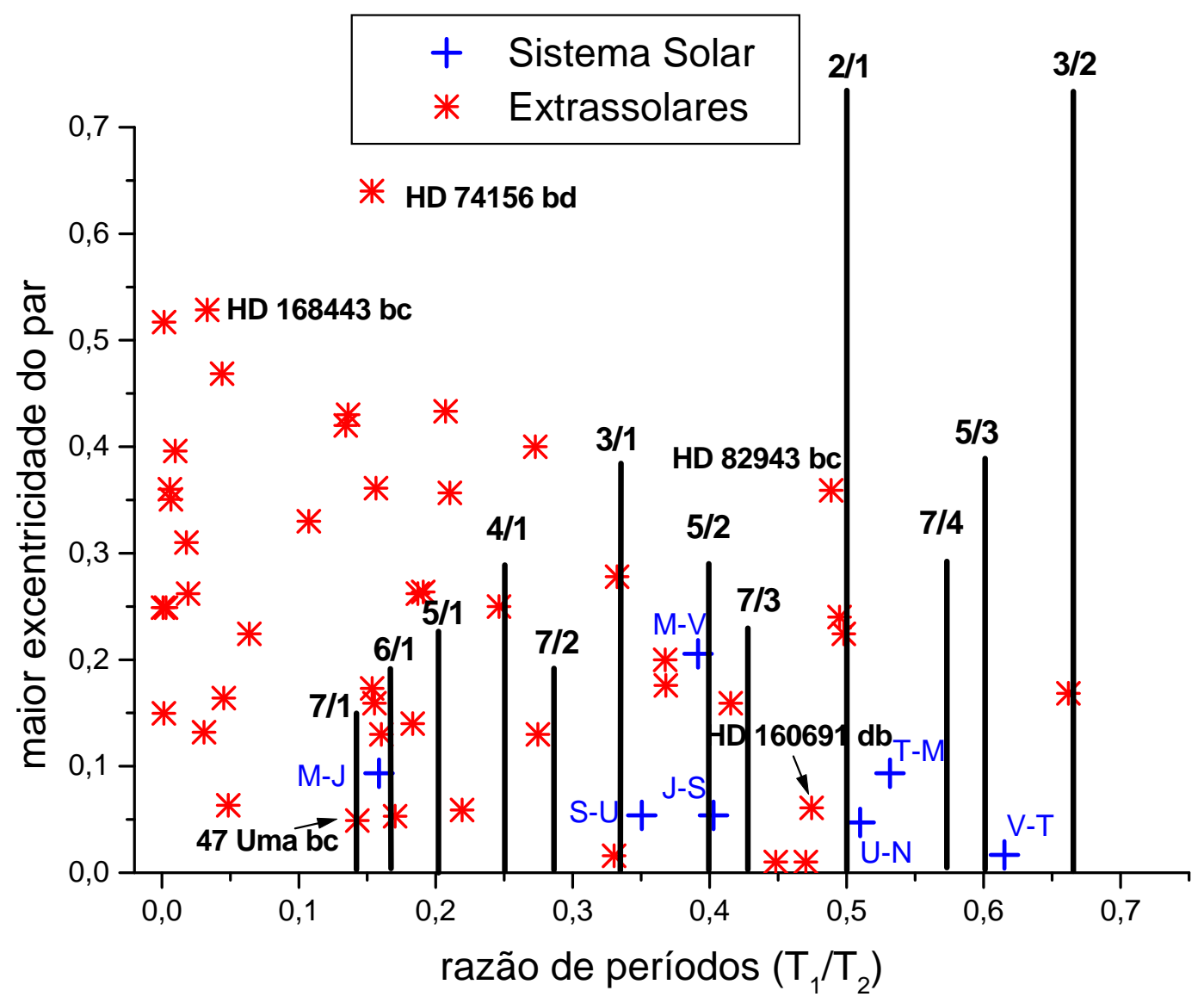

Figura 7.1: Distribuição dos pares planetários nas órbitas consecutivas no plano $\left(T_{1} / T_{2}\right.$, e), onde $T_{1}$ e $T_{2}$ são períodos dos planetas, e é a maior excentricidade do par. A posição nominal das ressonâncias de movimentos médios é dada por picos, cuja altura é inversa à ordem de ressonância. Os pares formados por planetas do Sistema Solar estão indicados por cruzes. Essa figura é similar a Figura 1.1 da Introdução, porém é construída com os dados compilados neste trabalho. 


\section{Capítulo 8}

\section{CONCLUSÃO}

A classificação aqui demonstrada provém de um catálogo próprio, construído com pesquisa em diversos meios de referência. As simulações são resultados diretos e exclusivos deste catálogo. Outros simuladores podem chegar a conclusões similares ou não. O programa fonte das simulações aqui calculadas foi desenvolvido pelo próprio autor, com o auxílio de sua orientadora, utilizando somente o integrador Radau15 (RA15) como fonte externa. As equações de dinâmica e as transformações necessárias de parâmetros orbitais para coordenadas retangulares e vice-versa foram escritas utilizando-se livros de Mecânica Celeste.

Pode-se afirmar que os sistemas que apresentaram configurações de instabilidade possuem inconsistências nos seus parâmetros orbitais iniciais. É improvável afirmar que se uma simulação aponta que determinado sistema apresentará configuração instável daqui a alguns milhares de anos - conforme demonstrado, semi-eixo maior aumentando indefinidamente e excentricidades muito altas, próximas a de cometas - signifique que ele realmente deixará de ser estável após este intervalo. Dos 10 sistemas que apresentaram instabilidades, 3 apresentaram estabilidade simulados com dados de fonte de referência diferente (47 Uma bc, HD 82943 cb e HD 183263 bc) e 2 apresentaram estabilidade com dados iniciais recalculados por Marcos Tadeu dos Santos (HD 73526 bc e HD 202206 bc). Desses 10 sistemas, apenas 3 (30\%) não seriam classificados como ressonantes, Classe I, se fossem estáveis; HAT-P-13 bc, HD 181433 cd e BD 202457 bc. Tal fato mostra o quão difícil é obter parâmetros orbitais de sistemas inseridos em algum tipo de ressonância de movimentos médios (Giuppone et al., 2009).

Um dos objetivo deste trabalho é o auxílio aos demais pesquisadores. Os dados aqui 
compilados devem oferecer subsídios imediatos para as pesquisas da Prof ${ }^{\mathrm{a}}$. Dr ${ }^{\mathrm{a}}$ Tatiana A. Michtchenko e aos demais colegas do Grupo de Dinâmica do IAG-SP.

Alguns dados compilados nesta dissertação são importantes para se avaliar o comportamento dos diversos sistemas. A classificação do sistema pela caracterização do ângulo $\Delta \varpi$ é importante pois sistemas ressonantes podem mudar de classificação com o tempo, devido às diversas perturbações que agem sobre sistemas deste tipo. As ressonâncias podem inverter o comportamento angular do $\Delta \varpi$ de retrógrado para prógrado, por exemplo. Neste trabalho pode-se notar que a grande maioria dos sistemas hierárquicos é circulatório retrógrado quanto ao movimento do ângulo $\Delta \varpi$. Apenas o sistema HIP 14810 bc (oscilatório em torno de $180^{\circ}$ ) foge a essa regra. Isso significa que dos 18 sistemas classificados como de Classe III, hierárquicos, $94 \%$ são circulatórios retrógrado quanto ao movimento do ângulo $\Delta \varpi$.

A classificação mostrada aqui é uma tentativa de entender melhor os sistemas extrassolares múltiplos, não significando uma classificação definitiva tampouco imutável. Outros autores, como por exemplo (Wright, 2009) também procuram estabelecer critérios de classificação desses sistemas. Atente-se que dentre as cinco categorias propostas por este último autor, três encaixam-se muito bem na classificação utilizada nesta dissertação, significando que, aos poucos, os critérios e premissas para classificar dinamicamente os sistemas extrassolares vão convergindo para um ponto em comum.

Finalmente, a caracterização dinâmica pode ser considerada como um importante auxílio para a escolha adequada da metodologia a ser utilizada para estudos estatísticos e de estabilidade dos sistemas. 


\section{Referências Bibliográficas}

Website da Wikipedia - http://en.wikipedia.org/wiki/List_of_extrasolar_planets

Website do California and Carnegie Planet Search http://exoplanets.org/almanacframe.html

Website do Grupo MOA - http://www.phys.canterbury.ac.nz/moa/

Website do Grupo OGLE - http://ogle.astrouw.edu.pl/

Website do IAG - página do Prof ${ }^{\circ}$ Dr ${ }^{\circ}$ Sylvio Ferraz-Mello ftp://www.astro.iag.usp.br/pub/sylvio/exosys.pdf

Website do Jet Propulsion Laboratory - http://ssd.jpl.nasa.gov/

Website do Observatoire de Genève - http://obswww.unige.ch/ ${ }^{\sim}$ udry/planet/planet.html Website do Observatoire de Paris-Meudon-Nancay- http://exoplanet.eu/

Website do OriginLab - http://originlab.com

Bakos G. A., Howard A., Noyes R., Hartman J., Torres G., Kovács G., Fischer D., Latham D., Johnson J., Marcy G., Sasselov D., Stefanik R., Sipőcz B., Kovács G., Esquerdo G., Pál A., Lázár J., Papp I., Sári P., HAT-P-13b,c: A Transiting Hot Jupiter with a Massive Outer Companion on an Eccentric Orbit, ApJ, 2009, vol. 707, p. 446

Bean J. L., McArthur B. E., Benedict G. F., Armstrong A., Detection of a Third Planet in the HD 74156 System Using the Hobby-Eberly Telescope, ApJ, 2008, vol. 672, p. 1202 
Beaugé C., Ferraz-Mello S., Michtchenko T. A., , 2007 Planetary Masses and Orbital Parameters from Radial Velocity Measurements. pp 1-+

Beaugé C., Giuppone C. A., Ferraz-Mello S., Michtchenko T. A., Reliability of orbital fits for resonant extrasolar planetary systems: the case of HD82943, MNRAS, 2008, vol. 385, p. 2151

Beust H., Bonfils X., Delfosse X., Udry S., Dynamical evolution of the Gliese 581 planetary system, A\&A, 2008, vol. 479, p. 277

Boczko R., Conceitos de Astronomia. Editora Edgard Blücher Ltda., 1984

Bouchy F., Mayor M., Lovis C., Udry S., Benz W., Bertaux J., Delfosse X., Mordasini C., Pepe F., Queloz D., Segransan D., The HARPS search for southern extra-solar planets. XVII. Super-Earth and Neptune-mass planets in multiple planet systems HD 47186 and HD 181 433, A\&A, 2009, vol. 496, p. 527

Burns J., Hamilton D. P., Showalter M. R., Bejeweled Worlds, Scientific American, 2003, pp $74-81$

Butler R. P., Marcy G. W., Fischer D. A., Brown T. M., Contos A. R., Korzennik S. G., Nisenson P., Noyes R. W., Evidence for Multiple Companions to $v$ Andromedae, ApJ, 1999, vol. 526 , p. 916

Butler R. P., Wright J. T., Marcy G. W., Fischer D. A., Vogt S. S., Tinney C. G., Jones H. R. A., Carter B. D., Johnson J. A., McCarthy C., Penny A. J., Catalog of Nearby Exoplanets, ApJ, 2006, vol. 646, p. 505

Callegari Jr. N., Ressonâncias e Marés em Sistemas de Satélites Naturais, Revista LatinoAmericana de Educação em Astronomia - RELEA, 2006, vol. 3, p. 39

Carrol B. W., Ostlie D. A., An Introduction to Modern Astrophysics, Second Edition. Addison-Wesley Pub, 1996

Cochran W. D., Endl M., Wittenmyer R. A., Bean J. L., A Planetary System around HD 155358: The Lowest Metallicity Planet Host Star, The Astrophysical Journal, 2007, vol. 665 , p. 1407 
Correia A. C. M., Udry S., Mayor M., Benz W., Bertaux J., Bouchy F., Laskar J., Lovis C., Mordasini C., Pepe F., Queloz D., The HARPS search for southern extra-solar planets. XVI. HD 45364, a pair of planets in a 3:2 mean motion resonance, A\&A, 2009, vol. 496, p. 521

Correia A. C. M., Udry S., Mayor M., Laskar J., Naef D., Pepe F., Queloz D., Santos N. C., The CORALIE survey for southern extra-solar planets. XIII. A pair of planets around HD202206 or a circumbinary planet?, A\&A, 2005, vol. 440, p. 751

Desidera S., Barbieri M., , 2006 Properties of planets in binary systems. The role of binary separation

Everhart E., Dynamics of Comets: Their Origin and Evolution, Carusi A., Valsecchi G.B. (eds.) IAU Coll. Reidel, Dordrecht, The Netherlands, 1985, vol. 592, p. 185

Ferraz-Mello S., Michtchenko T.A.and Beaugé C., Regular Motions in Extrasolar Planetary Systems, Chaotic Worlds: From Order to Disorder in Gravitational N-Body System, Academic Publishers, 2005

Ferraz-Mello S., Michtchenko T.A.and Beaugé C., Callegari Jr. N., Extrasolar Planetary Systems, Chaos and Stability in Extrasolar Planetary Systems, Springer, 2005

Fischer D. A., Marcy G. W., Butler R. P., Laughlin G., Vogt S. S., A Second Planet Orbiting 47 Ursae Majoris, ApJ, 2002, vol. 564, p. 1028

Fischer D. A., Marcy G. W., Butler R. P., Vogt S. S., Laughlin G., Henry G. W., Abouav D., Peek K. M. G., Wright J. T., Johnson J. A., McCarthy C., Isaacson H., Five Planets Orbiting 55 Cancri, ApJ, 2008, vol. 675, p. 790

Fischer D. A., Valenti J., The Planet-Metallicity Correlation, ApJ, 2005, vol. 622, p. 1102

Ford E. B., Quantifying the Uncertainty in the Orbits of Extrasolar Planets, AJ, 2005, vol. 129 , p. 1706

Ford E. B., Kozinsky B., Rasio F. A., Secular Evolution of Hierarchical Triple Star Systems, The Astrophysical Journal, 2000, vol. 535, p. 385 
Giuppone C., Tadeu dos Santos M., Beaugé C., Ferraz-Mello S., Michtchenko T., Detectability and Error Estimation in Orbital Fits of Resonant Extrasolar Planets, The Astrophysical Journal, 2009, vol. 699, p. 1321

Jones H. R. A., Butler R. P., Wright J. T., Marcy G. W., Fischer D. A., Vogt S. S., Tinney C. G., Carter B. D., Johnson J. A., McCarthy C., Penny A. J., A Catalogue of Nearby Exoplanets. In Precision Spectroscopy in Astrophysics , 2008, p. 205

Laskar J., Gastineau M., Existence of collisional trajectories of Mercury, Mars and Venus with the Earth, Nature, 2009, vol. 459, p. 817

Lee M. H., Peale S. J., Secular Evolution of Hierarchical Planetary Systems, The Astrophysical Journal, 2003, vol. 592, p. 1201

Mayor M., Bonfils X., Forveille T., Delfosse X., Udry S., Bertaux J., Beust H., Bouchy F., Lovis C., Pepe F., Perrier C., Queloz D., Santos N. C., The HARPS search for southern extra-solar planets. XVIII. An Earth-mass planet in the GJ 581 planetary system, A\&A, 2009, vol. 507 , p. 487

Mayor M., Queloz D., Marcy G., Butler P., Noyes R., Korzennik S., Krockenberger M., Nisenson P., Brown T., Kennelly T., Rowland C., Horner S., Burki G., Burnet M., Kunzli M., 51 Pegasi, IAU Circ., 1995, vol. 6251, p. 1

Mayor M., Udry S., Lovis C., Pepe F., Queloz D., Benz W., Bertaux J., Bouchy F., Mordasini C., Segransan D., The HARPS search for southern extra-solar planets. XIII. A planetary system with 3 super-Earths, A\&A, 2009, vol. 493, p. 639

Mayor M., Udry S., Naef D., Pepe F., Queloz D., Santos N. C., Burnet M., The CORALIE survey for southern extra-solar planets. XII. Orbital solutions for 16 extra-solar planets discovered with CORALIE, A\&A, 2004, vol. 415, p. 391

Michtchenko T., Ferraz-Mello S., Beaugé C., Dynamics of the Extra-solar Planetary Systems, Rudolf Dvorak, Wiley-VCH, multi author book, 2007, pp 153-180

Michtchenko T. A., Ferraz-Mello S., Modeling the 5 : 2 Mean-Motion Resonance in the Jupiter-Saturn Planetary System, Icarus, 2001a, vol. 149, p. 357 
Michtchenko T. A., Ferraz-Mello S., Resonant Structure of the Outer Solar System in the Neighborhood of the Planets, AJ, 2001b, vol. 122, p. 474

Michtchenko T. A., Malhotra R., Secular dynamics of the three-body problem: application to the $v$ Andromedae planetary system, Icarus, 2004, vol. 168, p. 237

Michtchenko T. A., Nesvorny D., Wavelet analysis of the asteroidal resonant motion., A\&A, 1996, vol. 313, p. 674

Niedzielski A., Goździewski K., Wolszczan A., Konacki M., Nowak G., Zieliński P., A Planet in a 0.6 AU Orbit Around the K0 Giant HD 102272, ApJ, 2009, vol. 693, p. 276

Niedzielski A., Nowak G., Adamów M., Wolszczan A., Substellar-mass Companions to the K-dwarf BD+14 4559 and the K-giants HD 240210 and BD+20 2457, ApJ, 2009, vol. 707 , p. 768

Press W. H., Teukolsky S. A., Vetterling W. T., Flannery B. P., Numerical Recipes in Fortran 77 - The Art of Scientific Computing - Second Edition. Press Syndicate of the University of Cambridge, 1986-1992

Raymond S. N., Barnes R., Armitage P. J., Gorelick N., Mean Motion Resonances from Planet-Planet Scattering, ApJ, 2008, vol. 687, p. L107

Rivera E. J., Lissauer J. J., Butler R. P., Marcy G. W., Vogt S. S., Fischer D. A., Brown T. M., Laughlin G., Henry G. W., A 7.5 Mt Planet Orbiting the Nearby Star, GJ 876, ApJ, 2005, vol. 634, p. 625

Roy A. E., Orbital Motion. Adam Hilger Ltd, Bristol, 1978

Ségransan D., Udry S., Mayor M., Naef D., Pepe F., Queloz D., Santos N. C., Demory B., Figueira P., Gillon M., Marmier M., Mégevand D., Sosnowska D., Tamuz O., Triaud A. H. M. J., The CORALIE survey for southern extrasolar planets. XVI. Discovery of a planetary system around HD 147018 and of two long period and massive planets orbiting HD 171238 and HD 204313, A\&A, 2010, vol. 511, p. A45+

Short D., Windmiller G., Orosz J. A., New solutions for the planetary dynamics in HD160691 using a Newtonian model and latest data, MNRAS, 2008, vol. 386, p. L43 
Tinney C. G., Butler R. P., Marcy G. W., Jones H. R. A., Laughlin G., Carter B. D., Bailey J. A., O’Toole S., The 2:1 Resonant Exoplanetary System Orbiting HD 73526, ApJ, 2006, vol. 647, p. 594

Tuomi M., Kotiranta S., Bayesian analysis of the radial velocities of HD 11506 reveals another planetary companion, A\&A, 2009, vol. 496, p. L13

Vogt S. S., Butler R. P., Marcy G. W., Fischer D. A., Henry G. W., Laughlin G., Wright J. T., Johnson J. A., Five New Multicomponent Planetary Systems, ApJ, 2005, vol. 632, p. 638

Wittenmyer R. A., Endl M., Cochran W. D., Long-Period Objects in the Extrasolar Planetary Systems 47 Ursae Majoris and 14 Herculis, ApJ, 2007, vol. 654, p. 625

Wittenmyer R. A., Endl M., Cochran W. D., Levison H. F., Henry G. W., A Search for Multi-Planet Systems Using the Hobby-Eberly Telescope, ApJS, 2009, vol. 182, p. 97

Wolszczan A., Frail D. A., A planetary system around the millisecond pulsar PSR1257 + 12, Nature, 1992, vol. 355, p. 145

Wright J. T., A Survey of Multiple Planet Systems, ArXiv e-prints, 2009

Wright J. T., Fischer D. A., Ford E. B., Veras D., Wang J., Henry G. W., Marcy G. W., Howard A. W., Johnson J. A., A Third Giant Planet Orbiting HIP 14810, ApJ, 2009, vol. 699, p. L97

Wright J. T., Marcy G. W., Fischer D. A., Butler R. P., Vogt S. S., Tinney C. G., Jones H. R. A., Carter B. D., Johnson J. A., McCarthy C., Apps K., Four New Exoplanets and Hints of Additional Substellar Companions to Exoplanet Host Stars, ApJ, 2007, vol. 657 , p. 533

Wright J. T., Upadhyay S., Marcy G. W., Fischer D. A., Ford E. B., Johnson J. A., Ten New and Updated Multiplanet Systems and a Survey of Exoplanetary Systems, The Astrophysical Journal, 2009, vol. 693, p. 1084 
Apêndice 

Este apêndice tem por objetivo exibir todos os resultados das simulações feitas nesta dissertação de mestrado. 
Apêndice A

\section{Demais simulações para o Sistema Solar}

\section{A.1 Sol-Mercúrio-Vênus}

O tempo de simulação para o sistema Sol-Mercúrio-Vênus foi de 3 milhões de anos. O movimento do ângulo $\Delta \varpi$ é circulatório retrógrado. Seu período secular é de aproximadamente 438.172 anos.

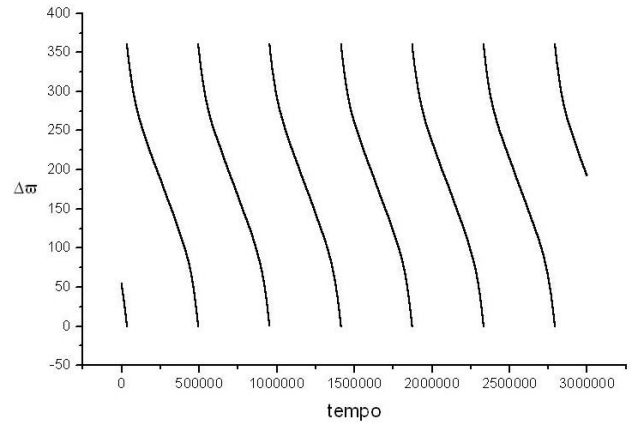

Figura A.1: Ângulo $\Delta \varpi$ em função do tempo para Sol-Mercúrio-Vênus

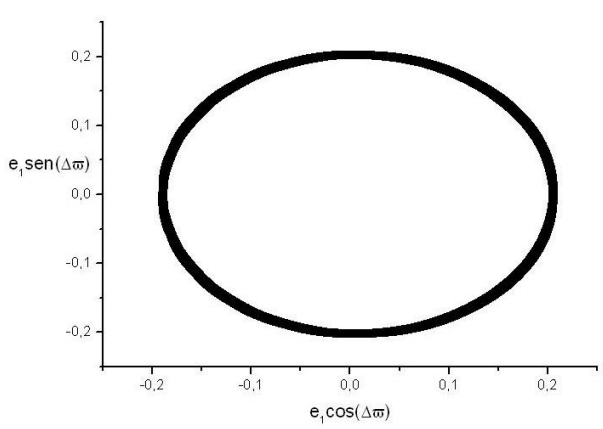

Figura A.2: KH de $e_{1}$ para Sol-Mercúrio-Vênus

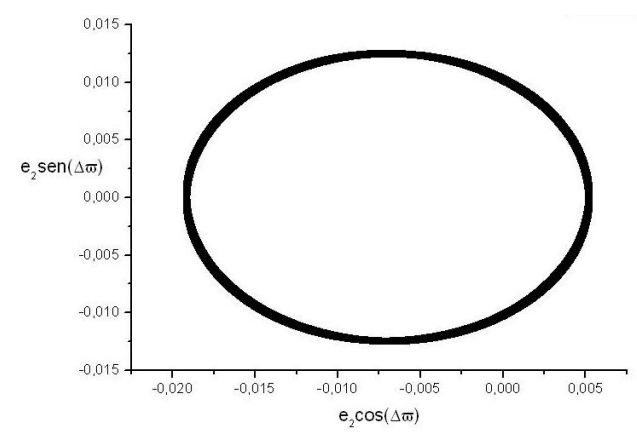

Figura A.3: KH de $e_{2}$ para Sol-Mercúrio-Vênus 


\section{A.2 Sol-Vênus-Terra}

O tempo de simulação para o sistema Sol-Vênus-Terra foi de 1 milhão de anos. O movimento do ângulo $\Delta \varpi$ é oscilatório em torno de $0^{\circ}$. Seu período secular é de aproximadamente 131.452 anos.
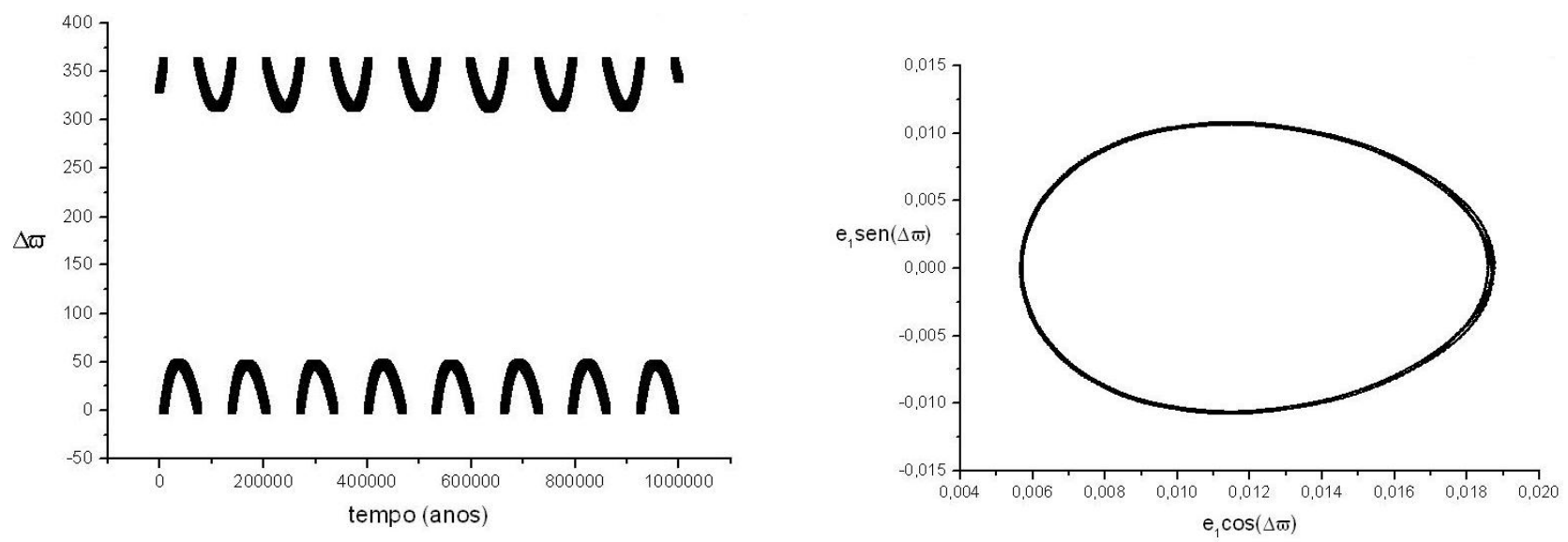

Figura A.4: Ângulo $\Delta \varpi$ em função do tempo para Sol-Vênus-Terra

Figura A.5: KH de $e_{1}$ para Sol-Vênus-Terra

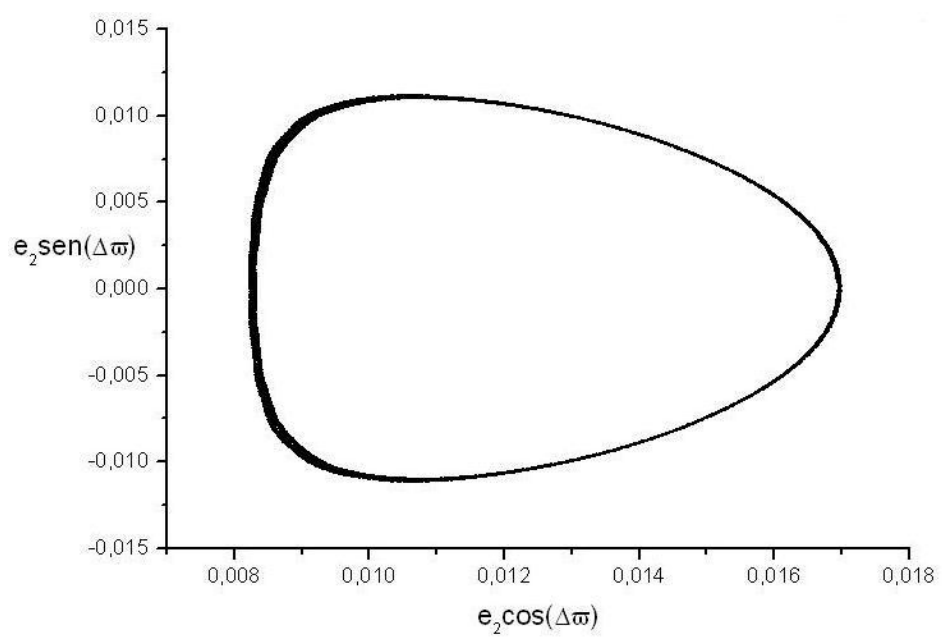

Figura A.6: KH de $e_{2}$ para Sol-Vênus-Terra 


\section{A.3 Sol-Terra-Marte}

O tempo de simulação para o sistema Sol-Terra-Marte foi de 5 milhões de anos. O movimento do ângulo $\Delta \varpi$ é circulatório prógrado. Seu período secular é de aproximadamente 582.143 anos.

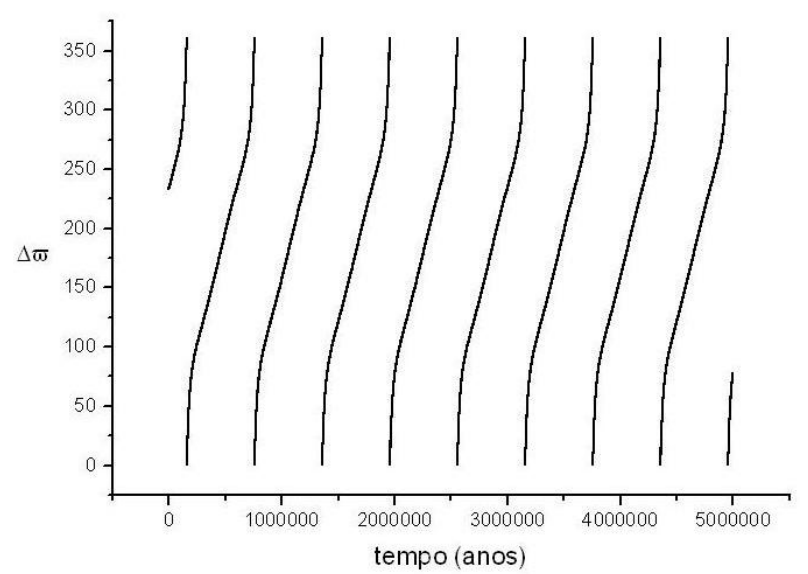

Figura A.7: Ângulo $\Delta \varpi$ em função do tempo para Sol-Terra-Marte

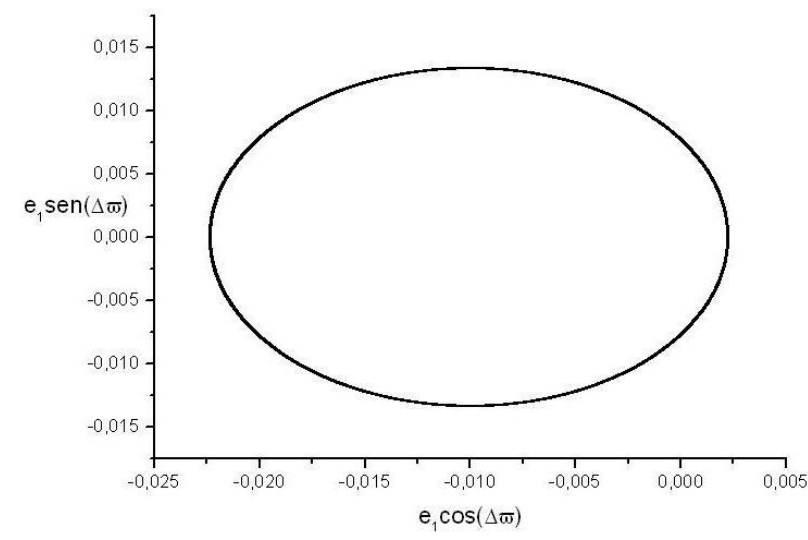

Figura A.8: KH de $e_{1}$ para Sol-Terra-Marte

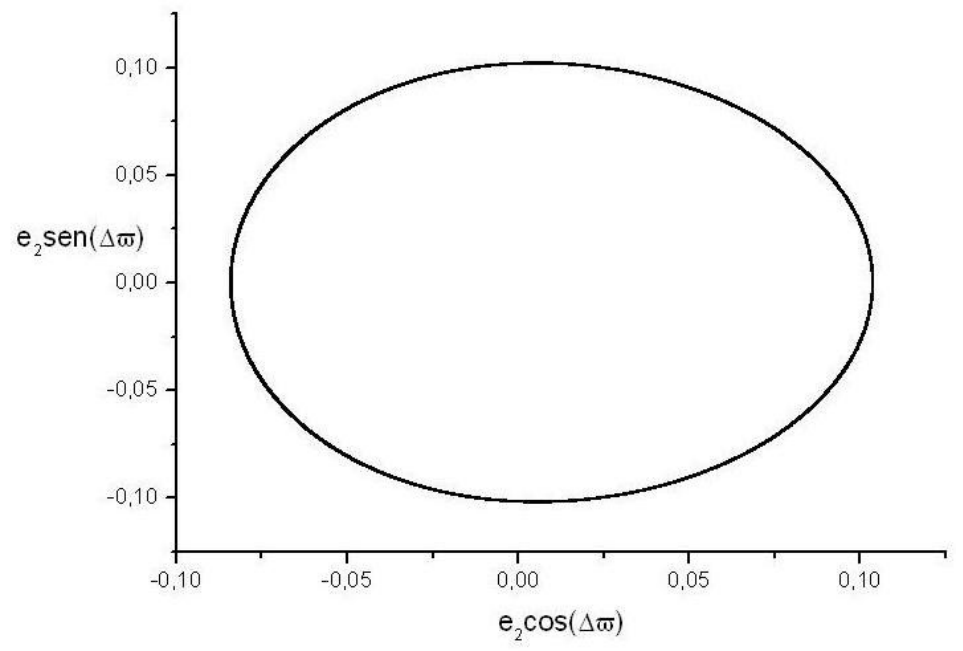

Figura A.9: KH de $e_{2}$ para Sol-Terra-Marte 


\section{A.4 Sol-Marte-Júpiter}

O tempo de simulação para o sistema Sol-Marte-Júpiter foi de 1 milhão de anos. O movimento do ângulo $\Delta \varpi$ é circulatório retrógrado. Seu período secular é de aproximadamente 87.634 anos.

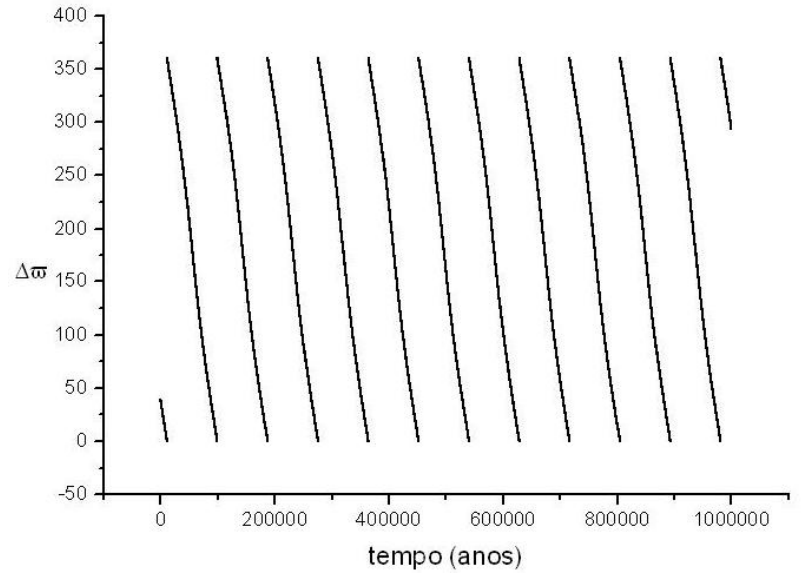

Figura A.10: Ângulo $\Delta \varpi$ em função do tempo para Sol-Marte-Júpiter

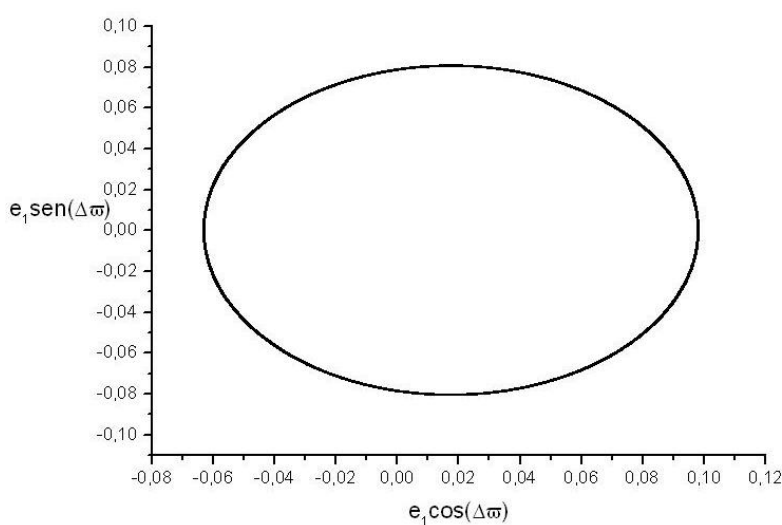

Figura A.11: KH de $e_{1}$ para Sol-Marte-Júpiter

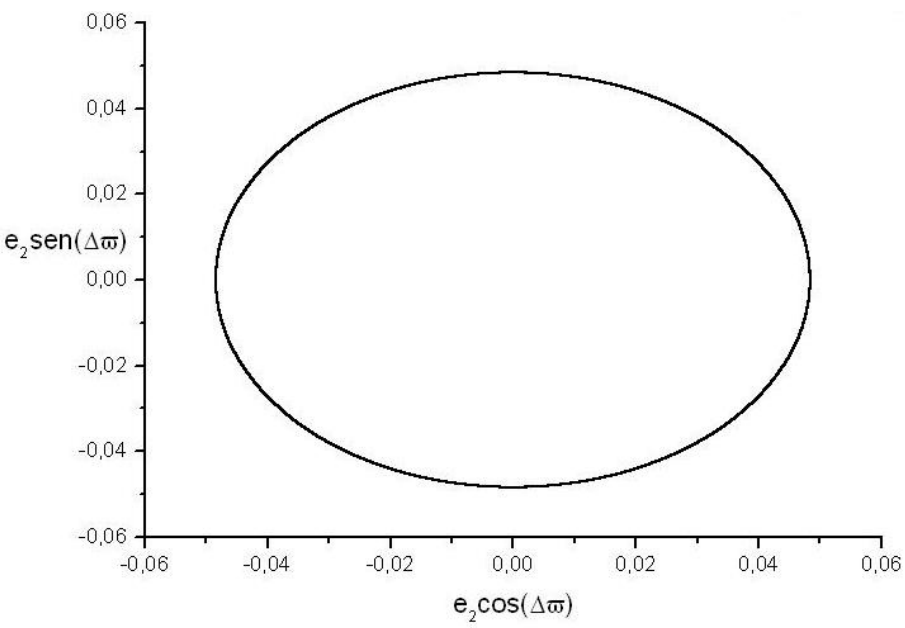

Figura A.12: $\mathrm{KH}$ de $e_{2}$ para Sol-Marte-Júpiter 


\section{A.5 Sol-Saturno-Urano}

O tempo de simulação para o sistema Sol-Saturno-Urano foi de 7 milhões de anos. O movimento do ângulo $\Delta \varpi$ é circulatório prógrado. Seu período secular é de aproximadamente 953.216 anos.

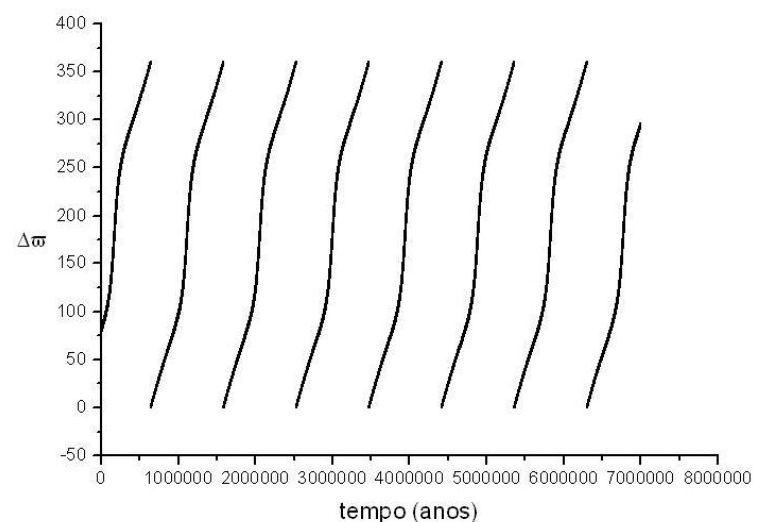

Figura A.13: Ângulo $\Delta \varpi$ em função do tempo para Sol-Saturno-Urano

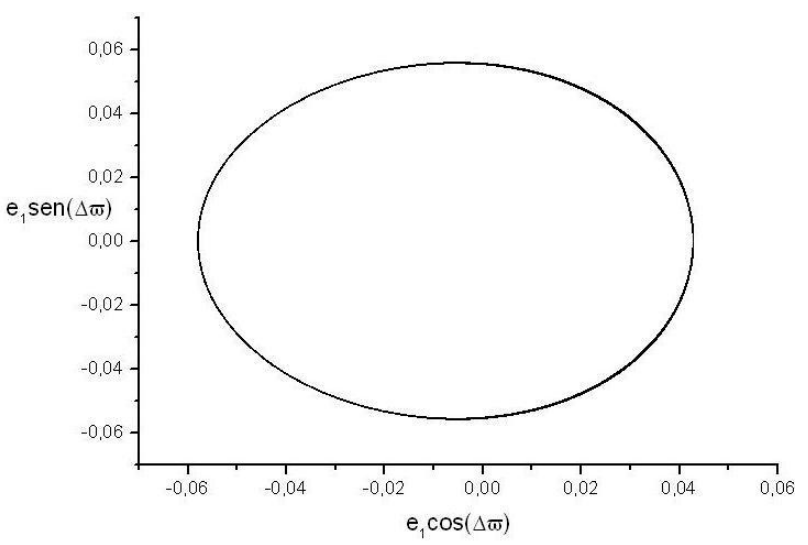

Figura A.14: KH de $e_{1}$ para Sol-Saturno-Urano

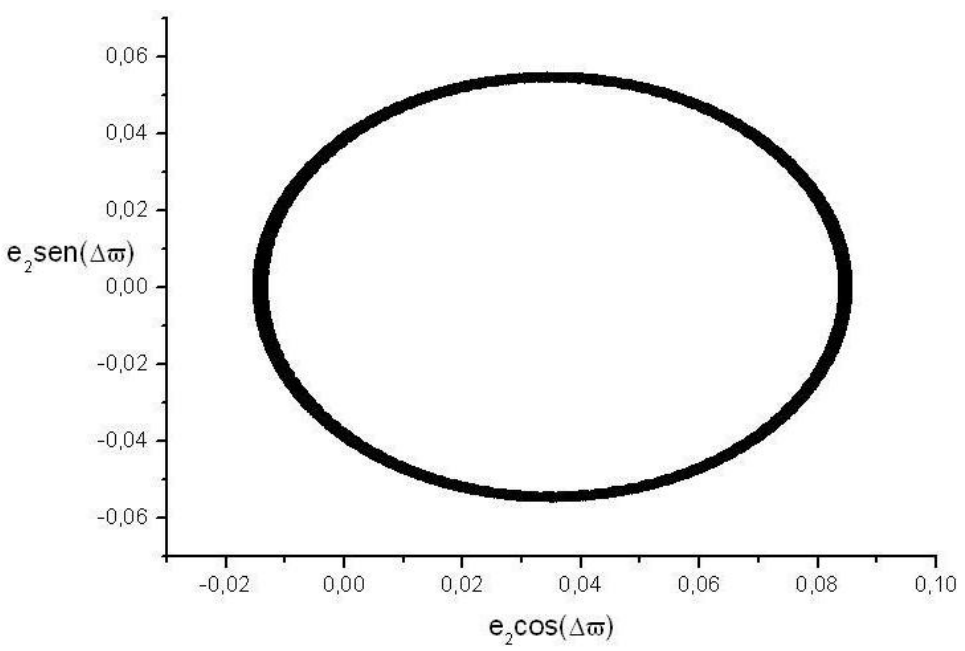

Figura A.15: KH de $e_{2}$ para Sol-Saturno-Urano 


\section{A.6 Sol-Urano-Netuno}

O tempo de simulação para o sistema Sol-Urano-Netuno foi de 12 milhões de anos. O movimento do ângulo $\Delta \varpi$ é oscilatório em torno de $180^{\circ}$. Seu período secular é de aproximadamente 1.750 .806 anos.

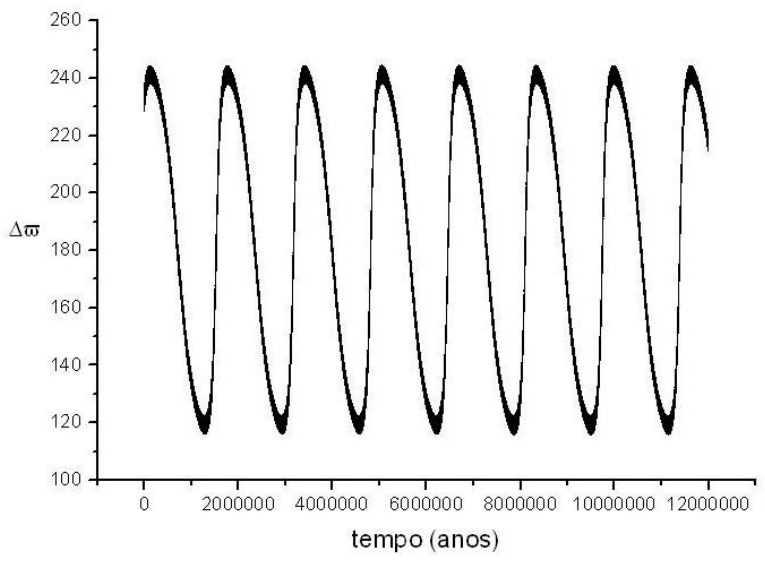

Figura A.16: Ângulo $\Delta \varpi$ em função do tempo para Sol-Urano-Netuno

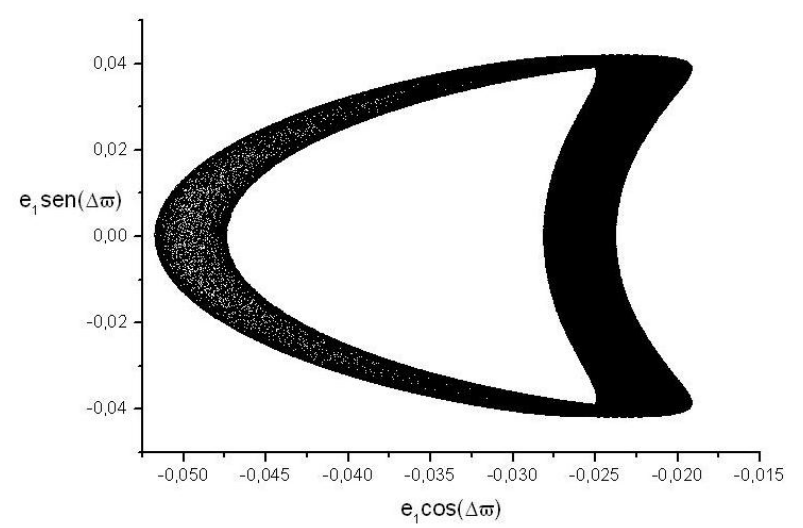

Figura A.17: KH de $e_{1}$ para Sol-Urano-Netuno

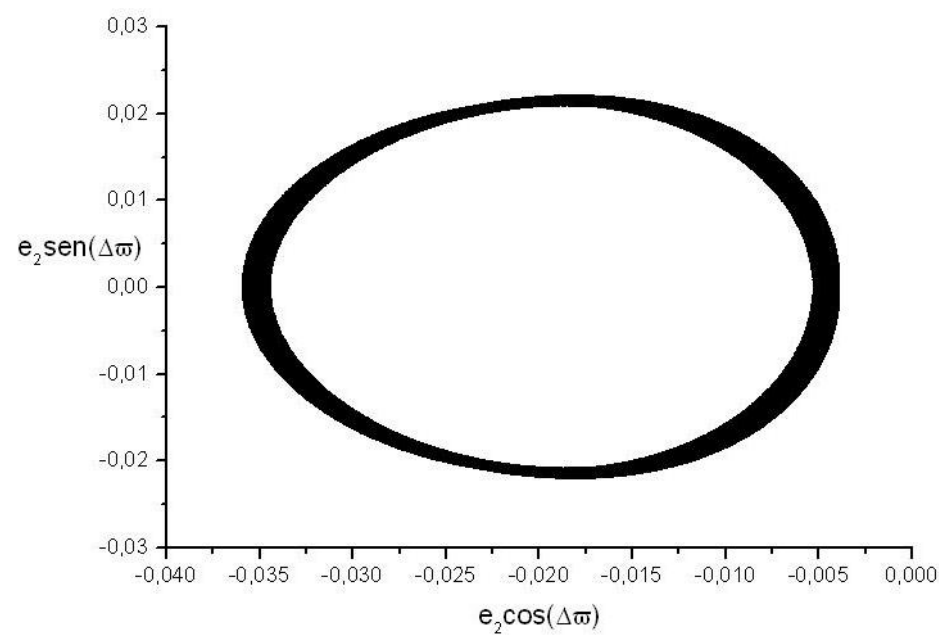

Figura A.18: KH de $e_{2}$ para Sol-Urano-Netuno 
Apêndice B

\section{Demais simulações para os sistemas extrassolares}

\section{B.1 Classe I - ressonantes}

\section{B.1.1 HD 45364 bc}

O tempo de simulação para o sistema HD 45364 bc foi de 200 mil anos. Trata-se de um sistema ressonante, Classe I, ressonância 3/2, $\left(T_{1} / T_{2}=1,5108\right)$. O movimento do ângulo $\Delta \varpi$ é oscilatório em torno de $180^{\circ}$. Seu período secular é de aproximadamente 407,8 anos.

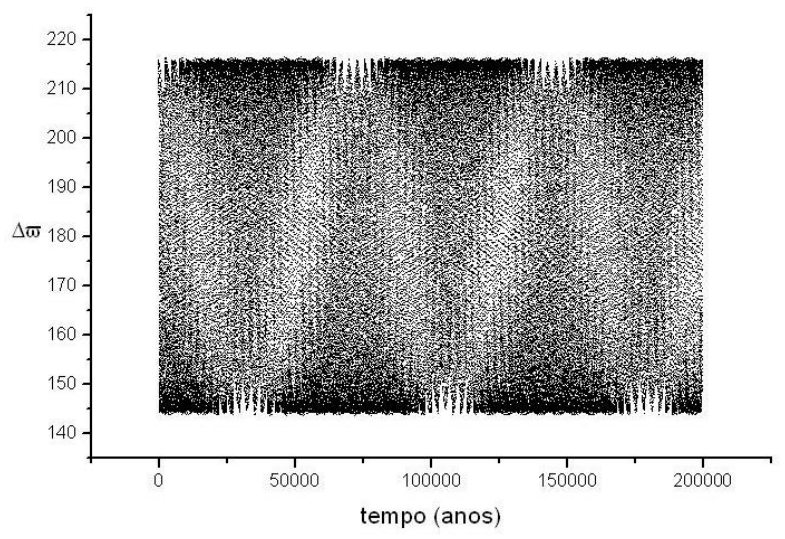

Figura B.1: Ângulo $\Delta \varpi$ em função do tempo para HD $45364 \mathrm{bc}$

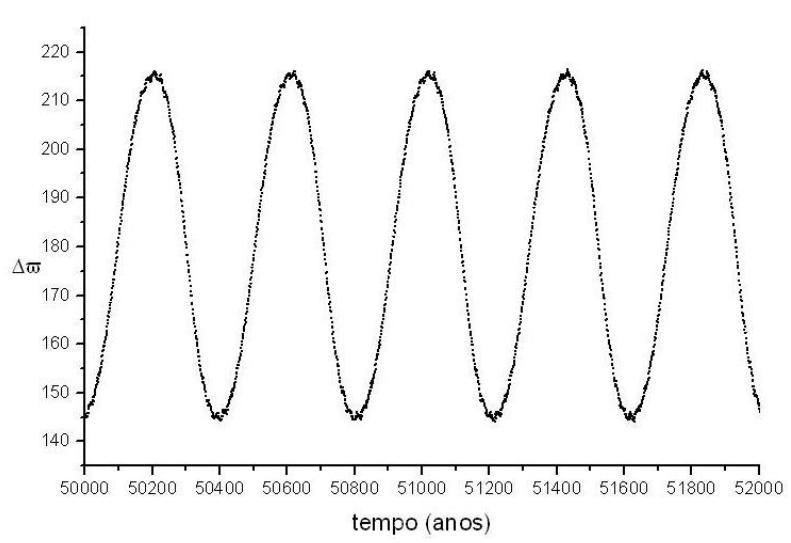

Figura B.2: Zoom do ângulo $\Delta \varpi$ em função do tempo para HD 45364 bc

A caracterização do ângulo $\Delta \varpi$ como oscilatório fica mais evidente no gráfico B.2. 


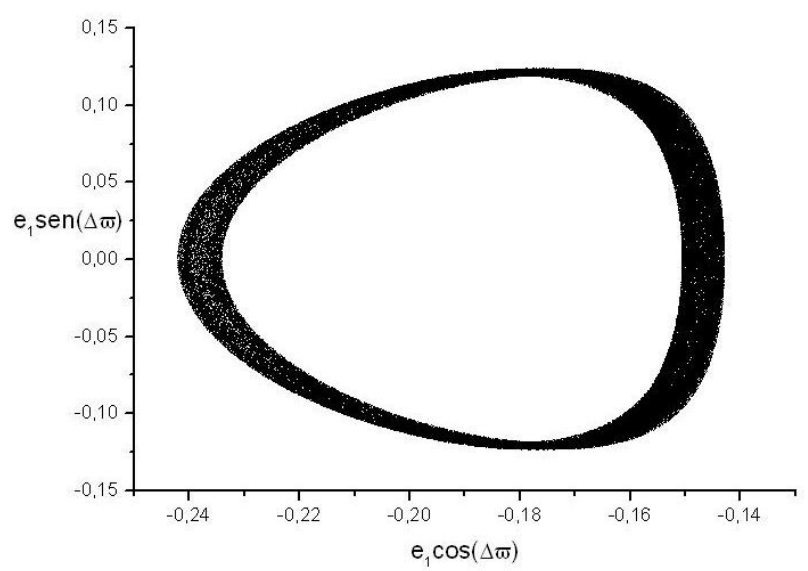

Figura B.3: KH de $e_{1}$ para HD 45364 bc

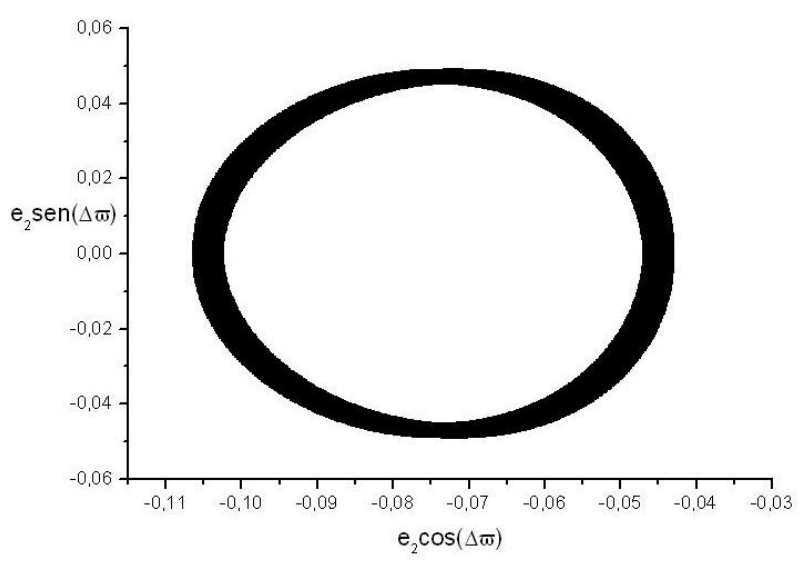

Figura B.4: KH de $e_{2}$ para HD 45364 bc

Utilizando o método de médias adjacentes, com 50 pontos, obtém-se dados mais precisos de KH de $e_{1}$ e $e_{2}$ para o sistema HD 45364 bc:

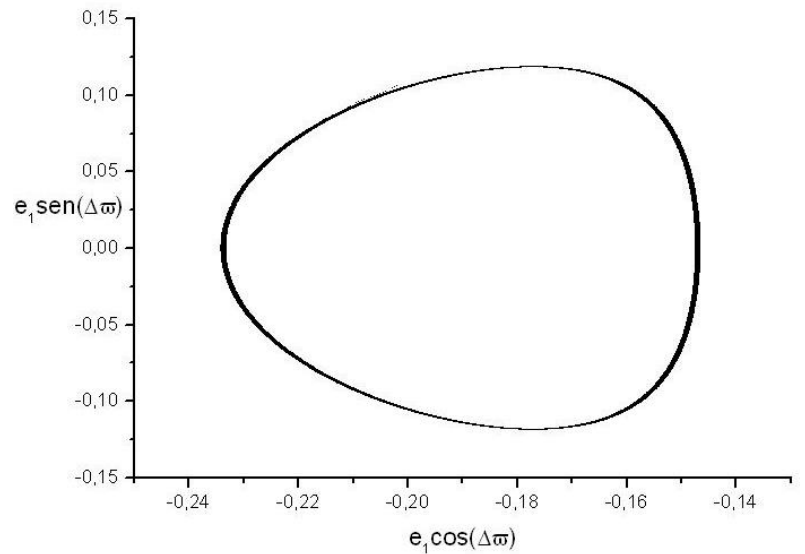

Figura B.5: KH de $e_{1}$ para HD 45364 bc com filtro

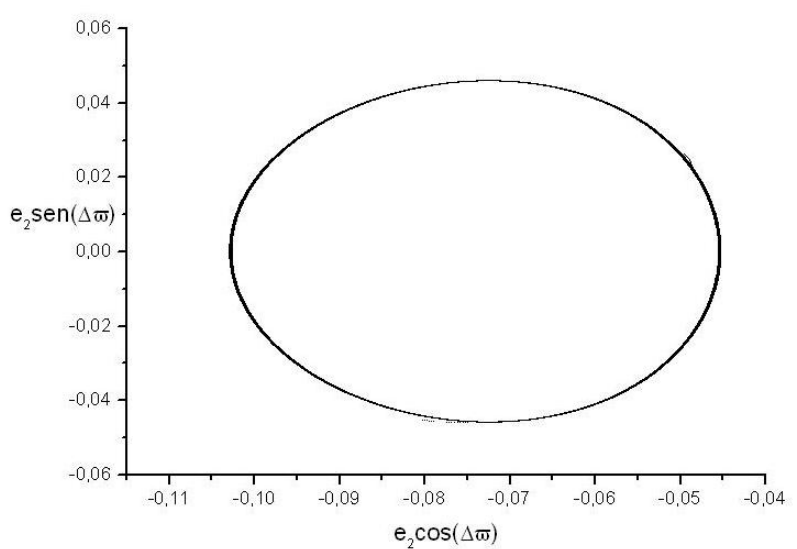

Figura B.6: KH de $e_{2}$ para HD 45364 bc com filtro 


\section{B.1.2 GJ 581 eb (Mayor et al., 2009)}

Para os planetas que orbitam a estrela Gliese 581 (GJ 581), também referenciada como Gl 581 e BD-07 4003, além das simulações estáveis com a configuração contendo 3 planetas (GJ 581 b, GJ 581 c, e GJ 581 d), utilizando-se a referência (Beust et al., 2008), uma outra configuração, com 4 planetas (os três anteriores mais GJ 581 e) também mostrou-se estável, tendo como fonte de referência (Mayor et al., 2009).

O tempo de simulação para o sistema GJ 581 eb foi de 1 milhão de anos. Trata-se de um sistema ressonante, Classe I, ressonância $5 / 3,\left(T_{1} / T_{2}=1,7046\right)$. O movimento do ângulo $\Delta \varpi$ é oscilatório em torno de $0^{\circ}$. O período secular é de aproximadamente 174 anos e tem amplitude muito baixa, como se vê na Figura (B.12), onde a frequência do período secular corresponde ao primeiro pico à esquerda no gráfico, que tem amplitude muito menor que os movimentos ressonantes.

Os valores de referência das excentricidades dos planetas GJ 581 e e GJ 581 b são arbitrariamente iguais a zero, assim como o valor da longitude do pericentro para o planeta GJ 581 b. Para efeito das simulações, às excentricidades desses planetas foram atribuídos valores iguais a 0,01 e ao valor da longitude do pericentro, $0,1^{\circ}$.

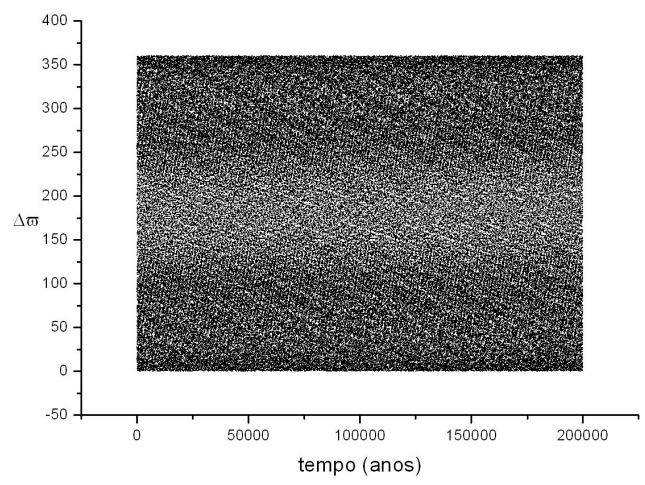

Figura B.7: Ângulo $\Delta \varpi$ em função do tempo para GJ 581 eb - Mayor

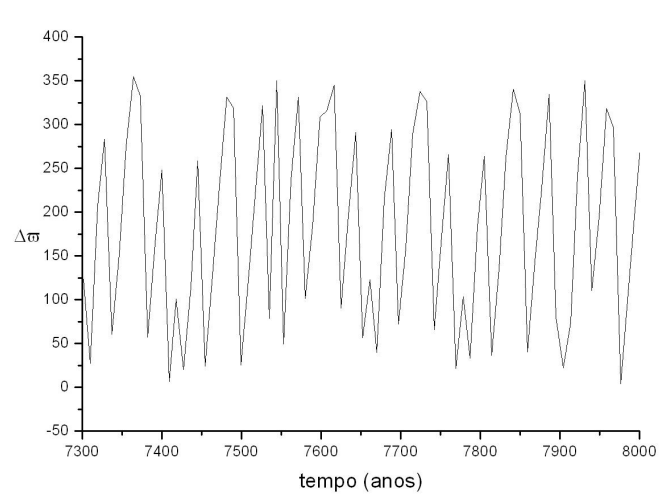

Figura B.8: Zoom do ângulo $\Delta \varpi$ em função do tempo para GJ 581 eb - Mayor 


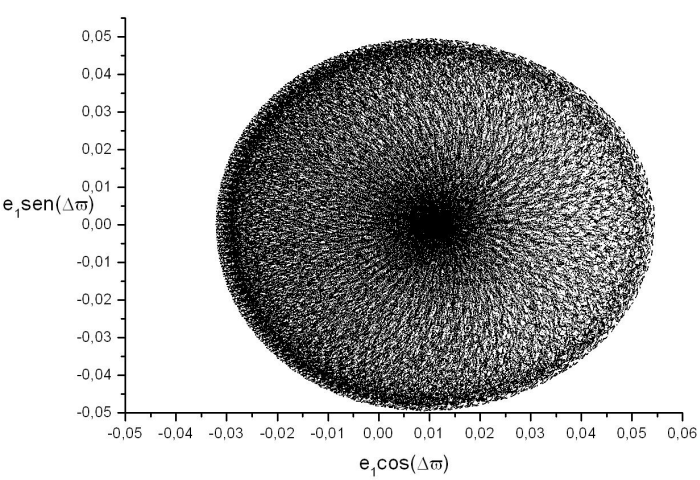

Figura B.9: $\mathrm{KH}$ de $e_{1}$ para GJ $581 \mathrm{eb}$

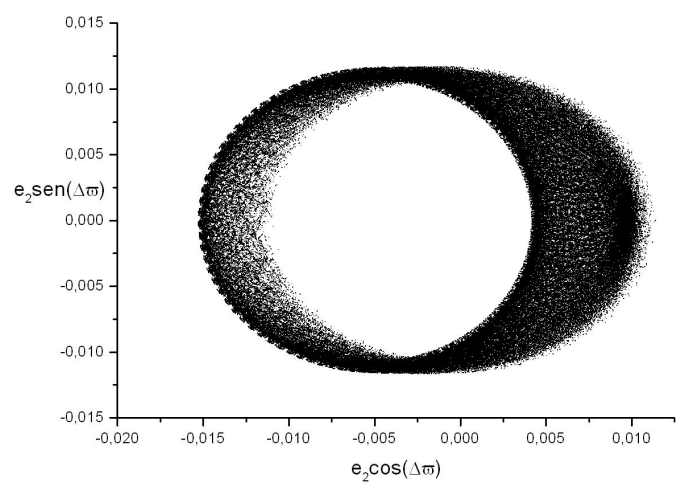

Figura B.10: $\mathrm{KH}$ de $e_{2}$ para GJ 581 eb

A filtragem faz-se necessária para inferir os valores do gráfico de $\mathrm{KH}$ de $e_{1}$. A filtragem pelo método de médias adjacentes não se mostrou adequada para este sistema. A filtragem pelo método de FFT fica mais acurada uma vez conhecido o valor do período secular. Como visto anteriormente, este valor é de aproximadamente 174 anos. Limitando a banda de filtragem entre 0,00571 1/ano (175 anos) e 0,00578 (173 anos), gera-se a Figura (B.11) onde se pode notar que os valores de $e_{1}$ mínimo e máximo são da ordem de $10^{-5}$, ou seja, muito próximos a zero, mostrando a condição de falsa separatriz que ocorre quando a excentricidade de um planeta assume valores próximos a zero, gerando a alternância entre os movimentos oscilatório em torno de $0^{\circ}$ e circulatório.

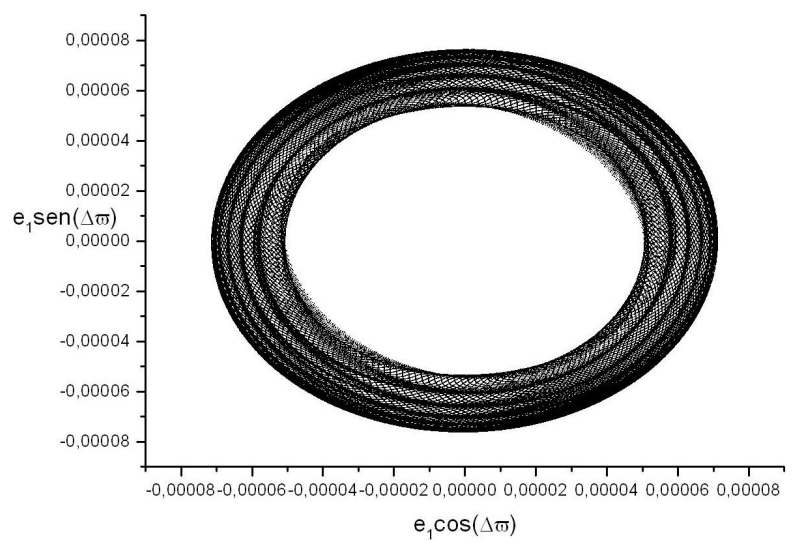

Figura B.11: KH de $e_{1}$ para GJ 581 eb - filtro 173 a 175 anos

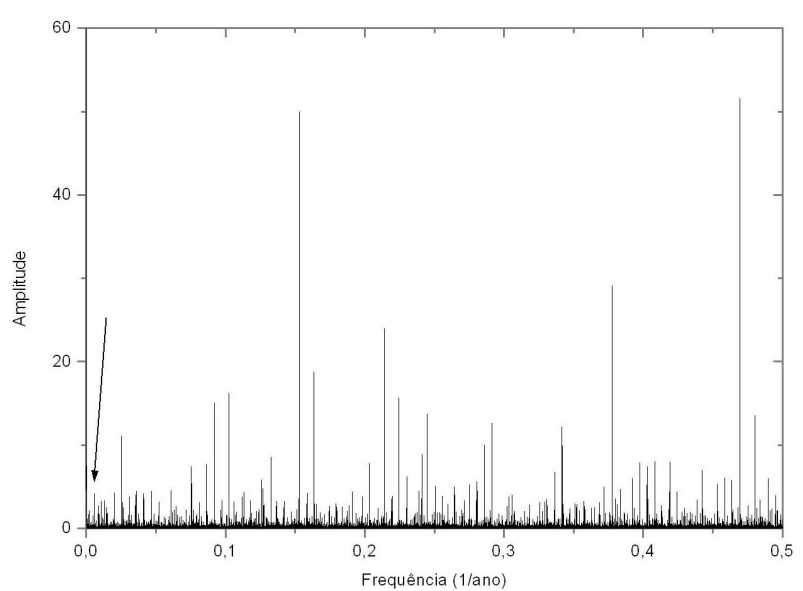

Figura B.12: FFT do ângulo $\Delta \varpi$ para GJ $581 \mathrm{eb}$ 


\section{B.1.3 47 Uma bc}

A estrela 47 Ursae Majoris, ou 47 Ursa Maior (47 Uma) é também chamada de HD 95128 e possui dois candidatos a planetas, 47 Uma b e 47 Uma c. A existência do segundo planeta (47 Uma c) é controversa, uma vez que Wittenmeyer confirmou sua existência em 2005 (Wittenmyer et al., 2007) mas não a confirmou em 2009 (Wittenmyer et al., 2009).

Em uma primeira simulação, com dados de (Fischer et al., 2002), este sistema seria classificado como ressonante, ressonância 2/1, Classe I, pois $T_{2} / T_{1}=2,022$ e $T_{1} / T_{2}=$ 0,494 mas a simulação mostrou-se instável após 6 mil anos aproximadamente.

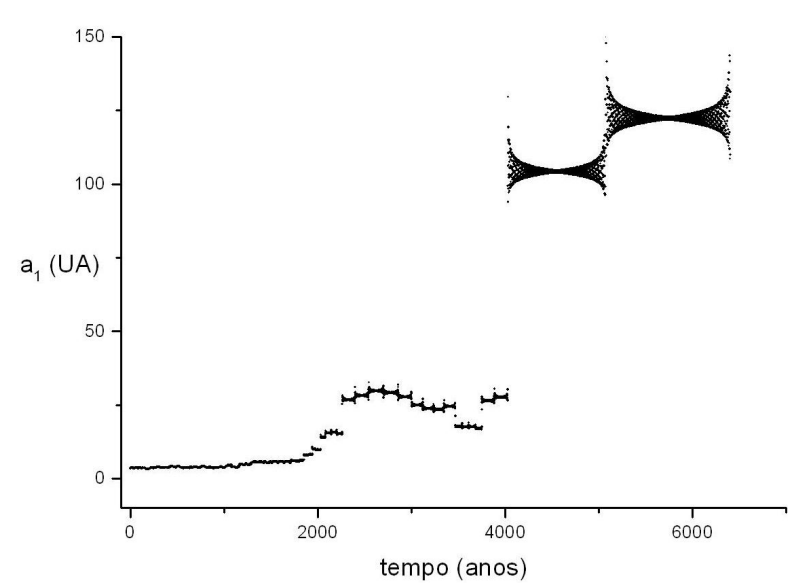

Figura B.13: Semi-eixo maior de 47 Uma b em função do tempo - Fischer, 2002

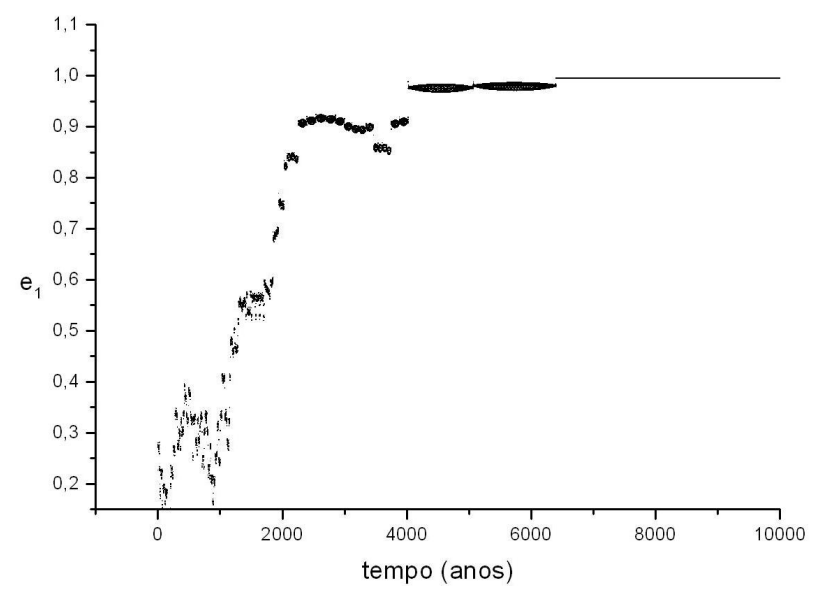

Figura B.14: Excentricidade de 47 Uma b em função do tempo - Fischer, 2002

Entretanto, simulação com dados de Wittenmeyer et al, 2005, mostram um sistema estável com dois planetas. A razão de períodos apresentada por este sistema com estes dados, $T_{2} / T_{1}=7,0033$ (ressonância $\left.7 / 1\right)$ e $T_{1} / T_{2}=0,1427(<0,2)$ não o permite classificá-lo especificamente em nenhuma das 3 classes utilizadas nesta dissertação, porém, apresenta características de sistema ressonante e pode ser classificado como pertencente à Classe I. O tempo de simulação foi de 2 milhões de anos. O movimento do ângulo $\Delta \varpi$ é oscilatório em torno de $0^{\circ}$, porém, quando a excentricidade do planeta 47 Uma c atinge valores próximos a zero, a excentricidade do planeta 47 Uma b assume valores de KH que caracterizam o comportamento do ângulo $\Delta \varpi$ como circulatório. Seu período secular é de aproximadamente 218.268 anos. 

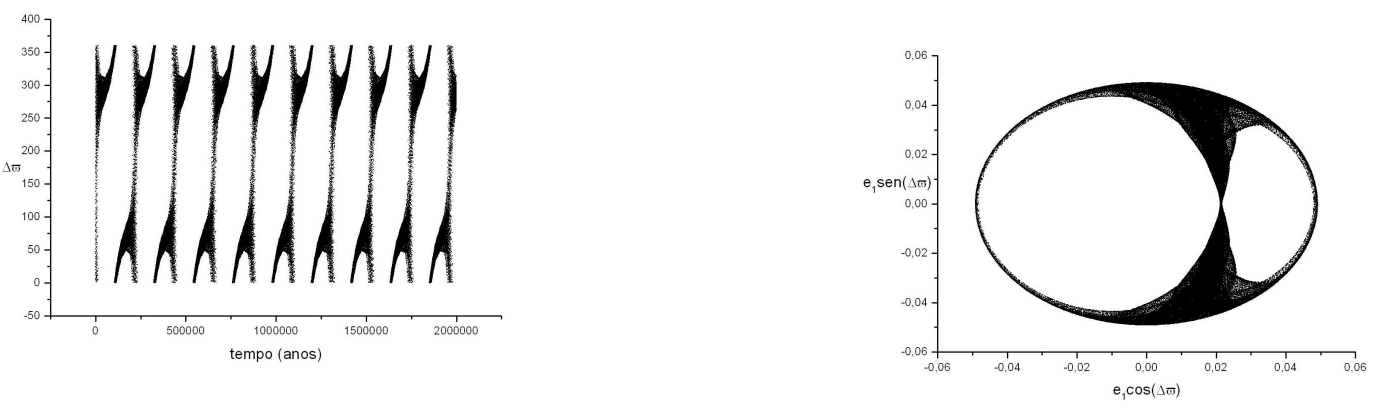

Figura B.15: Ângulo $\Delta \varpi$ em função do tempo para 47 Uma bc

Figura B.16: KH de $e_{1}$ para 47 Uma bc

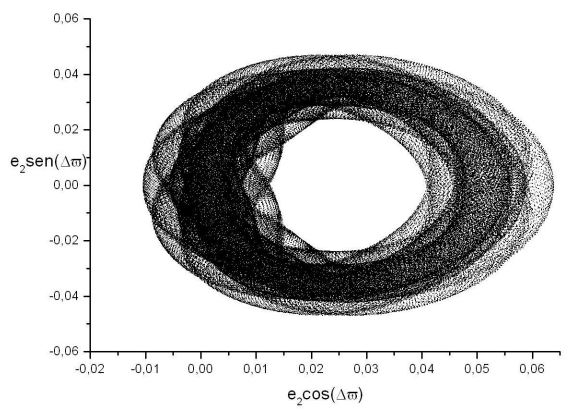

Figura B.17: KH de $e_{2}$ para $47 \mathrm{Uma}$ bc

O método de médias adjacentes, com 50 pontos, para se obter dados mais precisos de $\mathrm{KH}$, faz-se necessário para $e_{2}$ :

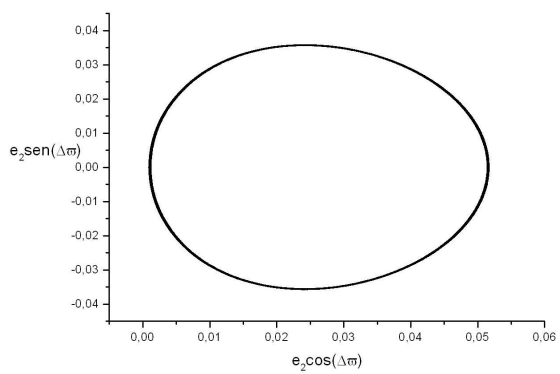

Figura B.18: KH de $e_{2}$ para 47 Uma bc filtrado 


\section{B.1.4 HD 128311 bc}

O sistema HD 128311 bc apresentou configuração instável em duas simulações de fontes distintas. Na primeira simulação, com dados de (Vogt et al., 2005), seria classificado como um sistema ressonante, ressonância $2 / 1, T_{1} / T_{2}=0,4940$, pertencente à Classe I.

Nesta simulação, nota-se que a partir de aproximadamente 33 mil anos o sistema não se mantém estável.

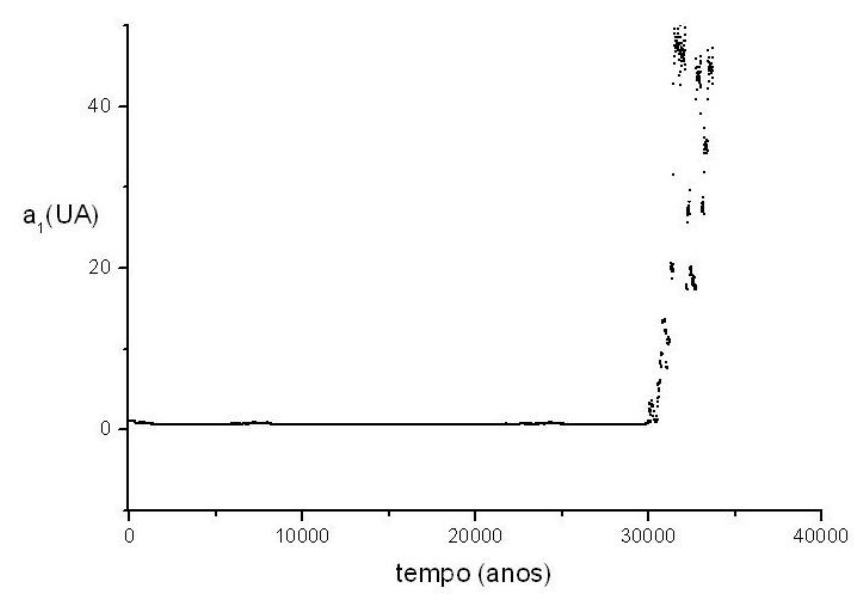

Figura B.19: Semi-eixo de HD 128311 b em função do tempo - (Vogt et al., 2005)

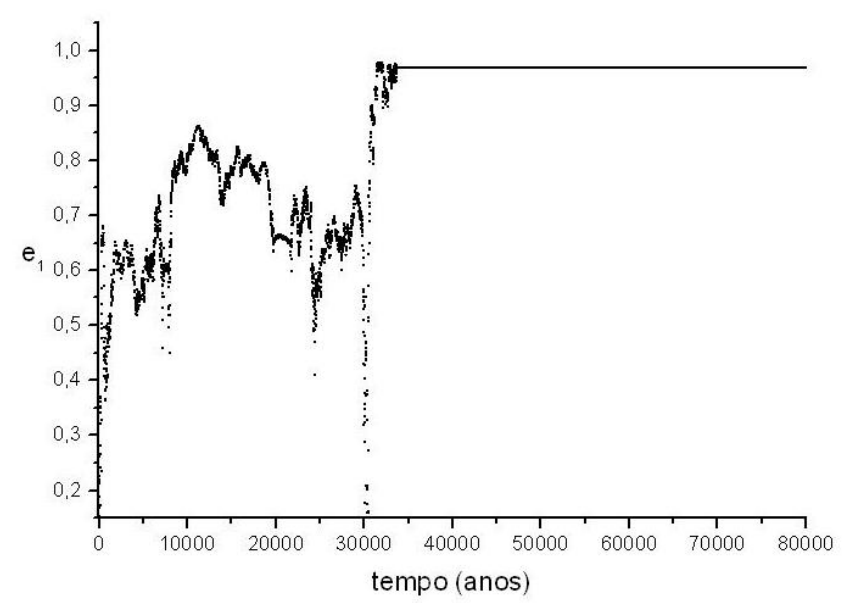

Figura B.20: Excentricidade de HD 128311 b em função do tempo - (Vogt et al., 2005)

Como nota-se dos gráficos, para o planeta HD 128311 b, após 33 mil anos o semi-eixo maior adquire valores muito grandes e sua excentricidade assume valores próximos a de um cometa. 
Na simulação com dados de (Fischer e Valenti, 2005), o sistema HD128311 bc seria classificado como quase-ressonante, Classe I, pois $T_{2} / T_{1}=2,1854$. Para esta simulação, a instabilidade ocorre a partir de 19 mil anos. Os valores de longitude do pericentro e anomalia média adotados foram os mesmos utilizados na simulação com dados de (Vogt et al., 2005) por não constarem em (Fischer e Valenti, 2005)

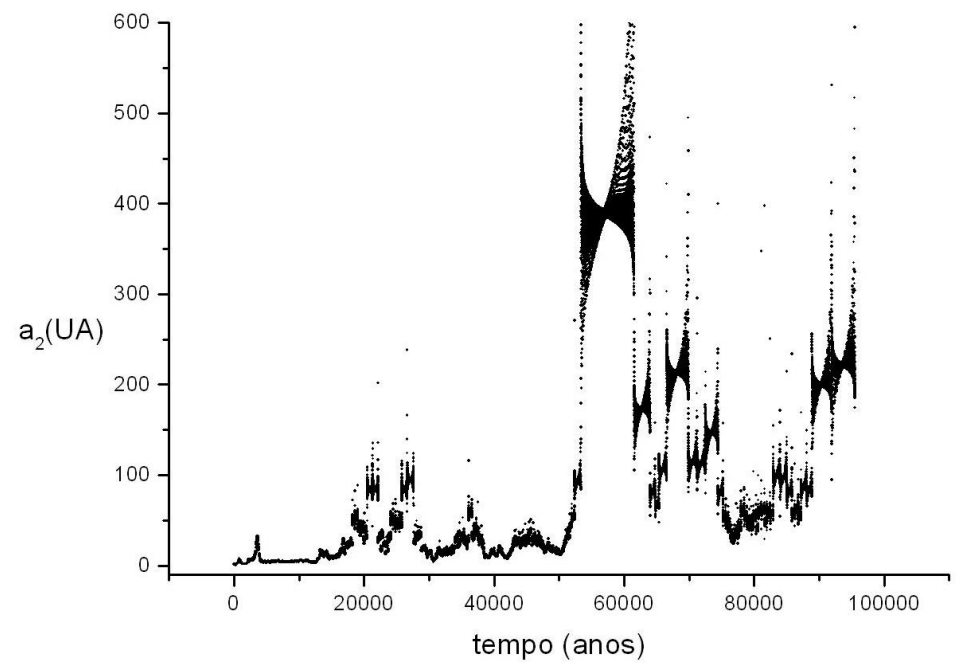

Figura B.21: Semi-eixo de HD 128311 c em função do tempo - (Fischer e Valenti, 2005)

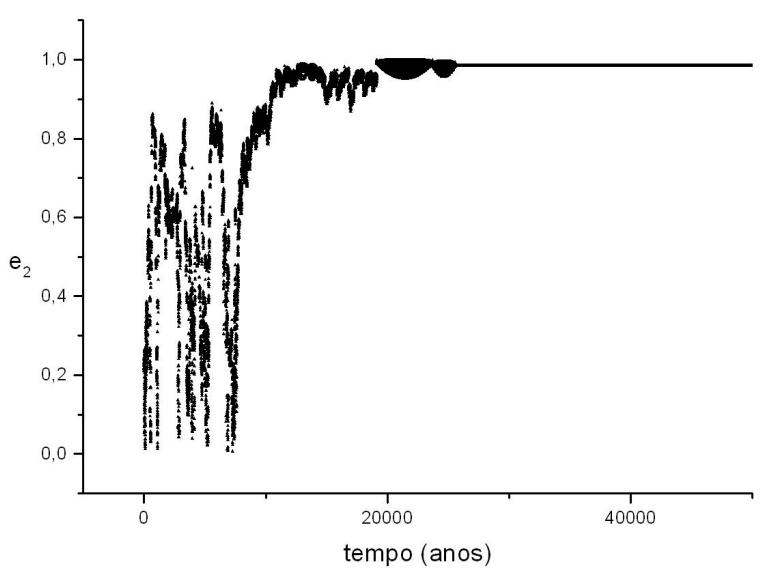

Figura B.22: Excentricidade de HD 128311 c em função do tempo - (Fischer e Valenti, 2005) 


\section{B.1.5 HD $82943 \mathrm{cb}$}

A primeira simulação para o sistema HD 82943 cb teve como fonte de referência (Mayor et al., 2004) e se mostrou instável. Como pode-se observar das figuras (B.23) e (B.24), a partir de aproximadamente 52 mil anos nas simulações, o semi-eixo de HD 82943 c assume valor muito grande e sua excentricidade fica parecida com a de um cometa.

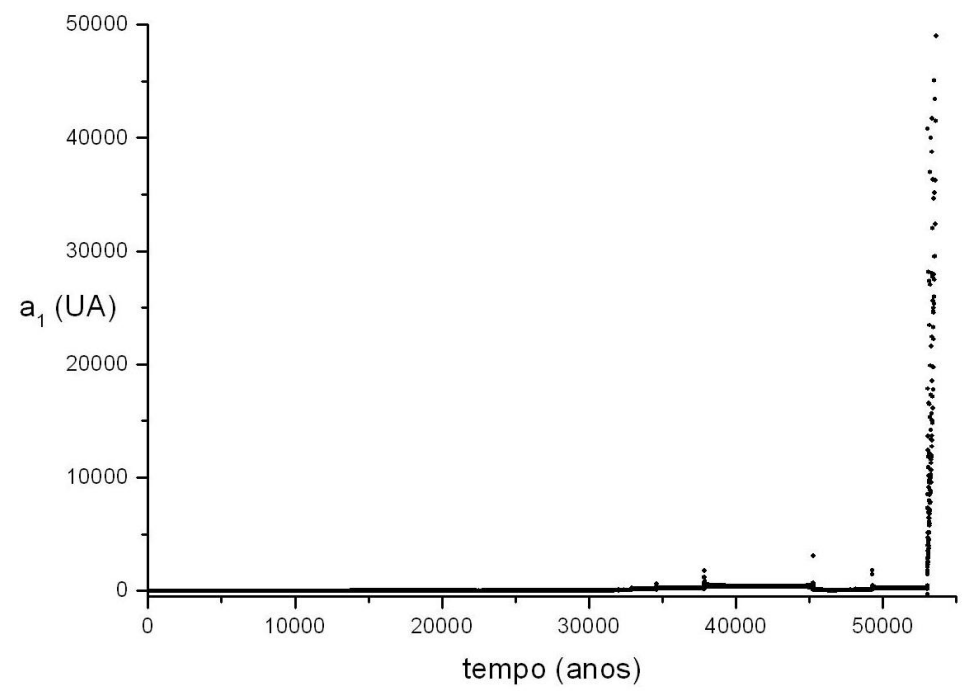

Figura B.23: Semi-eixo de HD 82943 c em função do tempo - (Mayor et al., 2004)

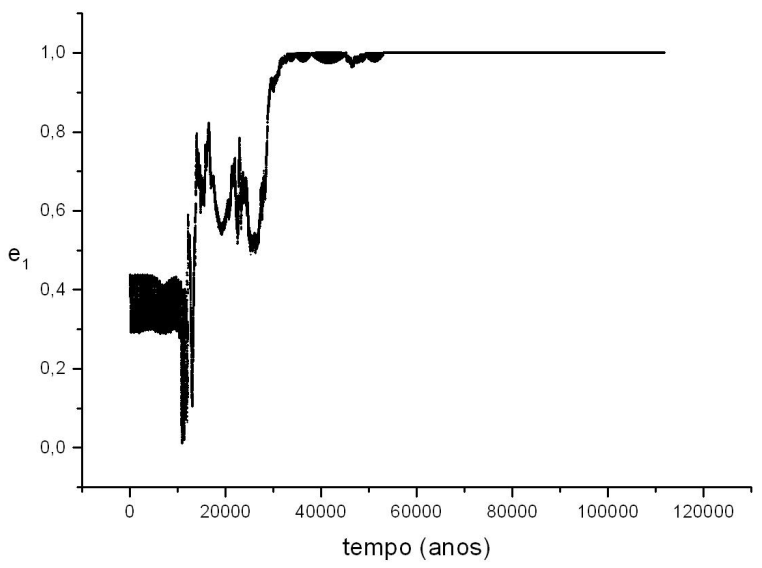

Figura B.24: Excentricidade de HD 82943 c em função do tempo - (Mayor et al., 2004) 
Uma segunda simulação, utilizando dados de (Beaugé et al., 2008), mostram um sistema estável, inserido na ressonância 2/1 $\left(T_{1} / T_{2}=2,046181\right)$, pertencente à Classe I. O movimento do ângulo $\Delta \varpi$ é oscilatório em torno de $0^{\circ}$. Seu período secular é de aproximadamente 701,8 anos.

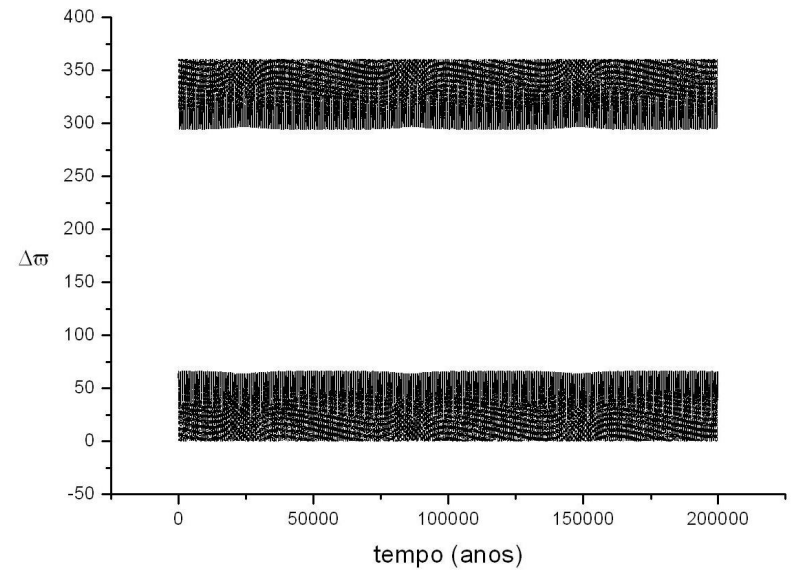

Figura B.25: Ângulo $\Delta \varpi$ em função do tempo para HD $82943 \mathrm{cb}$

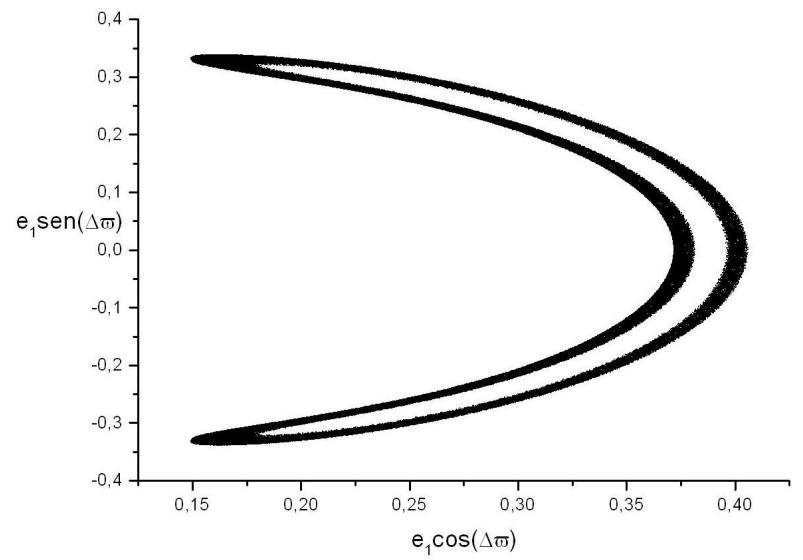

Figura B.27: KH de $e_{1}$ para HD $82943 \mathrm{cb}$

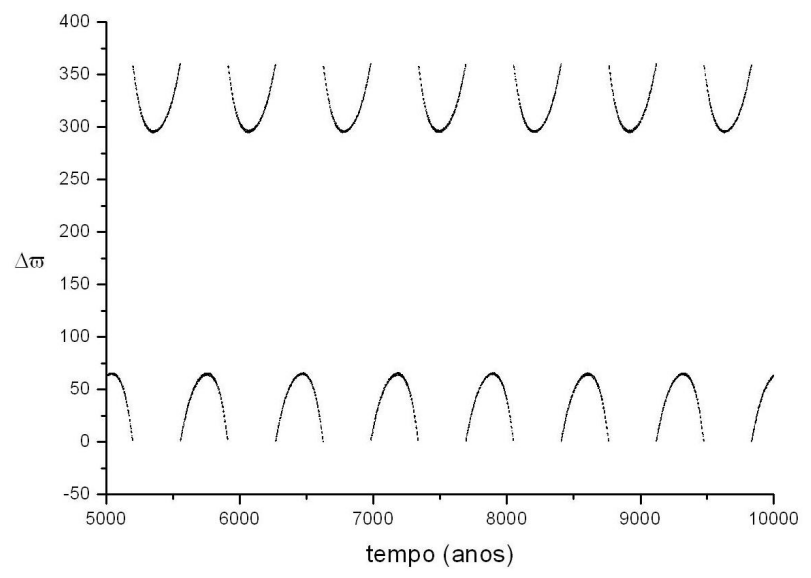

Figura B.26: Zoom do ângulo $\Delta \varpi$ em função do tempo para HD $82943 \mathrm{cb}$

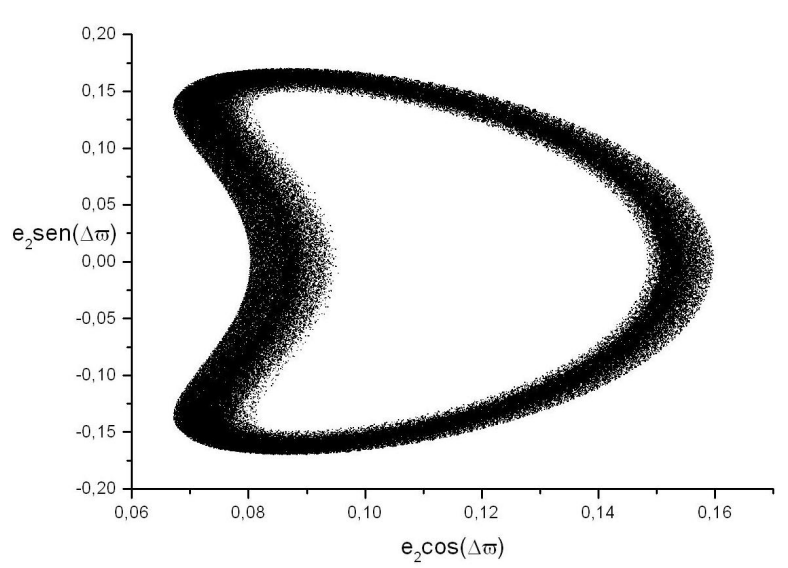

Figura B.28: KH de $e_{2}$ para HD $82943 \mathrm{cb}$ 
Entretanto, os dados do sistema HD82943 cb em (Beaugé et al., 2008) são obtidos de uma solução matemática contendo 3 planetas inseridos na ressonância de Laplace. A simulação supondo a existência do planeta HD82943 d também apresentou configuração estável. O movimento do ângulo $\Delta \varpi$ para o sistema HD 82943 bd é circulatório retrógrado. Seu período secular é de aproximadamente 843 anos.

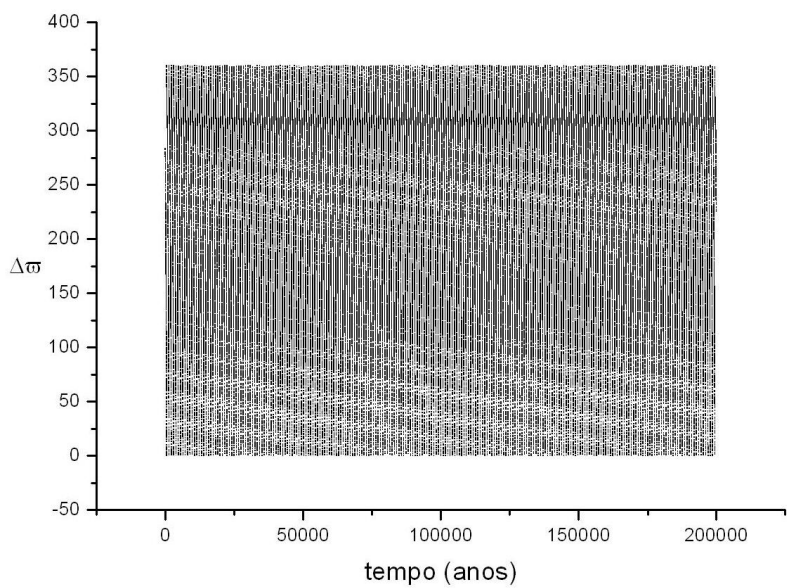

Figura B.29: Ângulo $\Delta \varpi$ em função do tempo para HD 82943 bd

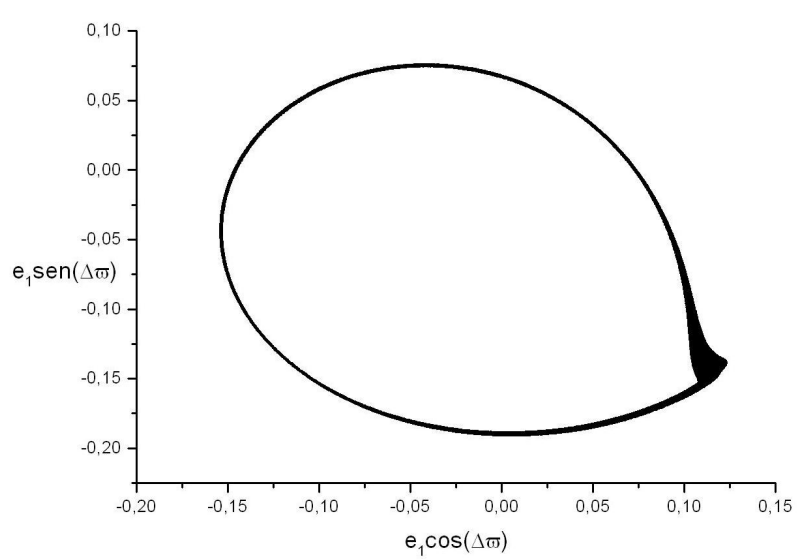

Figura B.31: KH de $e_{1}$ para HD 82943 bd

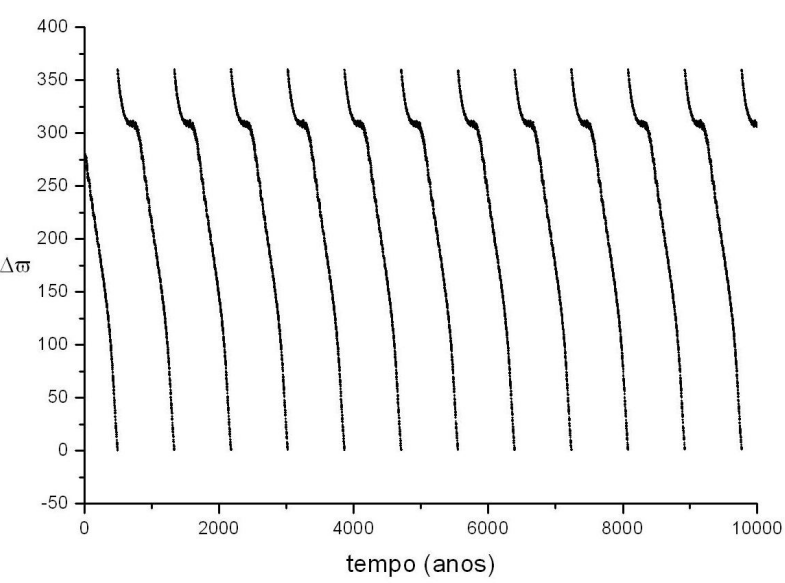

Figura B.30: Zoom do ângulo $\Delta \varpi$ em função do tempo para HD 82943 bd

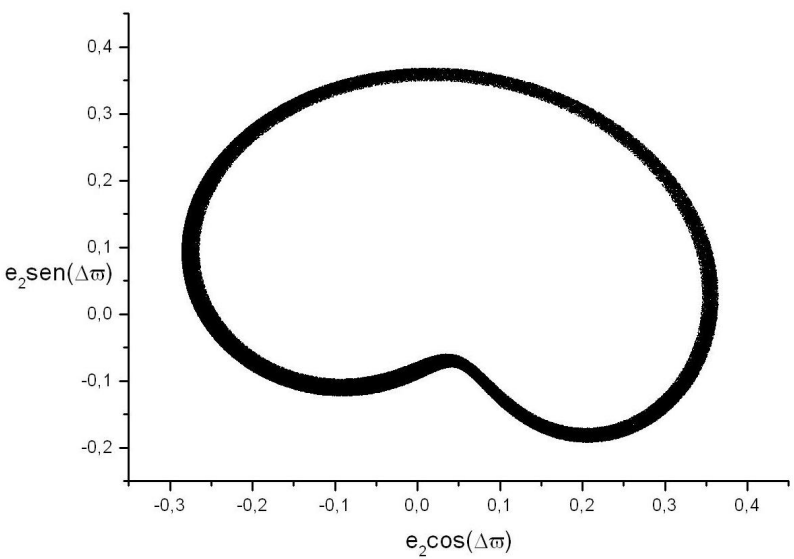

Figura B.32: KH de $e_{2}$ para HD 82943 bd 


\section{B.1.6 HD 60532 bc}

O tempo de simulação para o sistema HD 60532 bc foi de 200 mil anos. Trata-se de um sistema ressonante, Classe I, ressonância $3 / 1,\left(T_{1} / T_{2}=3,0077\right)$. O movimento do ângulo $\Delta \varpi$ é circulatório retrógrado. Seu período secular é de aproximadamente 412,9 anos.

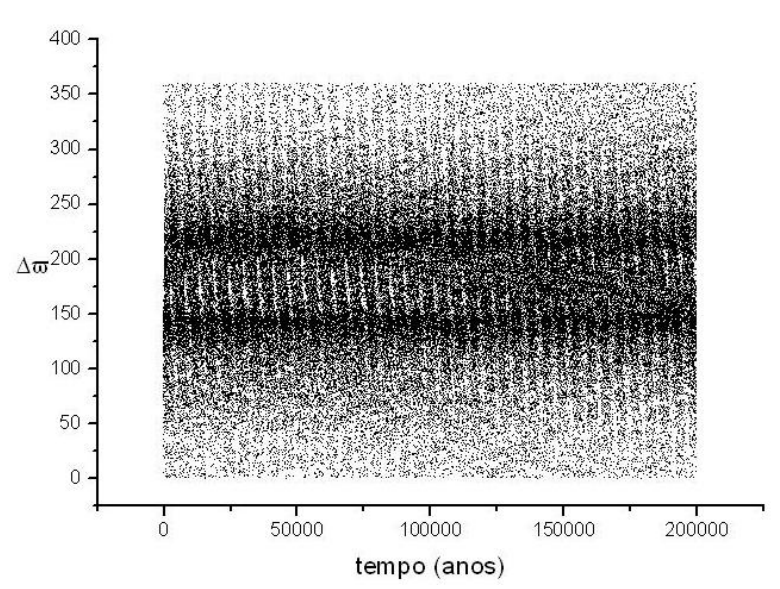

Figura B.33: Ângulo $\Delta \varpi$ em função do tempo para HD 60532 bc

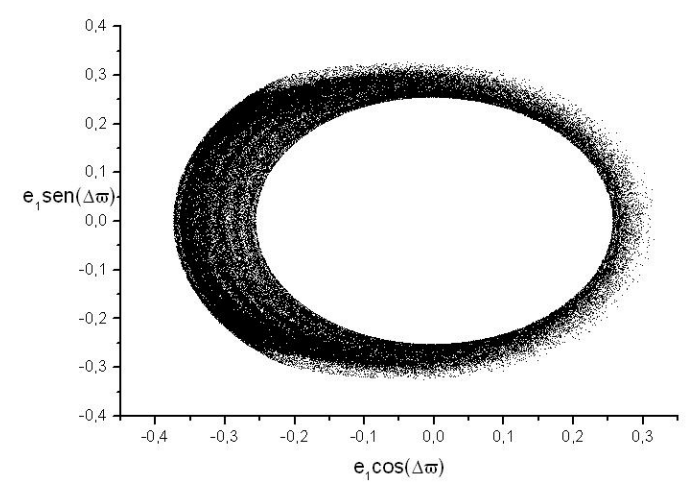

Figura B.35: KH de $e_{1}$ para HD 60532 bc

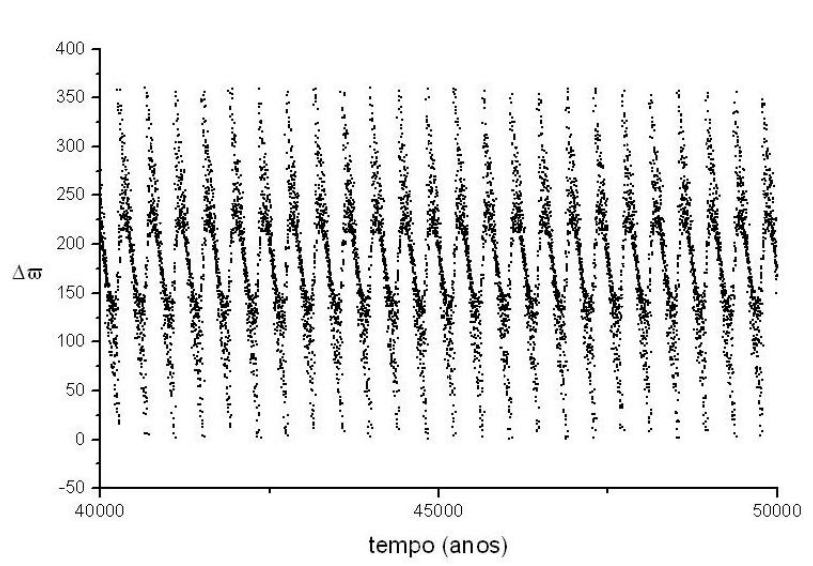

Figura B.34: Zoom do ângulo $\Delta \varpi$ em função do tempo para HD 60532 bc

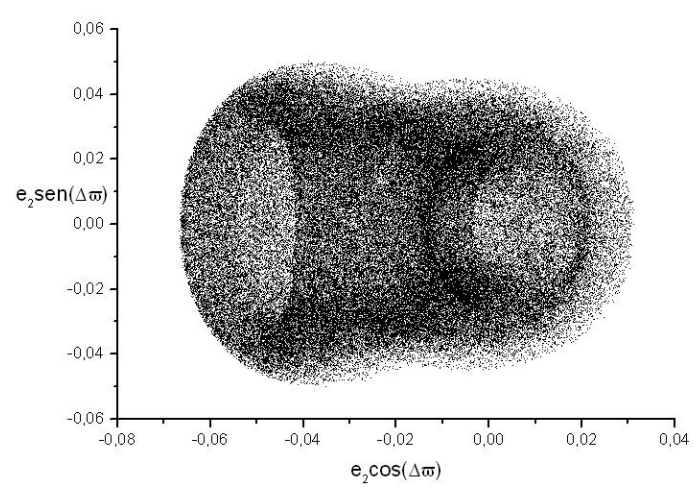

Figura B.36: KH de $e_{2}$ para HD 60532 bc

A filtragem faz-se necessária para inferir os valores dos gráficos de $\mathrm{KH}$ de $e_{1}$ e $e_{2}$. Como o período secular do ângulo $\Delta \varpi$ tem valor próximo de 413 anos, limitando a banda de filtragem entre 0,002222 1/ano (450anos) e 0,00286 1/ano (350 anos), os gráficos de $\mathrm{KH}$ de $e_{1}$ e $e_{2}$ assumem forma mais adequada à obtenção dos valores de $e_{1}$ e $e_{2}$ mínimos e máximos. 


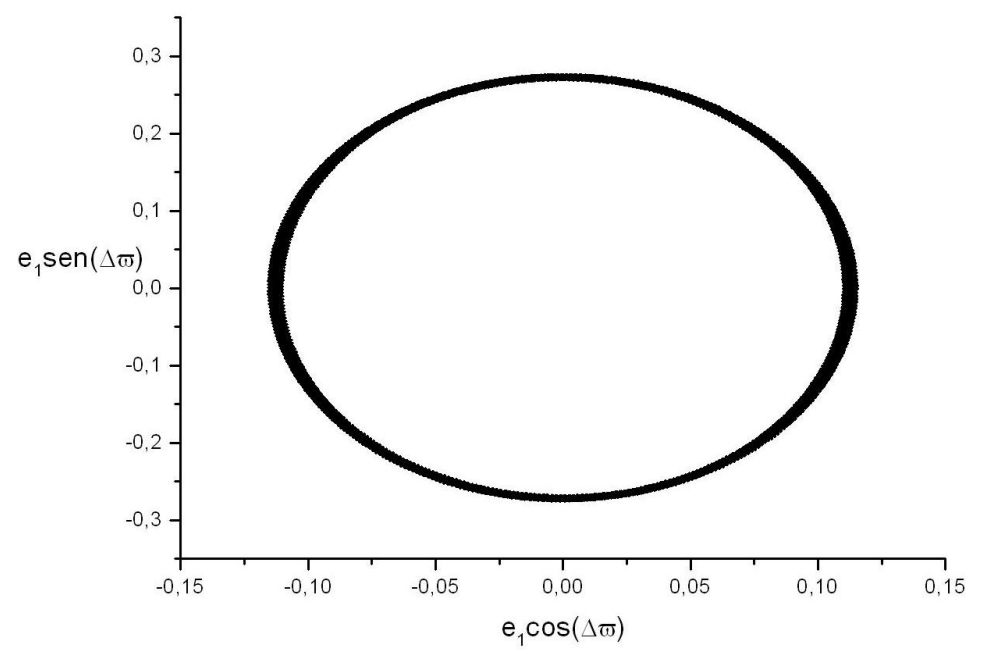

Figura B.37: KH de $e_{1}$ para HD 60532 bc - filtro de 350 a 450 anos

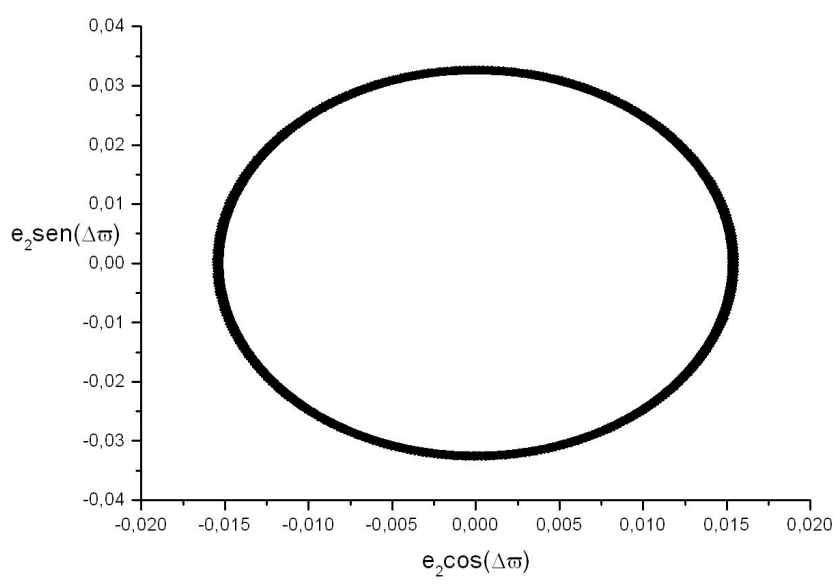

Figura B.38: KH de $e_{2}$ para HD 60532 bc - filtro de 350 a 450 anos 


\section{B.1.7 HD 108874 bc}

O tempo de simulação para o sistema HD 108874 bc foi de 200 mil anos. Trata-se de um sistema ressonante, ressonância $4 / 1, T_{1} / T_{2}=0,2462$, Classe I. O movimento do ângulo $\Delta \varpi$ é oscilatório em torno de $180^{\circ}$. Seu período secular é de aproximadamente 13.443 anos.

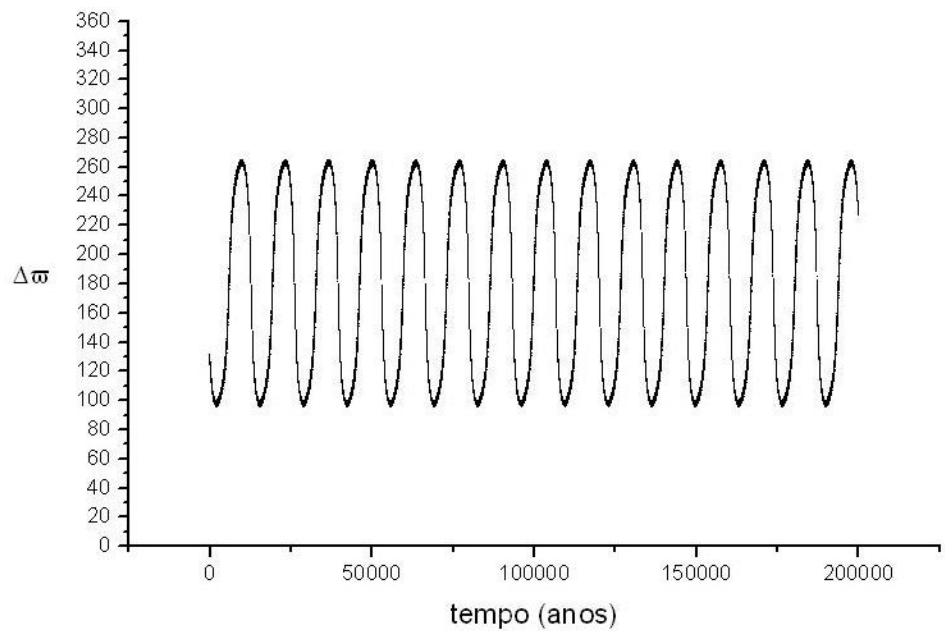

Figura B.39: Ângulo $\Delta \varpi$ em função do tempo para HD 108874 bc

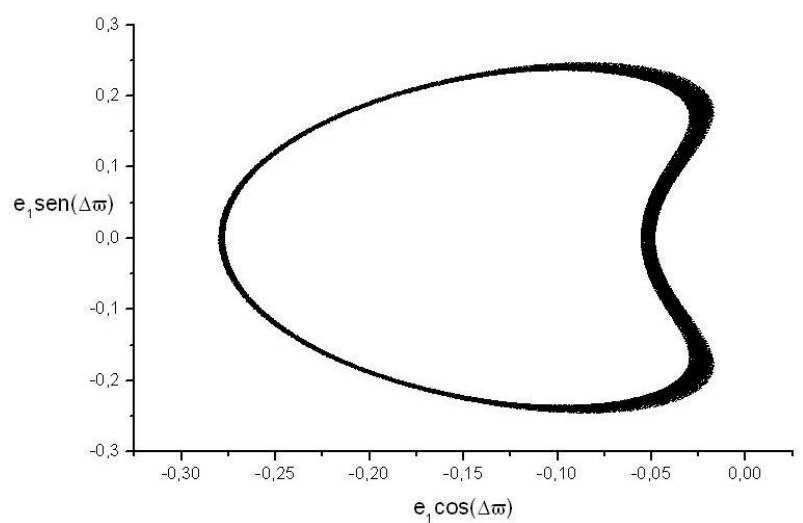

Figura B.40: KH de $e_{1}$ para HD 108874 bc

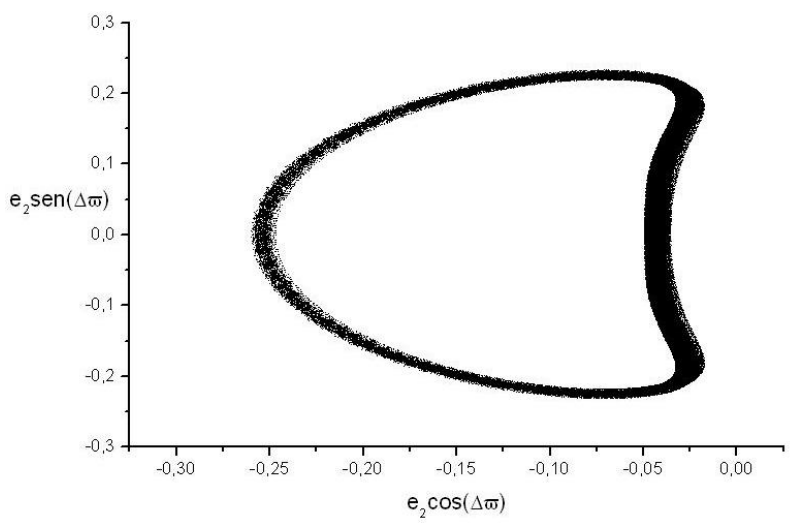

Figura B.41: KH de $e_{2}$ para HD 108874 bc 


\section{B.1.8 HD 102272 bc}

O sistema HD 102272 bc apresentou configuração instável nas simulações. Pela classificação, trata-se de um sistema ressonante, que se enquadra na ressonância $4 / 1, T_{1} / T_{2}=$ 0,2453, Classe I. Nas simulações, nota-se que em menos de 3 mil anos o sistema apresenta características de instabilidade.

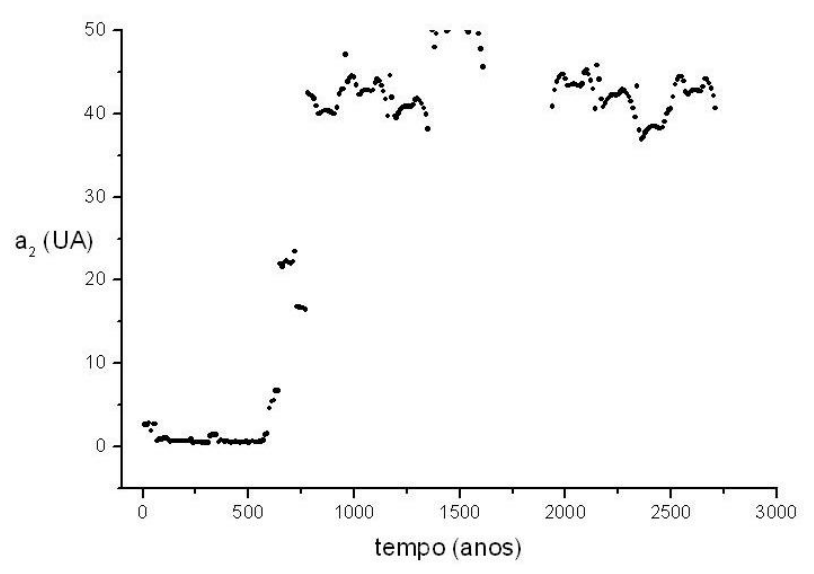

Figura B.42: Semi-eixo de HD 102272 c em função do tempo

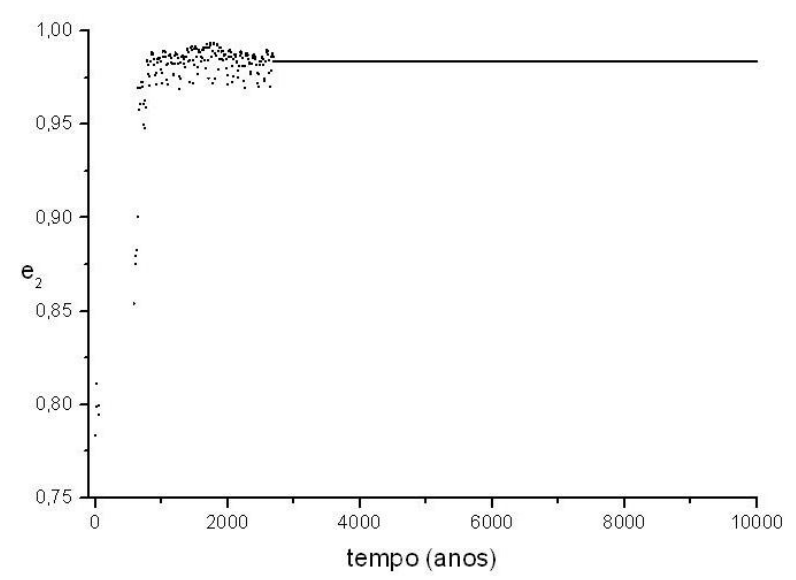

Figura B.43: Excentricidade de HD 102272 c em função do tempo

Como nota-se dos gráficos, para o planeta HD 102272 c, em menos de 3 mil anos, o semi-eixo maior adquire valor muito grande e sua excentricidade assume valor equivalente a de um cometa. 


\section{B.2 Classe II - seculares}

\section{B.2.1 BD 202457 bc}

O sistema BD 202457 bc seria classificado como secular, Classe II, porém, as simulações mostram que a partir de 23.400 anos de simulação o semi-eixo maior do planeta BD 20 2457 c fica muito grande, e a excentricidade assume valores próxímos à excentricidade de um cometa, mostrando que os dados disponíveis desse sistema não permitem classificá-lo como um sistema estável.

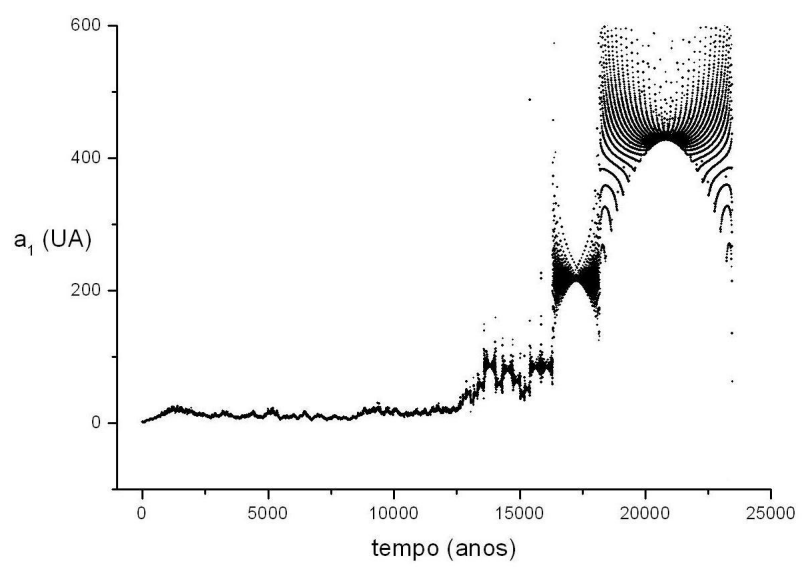

Figura B.44: Semi-eixo maior de BD 202457 b em função do tempo

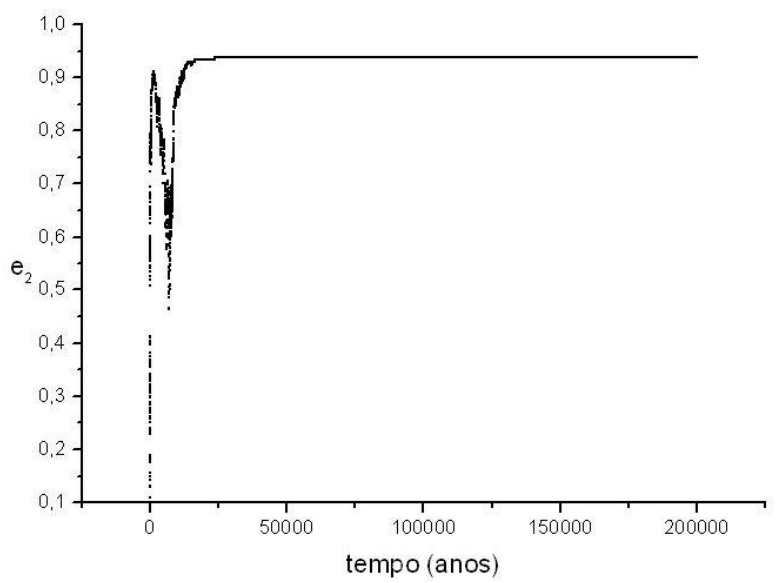

Figura B.45: Excentricidade de BD 202457 c em função do tempo 


\section{B.2.2 HD $181433 \mathrm{~cd}$}

O sistema HD 181433 bc seria classificado como secular, Classe II, porém, as simulações mostram que a partir de aproximadamente 974 mil anos de simulação o semi-eixo maior do planeta HD 181433 c assume valor muito grande, e a excentricidade deste mesmo planeta assume valor próximo a 1, mostrando que os dados disponíveis desse sistema não permitem classificá-lo como um sistema estável.

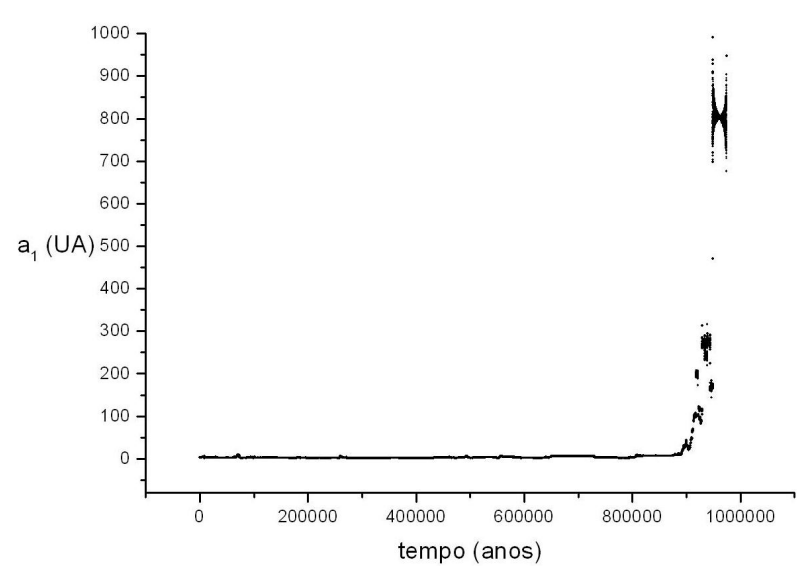

Figura B.46: Semi-eixo maior de HD 181433 c em função do tempo

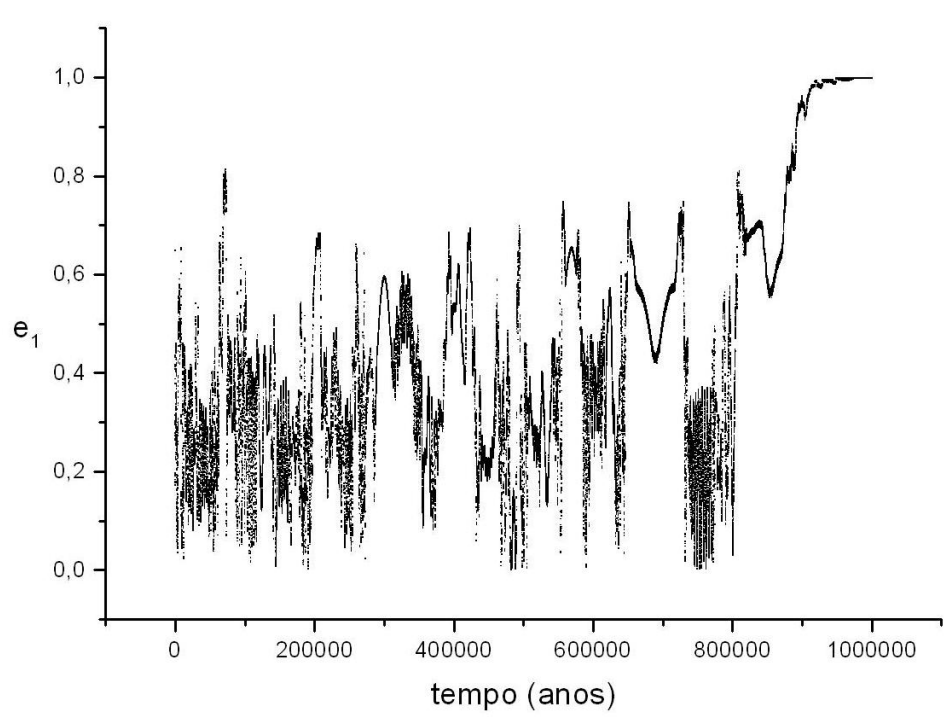

Figura B.47: Excentricidade de HD 181433 c em função do tempo 


\section{B.2.3 GJ 581 bc}

O tempo de simulação para o sistema GJ 581 bc foi de 200 mil anos. Trata-se de um sistema secular, Classe II. O movimento do ângulo $\Delta \varpi$ é circulatório prógrado. Seu período secular é de aproximadamente 401,9 anos.

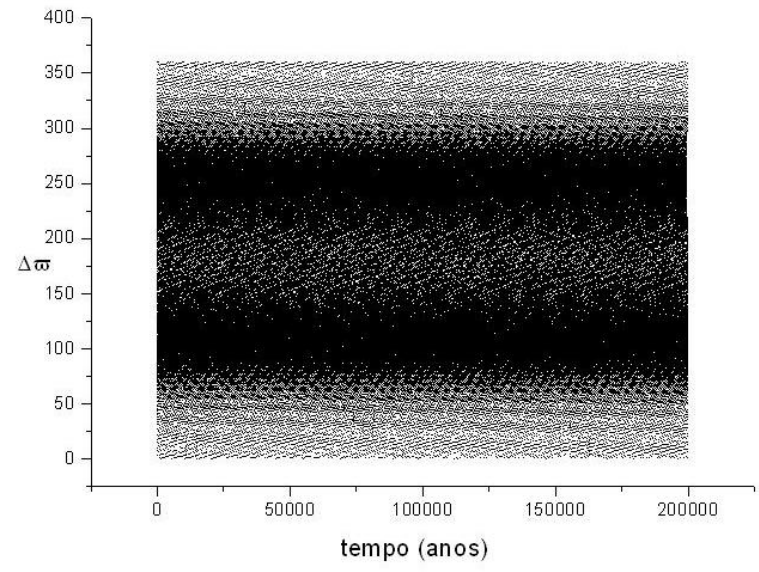

Figura B.48: Ângulo $\Delta \varpi$ em função do tempo para GJ 581 bc

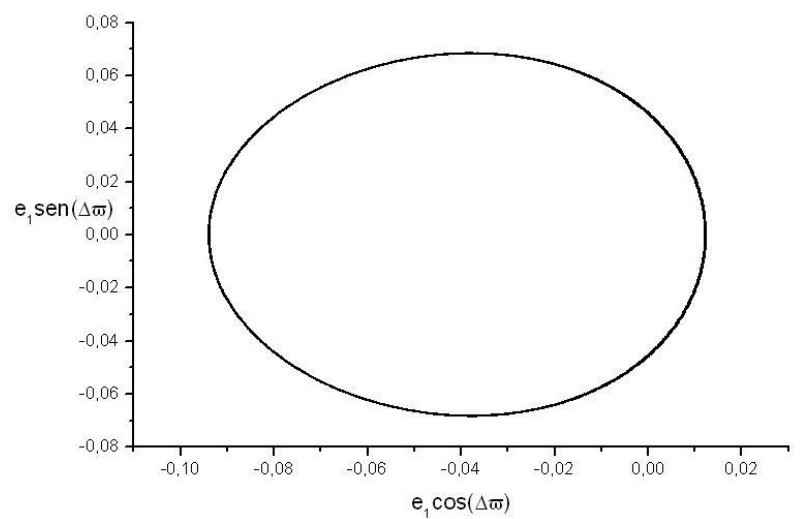

Figura B.50: $\mathrm{KH}$ de $e_{1}$ para GJ 581 bc

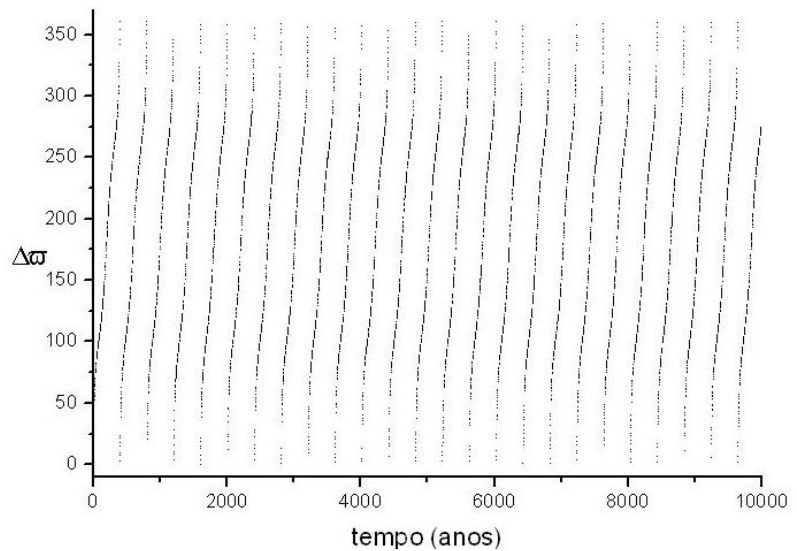

Figura B.49: Zoom do ângulo $\Delta \varpi$ em função do tempo para GJ 581 bc

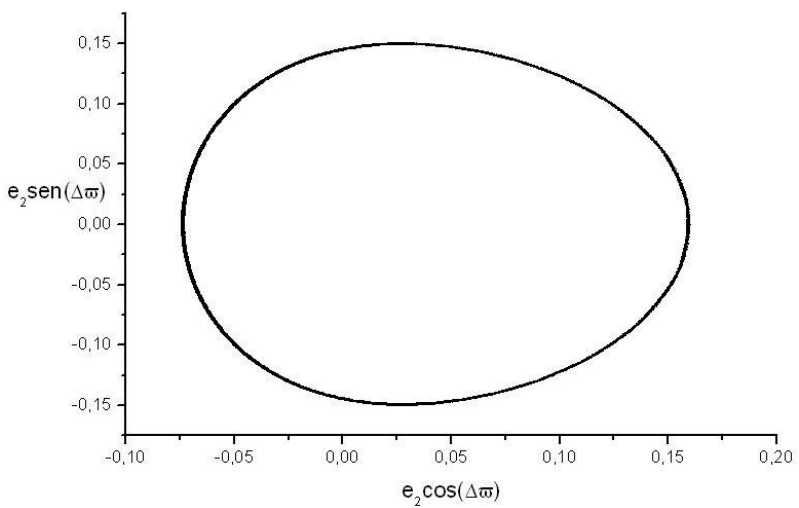

Figura B.51: KH de $e_{2}$ para GJ 581 bc 


\section{B.2.4 GJ $581 \mathrm{~cd}$}

O tempo de simulação para o sistema GJ 581 cd foi de 200 mil anos. Trata-se de um sistema secular, Classe II. O movimento do ângulo $\Delta \varpi$ é circulatório retrógrado. Seu período secular é de aproximadamente 28.850 anos.

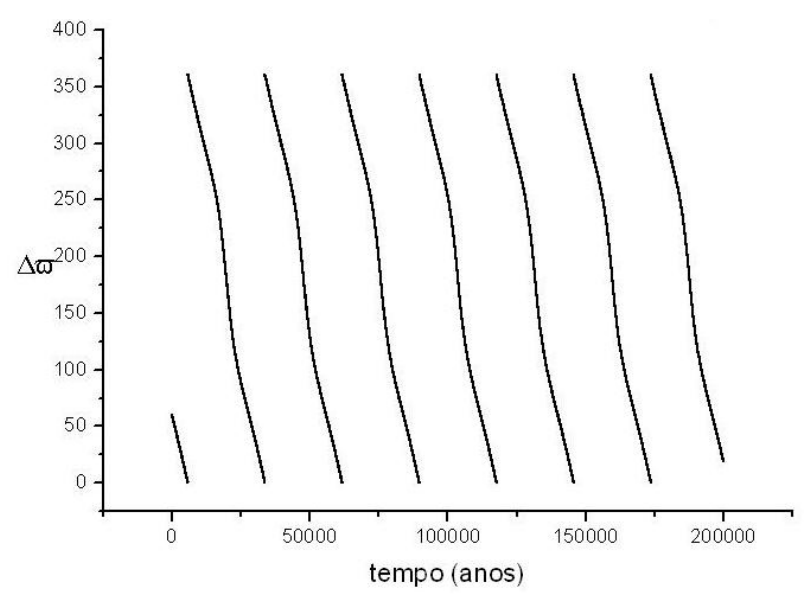

Figura B.52: Ângulo $\Delta \varpi$ em função do tempo para GJ $581 \mathrm{~cd}$

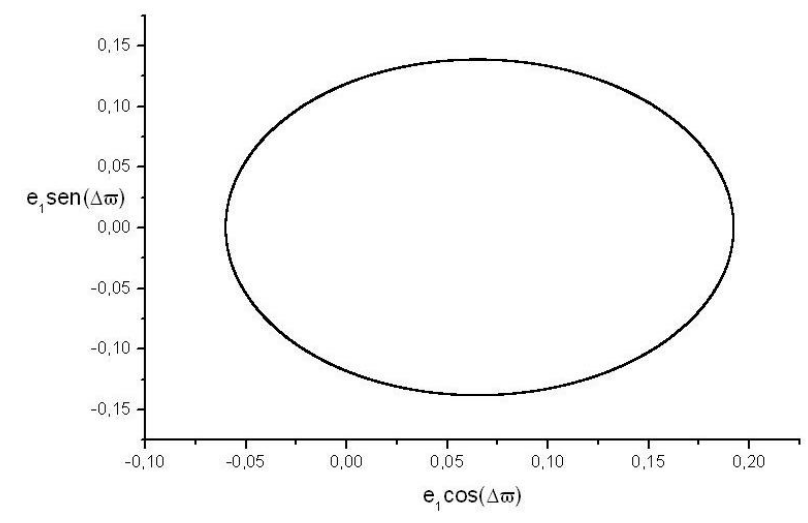

Figura B.53: KH de $e_{1}$ para GJ $581 \mathrm{~cd}$

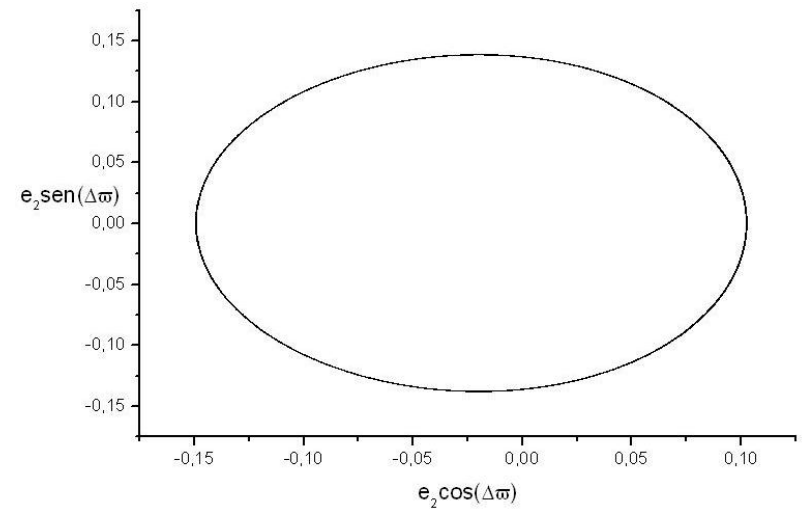

Figura B.54: KH de $e_{2}$ para GJ $581 \mathrm{~cd}$ 


\section{B.2.5 GJ 581 bc (Mayor et al., 2009)}

O tempo de simulação para o sistema GJ 581 bc (Mayor et al., 2009) foi de 200 mil anos. Trata-se de um sistema secular, Classe II. O movimento do ângulo $\Delta \varpi$ é oscilatório em torno de $180^{\circ}$. O movimento do ângulo $\Delta \varpi$ tem uma alternância entre oscilatório em torno de $180^{\circ}$ e circulatório devido a interferências de curto período, quando a excentricidade do planeta interno, $e_{1}$, tem valores muito próximos de zero, a excentricidade do planeta externo, $e_{2}$, é dispersada arbitrariamente. O período secular tem aproximadamente 40 anos.

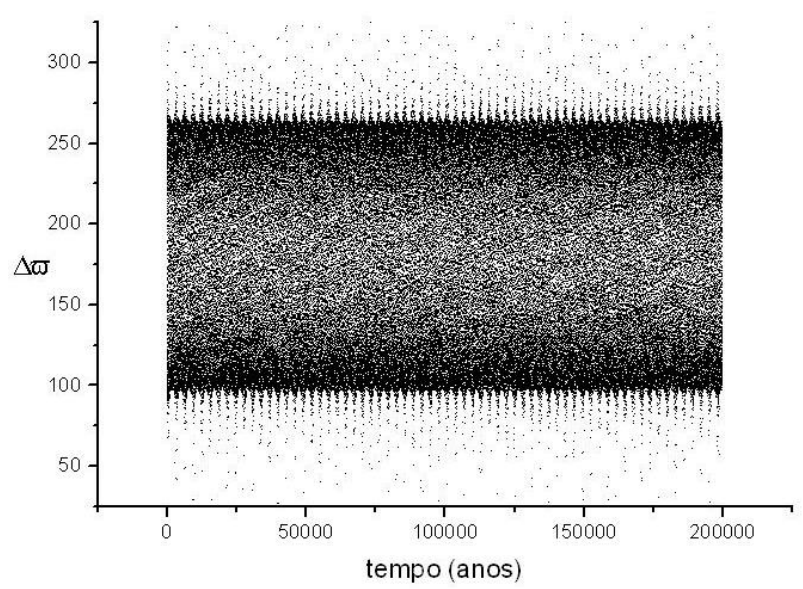

Figura B.55: Ângulo $\Delta \varpi$ em função do tempo para GJ 581 bc - Mayor

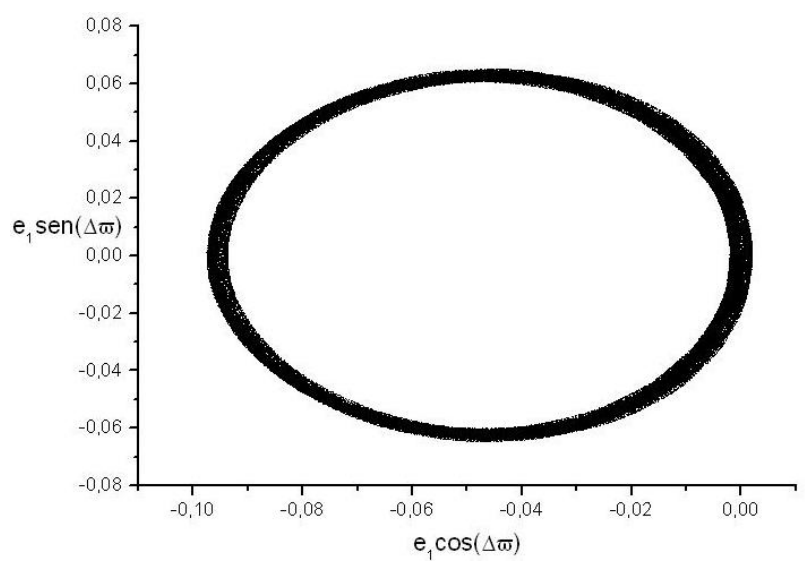

Figura B.57: KH de $e_{1}$ para GJ 581 bc - Mayor

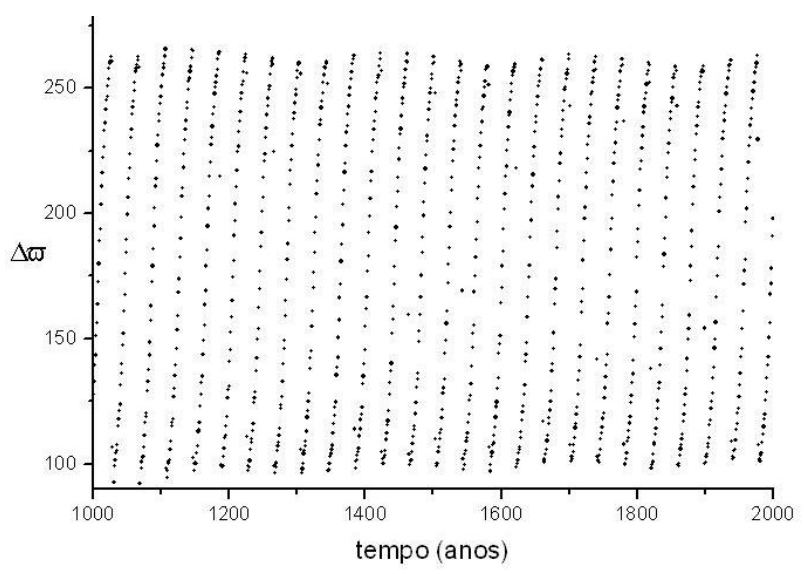

Figura B.56: Zoom do ângulo $\Delta \varpi$ em função do tempo para GJ 581 bc - Mayor

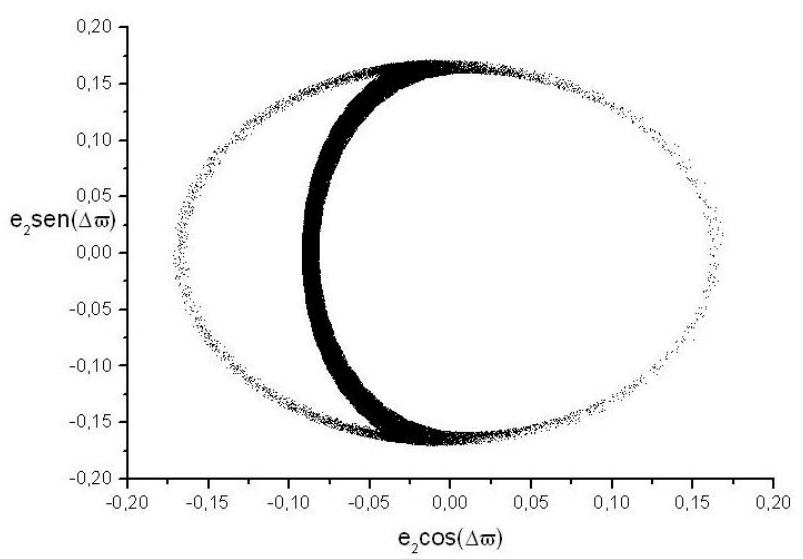

Figura B.58: KH de $e_{2}$ para GJ 581 bc - Mayor 


\section{B.2.6 GJ 581 cd (Mayor et al., 2009)}

O tempo de simulação para o sistema GJ 581 cd (Mayor et al., 2009) foi de 200 mil anos. Trata-se de um sistema secular, Classe II. O movimento do ângulo $\Delta \varpi$ é circulatório retrógrado. Seu período secular é de aproximadamente 3.273 anos.

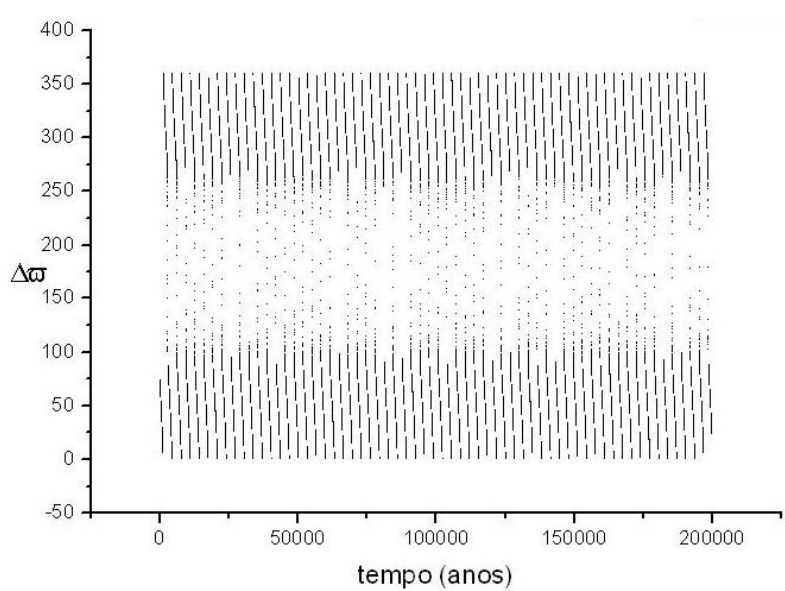

Figura B.59: Ângulo $\Delta \varpi$ em função do tempo para GJ 581 cd - Mayor

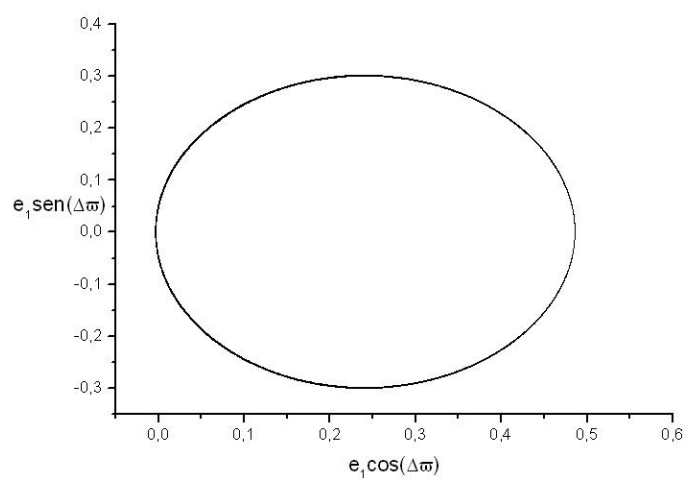

Figura B.61: KH de $e_{1}$ para GJ $581 \mathrm{~cd}-$ Mayor

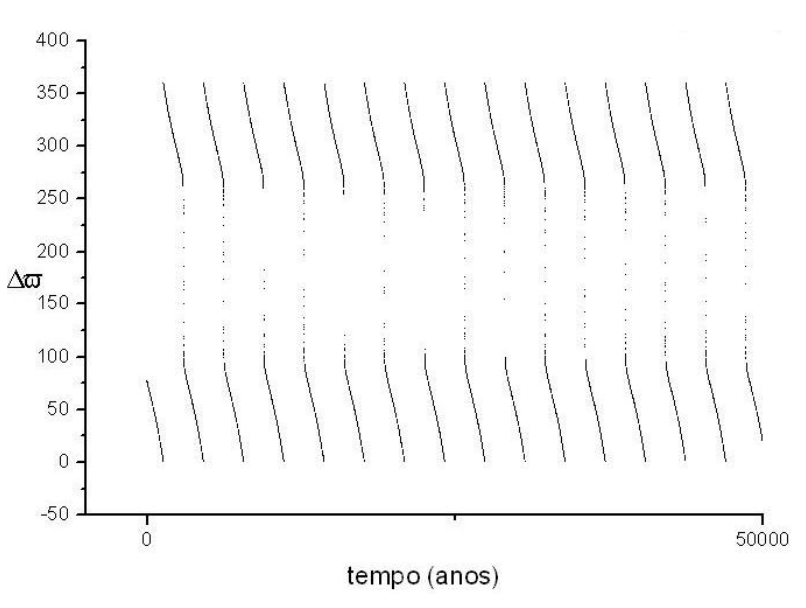

Figura B.60: Zoom do ângulo $\Delta \varpi$ em função do tempo para GJ $581 \mathrm{~cd}$ - Mayor

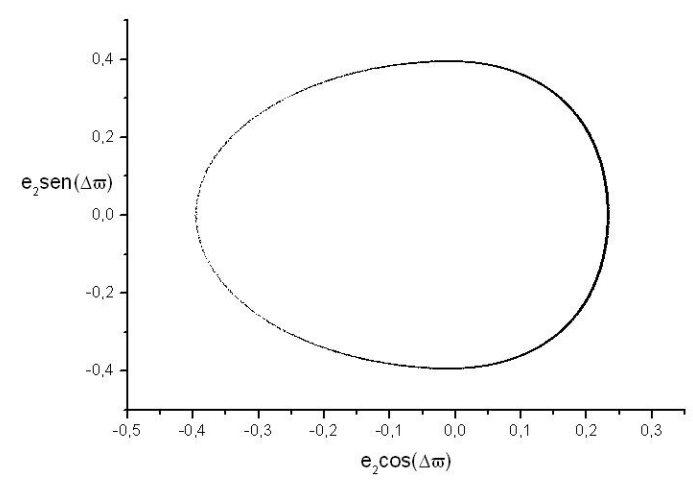

Figura B.62: KH de $e_{2}$ para GJ $581 \mathrm{~cd}$ - Mayor 


\section{B.2.7 HD 155358 bc}

O tempo de simulação para o sistema HD 155358 bc foi de 1 milhão de anos. Trata-se de um sistema secular, Classe II. O movimento do ângulo $\Delta \varpi$ é oscilatório em torno de $180^{\circ}$. Seu período secular é de aproximadamente 2.366 anos.

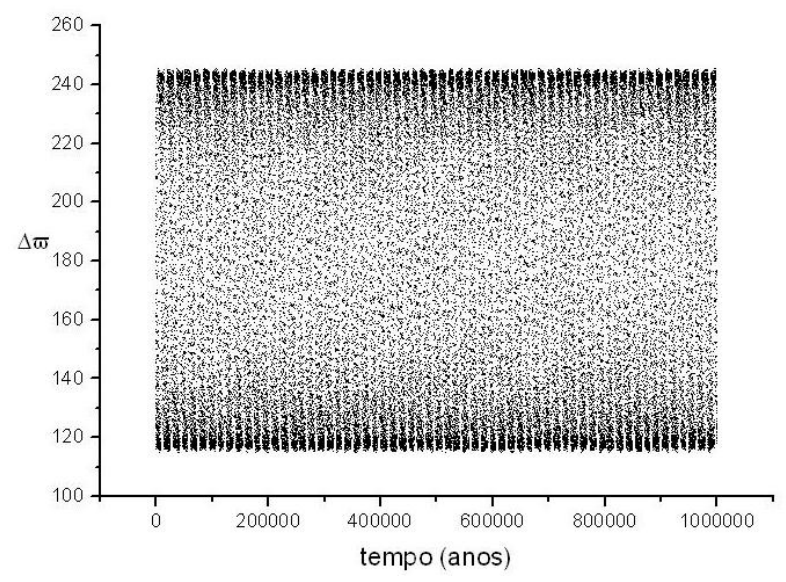

Figura B.63: Ângulo $\Delta \varpi$ em função do tempo para HD 155358 bc

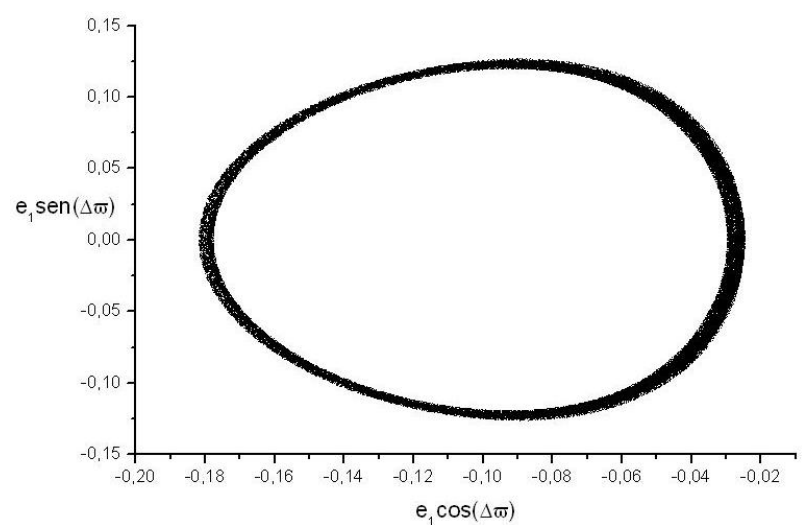

Figura B.64: KH de $e_{1}$ para HD 155358 bc

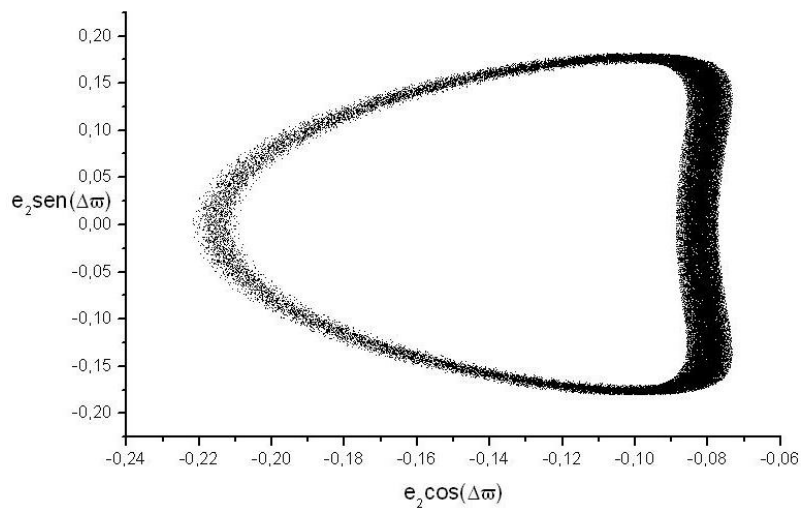

Figura B.65: KH de $e_{2}$ para HD 155358 bc 


\section{B.2.8 HD 37124 bd}

O tempo de simulação para o sistema HD 37124 bd foi de 200 mil anos. Trata-se de um sistema secular, Classe II. O movimento do ângulo $\Delta \varpi$ é circulatório retrógrado. Seu período secular é de aproximadamente 25.976 anos.

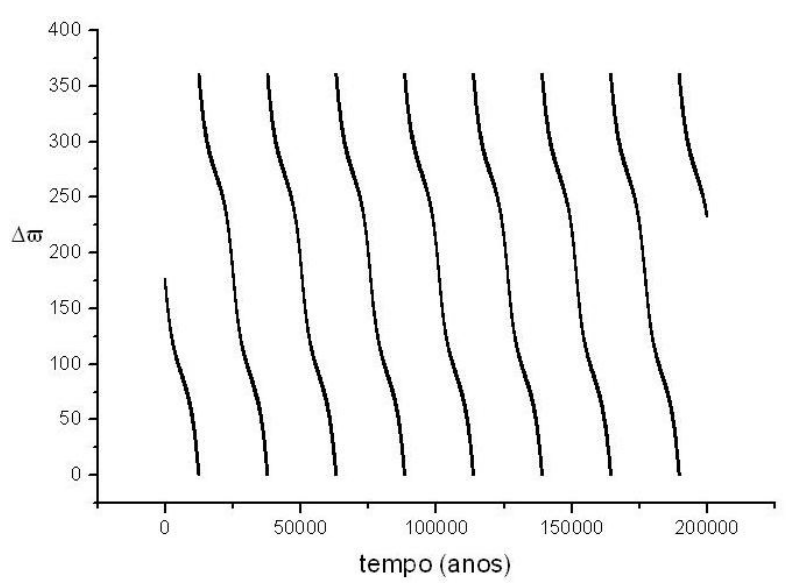

Figura B.66: Ângulo $\Delta \varpi$ em função do tempo para HD 37124 bd

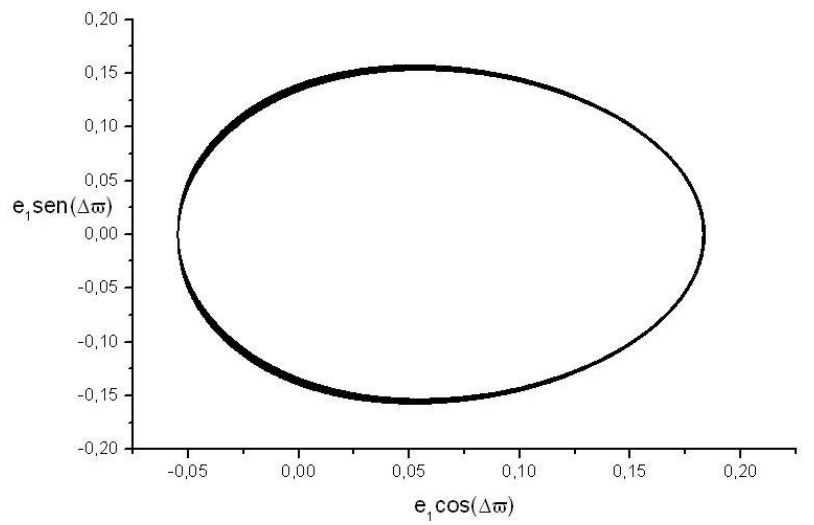

Figura B.67: KH de $e_{1}$ para HD 37124 bd

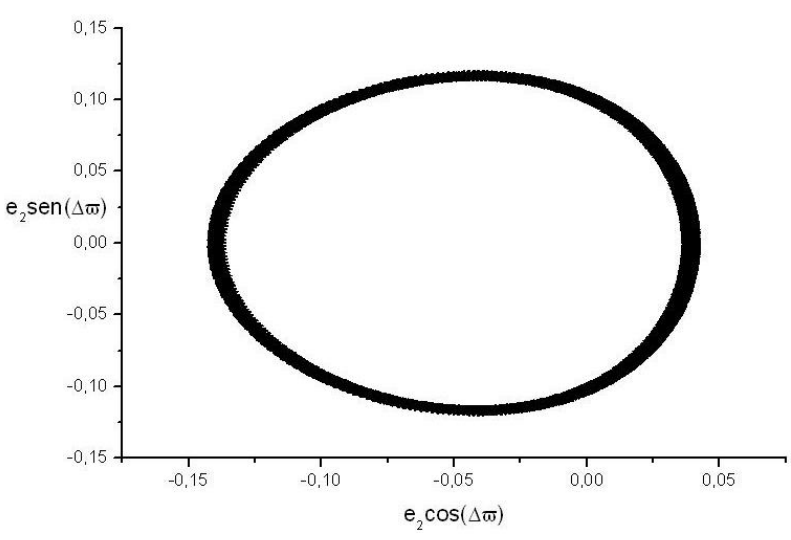

Figura B.68: KH de $e_{2}$ para HD 37124 bd 


\section{B.2.9 HD $37124 d c$}

O tempo de simulação para o sistema HD 37124 de foi de 200 mil anos. Trata-se de um sistema secular, Classe II. O movimento do ângulo $\Delta \varpi$ é oscilatório em torno de $0^{\circ}$. Seu período secular é de aproximadamente 12.164 anos.

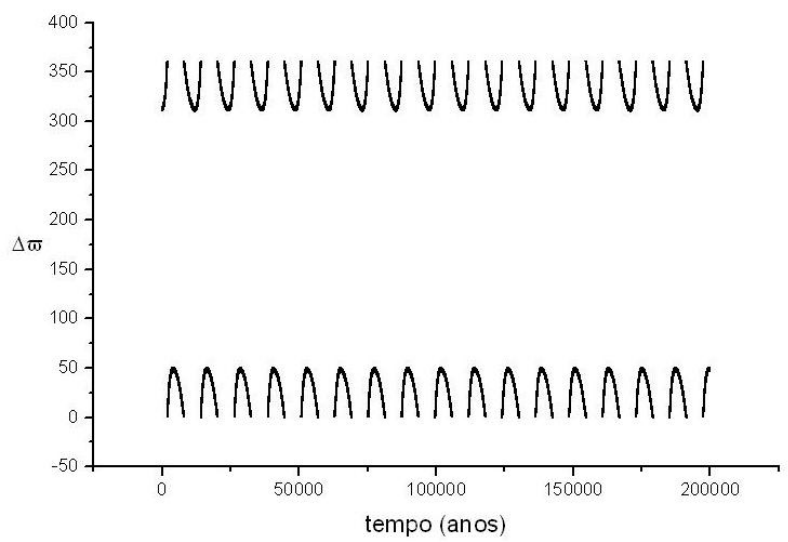

Figura B.69: Ângulo $\Delta \varpi$ em função do tempo para HD $37124 \mathrm{dc}$

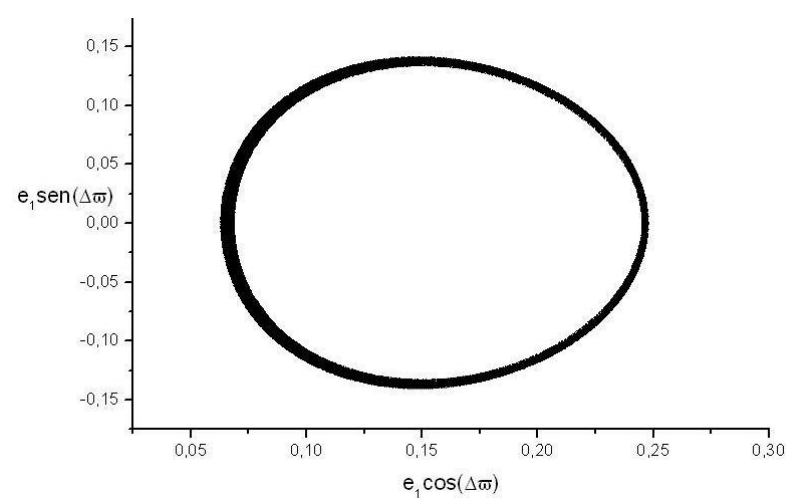

Figura B.70: KH de $e_{1}$ para HD $37124 \mathrm{dc}$

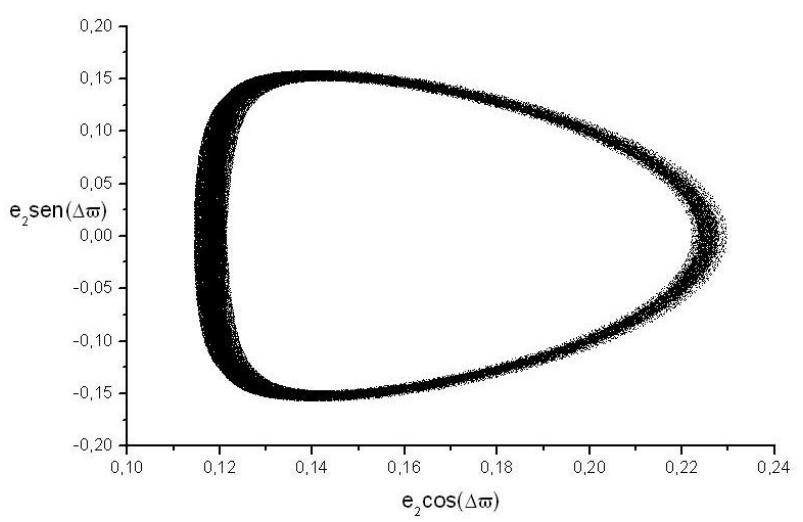

Figura B.71: KH de $e_{2}$ para HD $37124 \mathrm{dc}$ 


\section{B.2.10 HD 69830 bc}

O tempo de simulação para o sistema HD 69830 bc foi de 1 milhão de anos. Trata-se de um sistema secular, Classe II. O movimento do ângulo $\Delta \varpi$ é circulatório retrógrado. Seu período secular é de aproximadamente 7.617 anos.

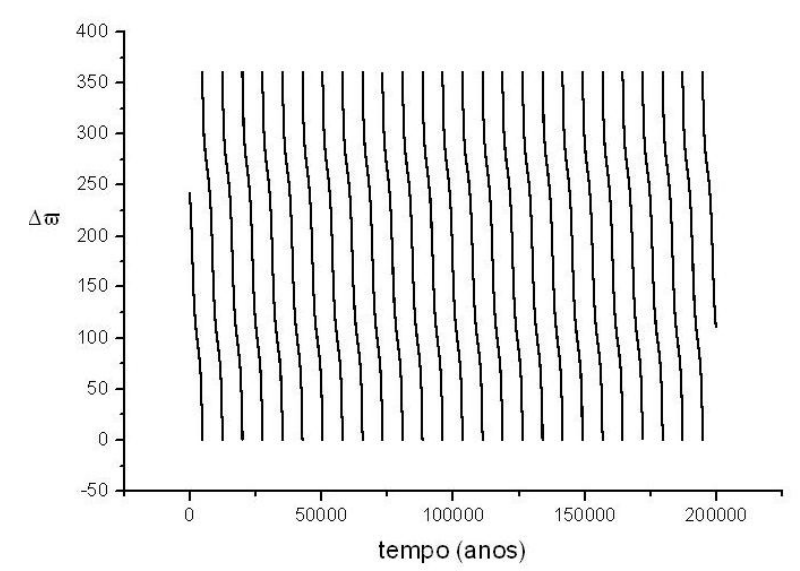

Figura B.72: Ângulo $\Delta \varpi$ em função do tempo para HD 69830 bc

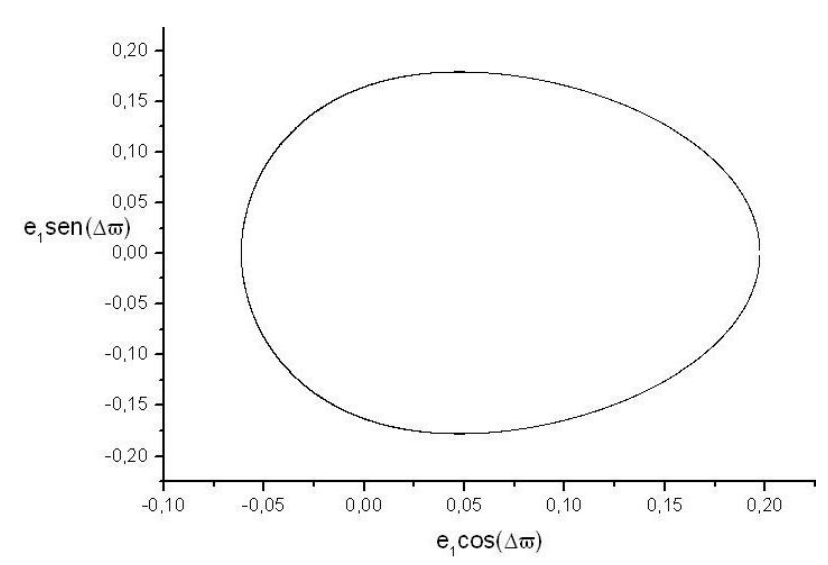

Figura B.73: KH de $e_{1}$ para HD 69830 bc

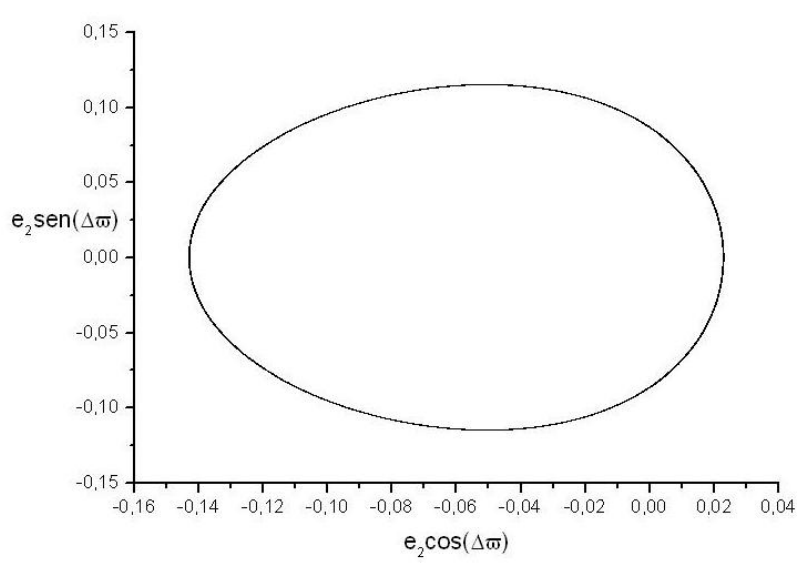

Figura B.74: KH de $e_{2}$ para HD 69830 bc 


\section{B.2.11 HD $69830 \mathrm{~cd}$}

O tempo de simulação para o sistema HD 69830 cd foi de 1 milhão de anos. Trata-se de um sistema secular, Classe II. O movimento do ângulo $\Delta \varpi$ é circulatório retrógrado. Seu período secular é de aproximadamente 76.887 anos.

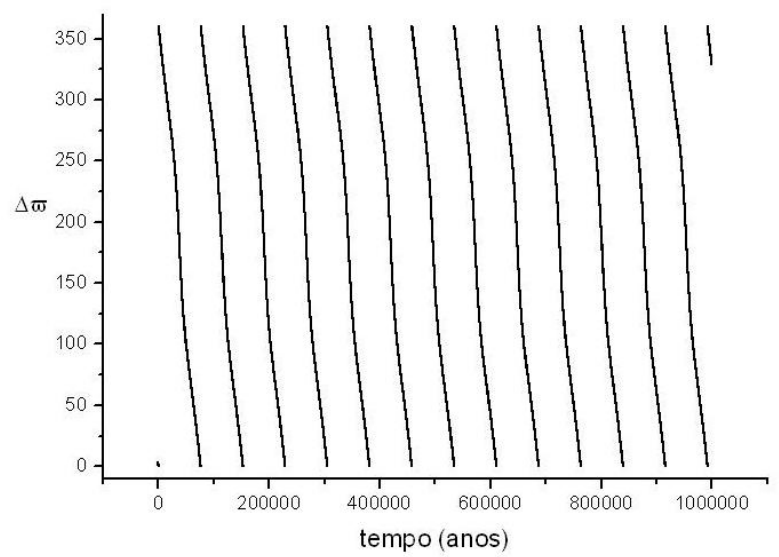

Figura B.75: Ângulo $\Delta \varpi$ em função do tempo para HD $69830 \mathrm{~cd}$

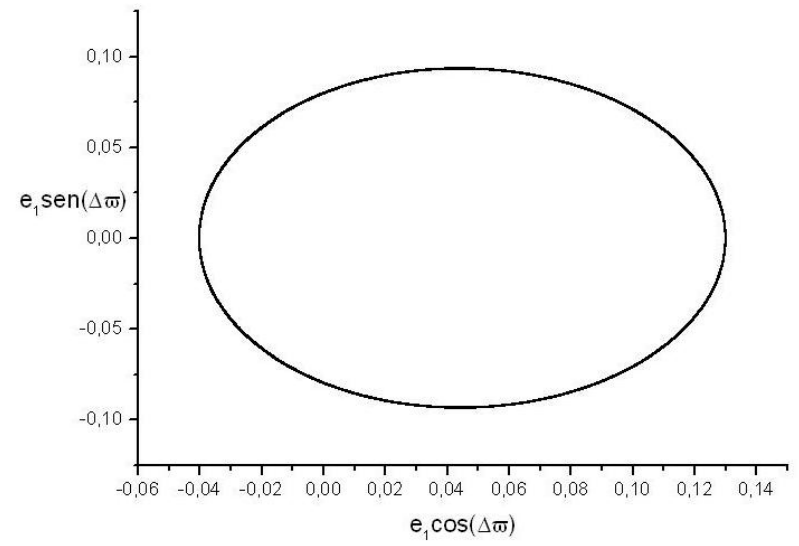

Figura B.76: KH de $e_{1}$ para HD $69830 \mathrm{~cd}$

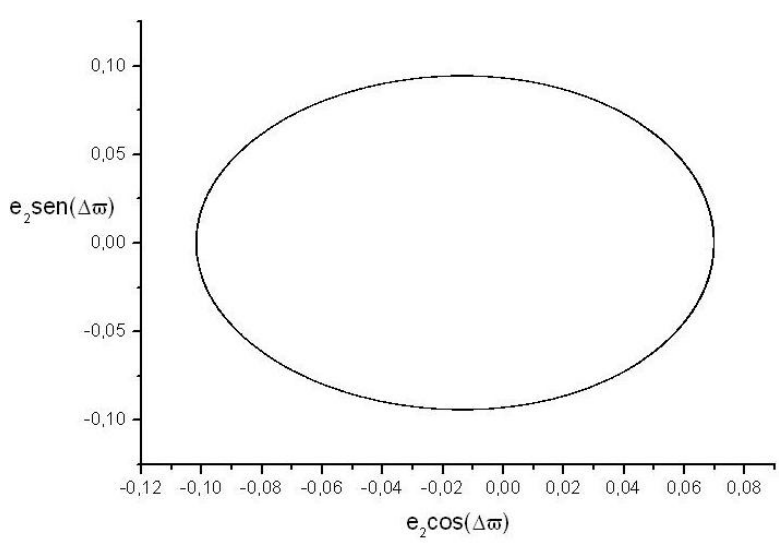

Figura B.77: KH de $e_{2}$ para HD $69830 \mathrm{~cd}$ 


\section{B.2.12 HD 177830 bc}

O tempo de simulação para o sistema HD 177830 bc foi de 200 mil anos. Trata-se de um sistema secular, Classe II. O movimento do ângulo $\Delta \varpi$ é circulatório retrógrado. Seu período secular é de aproximadamente 4.085 anos.

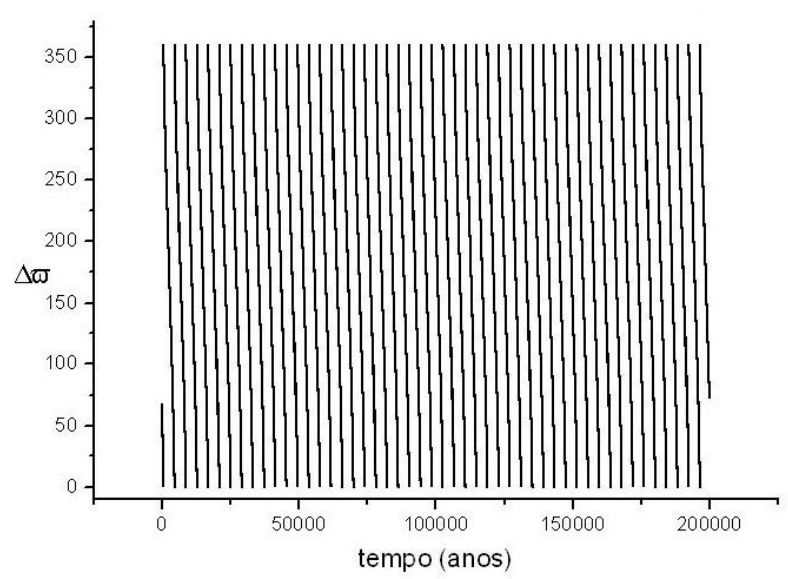

Figura B.78: Ângulo $\Delta \varpi$ em função do tempo para HD 177830 bc

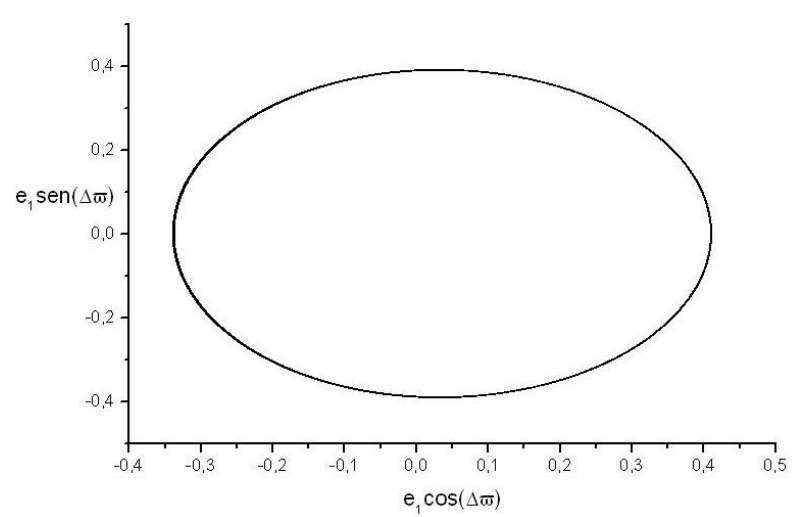

Figura B.80: KH de $e_{1}$ para HD 177830 bc

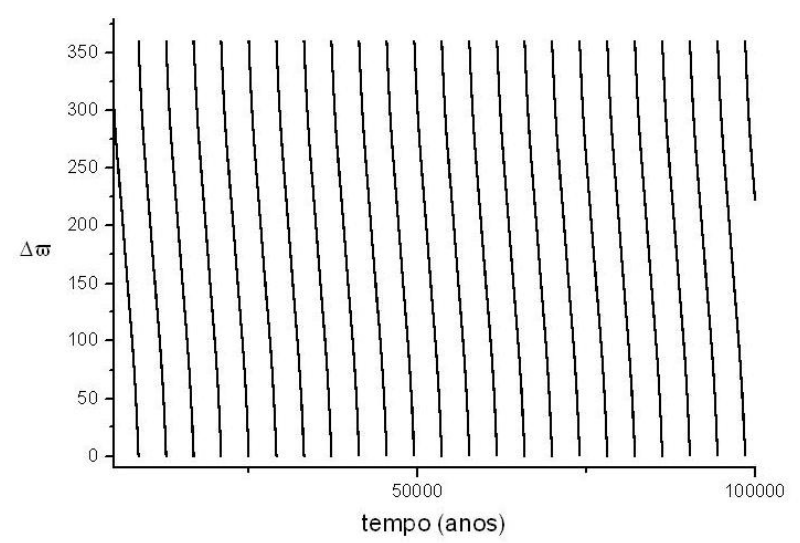

Figura B.79: Zoom do ângulo $\Delta \varpi$ em função do tempo para HD 177830 bc

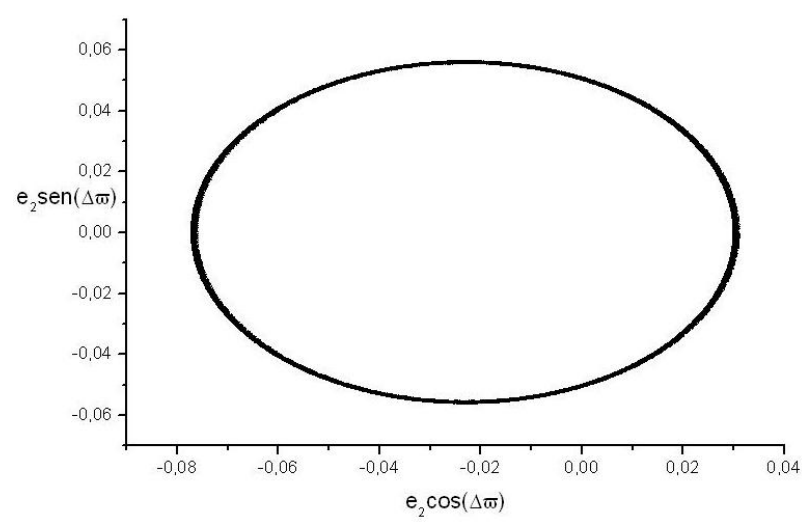

Figura B.81: KH de $e_{2}$ para HD 177830 bc 


\section{B.2.13 HD 183263 bc}

A primeira simulação feita para o sistema HD 183263 bc teve como fonte de referência o catálogo da OSPBM. Tais dados, porém, resultaram em uma simulação com configuração instável a partir de 380.430 anos.

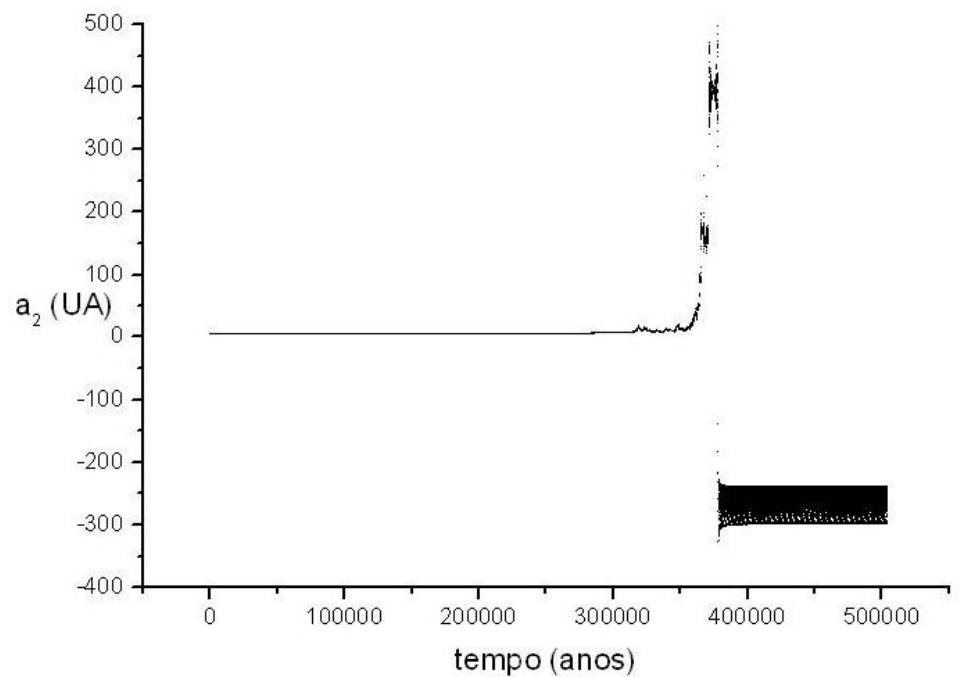

Figura B.82: Semi-eixo maior de HD 183263 c em função do tempo

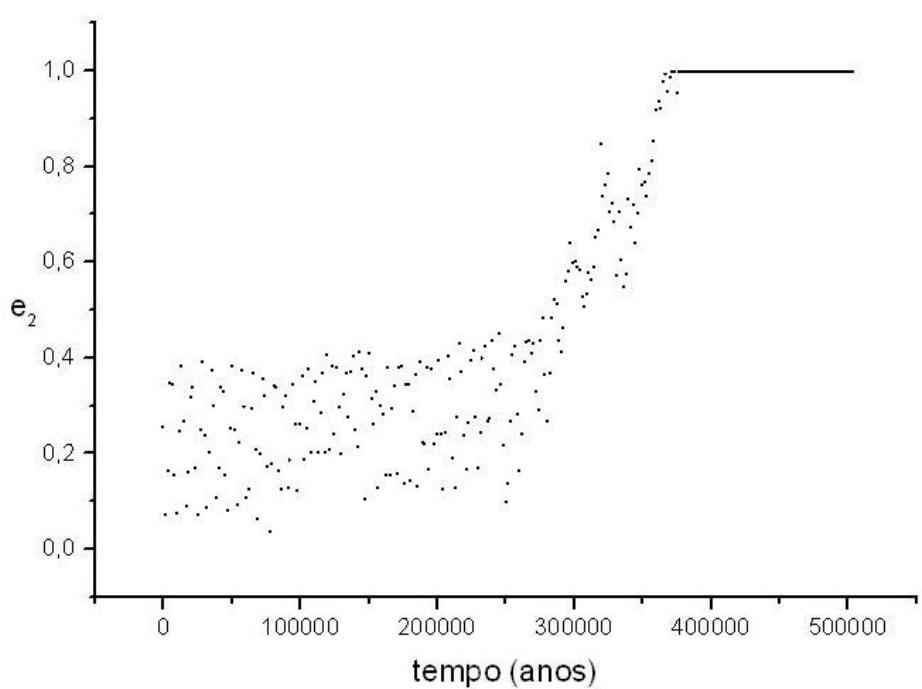

Figura B.83: Excentricidade de HD 183263 c em função do tempo 
Para os dados do sistema HD 183263 bc o catálogo da OSBPM cita (Wright et al., 2009). Utilizando os dados diretamente do artigo, a simulação resultou estável. Trata-se de um sistema secular, Classe II. O movimento do ângulo $\Delta \varpi$ é oscilatório em torno de $180^{\circ}$. Seu período secular é de aproximadamente 6.896 anos.

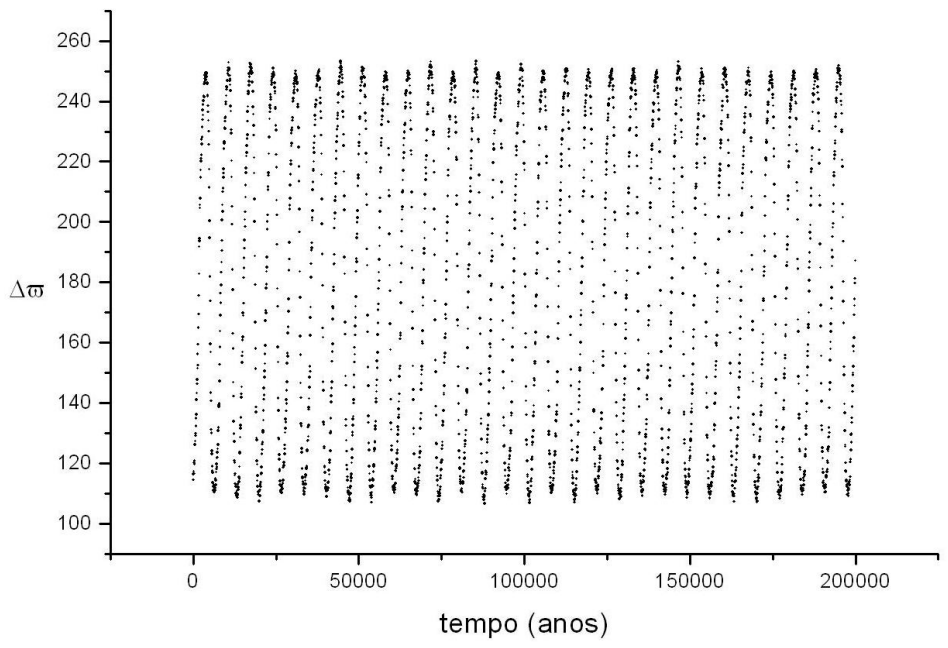

Figura B.84: Ângulo $\Delta \varpi$ em função do tempo para HD 183263 bc

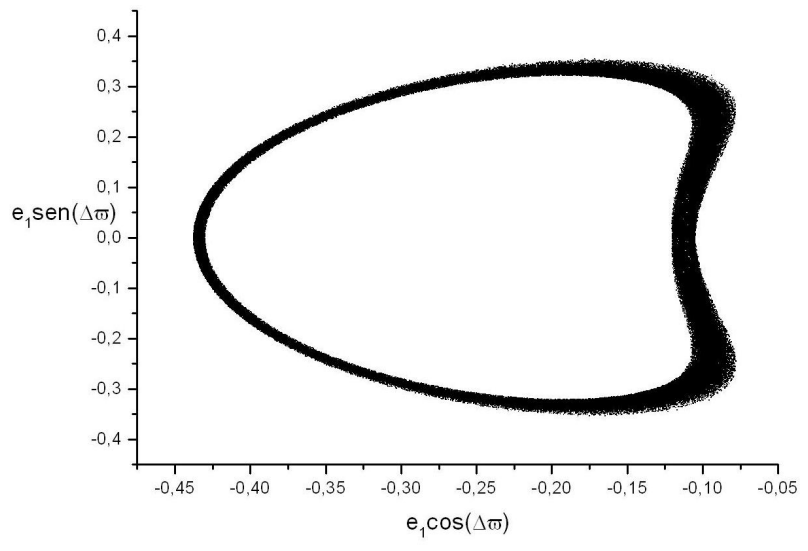

Figura B.85: KH de $e_{1}$ para HD 183263 bc

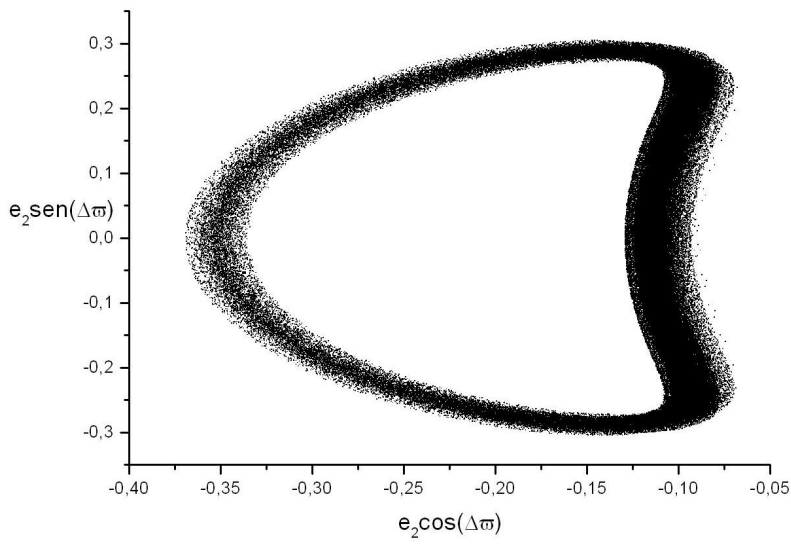

Figura B.86: KH de $e_{2}$ para HD 183263 bc 
Utilizando o método de médias adjacentes, com 50 pontos, obtém-se dados mais precisos de $\mathrm{KH}$ de $e_{2}$ para o sistema HD 183263 bc:

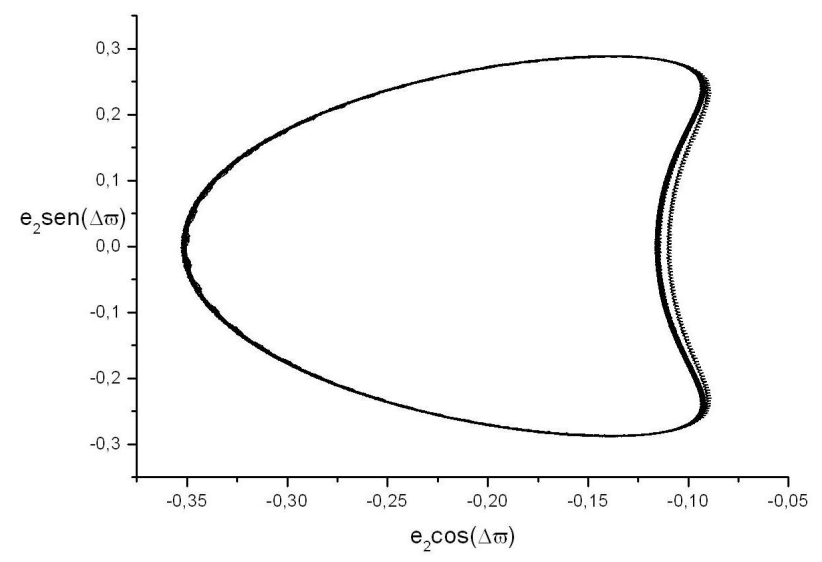

Figura B.87: KH de $e_{2}$ para HD 183263 bc com filtro

\section{B.2.14 HD 202206 bc}

Duas simulações iniciais foram feitas para o sistema HD 202206 bc, tendo como referência (Raymond et al., 2008) e (Correia et al., 2005). As duas simulações resultaram em sistemas de configurações instáveis. Uma terceira simulação, feita com dados recalculados por Marcos Tadeu, mostrou-se estável.

Na simulação com dados de (Raymond et al., 2008), o semi-eixo maior de HD 202206 c assume valores grandes em torno de 1460 anos de simulação:

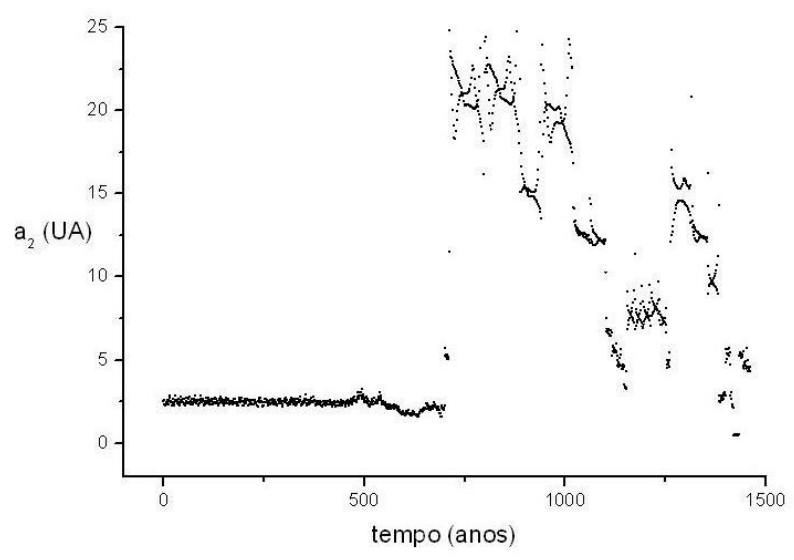

Figura B.88: Semi-eixo maior de HD 202206 c em função do tempo 
Já na simulação com os dados de (Correia et al., 2005), o semi-eixo maior de HD 202206 c adquire valores grandes a partir de aproximadamente 10 mil anos de simulação e a excentricidade do mesmo planeta para esta simulação oscila consideravelmente, até atingir valores compatíveis com os valores da excentricidade de um cometa:

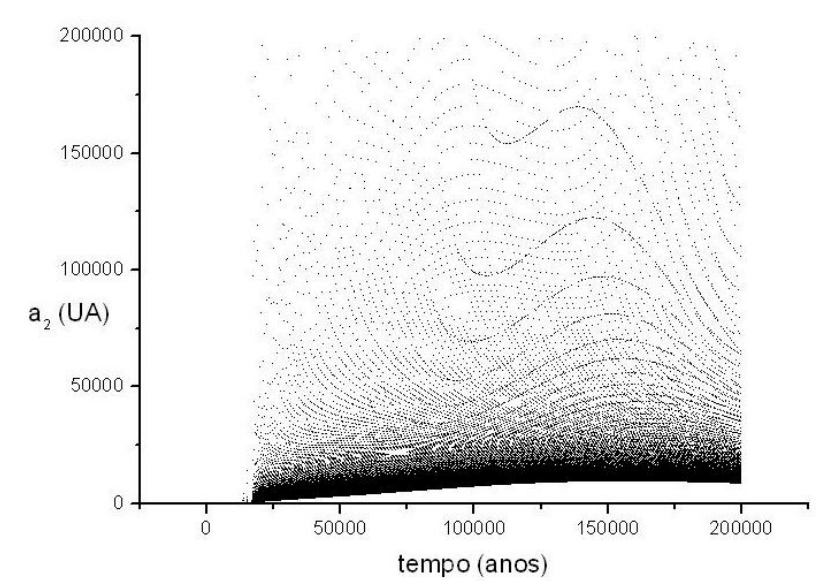

Figura B.89: Semi-eixo maior de HD 202206 c em função do tempo

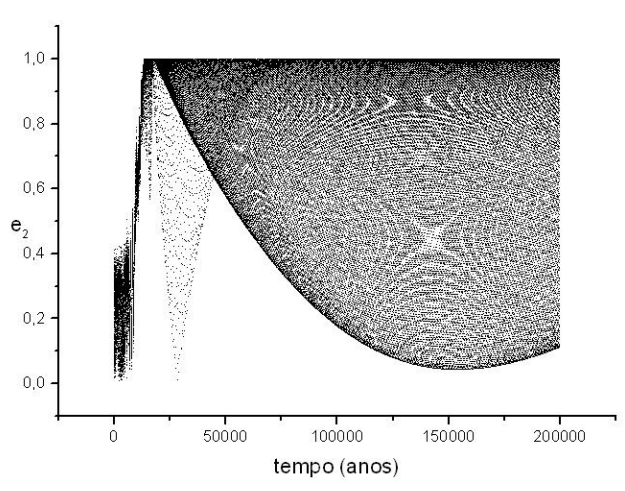

Figura B.90: Excentricidade de HD 202206 c em função do tempo

Para os valores recalculados por Marcos Tadeu, foi possível simular o sistema HD 202206 bc e obter um configuração estável durante 200 mil anos. Este sistema classifica-se como secular, Classe II. O movimento do ângulo $\Delta \varpi$ é circulatório prógrado. Seu período secular é de aproximadamente 436 anos.

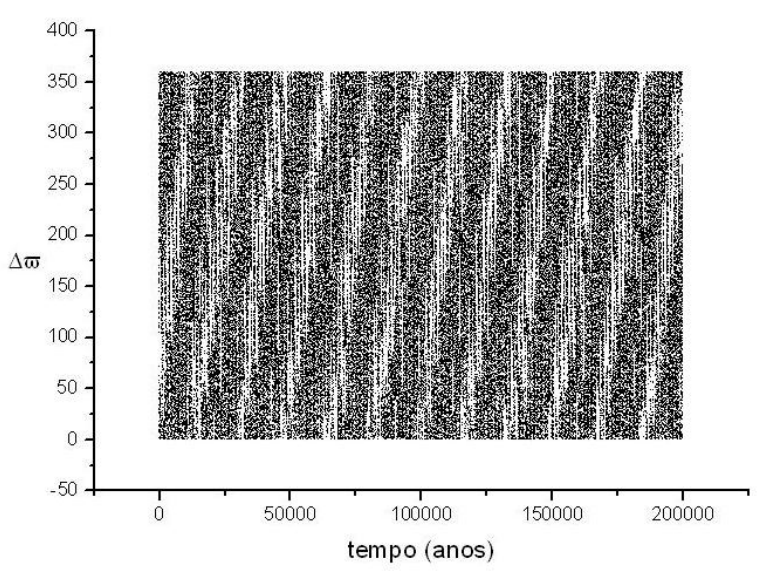

Figura B.91: Ângulo $\Delta \varpi$ em função do tempo para HD 202206 bc

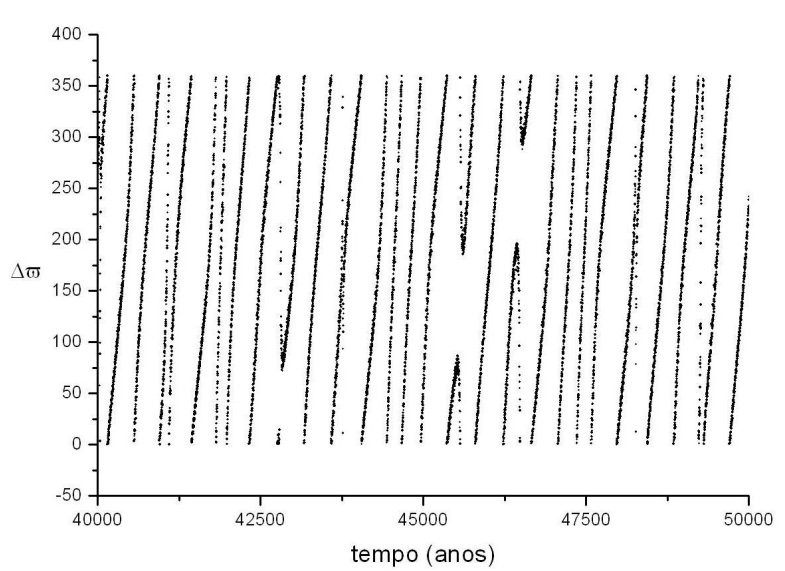

Figura B.92: Zoom do ângulo $\Delta \varpi$ em função do tempo para HD 202206 bc

A filtragem faz-se necessárias para inferir os valores do gráfico de $\mathrm{KH}$ de $e_{2}$. Como o período secular do ângulo $\Delta \varpi$ tem valor próximo de anos, limitando a banda de filtragem 


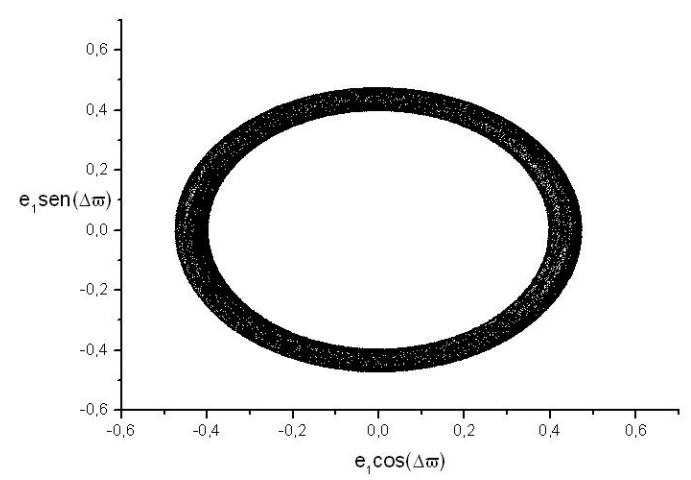

Figura B.93: $\mathrm{KH}$ de $e_{1}$ para HD 202206 bc com dados de Marcos Tadeu

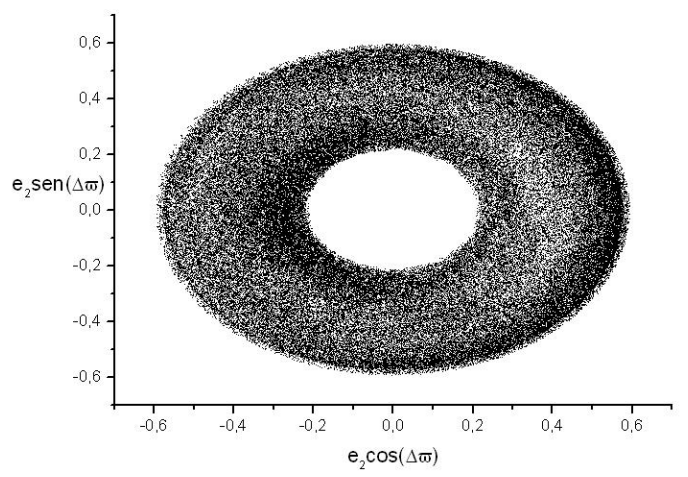

Figura B.94: $\mathrm{KH}$ de $e_{2}$ para HD 202206 bc com dados de Marcos Tadeu

entre 0,002272 1/ano (440 anos) e 0,002325 1/ano (430 anos), o gráfico de KH de $e_{2}$ assume forma mais adequada à obtenção dos valores de $e_{2}$ mínimo e máximo.

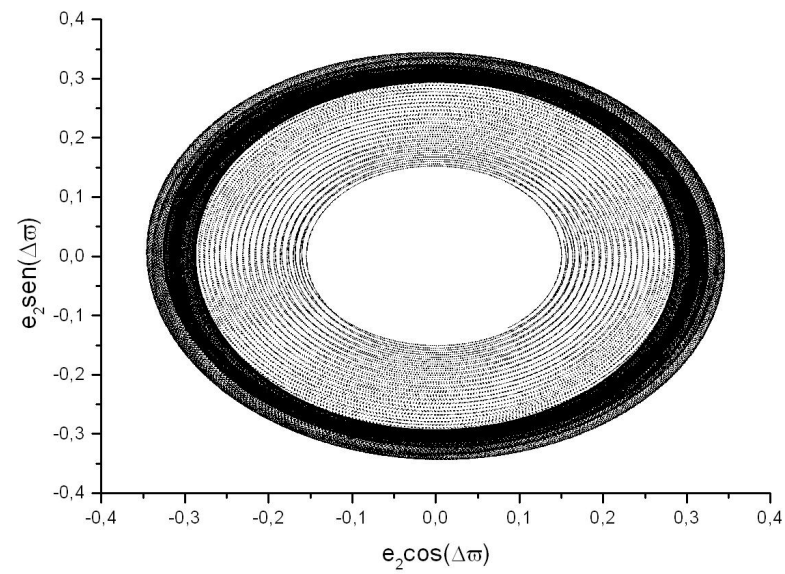

Figura B.95: KH de $e_{2}$ para HD 202206 bc com dados de Marcos Tadeu - filtro 430 a 440 anos 


\section{B.2.15 v Andrômeda cd}

O tempo de simulação para o sistema $v$ Andrômeda cd (Úpsilon Andromeda cd) foi de 200 mil anos. Trata-se de um sistema secular, Classe II. O movimento do ângulo $\Delta \varpi$ é circulatório retrógrado. Seu período secular é de aproximadamente 7.477 anos.

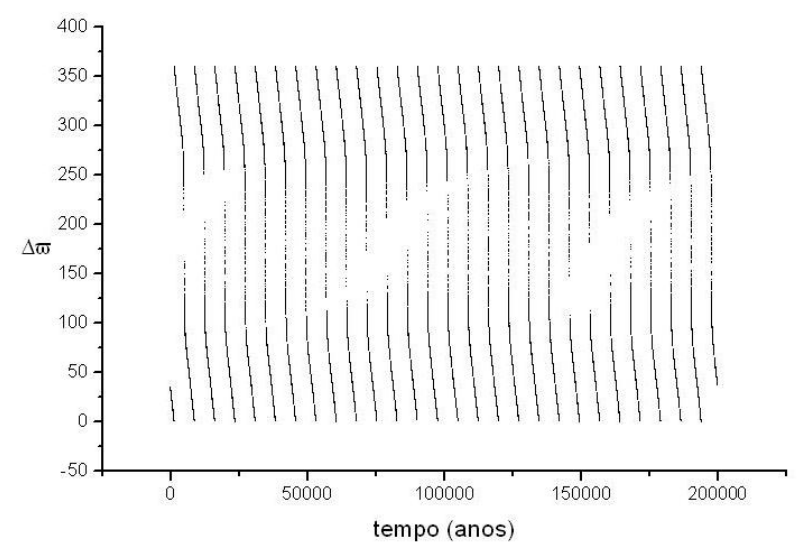

Figura B.96: Ângulo $\Delta \varpi$ em função do tempo para $v$ Andrômeda cd

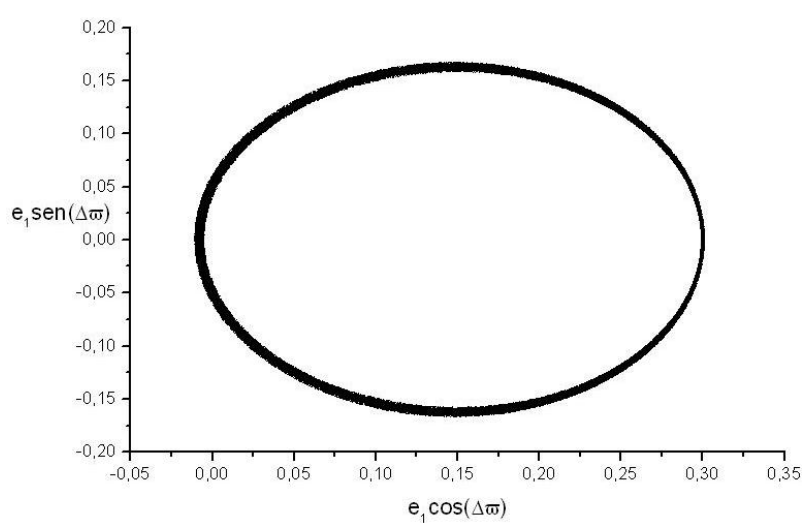

Figura B.97: KH de $e_{1}$ para $v$ Andrômeda cd

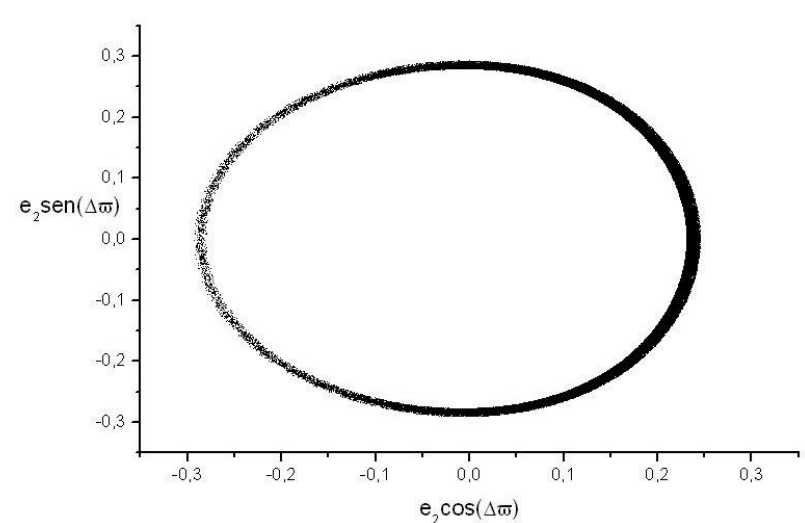

Figura B.98: KH de $e_{2}$ para $v$ Andrômeda cd 


\section{B.2.16 HD 12661 bc}

O tempo de simulação para o sistema HD 12661 bc foi de 200 mil anos. Trata-se de um sistema secular, Classe II. O movimento do ângulo $\Delta \varpi$ é oscilatório em torno de $180^{\circ}$. Seu período secular é de aproximadamente 26.205 anos.

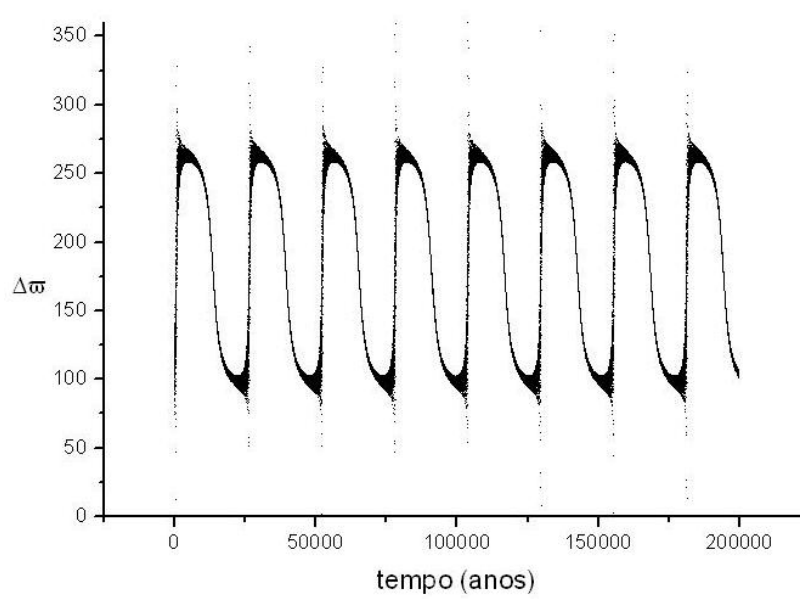

Figura B.99: Ângulo $\Delta \varpi$ em função do tempo para HD 12661 bc

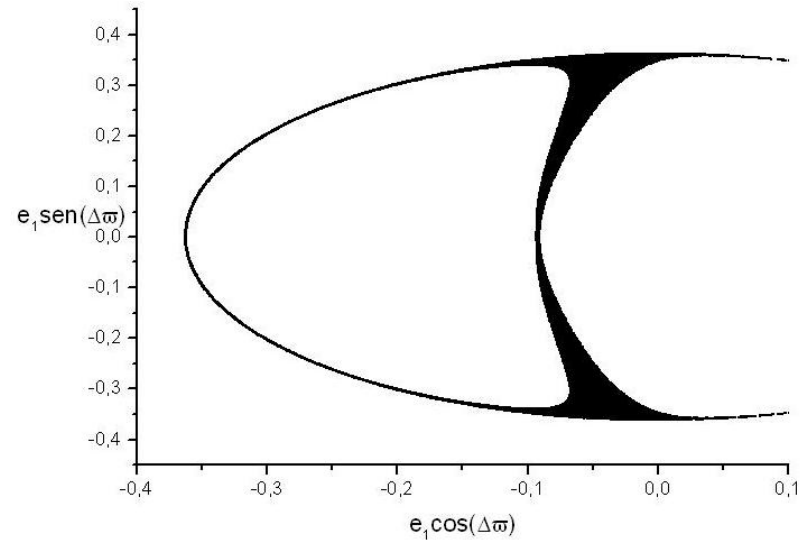

Figura B.100: KH de $e_{1}$ para HD 12661 bc

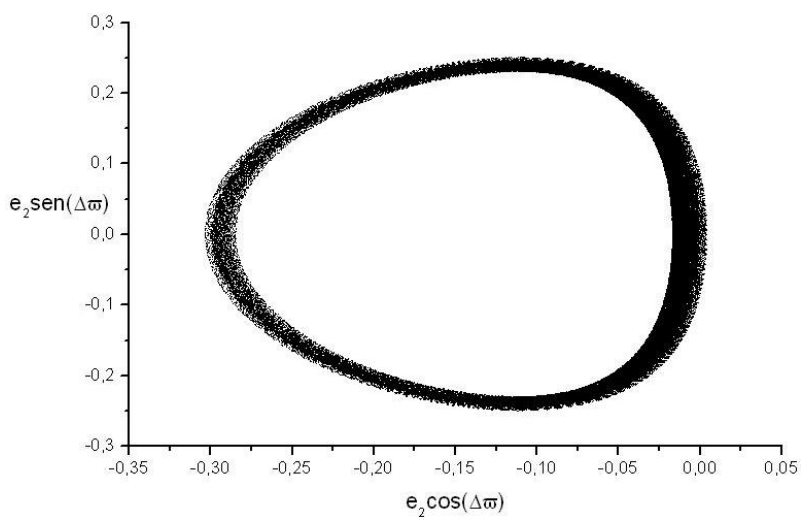

Figura B.101: KH de $e_{2}$ para HD 12661 bc 


\section{B.2.17 HD 74156 bd}

O tempo de simulação para o sistema HD 74156 bd foi de 200 mil anos. Trata-se de um sistema secular, Classe II. O movimento do ângulo $\Delta \varpi$ é oscilatório em torno de $0^{\circ}$. Seu período secular é de aproximadamente 6.408 anos.

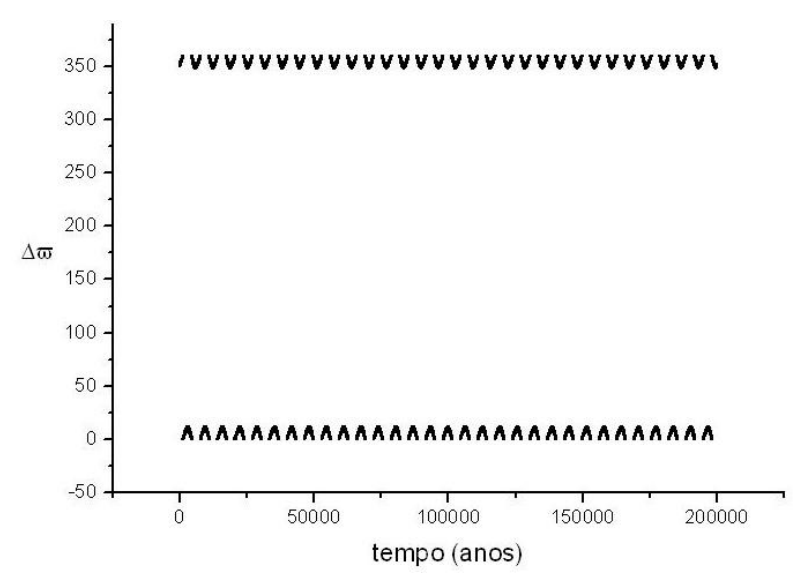

Figura B.102: Ângulo $\Delta \varpi$ em função do tempo para HD 74156 bd

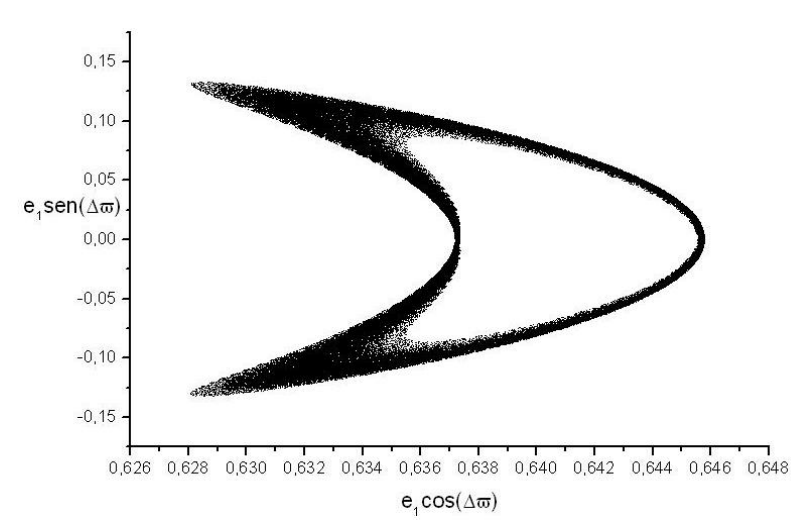

Figura B.103: KH de $e_{1}$ para HD 74156 bd

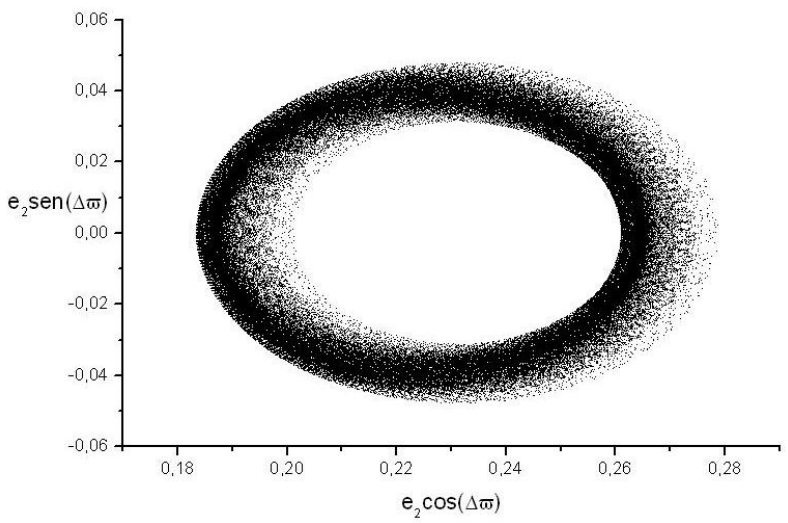

Figura B.104: $\mathrm{KH}$ de $e_{2}$ para HD 74156 bd 
Utilizando o método de médias adjacentes, com 50 pontos, obtém-se dados mais precisos de $\mathrm{KH}$ de $e_{1}$ e $e_{2}$ para o sistema HD 74156 bd:

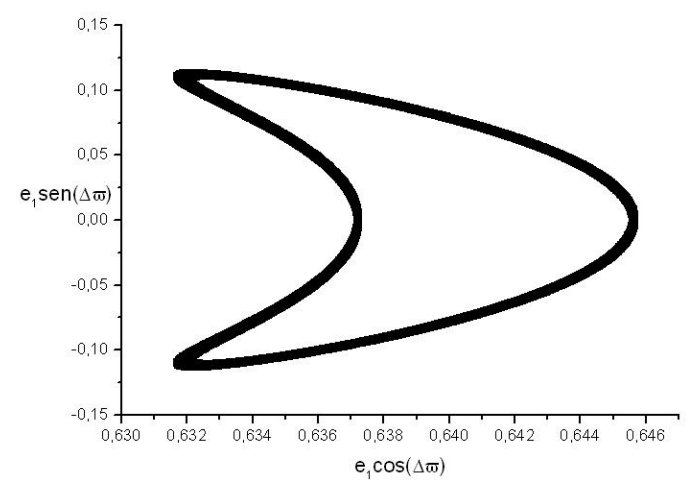

Figura B.105: KH de $e_{1}$ para HD 74156 bd com filtro

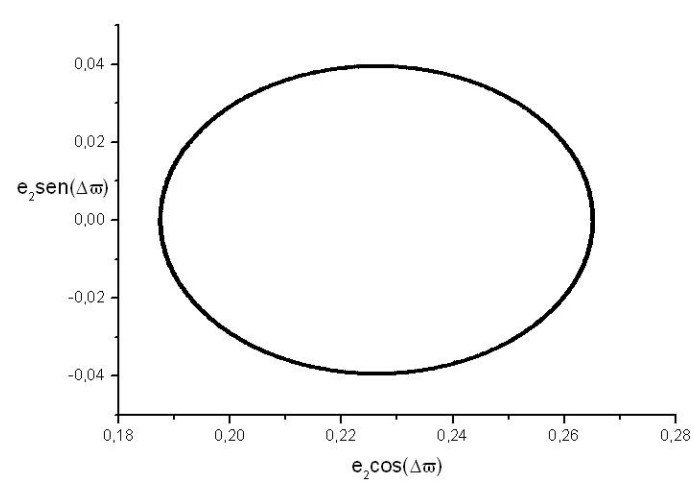

Figura B.106: $\mathrm{KH}$ de $e_{2}$ para HD 74156 bd com filtro 


\section{B.2.18 HIP $14810 \mathrm{~cd}$}

O tempo de simulação para o sistema HIP $14810 \mathrm{~cd}$ foi de 200 mil anos. Trata-se de um sistema secular, Classe II. O movimento do ângulo $\Delta \varpi$ é oscilatório em torno de $0^{\circ}$. Seu período secular é de aproximadamente 24.210 anos.

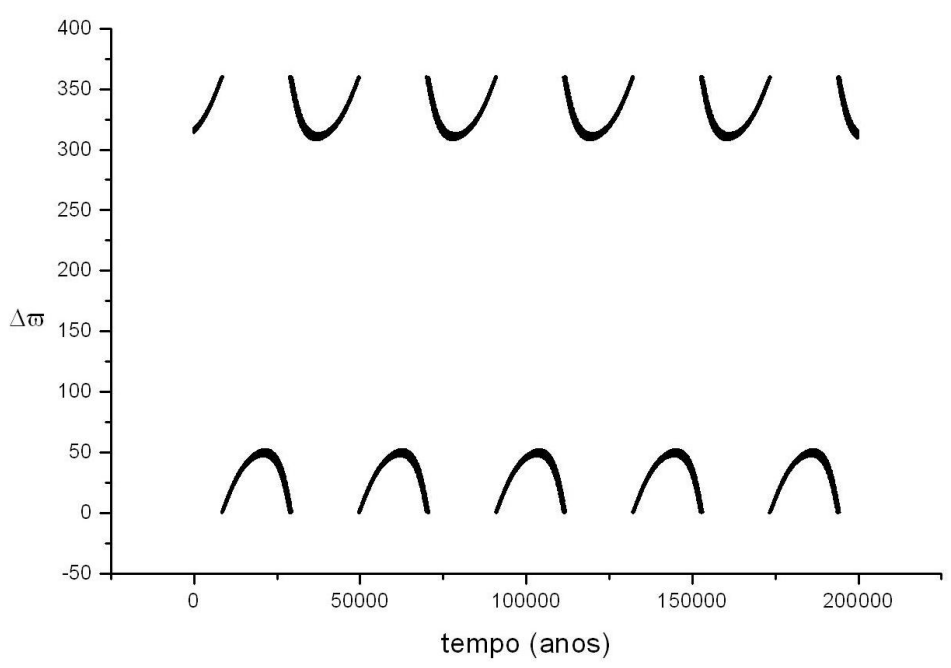

Figura B.107: Ângulo $\Delta \varpi$ em função do tempo para HIP $14810 \mathrm{~cd}$

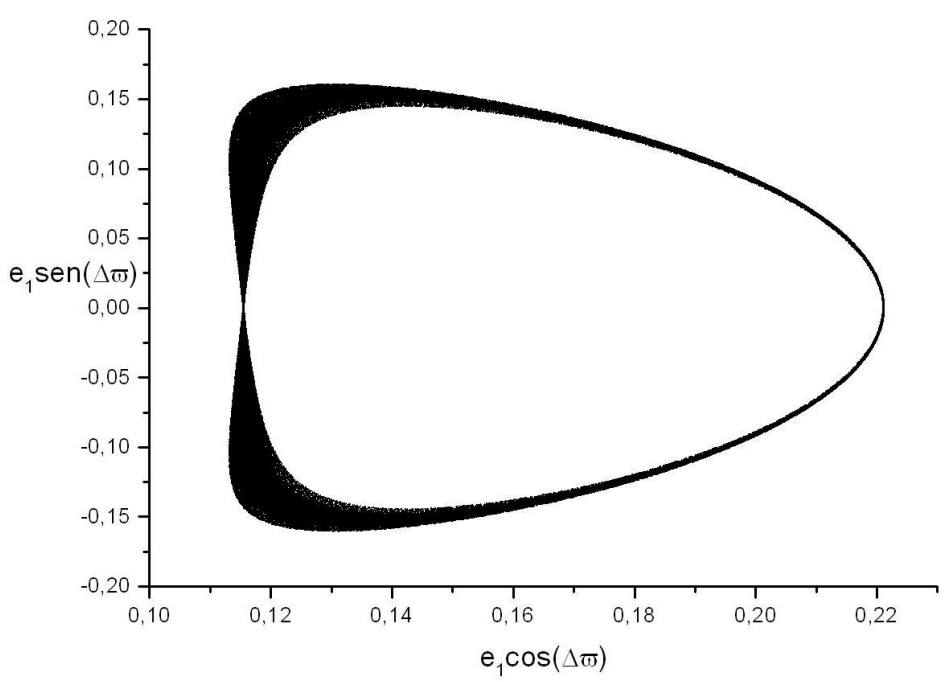

Figura B.108: KH de $e_{1}$ para HIP $14810 \mathrm{~cd}$ 


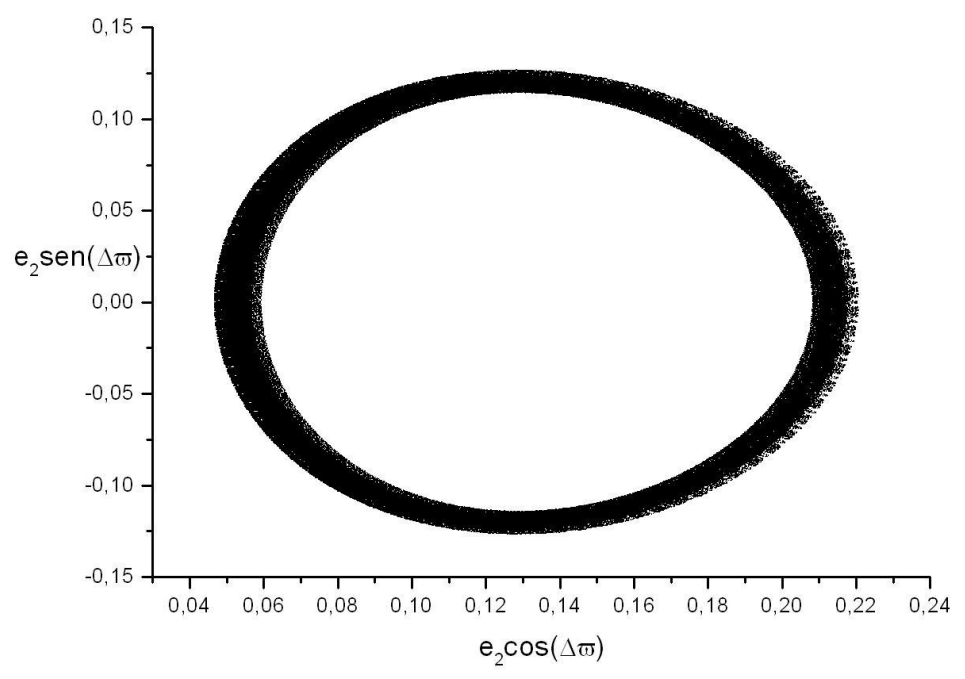

Figura B.109: KH de $e_{2}$ para HIP $14810 \mathrm{~cd}$

O método de médias adjacentes, com 50 pontos, para se obter dados mais precisos de $\mathrm{KH}$, é necessário neste sistema, somente para $e_{2}$ :

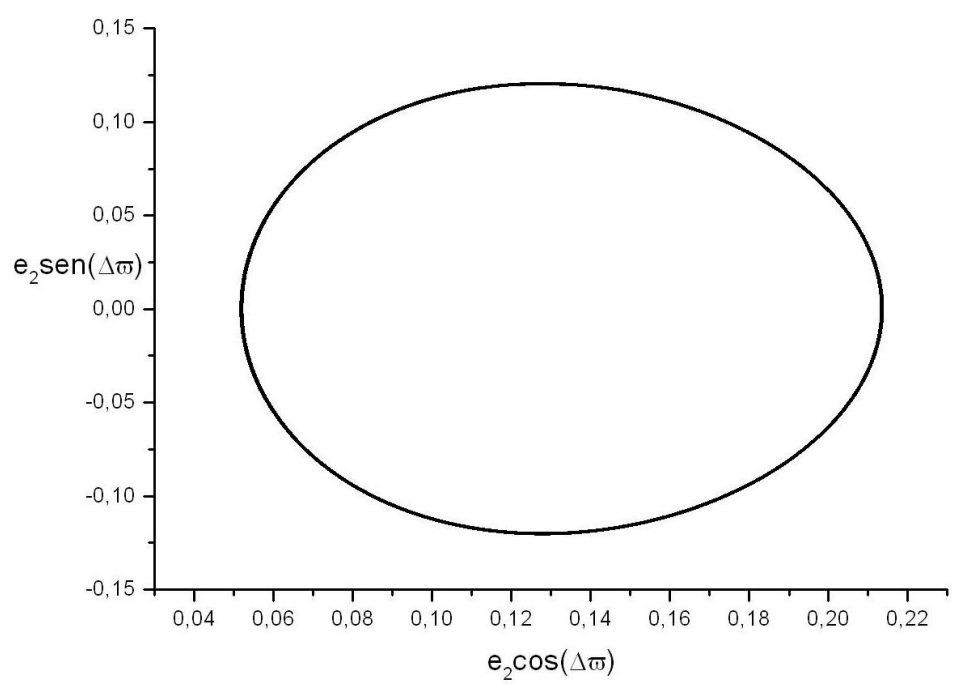

Figura B.110: KH de $e_{2}$ para HIP $14810 \mathrm{~cd}$ com filtro 


\section{B.3 Classe III - hierárquicos}

\section{B.3.1 HD 181433 bc}

O tempo de simulação para o sistema HD 181433 bc foi de 5,09 milhões de anos. Trata-se de um sistema hierárquico, Classe III. O movimento do ângulo $\Delta \varpi$ é circulatório retrógrado. Seu período secular é de aproximadamente 456.583 anos.

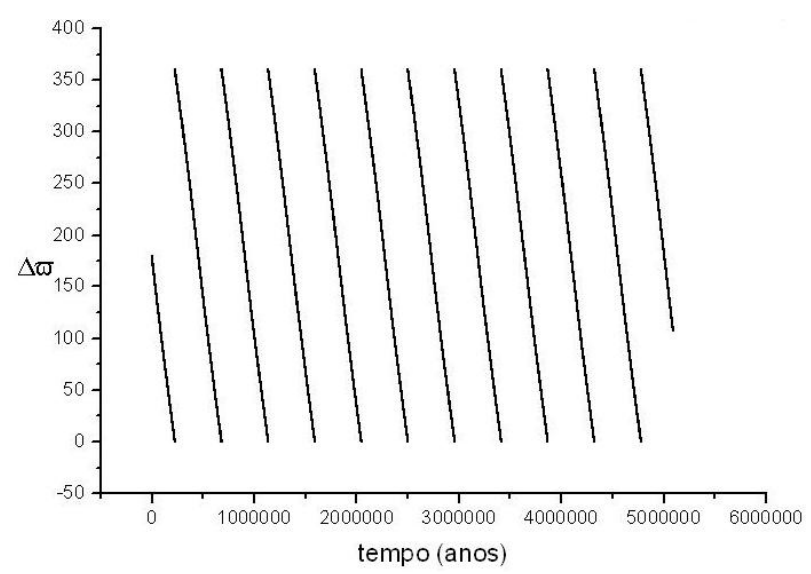

Figura B.111: Ângulo $\Delta \varpi$ em função do tempo para HD 181433 bc

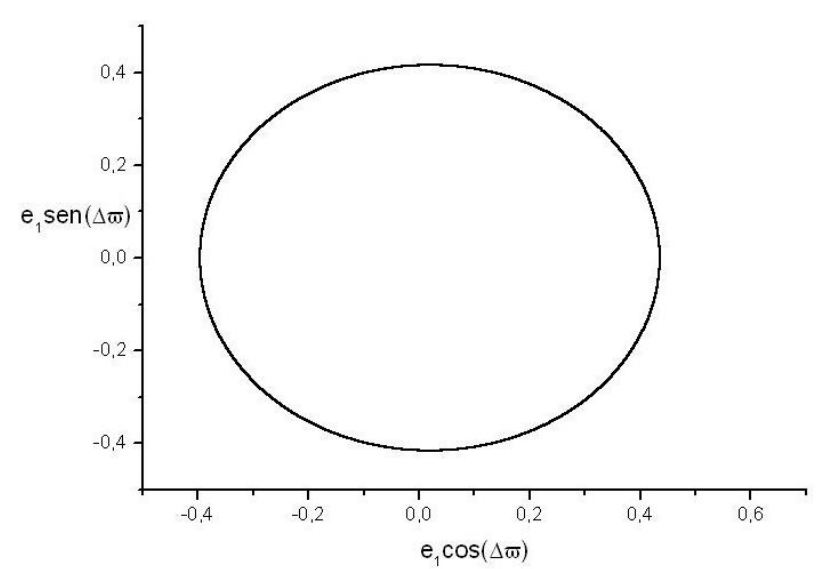

Figura B.112: $\mathrm{KH}$ de $e_{1}$ para HD 181433 bc

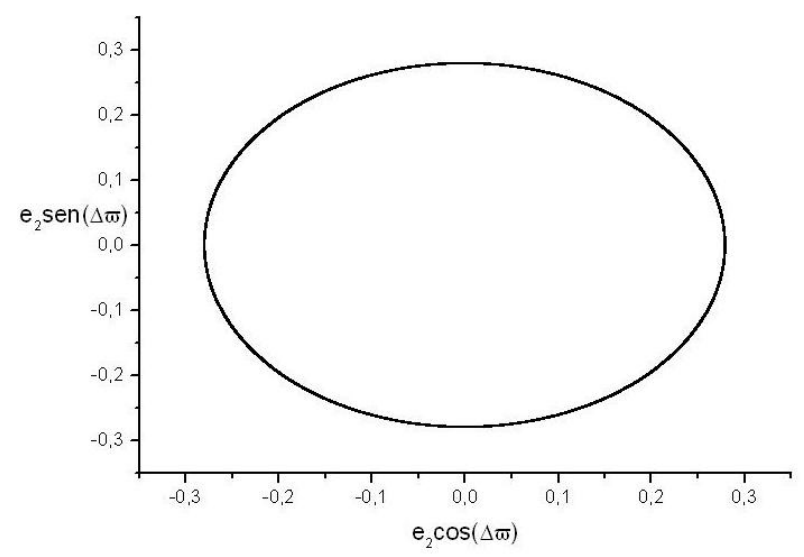

Figura B.113: KH de $e_{2}$ para HD 181433 bc 


\section{B.3.2 v Andrômeda bc}

O tempo de simulação para o sistema $v$ Andrômeda bc (Úpsilon Andrômeda bc) foi de 200 mil anos. Trata-se de um sistema hierárquico, Classe III. O movimento do ângulo $\Delta \varpi$ é circulatório retrógrado. Seu período secular é de aproximadamente 32.600 anos.

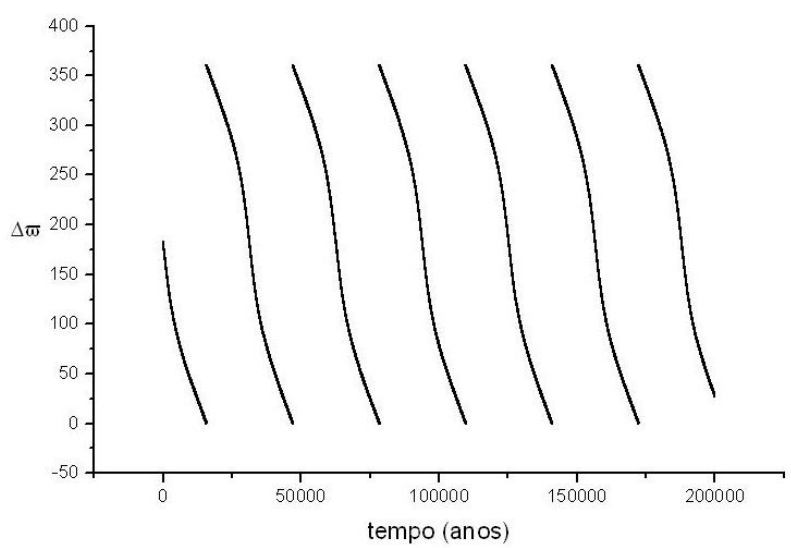

Figura B.114: Ângulo $\Delta \varpi$ em função do tempo para $v$ Andrômeda bc

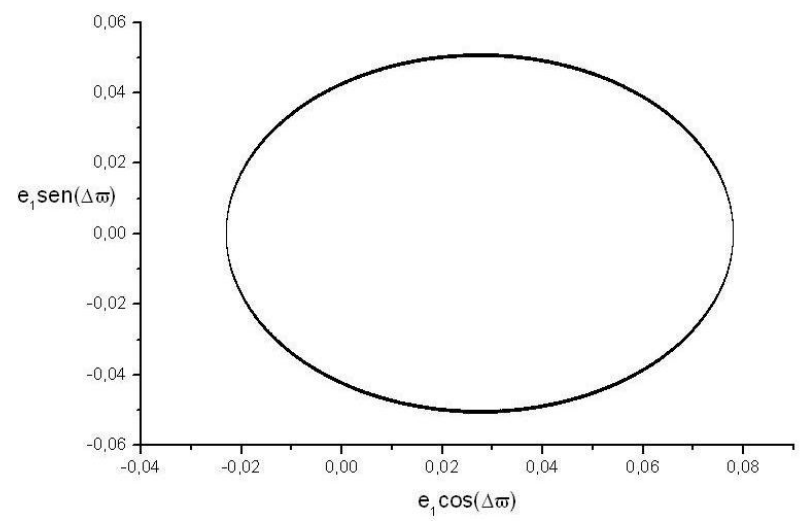

Figura B.115: $\mathrm{KH}$ de $e_{1}$ para $v$ Andrômeda bc

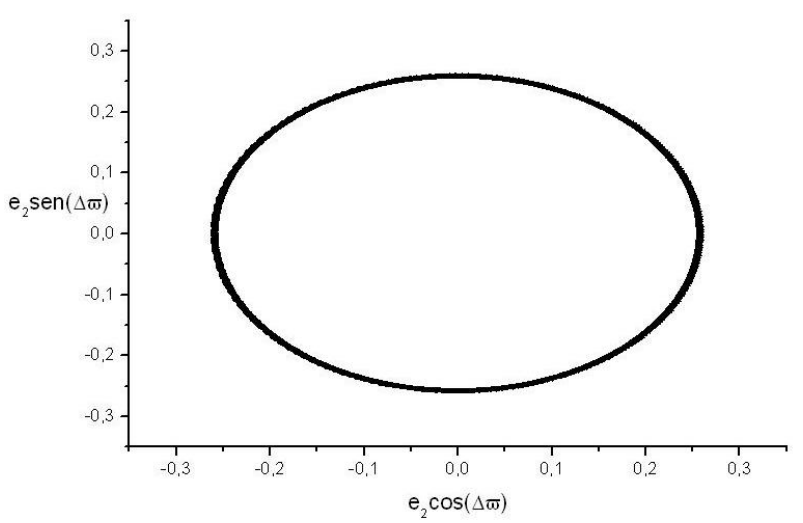

Figura B.116: $\mathrm{KH}$ de $e_{2}$ para $v$ Andrômeda bc 


\section{B.3.3 HD $74156 \mathrm{dc}$}

O tempo de simulação para o sistema HD 74156 dc foi de 200 mil anos. Trata-se de um sistema hierárquico, Classe III. O movimento do ângulo $\Delta \varpi$ é circulatório retrógrado. Seu período secular é de aproximadamente 7.087 anos.

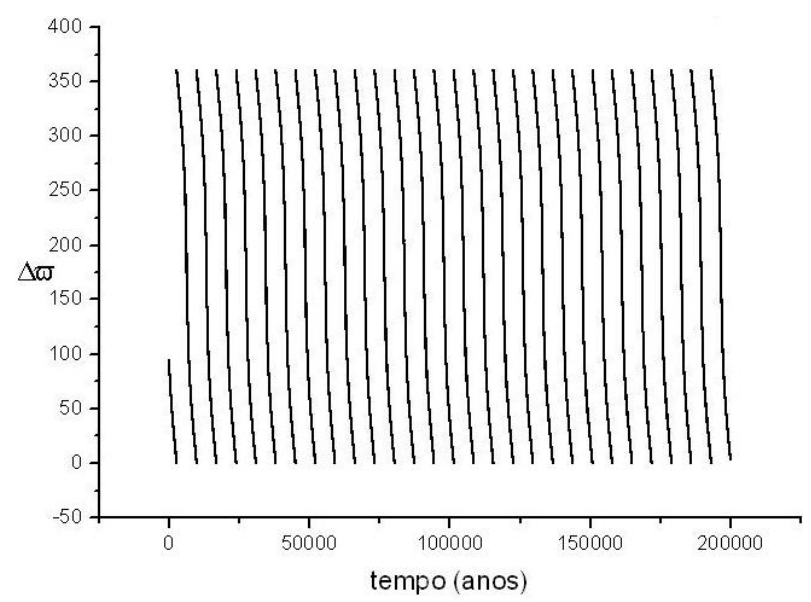

Figura B.117: Ângulo $\Delta \varpi$ em função do tempo para HD 74156 dc

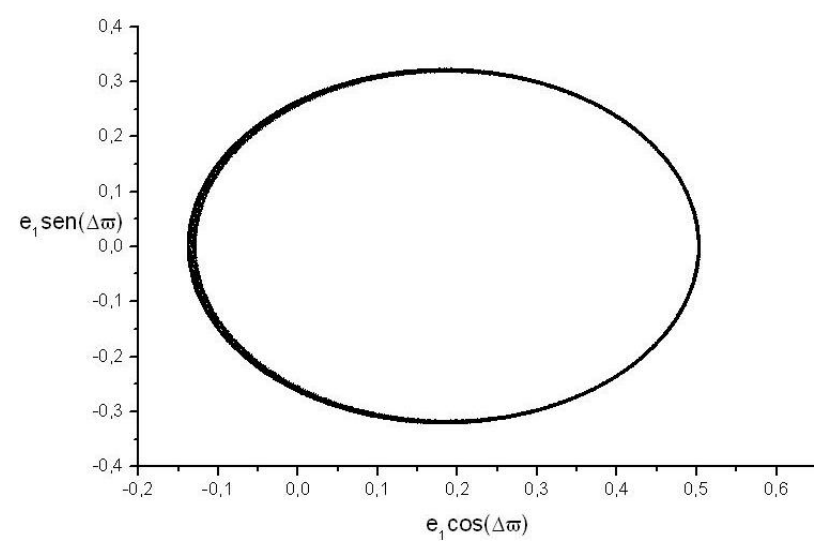

Figura B.118: $\mathrm{KH}$ de $e_{1}$ para HD 74156 dc

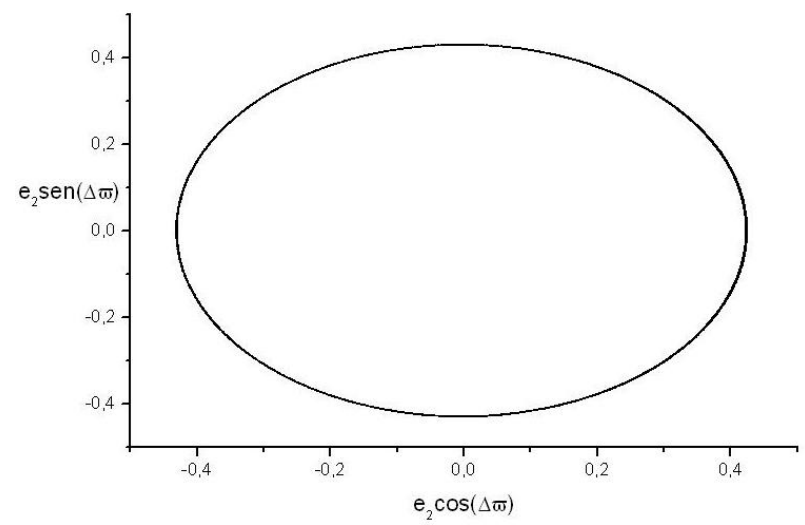

Figura B.119: $\mathrm{KH}$ de $e_{2}$ para HD $74156 \mathrm{dc}$ 


\section{B.3.4 HD $11506 \mathrm{cb}$}

O tempo de simulação para o sistema HD 11506 cb foi de 200 mil anos. Trata-se de um sistema hierárquico, Classe III. O movimento do ângulo $\Delta \varpi$ é circulatório retrógrado. Seu período secular é de aproximadamente 11.880 anos.

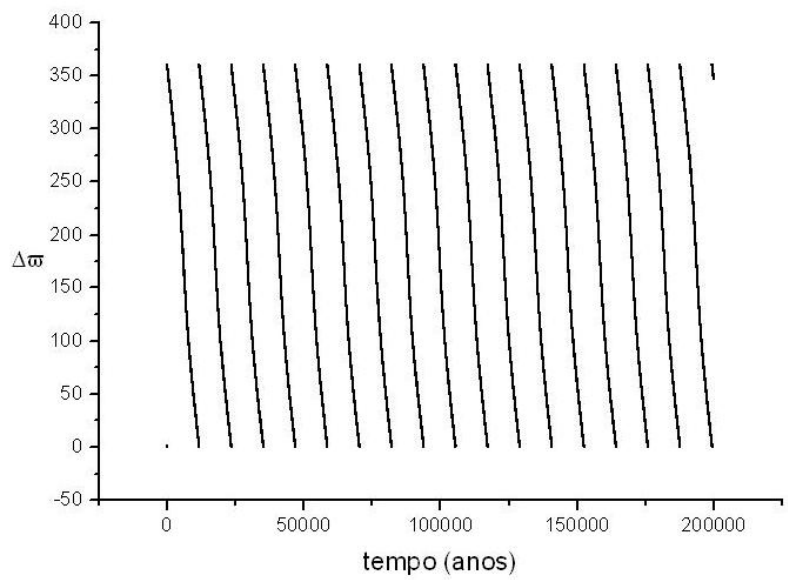

Figura B.120: Ângulo $\Delta \varpi$ em função do tempo para HD 11506 cb

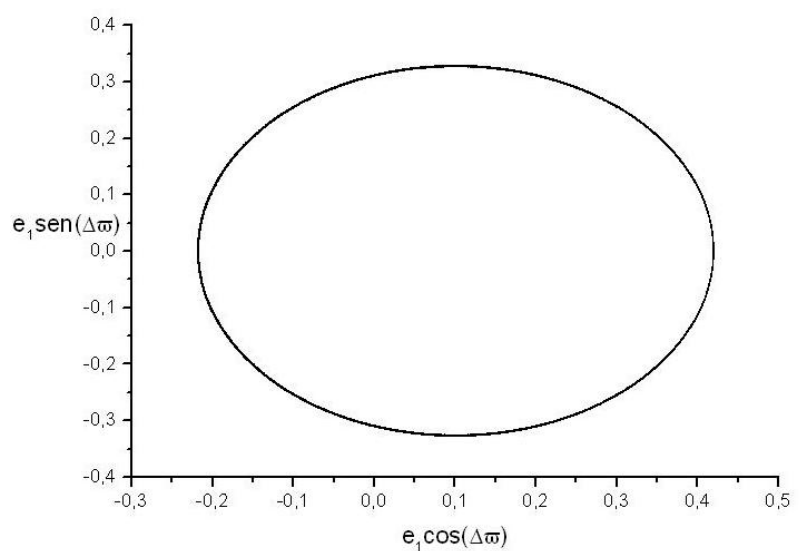

Figura B.121: KH de $e_{1}$ para HD $11506 \mathrm{cb}$

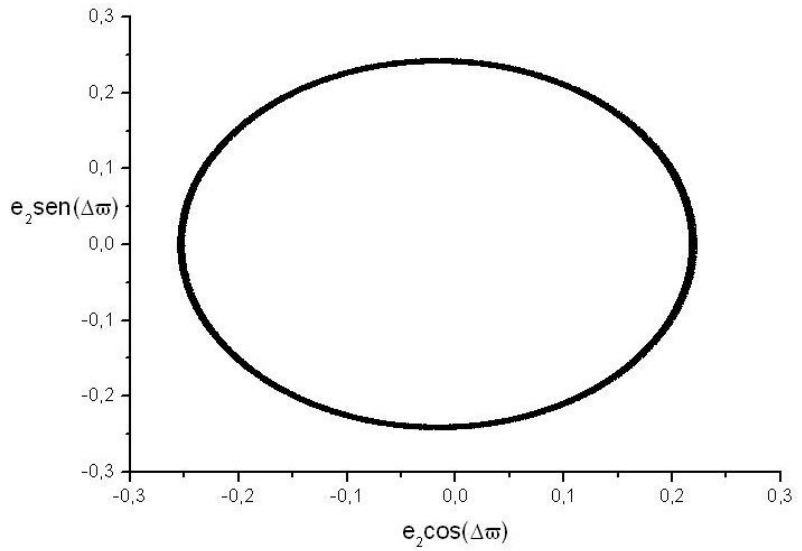

Figura B.122: $\mathrm{KH}$ de $e_{2}$ para HD $11506 \mathrm{cb}$ 


\section{B.3.5 HIP 14810 bc}

O tempo de simulação para o sistema HIP 14810 bc foi de 200 mil anos. Trata-se de um sistema hierárquico, Classe III. O movimento do ângulo $\Delta \varpi$ é oscilatório em torno de $180^{\circ}$. Seu período secular é de aproximadamente 37.766 anos.

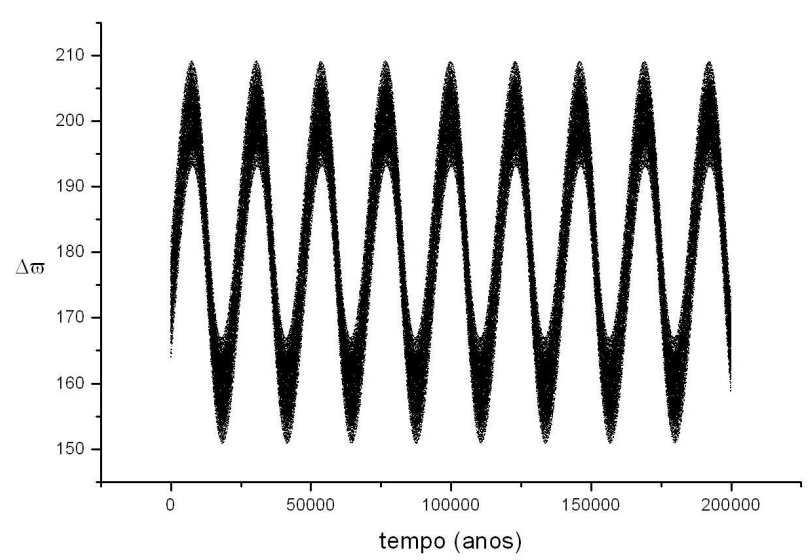

Figura B.123: Ângulo $\Delta \varpi$ em função do tempo para HIP 14810 bc

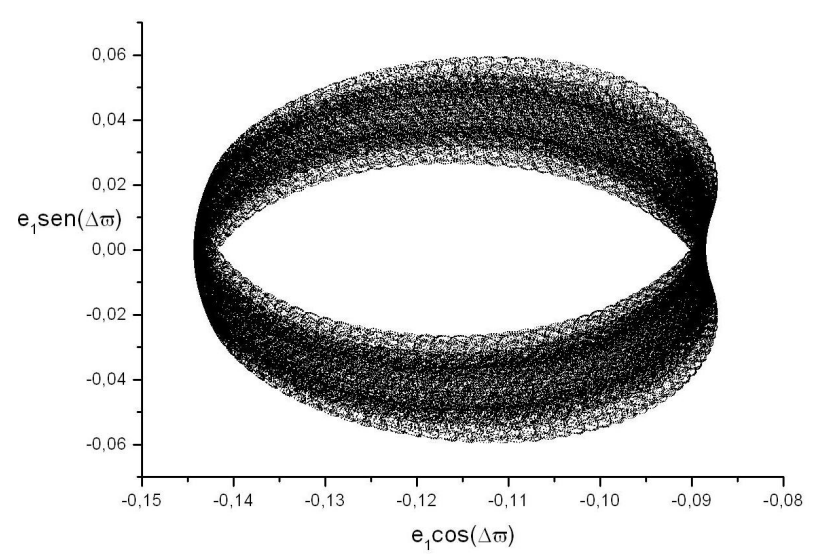

Figura B.124: KH de $e_{1}$ para HIP 14810 bc

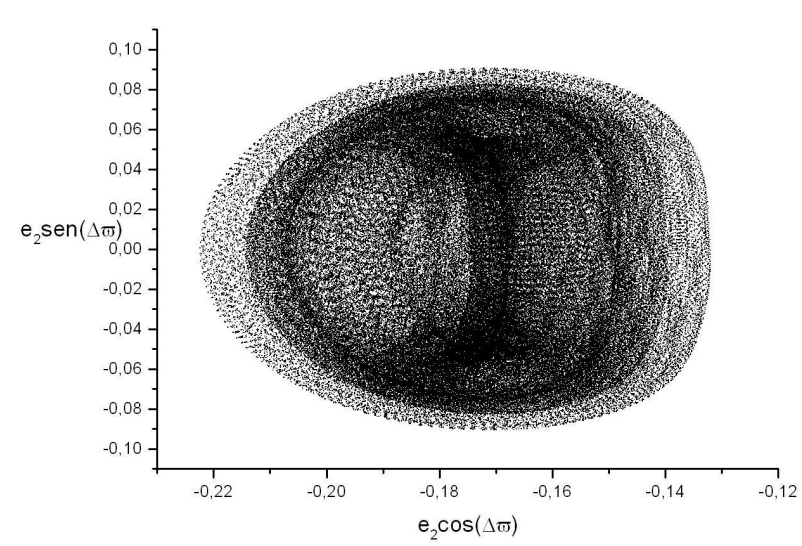

Figura B.125: KH de $e_{2}$ para HIP $14810 \mathrm{bc}$ 
Utilizando o método de médias adjacentes, com 50 pontos, obtém-se dados mais precisos de $\mathrm{KH}$ de $e_{1}$ e $e_{2}$ para o sistema HIP 14810 bc:

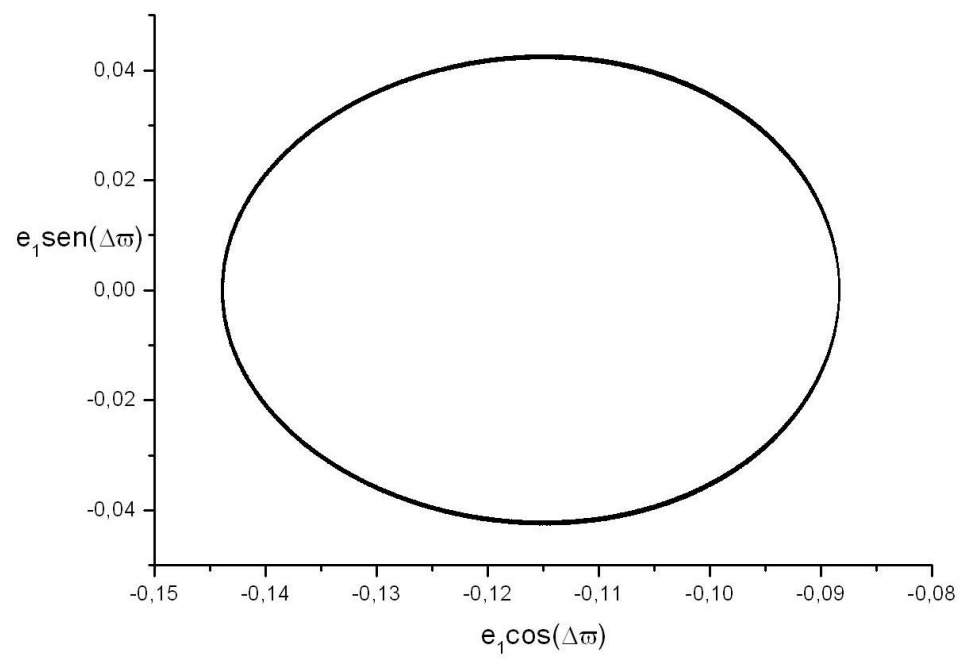

Figura B.126: KH de $e_{1}$ para HIP 14810 bc com filtro

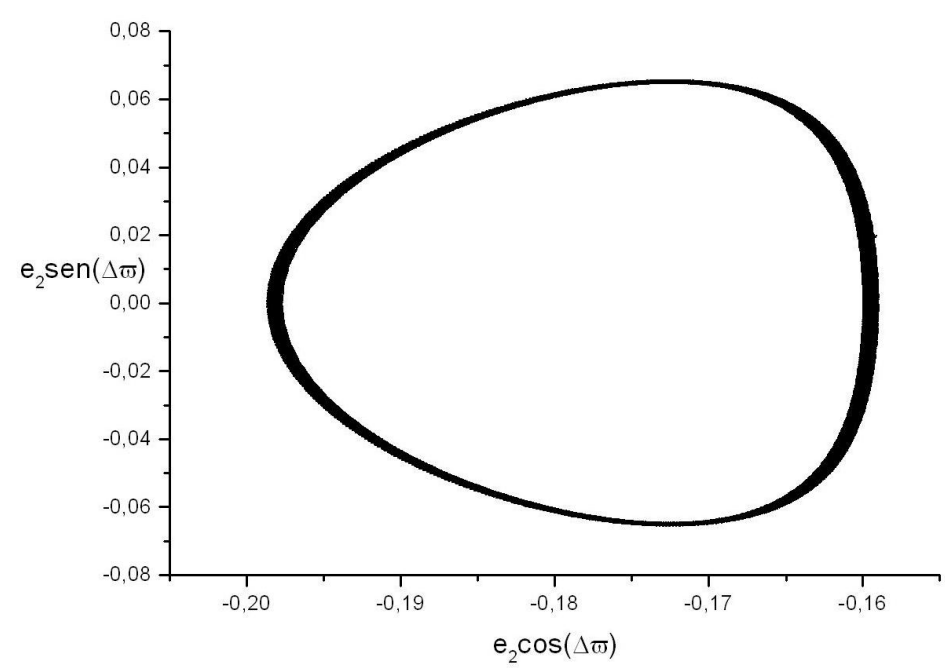

Figura B.127: KH de $e_{2}$ para HIP 14810 bc com filtro 


\section{B.3.6 HD 169830 bc}

O tempo de simulação para o sistema HD 169830 bc foi de 200 mil anos. Trata-se de um sistema hierárquico, Classe III. O movimento do ângulo $\Delta \varpi$ é circulatório retrógrado. Seu período secular é de aproximadamente 37.471 anos.

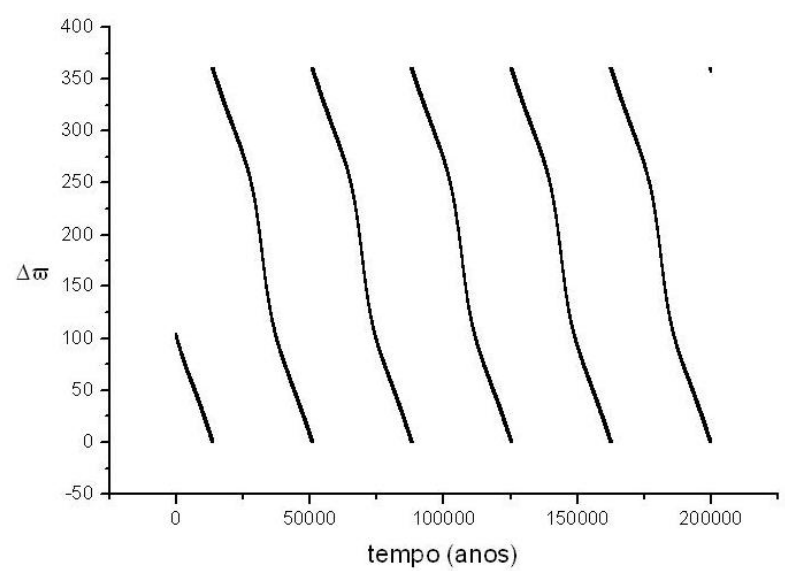

Figura B.128: Ângulo $\Delta \varpi$ em função do tempo para HD 169830 bc

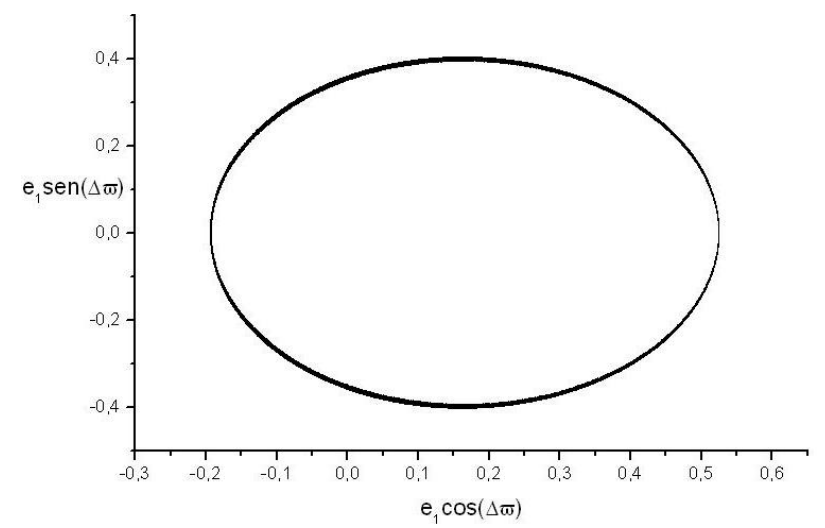

Figura B.129: $\mathrm{KH}$ de $e_{1}$ para HD 169830 bc

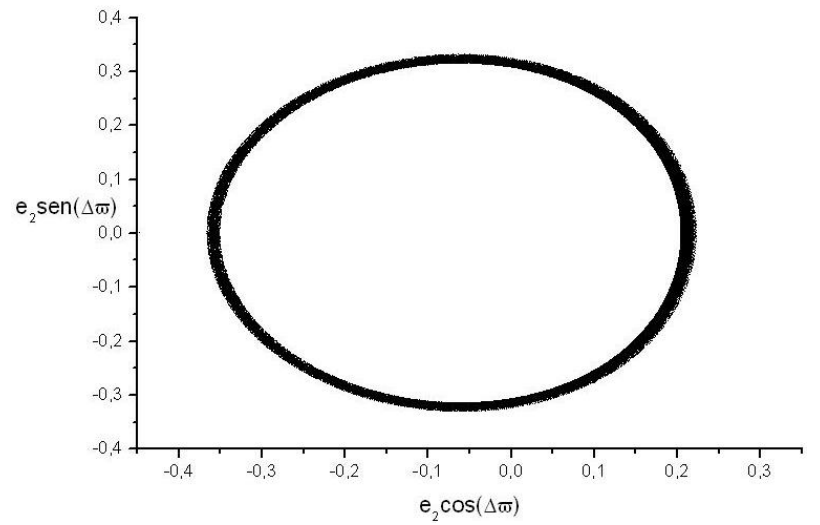

Figura B.130: $\mathrm{KH}$ de $e_{2}$ para HD 169830 bc 


\section{B.3.7 HD 147018 bc}

O tempo de simulação para o sistema HD 147018 bc foi de 200 mil anos. Trata-se de um sistema hierárquico, Classe III. O movimento do ângulo $\Delta \varpi$ é circulatório retrógrado. Seu período secular é de aproximadamente 15.450 anos.

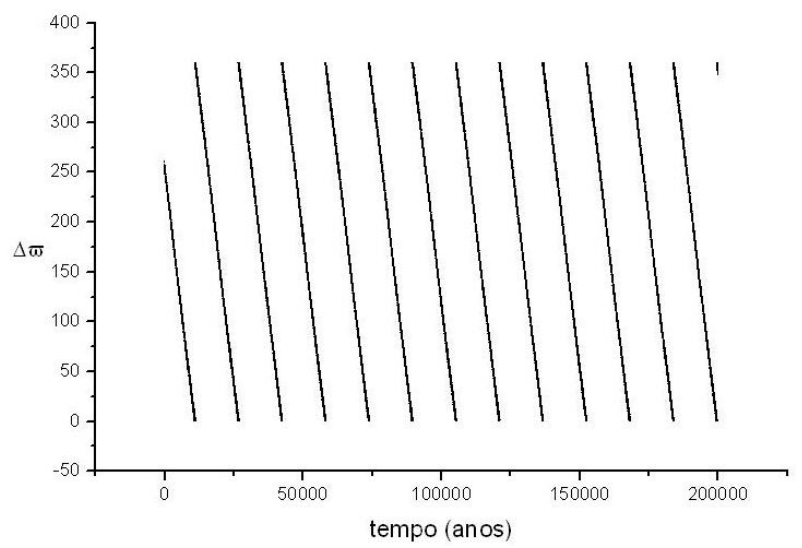

Figura B.131: Ângulo $\Delta \varpi$ em função do tempo para HD 147018 bc

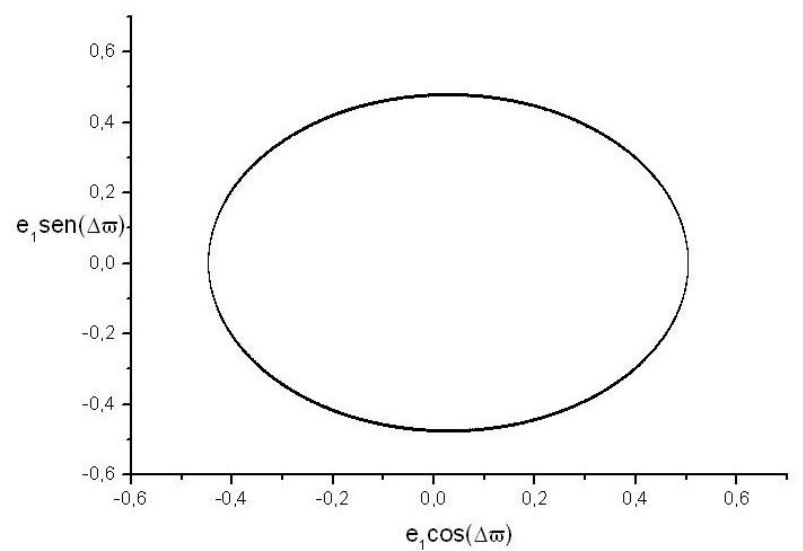

Figura B.132: KH de $e_{1}$ para HD 147018 bc

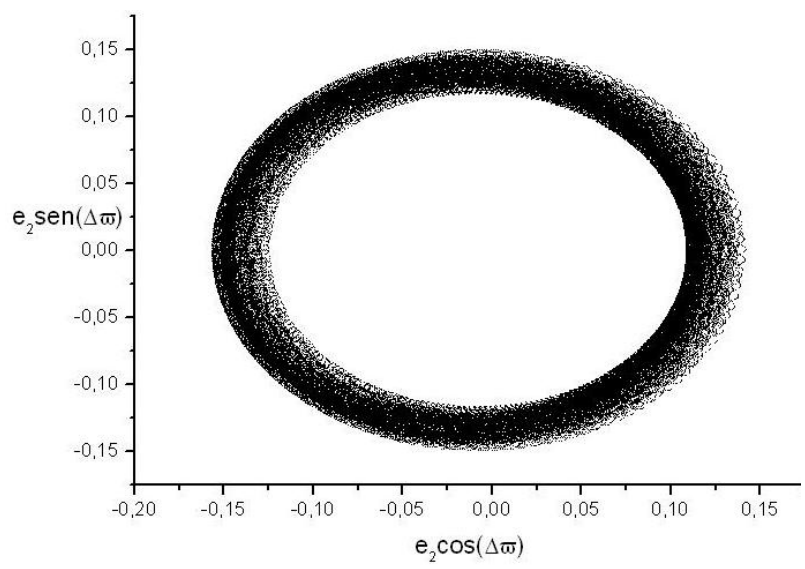

Figura B.133: $\mathrm{KH}$ de $e_{2}$ para HD 147018 bc 
Utilizando o método de médias adjacentes, com 50 pontos, obtém-se dados mais precisos de $\mathrm{KH}$ de $e_{1}$ e $e_{2}$ para o sistema HD 147018 bc:

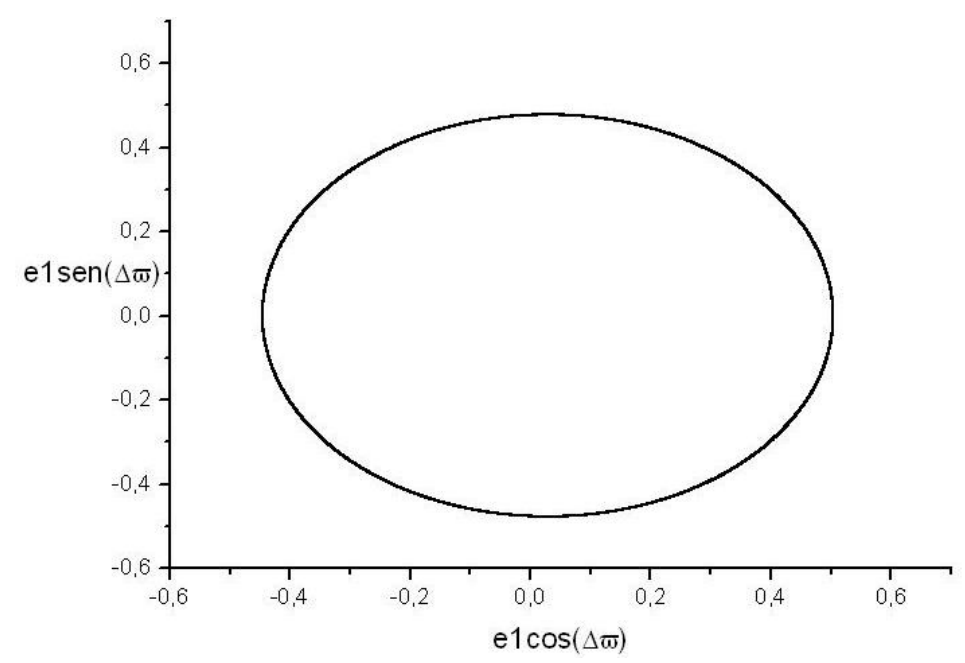

Figura B.134: KH de $e_{1}$ para HD 147018 bc com filtro

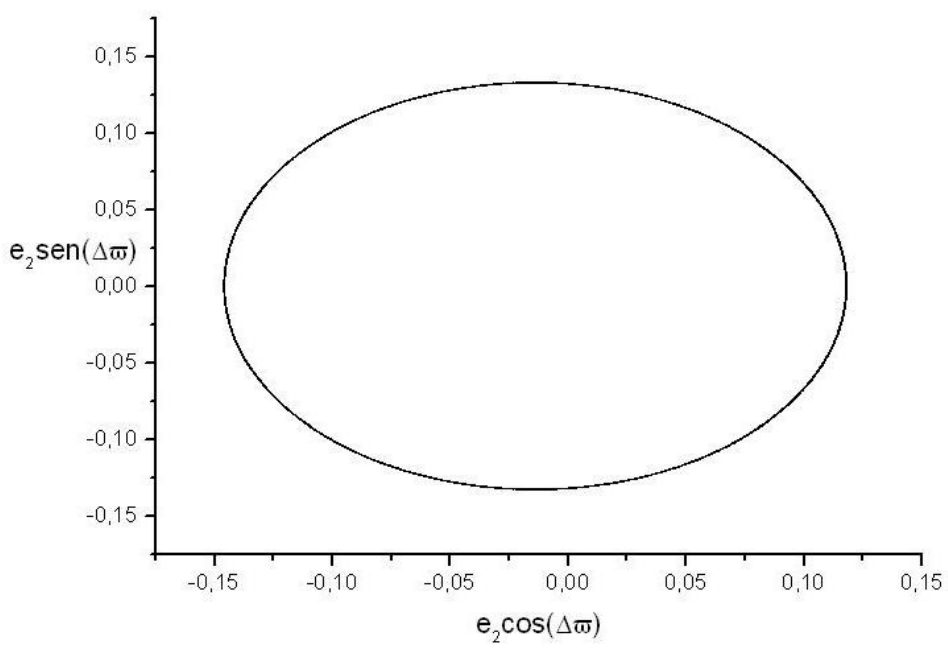

Figura B.135: KH de $e_{2}$ para HD 147018 bc com filtro 


\section{B.3.8 HD 168443 bc}

O tempo de simulação para o sistema HD 168443 bc foi de 200 mil anos. Trata-se de um sistema hierárquico, Classe III. O movimento do ângulo $\Delta \varpi$ é circulatório retrógrado. Seu período secular é de aproximadamente 17.433 anos.

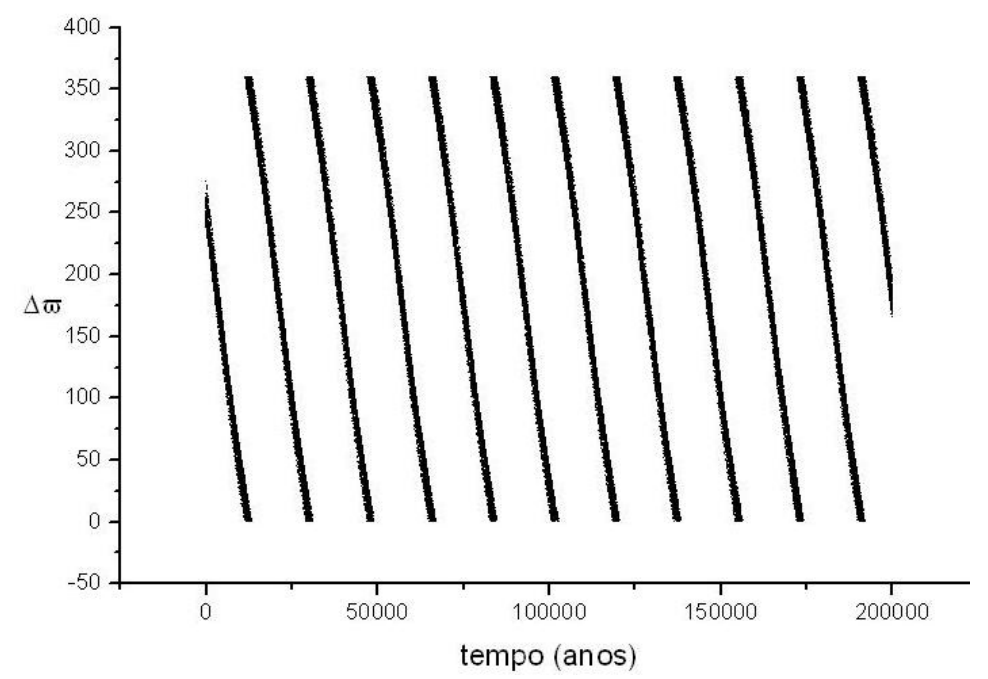

Figura B.136: Ângulo $\Delta \varpi$ em função do tempo para HD 168443 bc

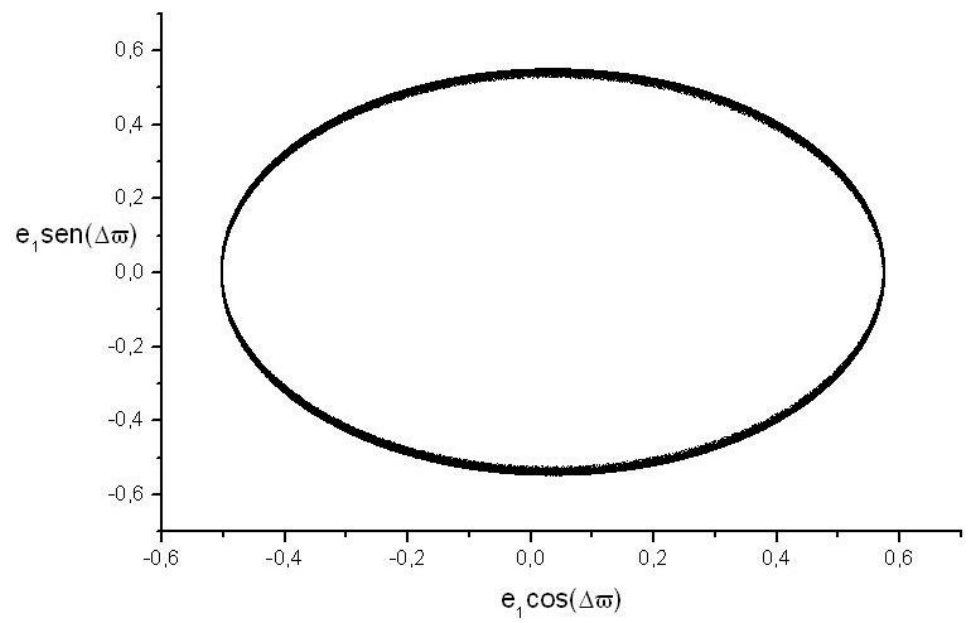

Figura B.137: KH de $e_{1}$ para HD 168443 bc 


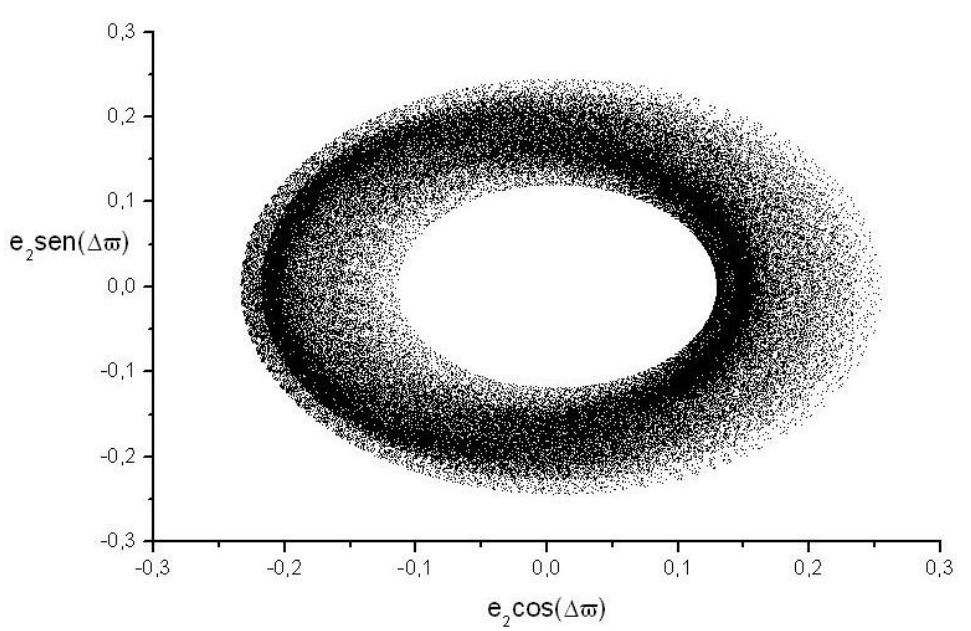

Figura B.138: $\mathrm{KH}$ de $e_{2}$ para HD 168443 bc

O método de médias adjacentes, com 50 pontos, foi aplicado para obter de $\mathrm{KH}$ de $e_{2}$ para o sistema HD 168443 bc:

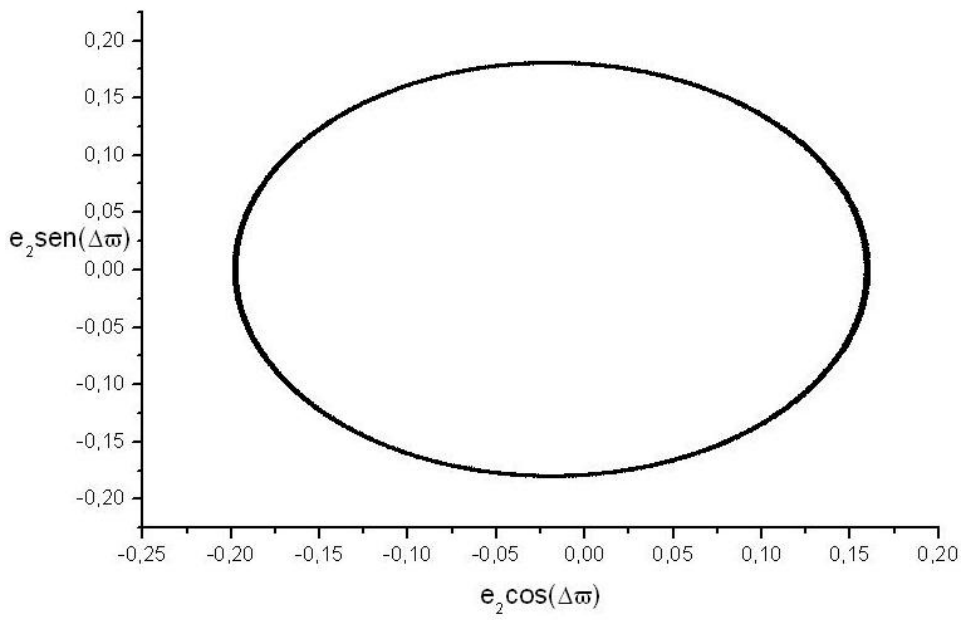

Figura B.139: $\mathrm{KH}$ de $e_{2}$ para HD 168443 bc com filtro 


\section{B.3.9 HD $11964 c b$}

O tempo de simulação para o sistema HD 11964 cb foi de 5 milhões de anos. Trata-se de um sistema hierárquico, Classe III. O movimento do ângulo $\Delta \varpi$ é circulatório retrógrado. Seu período secular é de aproximadamente 869.333 anos.

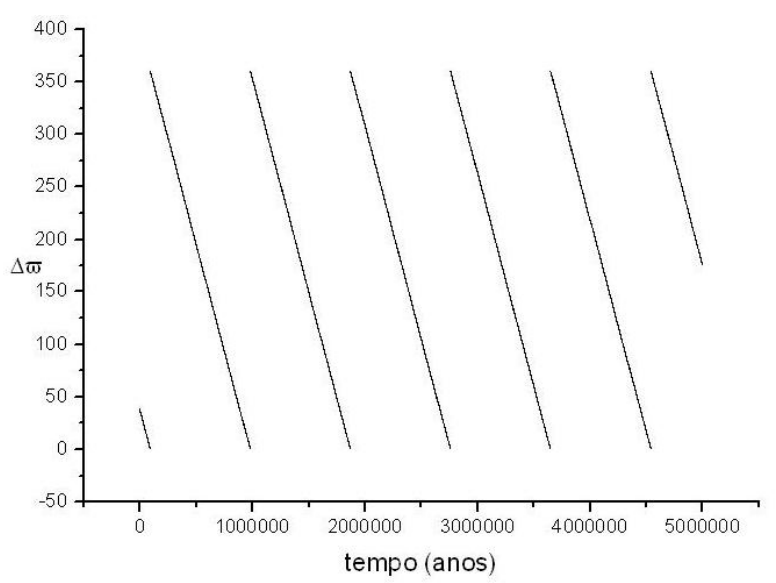

Figura B.140: Ângulo $\Delta \varpi$ em função do tempo para HD $11964 \mathrm{cb}$

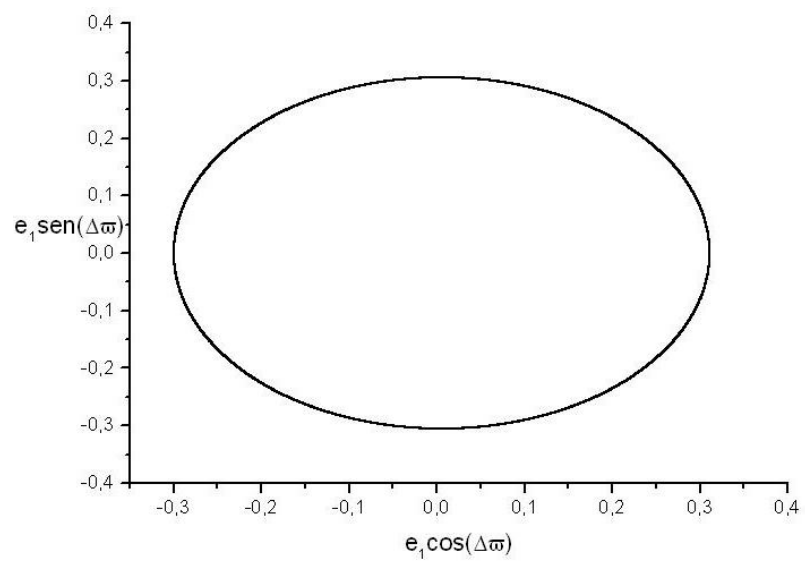

Figura B.141: KH de $e_{1}$ para HD $11964 \mathrm{cb}$

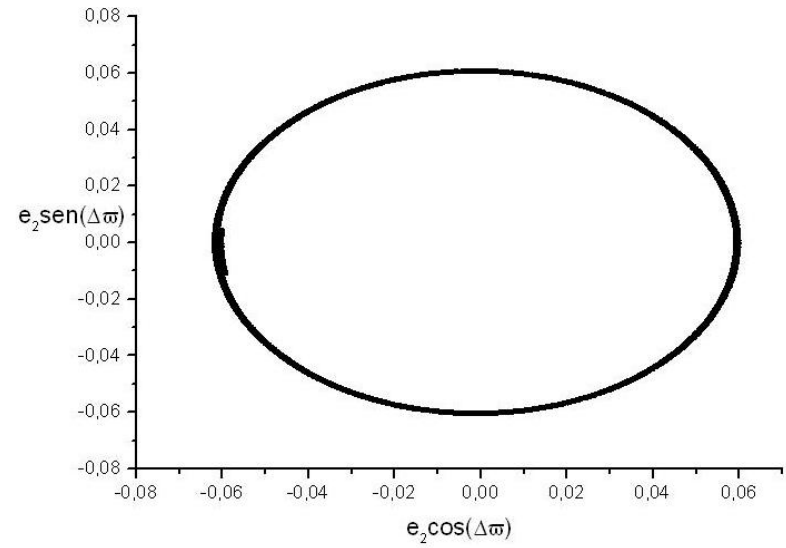

Figura B.142: KH de $e_{2}$ para HD $11964 \mathrm{cb}$ 


\section{B.3.10 HAT-P-13 bc}

O sistema HAT-P-13 bc seria classificado como hierárquico, Classe III, porém, as simulações mostram que a partir de aproximadamente 52.500 anos de simulação a excentricidade do planeta HAT-P-13 b assume valor igual a 1, não sendo mais considerado um movimento elíptico o do planeta em torno da estrela, mostrando que os dados disponíveis desse sistema não permitem classificá-lo como um sistema estável.

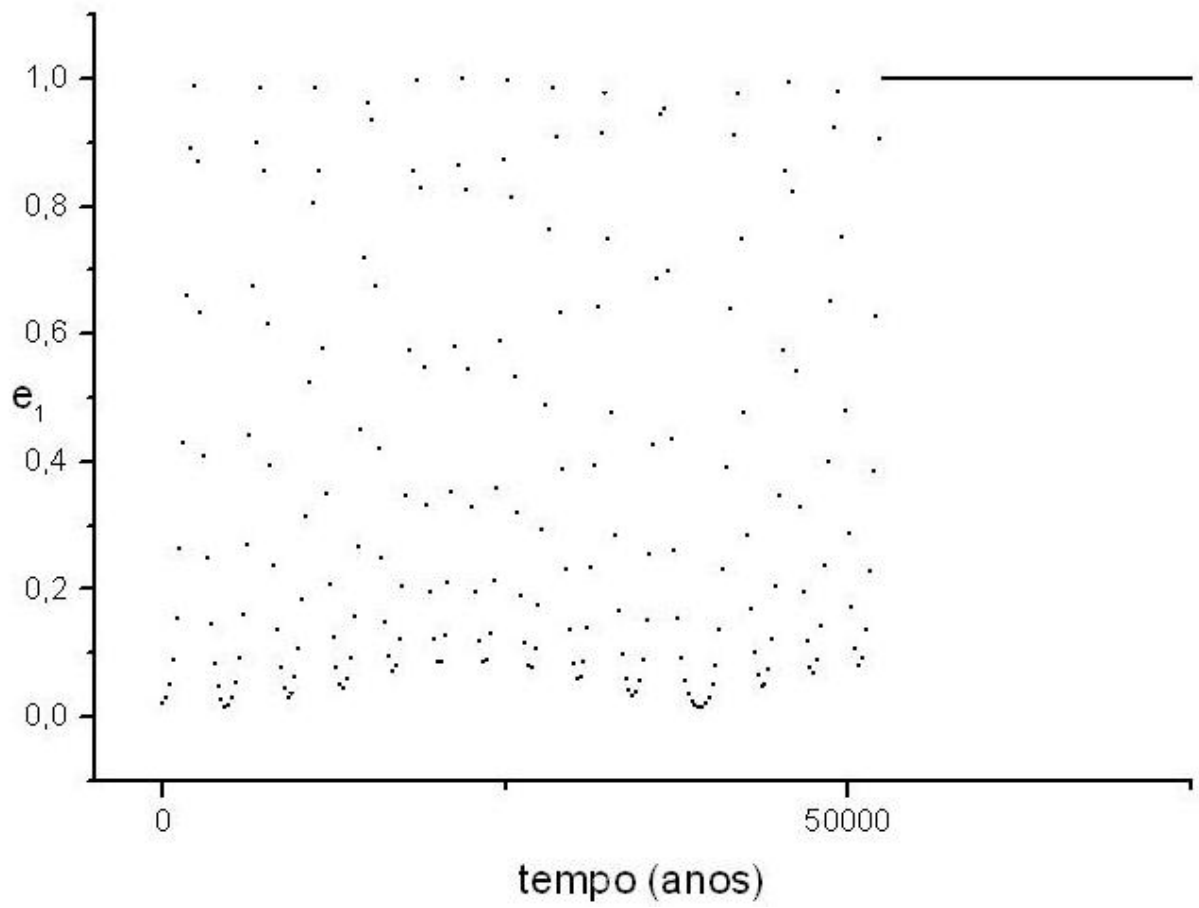

Figura B.143: Excentricidade de HAT-P-13 b em função do tempo 


\section{B.3.11 HD 38529 bc}

O tempo de simulação para o sistema HD 38529 bc foi de 1 milhão de anos. Trata-se de um sistema hierárquico, Classe III. O movimento do ângulo $\Delta \varpi$ é circulatório retrógrado. Seu período secular é de aproximadamente 118.978 anos.

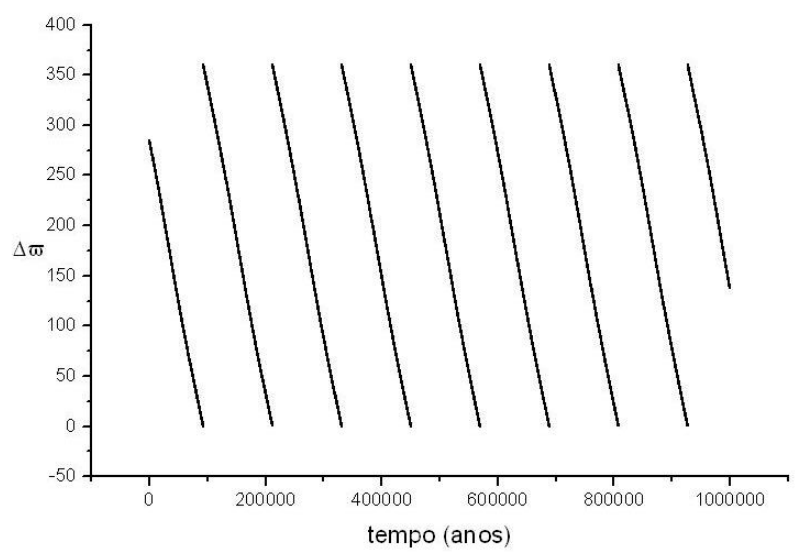

Figura B.144: Ângulo $\Delta \varpi$ em função do tempo para HD 38529 bc

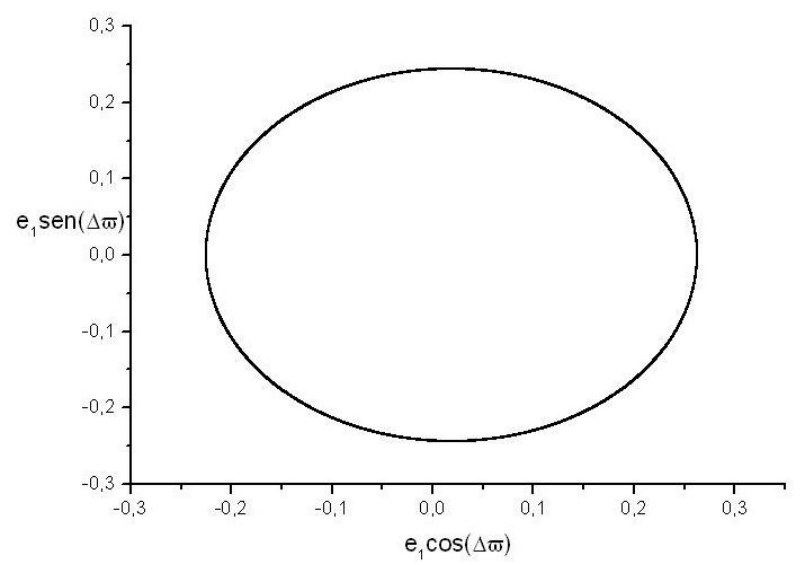

Figura B.145: KH de $e_{1}$ para HD 38529 bc

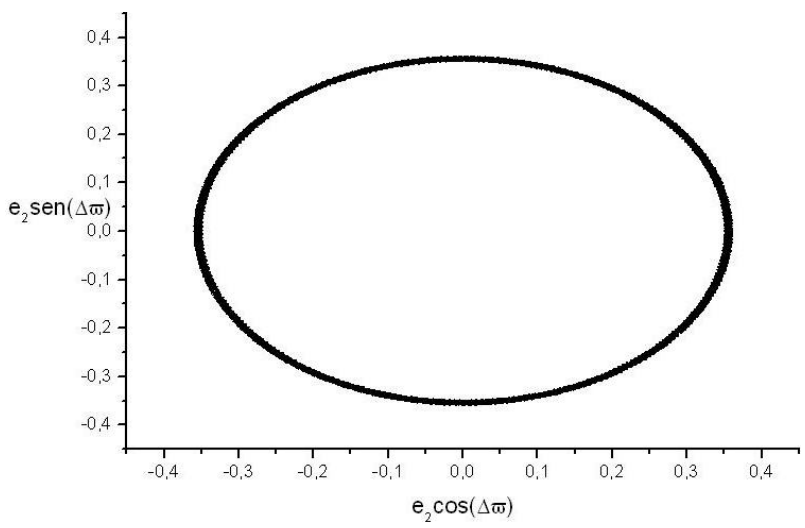

Figura B.146: KH de $e_{2}$ para HD 38529 bc 


\section{B.3.12 HD $190360 \mathrm{cb}$}

O tempo de simulação para o sistema HD 190360 cb foi de 5 milhões de anos. Trata-se de um sistema hierárquico, Classe III. O movimento do ângulo $\Delta \varpi$ é circulatório retrógrado. Seu período secular é de aproximadamente 1.044.871 anos.

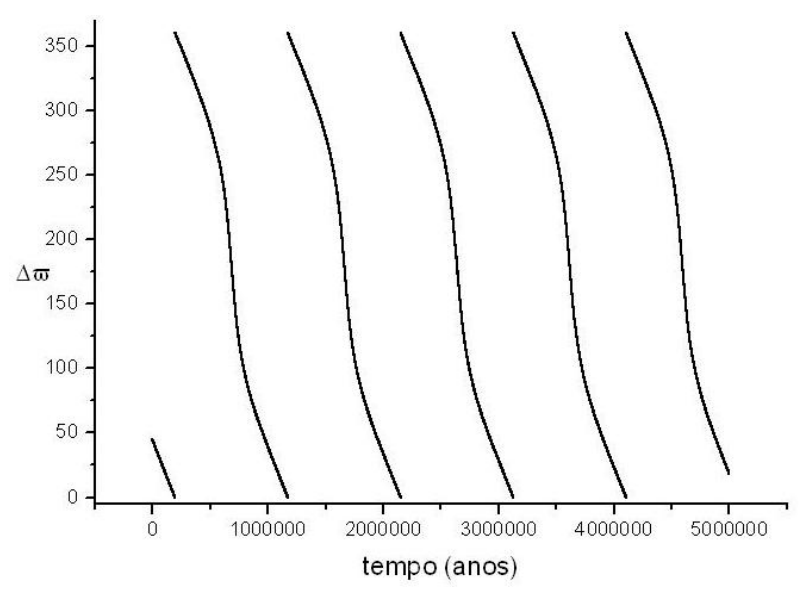

Figura B.147: Ângulo $\Delta \varpi$ em função do tempo para HD $190360 \mathrm{cb}$

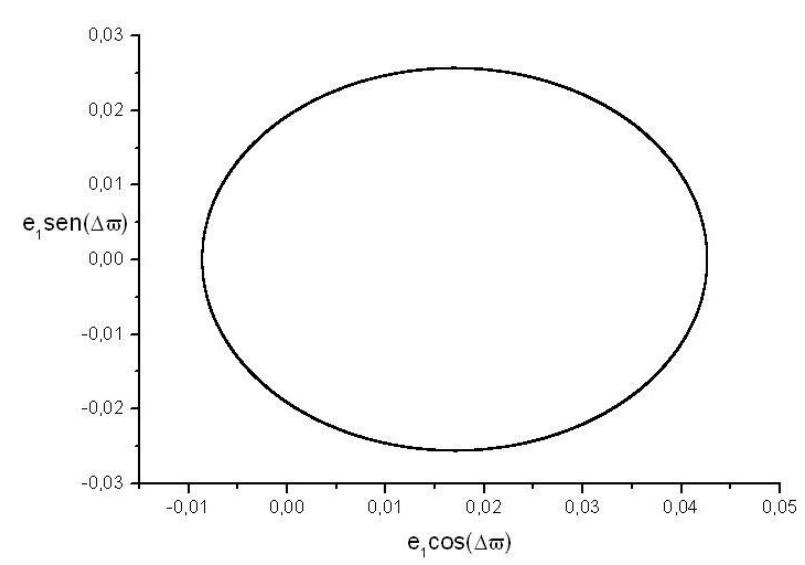

Figura B.148: KH de $e_{1}$ para HD $190360 \mathrm{cb}$

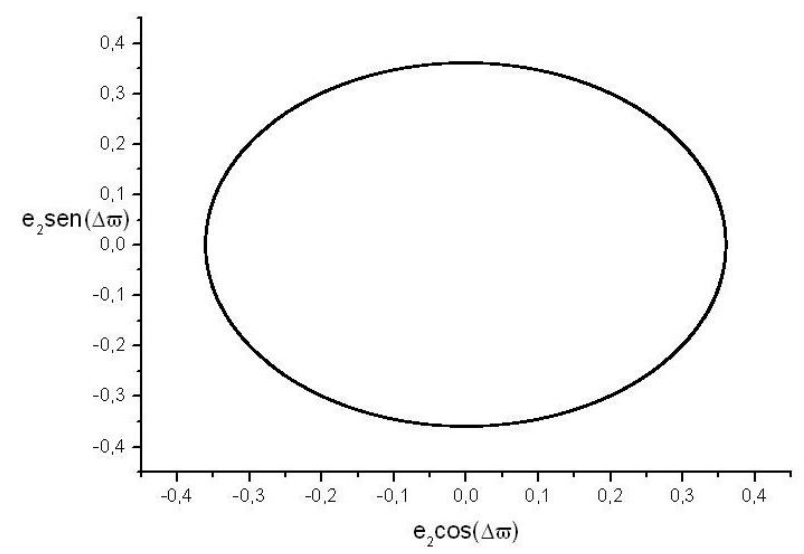

Figura B.149: KH de $e_{2}$ para HD $190360 \mathrm{cb}$ 


\section{B.3.13 HD 47186 bc}

O tempo de simulação para o sistema HD 47186 bc foi de 20,5 milhões de anos. Trata-se de um sistema hierárquico, Classe III. O movimento do ângulo $\Delta \varpi$ é circulatório retrógrado. Seu período secular é de aproximadamente 5.419.355 anos.

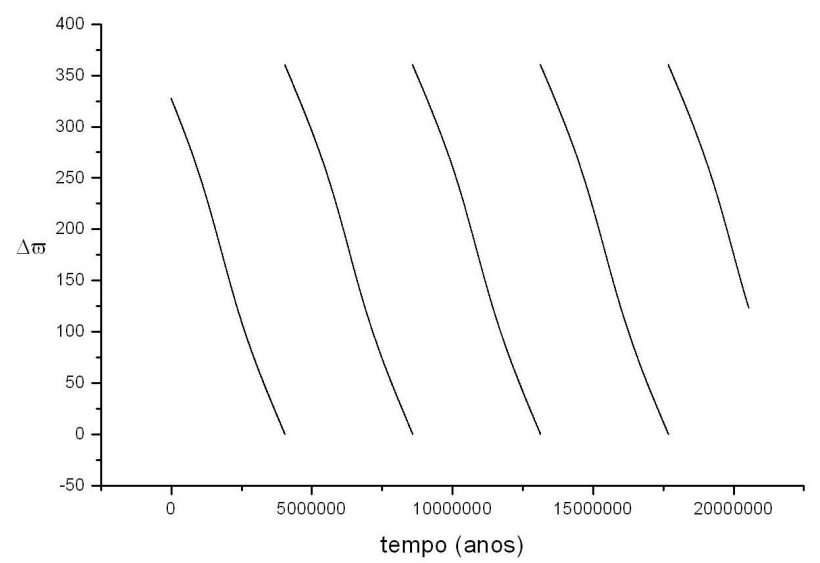

Figura B.150: Ângulo $\Delta \varpi$ em função do tempo para HD 47186 bc

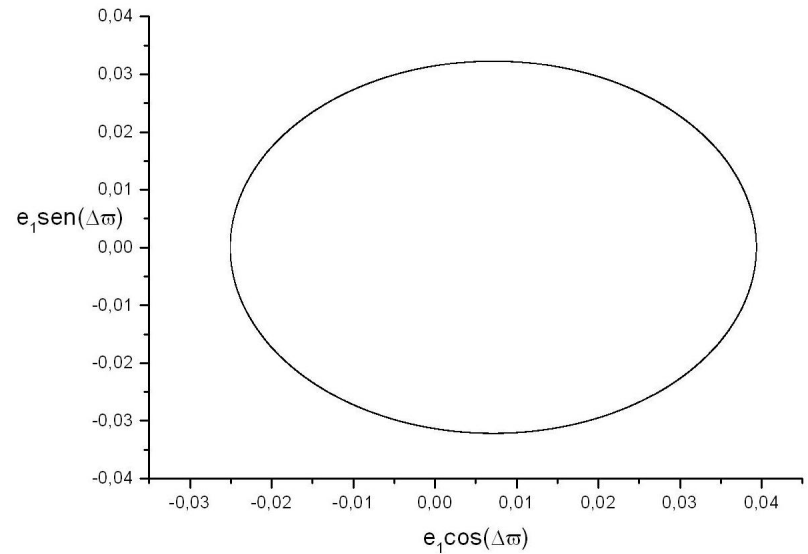

Figura B.151: KH de $e_{1}$ para HD 47186 bc

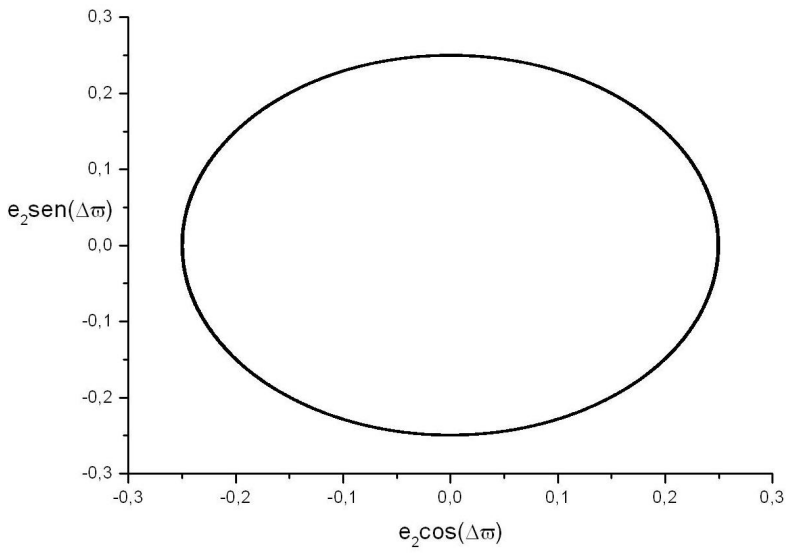

Figura B.152: $\mathrm{KH}$ de $e_{2}$ para HD 47186 bc 


\section{B.3.14 HD 217107 bc}

O tempo de simulação para o sistema HD 217107 bc foi de 18 milhões de anos. Tratase de um sistema hierárquico, Classe III. O movimento do ângulo $\Delta \varpi$ é circulatório retrógrado. Seu período secular é de aproximadamente 2.618.474 anos.

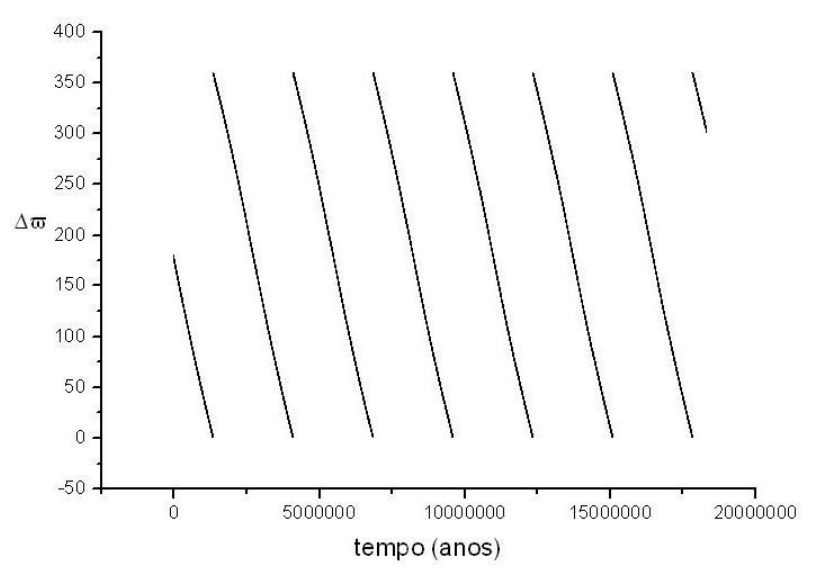

Figura B.153: Ângulo $\Delta \varpi$ em função do tempo para HD 217107 bc

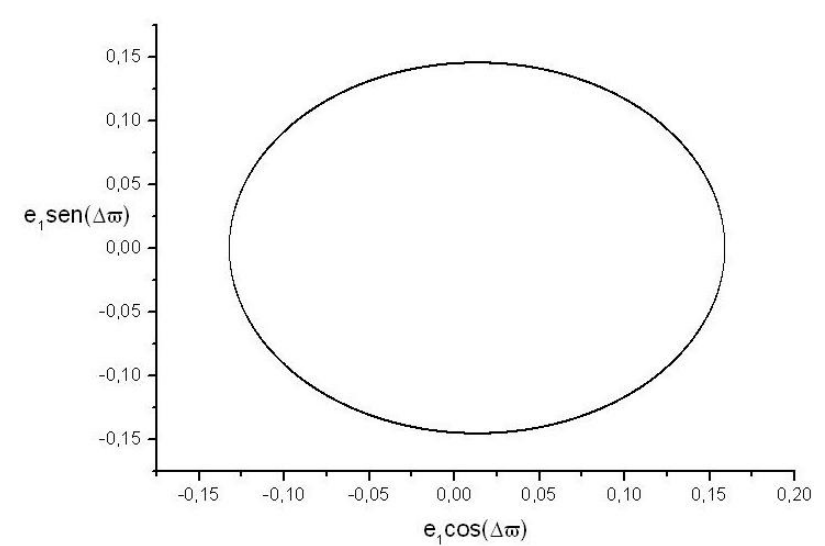

Figura B.154: $\quad$ KH de $e_{1}$ para HD 217107 bc

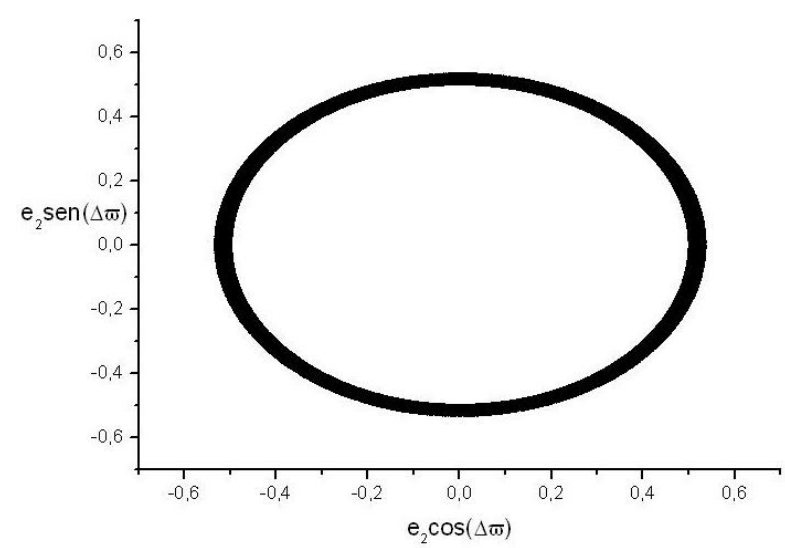

Figura B.155: KH de $e_{2}$ para HD 217107 bc 


\section{B.3.15 HD 68988 bc}

O tempo de simulação para o sistema HD 68988 bc foi de 200 mil anos. Trata-se de um sistema hierárquico, Classe III. O movimento do ângulo $\Delta \varpi$ é circulatório retrógrado. Seu período secular é de aproximadamente 616,5 anos.

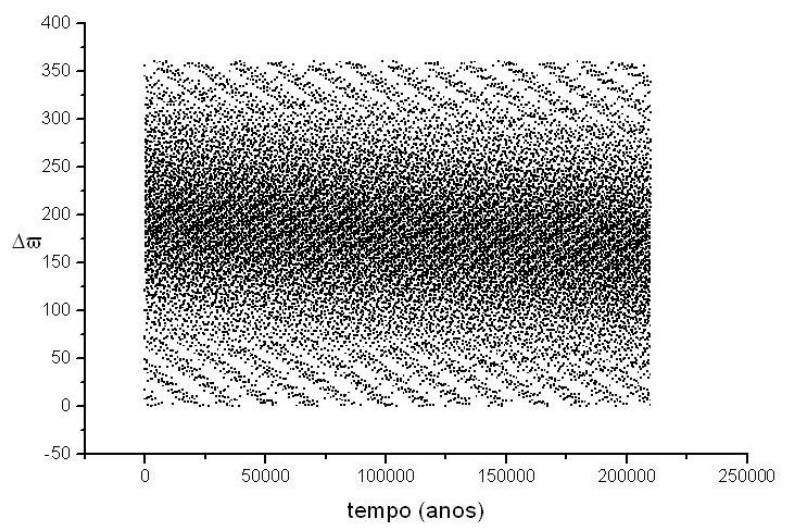

Figura B.156: Ângulo $\Delta \varpi$ em função do tempo para HD 68988 bc

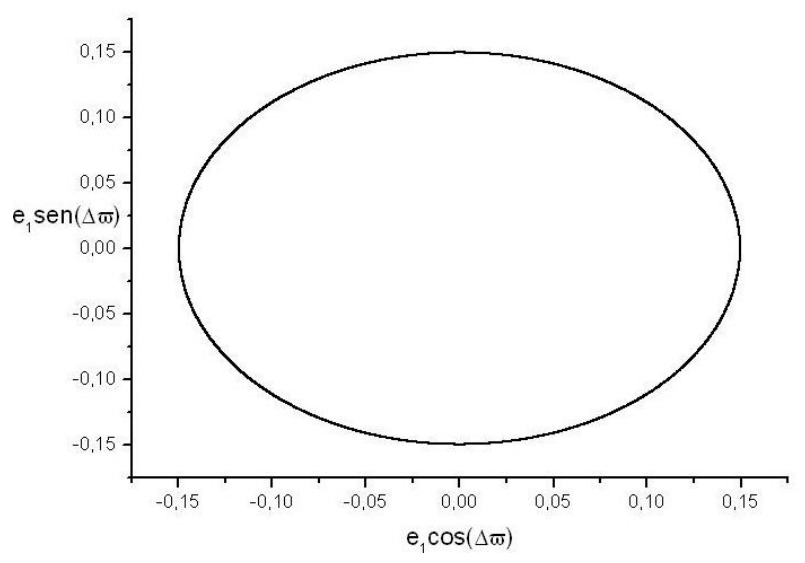

Figura B.157: KH de $e_{1}$ para HD 68988 bc

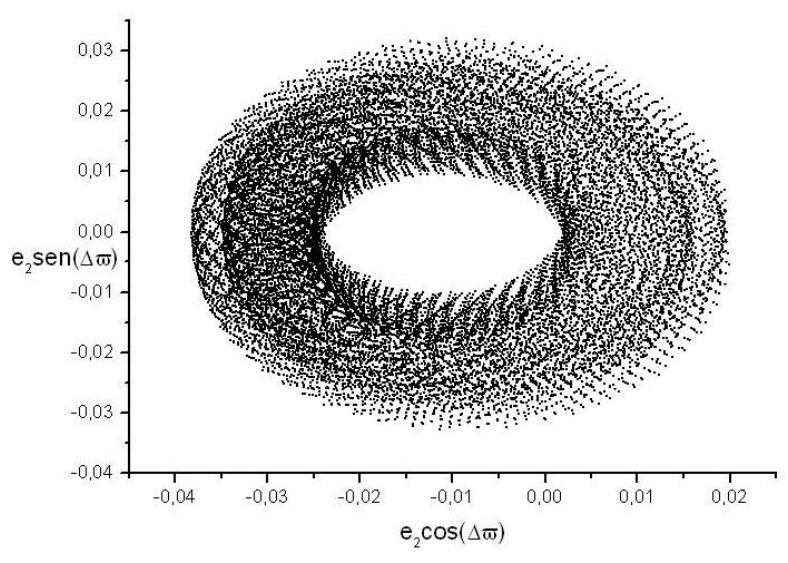

Figura B.158: $\mathrm{KH}$ de $e_{2}$ para HD 68988 bc 


\section{B.3.16 HD 187123 bc}

O tempo de simulação para o sistema HD 187123 bc foi de 21 milhões de anos. Apesar do longo tempo de simulação, só foi possível obter 2 períodos completos do ângulo $\Delta \varpi$. Trata-se de um sistema hierárquico, Classe III. O movimento do ângulo $\Delta \varpi$ é circulatório retrógrado. Seu período secular é de aproximadamente 13.252.033 anos.

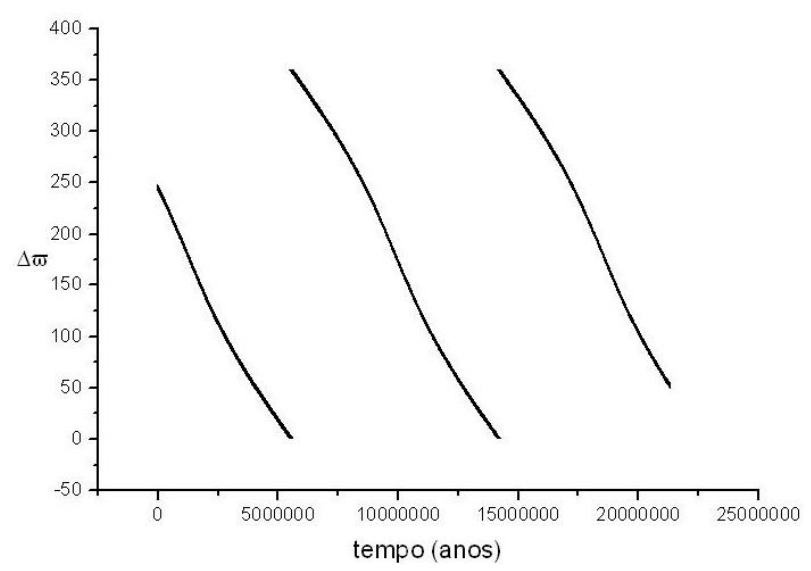

Figura B.159: Ângulo $\Delta \varpi$ em função do tempo para HD 187123 bc

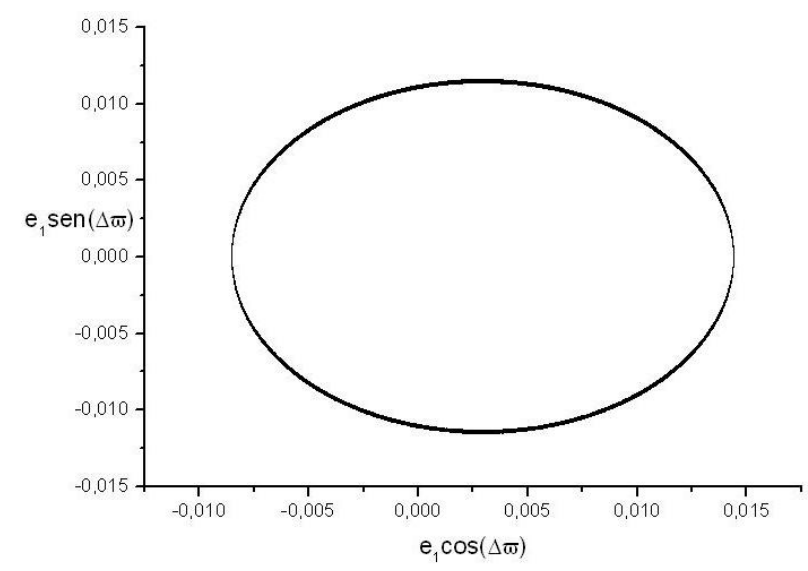

Figura B.160: KH de $e_{1}$ para HD 187123 bc

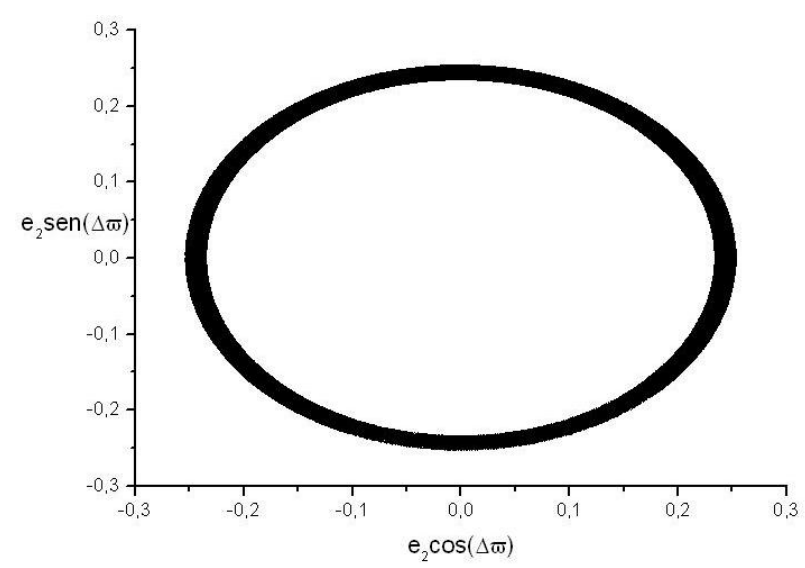

Figura B.161: KH de $e_{2}$ para HD 187123 bc 


\section{Apêndice C}

\section{Parâmetros orbitais utilizados nas simulações}

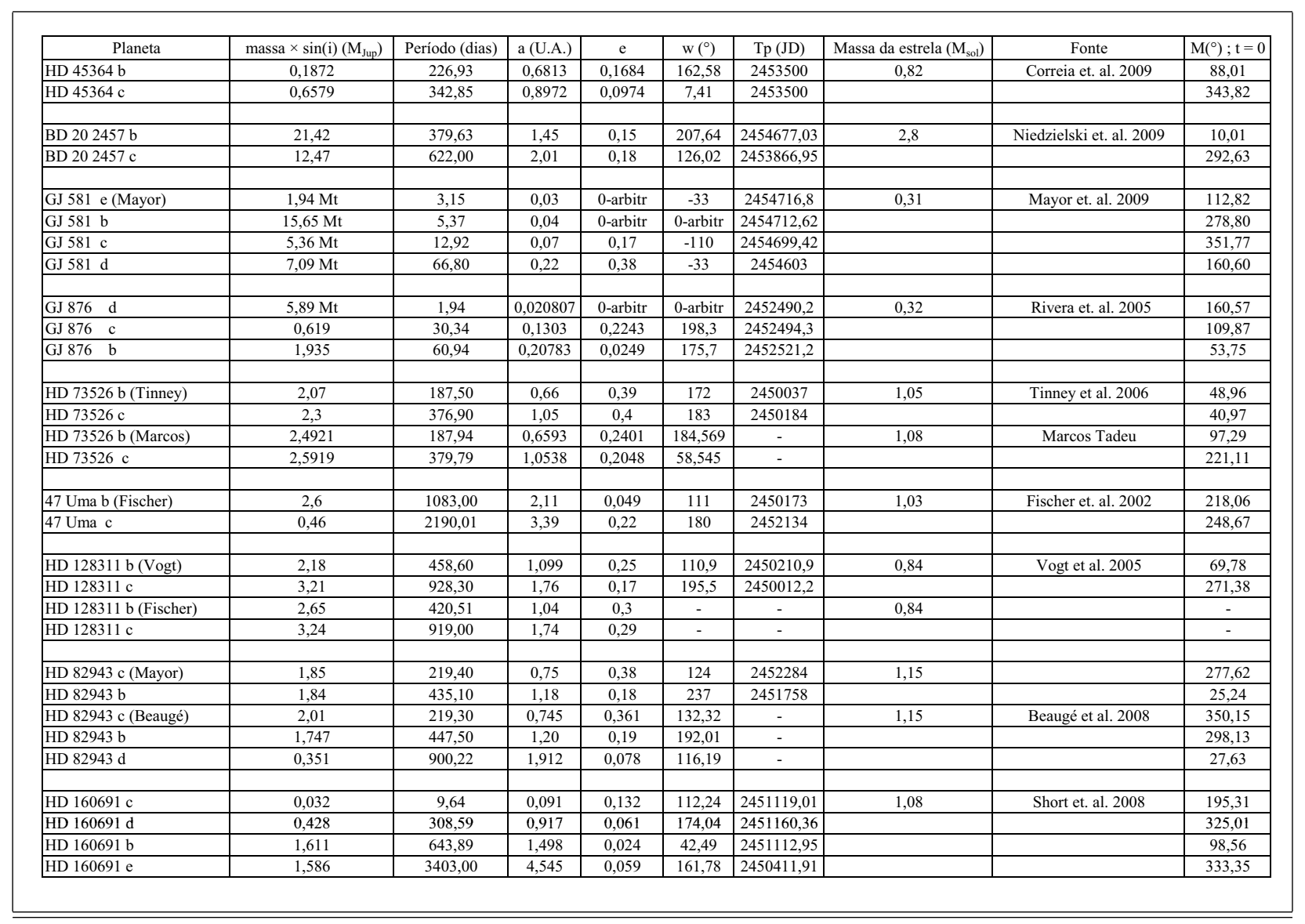

Tabela C.1 - Tabela dos parâmetros orbitais utilizados nas simulações 


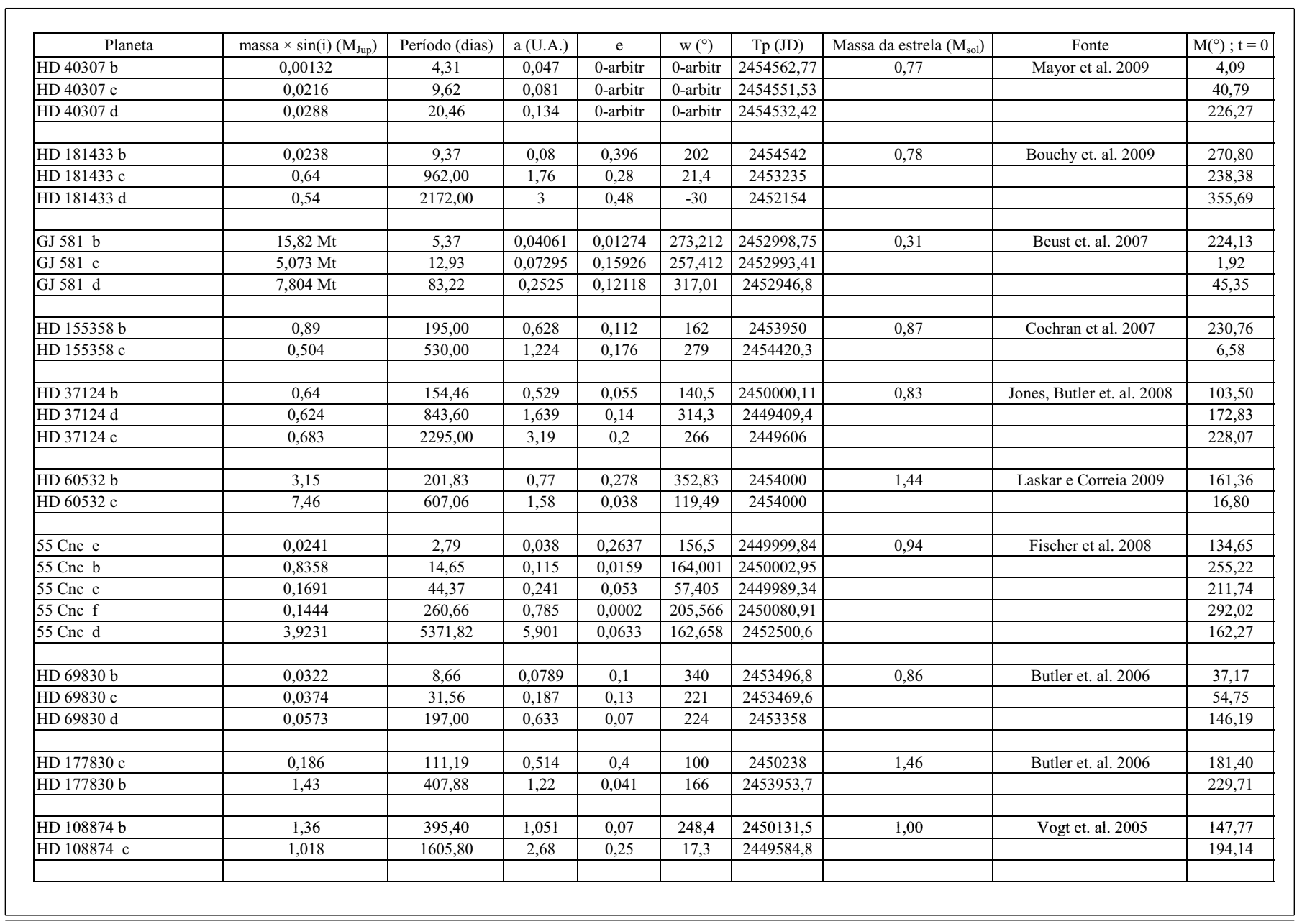

Tabela C.2 - Tabela dos parâmetros orbitais utilizados nas simulações - continuação 


\begin{tabular}{|c|c|c|c|c|c|c|c|c|c|}
\hline Planeta & $\operatorname{massa} \times \sin (\mathrm{i})\left(\mathrm{M}_{\text {Jup }}\right)$ & Período (dias) & $\mathrm{a}$ (U.A.) & $\mathrm{e}$ & $\mathrm{w}\left({ }^{\circ}\right)$ & $\mathrm{Tp}(\mathrm{JD})$ & Massa da estrela $\left(\mathrm{M}_{\mathrm{sol}}\right)$ & Fonte & $\mathrm{M}\left({ }^{\circ}\right) ; \mathrm{t}=0$ \\
\hline HD $102272 \mathrm{~b}$ & 5,9 & 127,58 & 0,614 & 0,05 & 118 & 2452146,5 & 1,90 & Niedzielski et al. 2009 & 193,79 \\
\hline \multirow[t]{2}{*}{ HD $102272 \mathrm{c}$} & 2,6 & 520,00 & 1,57 & 0,68 & 320 & 2454135,5 & & & 183,11 \\
\hline & 3.69 & 634,23 & 1,52 & 0,38 & 242 & 2452120.61 & 117 & OSBPM & 29543 \\
\hline \begin{tabular}{|l|l} 
HD $183263 \mathrm{c}$ \\
\end{tabular} & 3,82 & 2950,00 & 4,25 & 0,253 & 339,6 & 2411910 & & & 346,58 \\
\hline HD 183263 b (Wright) & 3,67 & 626,50 & 1,51 & 0,3567 & 233,5 & 2452111,7 & 1,17 & Wright et. al. 2009 & 5,34 \\
\hline HD $183263 \mathrm{c}$ & 3,54 & 2980,00 & 4,28 & 0,239 & 345 & 2451971 & & & 68,73 \\
\hline HD 202206 b (Marcos) & 17,4168 & 255,79 & 0,8302 & 0,4333 & 161,125 & - & 1,15 & Marcos Tadeu & 353,40 \\
\hline HD $202206 \mathrm{c}$ & 2,7195 & 1235,28 & 2,3623 & 0,4012 & 277,846 & - & & & 71,40 \\
\hline HD 202206 b (Raymond) & 17,4 & 255,87 & 0,83 & 0,435 & 161,18 & 2452250 & 1,15 & Raymond et al.2008 & 11,36 \\
\hline HD $202206 \mathrm{c}$ & 2,44 & 1383,40 & 2,55 & 0,267 & 78,99 & 2452250 & & & 134,85 \\
\hline HD 202206 b (Correia) & 17,5 & 256,20 & 0,83 & 0,433 & 161,1 & 2452175,6 & 1,15 & Correia et al. 2005 & 240,00 \\
\hline \multirow[t]{2}{*}{ HD $202206 \mathrm{c}$} & 2,41 & 1296,80 & 2,44 & 0,284 & 101,8 & 2451206,4 & & & 289,38 \\
\hline & & & & & & & & & \\
\hline$v$ And $b$ & 0,687 & 4,62 & 0,0595 & 0,023 & 63 & 2450004,28 & 1,32 & Jones, Butler et. al. 2008 & 163,26 \\
\hline$v$ And $c$ & 1,97 & 241,23 & 0,83 & 0,262 & 245,5 & 2450159,4 & & & 20,46 \\
\hline$v$ And d & 3,93 & 1290,10 & 2,54 & 0,258 & 279 & 2449963 & & & 342,39 \\
\hline & & & & & & & & & \\
\hline HD $12661 \mathrm{~b}$ & 2,34 & 262,53 & 0,831 & 0,361 & 296,3 & 2450214,1 & 1,11 & Butler et. al. 2006 & 330,36 \\
\hline HD $12661 \mathrm{c}$ & 1,83 & 1679 & 2,86 & 0,017 & 38 & 2452130 & & & 190,61 \\
\hline 47 Uma b (Wittenmeyer) & 2,6 & 1083,20 & 2,11 & 0,049 & 111 & 2490173 & 1,07 & Wittenmyer et al. 2005 & 34,49 \\
\hline 47 Uma c & 1,34 & 7586,00 & 7,73 & 0,005-arbtr & 127-arbtr & 2492134 & & & 278,34 \\
\hline HD $74156 \mathrm{~b}$ & 1,88 & 51,65 & 0,294 & 0,64 & 175,8 & \begin{tabular}{|l|}
2451980,8 \\
\end{tabular} & 1,27 & Bean et. al. 2008 & 357,56 \\
\hline HD 74156 d & 0,396 & 336,60 & 1,01 & 0,25 & 166,5 & 2450678,2 & & & 113,79 \\
\hline HD 74156 c & 8,03 & 2476,00 & 3,85 & 0,43 & 261,3 & \begin{tabular}{|l|}
2450952,2 \\
\end{tabular} & & & 41,84 \\
\hline HD $11506 \mathrm{c}$ & 0,82 & 170,46 & 0,639 & 0,42 & 4,1 & - & 1,19 & Tuomi e Kotiranta 2009 & 343,27 \\
\hline HD $11506 \mathrm{~b}$ & 3,44 & 1270,00 & 2,43 & 0,22 & 4,5 & \begin{tabular}{|l|}
2463666,3 \\
\end{tabular} & & & 86,08 \\
\hline HIP $14810 \mathrm{~b}$ & 3,88 & 6,67 & 0,0692 & 0,1427 & 159,32 & \begin{tabular}{|l|}
245369466 \\
\end{tabular} & 0,99 & Wright et. al. 2009 & 85,42 \\
\hline HIP $14810 \mathrm{c}$ & 1,28 & 147,73 & 0,545 & 0,164 & 329 & 2454672,24 & & & 23,00 \\
\hline HIP $14810 \mathrm{~d}$ & 0,57 & 962,00 & 1,89 & 0,173 & 286 & 2454317,2 & & & 264,50 \\
\hline HD $169830 \mathrm{~b}$ & 2,88 & 225,62 & 0,81 & 0,31 & 148 & 2451923 & 1,4 & Mayor et al. 2004 & 183,74 \\
\hline \multirow[t]{2}{*}{ HD $169830 \mathrm{c}$} & 4,04 & 2102,00 & 3,6 & 0,33 & 252 & 2452516 & & & 88,71 \\
\hline & & & & & & & & & \\
\hline
\end{tabular}

Tabela C.3 - Tabela dos parâmetros orbitais utilizados nas simulações - continuação 


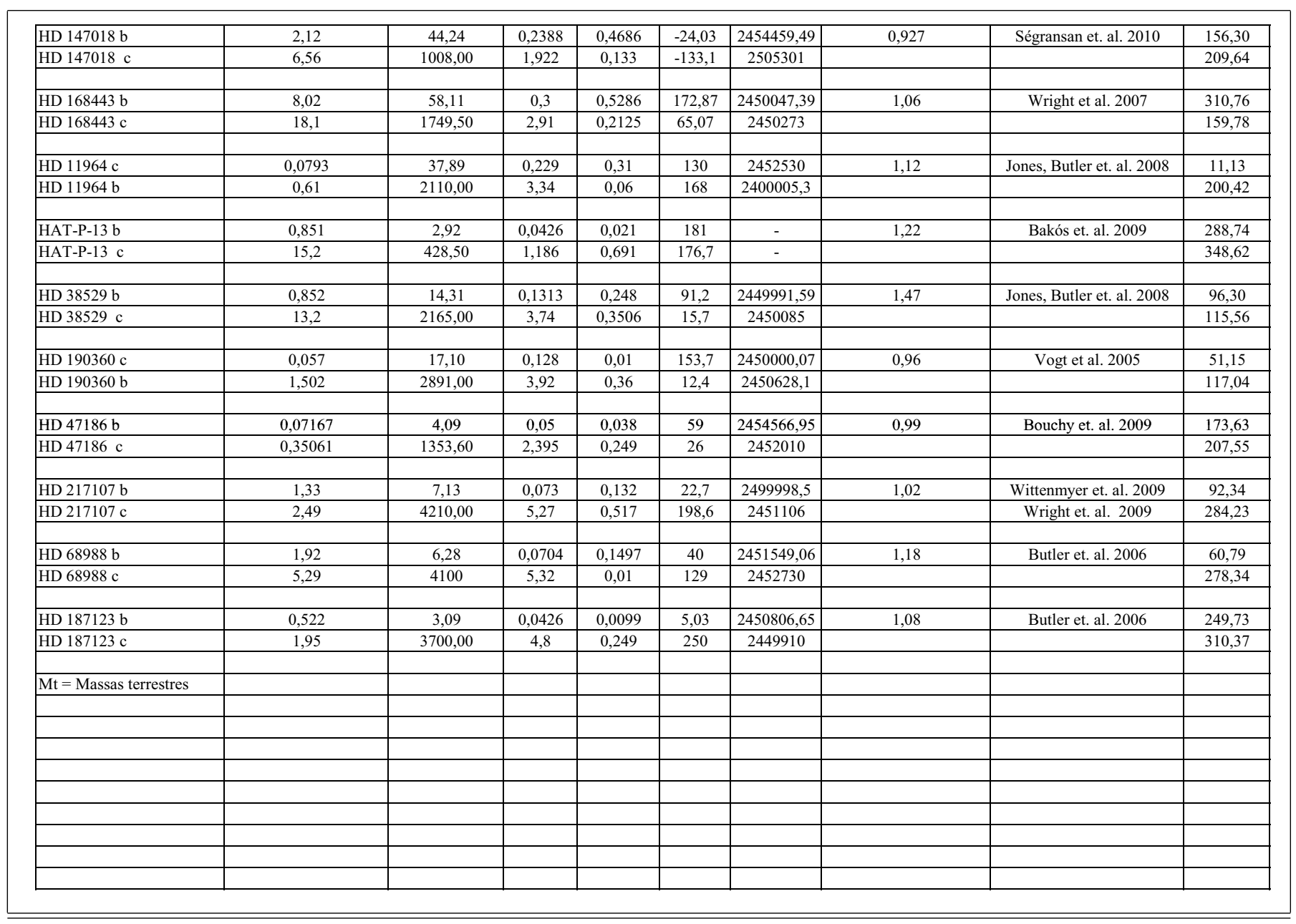

Tabela C.4 - Tabela dos parâmetros orbitais utilizados nas simulações - continuação 